\title{
Barriers to Accessibility for Skiing
}

by

Lindsay McCauley

A thesis submitted to the Faculty of Graduate and Postdoctoral Affairs in partial fulfillment of the requirements for the degree of

Master of Design

in

Industrial Design

Carleton University

Ottawa, Ontario

(C) 2021, Lindsay McCauley 


\begin{abstract}
Across Canada, ski areas do not consistently or thoroughly recognize the experiences of persons with disabilities. Consequently, barriers to accessibility exist and impede inclusion for skiing. Five types of barriers to accessibility are experienced for skiing: architectural and physical, attitudinal, organizational and systemic, informational and communicational, and technological barriers. This thesis explores how design research can be used to identify and address barriers to accessibility for skiing. Three research phases are conducted: discovery, definition, and design. Phase 1 consists of a preliminary field study to discover issues within the experience of adaptive skiing and to inform the thesis direction: barriers to accessibility for skiing. Phase 2 employs a questionnaire to further define the barriers to accessibility that are encountered when skiing. Phase 3 uses directed storytelling as a participatory design approach to seek solutions for addressing the barriers. The outcome is the emergence of design recommendations and practical approaches that may improve accessibility and inclusivity for skiing. The findings highlight limited provision of accessibility information on behalf of ski areas, which is an informational and communicational barrier to skiing. As a novel method for improving information provision, the concept of an interactive accessibility map is introduced. This thesis aims to bring awareness to and encourage ski areas to eliminate and prevent barriers to accessibility for skiing.
\end{abstract}

Keywords: Barriers; Accessibility; Inclusion; Skiing; Collaboration 


\section{Acknowledgments}

\section{To my Co-Supervisors:}

Lois Frankel, I would like to extend my deepest appreciation. Thank you for believing in me and introducing me to so many wonderful opportunities. Your mentorship has helped me grow as a designer and as a person. I am grateful for your generosity and guidance.

Adrian Chan, I would like to express my sincere gratitude for your invaluable supervision, continuous support, and patience. Thank you for contributing your perspectives to this thesis.

Dean Mellway, I would like to offer my special thanks for your insights and encouragement. Your knowledge and experiences have been an invaluable contribution to this thesis.

\section{To Canadian Adaptive Snowsports (CADS):}

CADS, I am deeply grateful for your willingness and engagement. This thesis would not have been possible without your contributions.

\section{To my Family and Friends:}

My appreciation also goes out to my family and friends for their encouragement and support all through my studies. Thank you for the tremendous love and care that you have shown me. 


\section{Table of Contents}

$\begin{array}{ll}\text { Abstract } & 2\end{array}$

Acknowledgments 3

Table of Contents 4

List of Tables $\quad 9$

List of Illustrations 11

$\begin{array}{ll}\text { List of Appendices } & 14\end{array}$

$\begin{array}{lll}\text { Chapter 1: } & \text { Introduction } & 15\end{array}$

1.1 Problem Statement 15

$\begin{array}{lll}1.2 & \text { Background } & 16\end{array}$

$\begin{array}{lll}1.3 & \text { Objective and Outcomes } & 17\end{array}$

1.4 Main Research Question and Sub-Research Questions 17

$\begin{array}{llr}1.5 & \text { Scope } & 18\end{array}$

$\begin{array}{lll}1.6 & \text { Significance to the Field } & 19\end{array}$

$\begin{array}{lll}1.7 & \text { Overview of Chapters } & 19\end{array}$

Chapter 2: Literature Review 21

$\begin{array}{lll}2.1 & \text { Overview } & 21\end{array}$

$2.2 \quad$ Design and (Dis)Ability 21

2.2.1 Universal Design 22

2.2.2 Ability-Based Design 24

2.2.3 Design for Users versus Design with Users 25

2.3 Motivations for Accessibility 26

$\begin{array}{lll}\text { 2.3.1 The Skier Experience } & 27\end{array}$ 
2.3.2 Human Rights 28

$\begin{array}{lll}2.3 .3 & \text { Social } & 28\end{array}$

2.3.4 Health and Wellness 29

$\begin{array}{lll}2.3 .5 & \text { Standards } & 30\end{array}$

$\begin{array}{lll}2.3 .6 & \text { Economies } & 31\end{array}$

$2.4 \quad$ History of Skiing and Persons with Disabilities 31

2.5 Adaptive Ski Programs 34

2.6 Skiing with a Disability 35

$2.7 \quad$ Adaptive Ski Equipment 36

$\begin{array}{lll}\text { 2.7.1 Sit Ski } & 37\end{array}$

$\begin{array}{lll}\text { 2.7.2 } & \text { Outrigger Poles } & 37\end{array}$

2.7.3 Snow Slider 38

$\begin{array}{lll}2.7 .4 & \text { Tethers } & 38\end{array}$

2.7.5 Adaptability and Modifications 39

2.8 Barriers to Accessibility for Skiing 40

$2.9 \quad$ Information Provision 44

2.9.1 Example 1: Whistler's Accessibility Map 44

2.9.2 Example 2: Google Local Guides 46

2.9.3 Example 3: AccessNow 47

2.10 Summary of Literature Review Findings 48

Chapter 3: $\quad$ Research Design 50

3.1 Exploratory Sequential Design 50

3.2 Overview of Sequential Phases 51

$\begin{array}{lll}\text { Chapter 4: } & \text { Phase 1: Discovery } & 54\end{array}$

$\begin{array}{lll}4.1 & \text { Overview } & 54\end{array}$ 
$\begin{array}{lll}4.2 & \text { Setting } & 55\end{array}$

4.3 Method Design 55

$\begin{array}{lll}4.4 & \text { Participants } & 58\end{array}$

4.5 Recruitment $\quad 59$

4.6 Data Gathering $\quad 61$

4.7 Exploration of Adaptive Ski Equipment 62

$\begin{array}{lll}4.8 & \text { Exploration of Ski Areas }\end{array}$

$\begin{array}{lll}4.9 & \text { Analysis } & 68\end{array}$

$\begin{array}{lll}4.10 & \text { Content Analysis } & 76\end{array}$

4.11 Summary of Phase 1 Findings 78

$\begin{array}{ll}\text { Chapter 5: } & \text { Phase 2: Definition }\end{array}$

$\begin{array}{lll}5.1 & \text { Overview } & 80\end{array}$

5.2 Method Design $\quad 80$

$\begin{array}{lll}5.3 & \text { Setting } & 82\end{array}$

$\begin{array}{lll}5.4 & \text { Participants } & 82\end{array}$

$\begin{array}{llr}5.5 & \text { Recruitment } & 82\end{array}$

5.6 Data Gathering $\quad 83$

$\begin{array}{lll}5.7 & \text { Findings } & 83\end{array}$

5.8 Analysis of Barriers to Accessibility 85

5.9 Analysis of Information Provision at Ski Areas 91

5.10 Summary of Phase 2 Findings 93

Chapter 6: $\quad$ Phase 3: Design 95

$\begin{array}{lll}6.1 & \text { Overview } & 95\end{array}$

6.2 Method Design 95

$\begin{array}{lll}6.3 & \text { Setting } & 100\end{array}$ 
$\begin{array}{lll}6.4 & \text { Participants } & 100\end{array}$

$\begin{array}{lll}6.5 & \text { Recruitment } & 101\end{array}$

6.6 Data Gathering 101

6.7 Findings 102

6.8 User Journey Maps 103

$\begin{array}{lll}\text { 6.8.1 Participant } 1 & 103\end{array}$

$\begin{array}{lll}\text { 6.8.2 Participant } 2 & 105\end{array}$

$\begin{array}{lll}\text { 6.8.3 } & \text { Participant } 3 & 108\end{array}$

$\begin{array}{lll}\text { 6.8.4 Participant } 4 & 110\end{array}$

$\begin{array}{lll}\text { 6.8.5 Participant 5 } & 112\end{array}$

$\begin{array}{lll}\text { 6.8.6 Participant } 6 & 114\end{array}$

6.9 Analysis of Barriers to Accessibility 116

$\begin{array}{lll}6.10 & \text { Summary of Phase 3 Findings } & 119\end{array}$

$\begin{array}{lll}\text { Chapter 7: } & \text { Analysis Methods and Findings } & 121\end{array}$

7.3.1 Affinity Diagramming and Ski Area Map Exercise 130

7.3.2 Similarities, Differences, and Outlying Information 138

Chapter 8: Discussion 142

8.1 Interpretation of Findings 142

8.1.1 Evaluation of Main Research Question 142

8.1.2 Evaluation of Sub-Research Question 1

8.1.3 Evaluation of Research Question 2 145

8.1.4 Evaluation of Research Question 3 146

8.2 Design Recommendations and Opportunities 152

$\begin{array}{lll}\text { 8.2.1 Universal Design } & 152\end{array}$

$\begin{array}{lll}\text { 8.2.2 } & \text { Ability-Based Design } & 155\end{array}$ 
$\begin{array}{lll}\text { 8.3 Novel Method } & 158\end{array}$

$\begin{array}{lll}8.4 & \text { Limitations } & 160\end{array}$

8.5 Effects of COVID-19 Pandemic on Thesis 163

8.6 Recommendations for Future Research 164

8.6.1 Evaluation of Design Recommendations 164

8.6.2 Severity of Barriers 165

$\begin{array}{lll}\text { 8.6.3 Generalizability } & 165\end{array}$

$\begin{array}{lll}\text { 8.6.4 Disaggregation of Impairments } & 166\end{array}$

8.6.5 Novel Method: Interactive Accessibility Map 167

$\begin{array}{lll}\text { Chapter 9: } & \text { Conclusion } & 168\end{array}$

$\begin{array}{ll}\text { References } & 171\end{array}$

$\begin{array}{lr}\text { Appendices } & 182\end{array}$ 


\section{List of Tables}

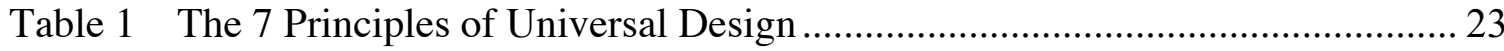

Table 2 Examples of Questions to Ask Adaptive Ski Students ....................................... 57

Table 3 Examples of Questions to Ask Adaptive Ski Volunteers/Instructor................. 57

Table 4 Barrier Type \#1: Architectural/Physical Barriers .............................................. 69

Table 5 Barrier Type \#2: Attitudinal Barriers............................................................. 73

Table 6 Barrier Type \#3: Organizational/Systemic Barriers ...................................... 74

Table 7 Barrier Type \#4: Informational/Communicational Barriers ............................ 75

Table 8 Barrier Type \#5: Technological Barriers ................................................... 76

Table 9 Accessible Facilities \& Services at Ontario Ski Areas ..................................... 77

Table 10 Barrier Type \#1: Architectural/Physical Barriers ......................................... 86

Table 11 Barrier Type \#2: Attitudinal Barriers........................................................ 88

Table 12 Barrier Type \#3: Organizational/Systemic Barriers .................................... 89

Table 13 Barrier Type \#4: Informational/Communicational Barriers ........................... 90

Table 14 Barrier Type \#5: Technological Barriers .................................................... 90

Table 15 Directed Storytelling Participants ............................................................... 102

Table 16 Participant 4's negative experiences and recommendations......................... 110

Table 17 Barrier Type \#1: Architectural/Physical Barriers ......................................... 116

Table 18 Barrier Type \#2: Attitudinal Barriers......................................................... 118

Table 19 Barrier Type \#3: Organizational/Systemic Barriers ................................... 118

Table 20 Barrier Type \#4: Informational/Communicational Barriers .......................... 119

Table 21 Barrier Type \#5: Technological Barriers ................................................. 119

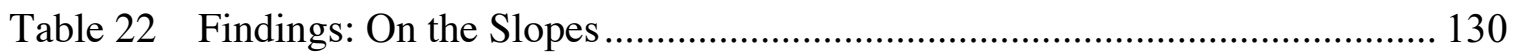




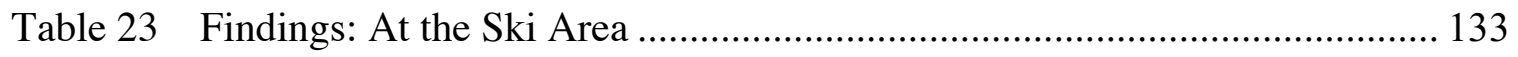

Table 24 Findings: Outside of the Ski Area......................................................... 138

Table 25 Frequency of Themes of Barriers to Accessibility .................................. 139

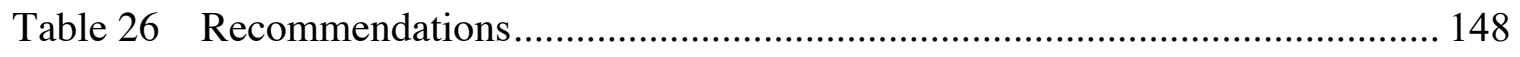

Table 277 Principles of Universal Design for Skiing .......................................... 153 


\section{List of Illustrations}

Illustration 1 Research Question and Sub-Research Questions ...................................... 18

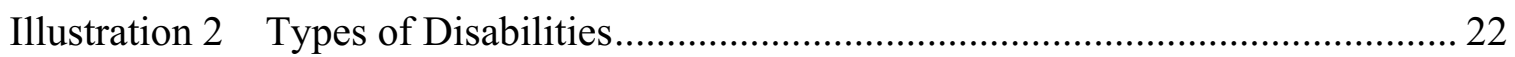

Illustration 3 Equity versus Equality (Hawranik, 2020) .............................................. 23

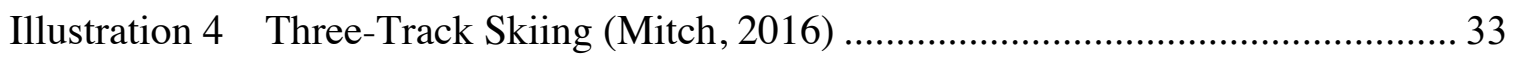

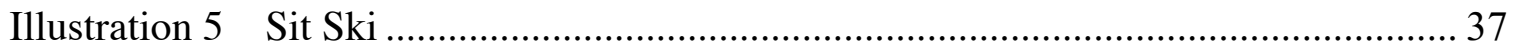

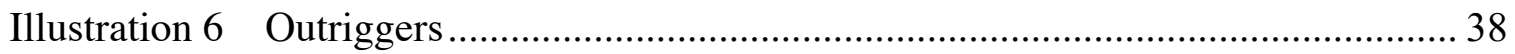

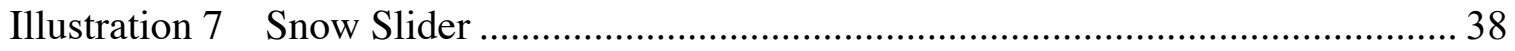

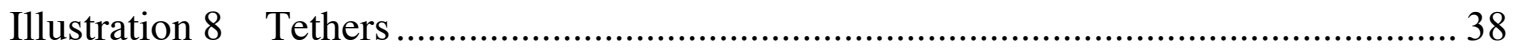

Illustration 9 Temporary Modifications of Adaptive Ski Equipment (Moden, 2019) ... 40

Illustration 10 Whistler's Accessibility Map (Resort Municipality of Whistler, n.d.) .. 46

Illustration 11 Google Local Guides User Interface (TraciC, 2017) ............................ 47

Illustration 12 AccessNow rating system and pin-point map (AccessNow, 2016) ....... 48

Illustration 13 Research Phases ........................................................................... 53

Illustration 14 Two Stages of Participant Recruitment ................................................ 59

Illustration 15 CADS Adaptive Ski Equipment at Snow Mountain ............................... 63

Illustration 16 Modified Adaptive Ski Equipment...................................................... 64

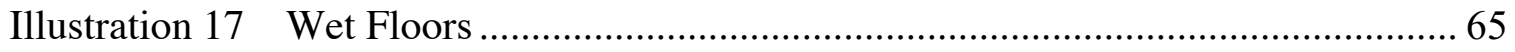

Illustration 18 Shoveling snow to create a ramp into the lodge..................................... 66

Illustration 19 Accessibility Challenges in the Lodge .................................................. 67

Illustration 20 Ontario ski areas that provide accessibility information on their website

Illustration 21 Participants' relationships to adaptive skiing ......................................... 84 
Illustration $2225(32.9 \%)$ participants described themselves as a person with a disability 85

Illustration 23 Barriers to Accessibility Experienced/Witnessed by Participants ......... 86

Illustration 24 "If you were planning to visit a ski area for the first time, would you

seek information about the accessibility of the ski area?" ......................................... 91

Illustration 25 "How would you seek the accessibility information?" ........................ 92

Illustration 26 "Has there ever been a time that you could not find accessibility

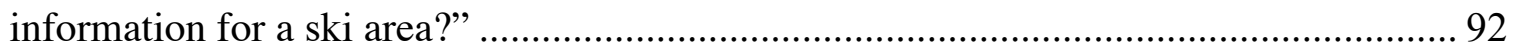

Illustration 27 The path of expression framework (Sanders \& Stappers, 2014)........... 96

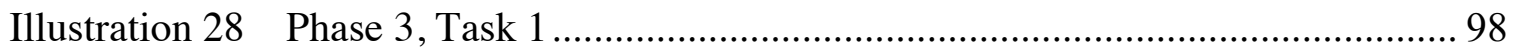

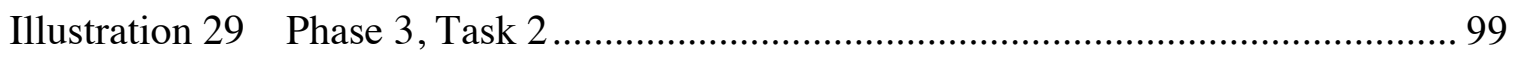

Illustration 30 Participant 1: User Journey Map ..................................................... 104

Illustration 31 Participant 2: User Journey Map .................................................... 107

Illustration 32 Participant 3: User Journey Map ................................................... 109

Illustration 33 Participant 4: User Journey Map .................................................... 111

Illustration 34 Participant 5: User Journey Map ................................................. 113

Illustration 35 Participant 6: User Journey Map ................................................... 115

Illustration 36 Initial Round of Triangulation using Affinity Diagramming .............. 123

Illustration 37 Where barriers to accessibility are encountered ................................ 125

Illustration 38 Second Round of Triangulation Using Affinity Diagramming ........... 127

Illustration 39 Triangulation: Ski Area Map Exercise .......................................... 129

Illustration 40 Findings: Ski Area Map Exercise ................................................ 130

Illustration 41 Fuzzy Front End ....................................................................... 143 
Illustration 42 Participant Moods Throughout User Journey Maps........................... 147

Illustration 43 Participants' Average Moods Throughout User Journey Maps............ 147

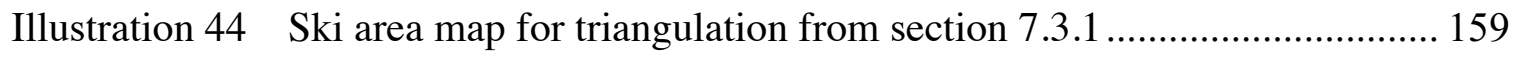

Illustration 45 Interactive Accessibility Map.................................................... 160 


\section{List of Appendices}

Appendix A.

A.1 Adaptive Ski Programs in Canada.........................................................182

Appendix B.

B.1 Phase 1 Research Ethics Protocol......................................................185

B.2 Phase 2 and Phase 3 Research Ethics Protocol.....................................199

Appendix C.

C.1 Ontario Ski Areas Provision of Accessibility......................................204

Appendix D.

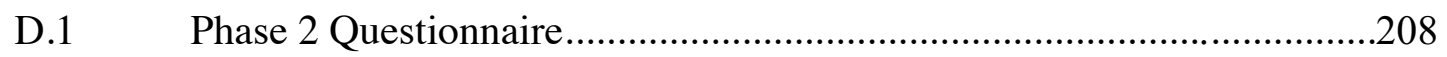

Appendix E.

E.1 Initial Round of Triangulation Using Affinity Diagramming.................218

E.2 Second Round of Triangulation Using Affinity Diagramming..............219 Appendix F.

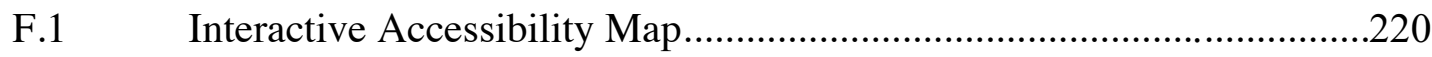




\section{Chapter 1: Introduction}

\subsection{Problem Statement}

Despite significant progress in accessibility and inclusivity, Canadians with disabilities experience indignities and exclusions regularly. Canada has yet to achieve a barrier-free society. Alpine ski areas reflect society's insufficient implementation of accessibility. Across Canada, ski areas do not consistently or thoroughly recognize the experiences of skiers with disabilities, which are often different from what non-disabled people take for granted. The types of barriers to accessibility that skiers with disabilities encounter include architectural and physical, attitudinal, organizational and systemic, informational and communicational, and technological barriers.

Skiers and snowboarders with disabilities are often referred to as adaptive skiers. Generally, adaptive skiers require specialized equipment or support to participate in skiing. Over the years, a range of adaptive ski equipment has been designed to meet the diverse needs of adaptive skiers. Likewise, adaptive ski programs, such as the Canadian Adaptive Snowsports (CADS), offer persons with physical, cognitive, and/or sensory impairments opportunities to participate in skiing. Despite the presence of adaptive skiers and adaptive ski programs, it appears that numerous ski areas in Canada do not adequately identify and address their barriers to accessibility (Mayer, 2020; Conference Board of Canada, 2018; Wheelchair Traveling, 2011). 


\subsection{Background}

The researcher has a formal background in Industrial Design. Suitably, this thesis is approached through the lens of design research. Design research focuses on a usercentered approach that aims to understand target users, their behaviours, and experiences-discovering how and why people behave as they do can present research opportunities and lead to more appropriate design outcomes. According to Fulton Suri (2013), “design research both inspires imagination and informs intuition through a variety of methods with related intents: to expose patterns underlying the rich reality of people's behaviours and experiences, to explore reactions to probes and prototypes, and to shed light on the unknown through iterative hypothesis and experiment" (Fulton Suri, 2013).

As an Industrial Designer, the researcher acknowledges the social responsibility to design products, services, and environments that are accessible and inclusive to persons of all abilities and disabilities. This thesis marries the researcher's dedication to accessibility and inclusivity with her passion for alpine skiing.

Initially, the researcher anticipated that this thesis would explore a product-focused issue related to adaptive skiing. The first of three research phases in this thesis considers the interactions between adaptive skiers and products. For example, the design of adaptive ski equipment is examined with the intent of uncovering issues such as ergonomics, ease of use, or performance. However, the first research phase warns that a greater underlying issue is encumbering adaptive skiing: the design of ski areas. Ski areas are not always designed to be usable by persons with disabilities. Adaptive ski equipment pales in 
comparison to the need to address the accessibility and inclusivity of ski areas. If persons with disabilities cannot access or use ski areas, they cannot partake in adaptive skiing. Thus, this thesis explores how design research can be used to identify and address the barriers to accessibility for skiing.

\subsection{Objective and Outcomes}

The objective of this thesis is to review and analyze challenges that persons with disabilities experience that impede accessibility and inclusion for skiing. The intended outcomes include:

1) The identification of barriers to accessibility that are experienced by adaptive skiers

2) Design recommendations and practical approaches for addressing the barriers to accessibility for skiing

\subsection{Main Research Question and Sub-Research Questions}

This research asks: How can design research be used to identify and address barriers to accessibility for skiing?

Three research phases facilitate the exploration of this main research question. Phase 1 and Phase 2 ask "what is?", to discover and define barriers to accessibility for skiing. Phase 3 seeks solutions to address the barriers to accessibility by asking "what could be?". Participatory design facilitates target users and subject matter experts of adaptive skiing to contribute to the development of design recommendations and practical 
approaches. Each research phase explores a sub-research question to support the pursuit of answering the main research question. Illustration 1 presents a breakdown of the main research question in relation to three research phases and sub-research questions.

Research Question:

How can design research be used to identify and address barriers to accessibility for skiing?

\begin{tabular}{|c|c|c|}
\hline Phase 1: Discovery & Phase 2: Definition & Phase 3: Design \\
\hline $\begin{array}{l}\text { Research Question Aim: } \\
\text { Identify ("What is?") }\end{array}$ & $\begin{array}{l}\text { Research Question Aim: } \\
\text { Identify ("What is?") }\end{array}$ & $\begin{array}{l}\text { Research Question Aim: } \\
\text { Address ("What could be?") }\end{array}$ \\
\hline $\begin{array}{l}\text { Sub-Research Question 1: } \\
\text { "What is the experience of adaptive } \\
\text { skiing?" }\end{array}$ & $\begin{array}{l}\text { Sub-Research Question 2: } \\
\text { "Have you ever experienced or } \\
\text { witnessed someone else experience } \\
\text { a barrier to accessibility for skiing?" }\end{array}$ & $\begin{array}{l}\text { Sub-Research Question 3: } \\
\text { "What are your past experiences and } \\
\text { future dreams for skiing for persons } \\
\text { with disabilities?" }\end{array}$ \\
\hline
\end{tabular}

\section{Illustration 1 Research Question and Sub-Research Questions}

\subsection{Scope}

This thesis takes place from January 2020 to May 2021. The scope of the thesis and rationale include:

1) Adaptive Ski Programs and Ski Areas in Canada: Adaptive ski programs and ski areas across Canada are examined and contribute to this thesis. Due to proximity to the researcher, the thesis focuses closest on adaptive ski programs and ski areas in Ontario and Québec.

2) Skiers with Disabilities: This thesis does not focus on a specific type of disability. Instead, it aims to encompass a spectrum of disabilities because most adaptive ski programs serve persons with physical, cognitive, and/or sensory impairments. 


\subsection{Significance to the Field}

This thesis presents an overview of barriers to accessibility that persons with disabilities experience when skiing and the factors that lead to these barriers. It contributes design recommendations for adaptive ski programs and ski areas, as well as practical approaches for implementing accessibility. The future research and design of a novel method is proposed. Accordingly, an interactive accessibility map may offer an opportunity for information provision and to minimize the impact of barriers to accessibility. Lastly, the thesis demonstrates the value of collaboration between the design researcher, subject matter experts, and target users to develop insightful recommendations for addressing barriers to accessibility for skiing.

Notably, the findings emerge based on adaptive ski programs and ski areas in Canada, however, they may also be valuable to the global community.

\subsection{Overview of Chapters}

Chapter 2 reviews existing literature to explore how barriers to accessibility are discussed in relation to the experience of skiing. The literature reviews the historical relationship between skiing and persons with disabilities to seek insights into Canada's limited implementation of accessibility and inclusivity at ski areas.

Next, Chapter 3 discusses the thesis's research design and explains the rationale for the approaches and research methods that are used. An exploratory sequential approach guides the research design and allows the methods and analysis from one phase to inform 
the next phase and then the next. Accordingly, Chapter 3 provides an overview of the three research phases and their methods. Chapter 4 details Phase 1: Discovery, a preliminary field study; Chapter 5 details Phase 2: Definition, a questionnaire; Chapter 6 details Phase 3: Design, directed storytelling. Next, Chapter 7 triangulates the methods from the three research phases to analyze and synthesize the findings together.

Chapter 8 is a discussion of the research findings and offers design recommendations and practical approaches for addressing barriers to accessibility for skiing. Chapter 8 also suggests the future research and design of a novel method, an interactive accessibility map, that might improve the experience of adaptive skiing. Lastly, Chapter 9 is the conclusion, which highlights the thesis's contributions. 


\section{Chapter 2: Literature Review}

\subsection{Overview}

The key aim of the literature review is to explore how barriers to accessibility are discussed in relation to the experience of skiing. The literature review highlights design research approaches that may be useful for studies concerning accessibility and persons with disabilities. To set the groundwork, the literature discusses the importance of accessibility and the motivations for making skiing inclusive. Next, to provide insights into why accessibility is not consistently and thoroughly implemented at ski areas across Canada, the literature explores the historical relationship between skiing and persons with disabilities.

The topics explored in the literature review provide background on the experience of skiing with a disability. The literature serves as a guide for using design research to identify and address barriers to accessibility for skiing.

\subsection{Design and (Dis)Ability}

According to Statistics Canada (2017), one in seven Canadians report living with a disability (Statistics Canada, 2017). Many people will experience some form of disability within their lifetime (Illustration 2), be it permanent, temporary, episodic, or situational (Bradshaw, 2019). From 2017 to 2037, Canada's senior population is expected to grow by $68 \%$ (Canadian Institute for Health Information, 2017). 


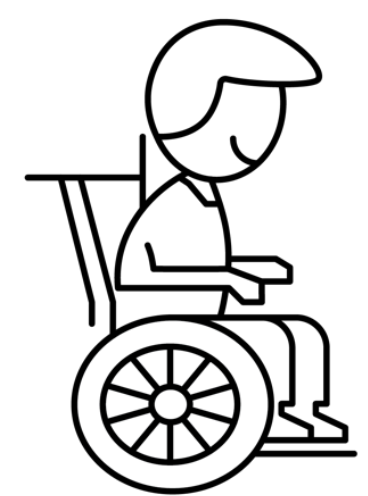

Permanent Disability

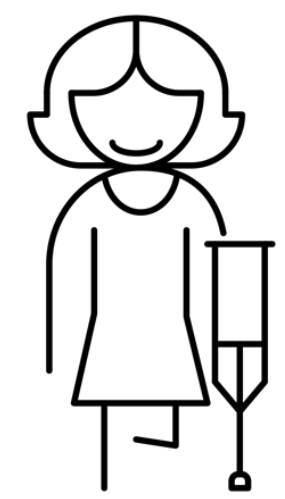

Temporary Disability

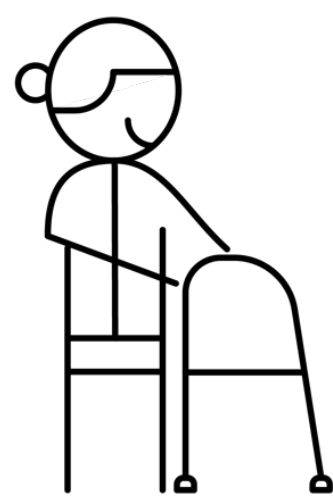

Episodic Disability

\section{Illustration 2 Types of Disabilities}

Designers have a responsibility to consider the diversity in user needs to achieve usable products, services, and environments. The following are multiple design approaches that aim to include users of all abilities and disabilities.

\subsubsection{Universal Design}

Universal design is the design of products, services, and environments that are "usable by all people, to the greatest extent possible, without the need for adaptation or specialized design" (Mace et al., 1997). In the broadest terms, universal design is design for all people, which emphasizes user-centered design to accommodate the needs of people of all ages, sizes, and abilities (Null, 2014). As seen in Illustration 3, universal design does not encompass the same treatment or equitable treatment of people. Instead, it advocates for barrier-free designs that allow as many people as possible to interact with a product, service, or environment equally (Hawranik, 2020). 


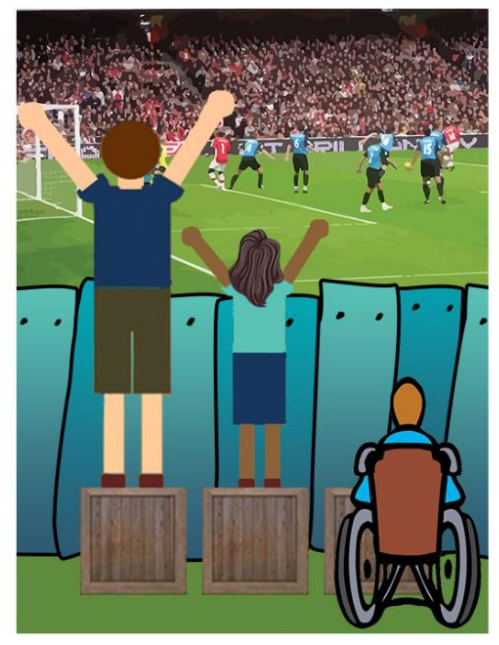

Same Treatment

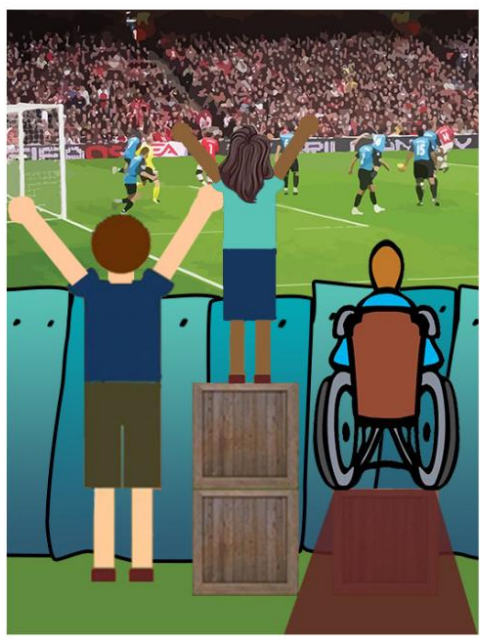

Equitable Treatment

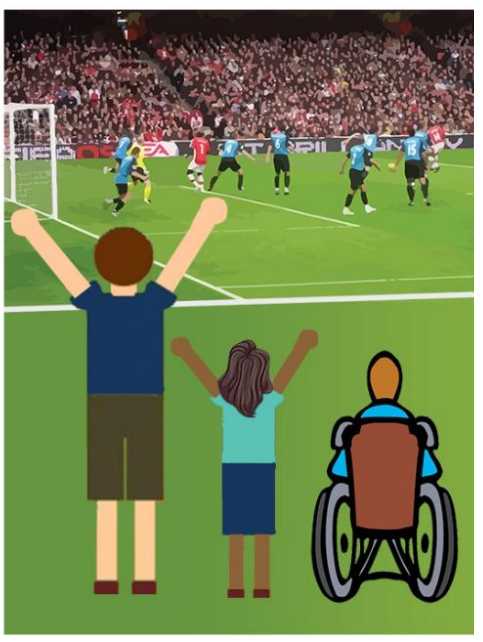

Equal Treatment

\section{Illustration 3 Equity versus Equality (Hawranik, 2020)}

The term universal design was coined in 1997 by the architect Ronald Mace. Mace et al.

(1997) present the 7 Principles of Universal Design, which may be applied to evaluate existing designs, guide the design process and educate both designers and consumers about the characteristics of more usable products, services, and environments. Table 1 outlines the 7 Principles of Universal Design.

\section{Table 1 The 7 Principles of Universal Design}

\begin{tabular}{|l|l|}
\hline Principle & Guidelines \\
\hline Principle 1: & Provide the same means of use for all users: identical \\
Equitable Use & whenever possible; equivalent when not. \\
\cline { 2 - 2 } $\begin{array}{l}\text { The design is useful and marketable to } \\
\text { people with diverse abilities. }\end{array}$ & $\begin{array}{l}\text { Provisions for privacy, security, and safety should be } \\
\text { equally available to all users. }\end{array}$ \\
\cline { 2 - 2 } & Make the design appealing to all users. \\
\hline Principle 2: & Provide choice in methods of use. \\
\cline { 2 - 2 } Flexibility in Use & Accommodate right- or left-handed access and use. \\
\cline { 2 - 2 } $\begin{array}{l}\text { The design accommodates a wide range of } \\
\text { individual preferences and abilities. }\end{array}$ & Facilitate the user's accuracy and precision. \\
\cline { 2 - 2 } & Provide adaptability to the user's pace. \\
\hline Principle 3: & Eliminate unnecessary complexity. \\
\hline
\end{tabular}




\begin{tabular}{|c|c|}
\hline \multirow{4}{*}{$\begin{array}{l}\text { Simple and Intuitive Use } \\
\text { Use of the design is easy to understand, } \\
\text { regardless of the user's experience, } \\
\text { knowledge, language skills, or current } \\
\text { concentration level. }\end{array}$} & Be consistent with user expectations and intuition. \\
\hline & $\begin{array}{l}\text { Accommodate a wide range of literacy and language } \\
\text { skills. }\end{array}$ \\
\hline & Arrange information consistent with its importance. \\
\hline & $\begin{array}{l}\text { Provide effective prompting and feedback during and after } \\
\text { task completion. }\end{array}$ \\
\hline \multirow{5}{*}{$\begin{array}{l}\text { Principle 4: } \\
\text { Perceptible Information } \\
\text { The design communicates necessary } \\
\text { information effectively to the user, } \\
\text { regardless of ambient conditions or the } \\
\text { user's sensory abilities. }\end{array}$} & $\begin{array}{l}\text { Use different modes (pictorial, verbal, tactile) for } \\
\text { redundant presentation of essential information. }\end{array}$ \\
\hline & $\begin{array}{l}\text { Provide adequate contrast between essential information } \\
\text { and its surroundings. }\end{array}$ \\
\hline & Maximize "legibility" of essential information. \\
\hline & $\begin{array}{l}\text { Differentiate elements in ways that can be described (i.e., } \\
\text { make it easy to give instructions or directions). }\end{array}$ \\
\hline & $\begin{array}{l}\text { Provide compatibility with a variety of techniques or } \\
\text { devices used by people with sensory limitations. }\end{array}$ \\
\hline \multirow{4}{*}{$\begin{array}{l}\text { Principle 5: } \\
\text { Tolerance for Error } \\
\text { The design minimizes hazards and the } \\
\text { adverse consequences of accidental or } \\
\text { unintended actions. }\end{array}$} & $\begin{array}{l}\text { Arrange elements to minimize hazards and errors: most } \\
\text { used elements, most accessible; hazardous elements } \\
\text { eliminated, isolated, or shielded. }\end{array}$ \\
\hline & Provide warnings of hazards and errors. \\
\hline & Provide fail safe features. \\
\hline & $\begin{array}{l}\text { Discourage unconscious action in tasks that require } \\
\text { vigilance. }\end{array}$ \\
\hline \multirow{3}{*}{$\begin{array}{l}\text { Principle 6: } \\
\text { Low Physical Effort }\end{array}$} & Allow user to maintain a neutral body position. \\
\hline & Use reasonable operating forces. \\
\hline & Minimize repetitive actions. \\
\hline $\begin{array}{l}\text { The design can be used efficiently and } \\
\text { comfortably and with a minimum of fatigue. }\end{array}$ & Minimize sustained physical effort. \\
\hline \multirow{4}{*}{$\begin{array}{l}\text { Principle 7: } \\
\text { Size and Space for Approach and Use } \\
\text { Appropriate size and space is provided for } \\
\text { approach, reach, manipulation, and use, } \\
\text { regardless of user's body size, posture, or } \\
\text { mobility. }\end{array}$} & $\begin{array}{l}\text { Provide a clear line of sight to important elements for any } \\
\text { seated or standing user. }\end{array}$ \\
\hline & $\begin{array}{l}\text { Make reach to all components comfortable for any seated } \\
\text { or standing user. }\end{array}$ \\
\hline & Accommodate variations in hand and grip size. \\
\hline & $\begin{array}{l}\text { Provide adequate space for the use of assistive devices or } \\
\text { personal assistance. }\end{array}$ \\
\hline
\end{tabular}

\subsubsection{Ability-Based Design}

Many approaches for designing for persons with disabilities centralize disability. In other

words, traditional design for disability approaches seek solutions to compensate for the

limitations of disabled users. The term disability indicates the lack of ability and focuses

on what a person cannot do. Wobbrock et al. (2011) introduce a refocused perspective

called ability-based design. Rather than asking, "what disability does a person have?",

ability-based design asks, "what can a person do?" (Wobbrock et al., 2011). Approaching 
design from an ability-based perspective seeks to leverage the full range of human potential. For example, in 2019, a CADS volunteer recognized that a skier in the program was having difficulty pulling an adjustment cord attached to their sit-ski. Due to limited dexterity from progressive multiple sclerosis, the skier could not firmly grip the cord. The CADS volunteer applied an ability-based approach and explored cord solutions to work with the skier's abilities. Inspired by life-preserver ripcords, a small ball was attached to the end of the cord for quick and effective use (Canadian Adaptive Snowsports, 2019).

\subsubsection{Design for Users versus Design with Users}

Design for Users and Design with Users are two approaches that emphasize the needs of target users. Design for Users occurs when users are considered during the design process to make user-friendly products, services, and environments (Nielson, 2019). Studying users through interviews, observations, and focus groups can lead to insights about needs, desires, and problems (Laurel, 2003). Seeking user input can help designers gain empathy, which is essential for understanding alternative perspectives. Kouprie and Visser (2009) propose a framework for supporting empathic approaches for design. This framework recommends that designers attempt to gain a greater appreciation of the user's world, memories, and experiences. By developing empathy, the designer may better understand how to design for the user (Kouprie \& Visser, 2009). However, empathy is not equivalent to lived experience. Designer, Liz Sanders, is known for saying, "we are all experts of our own experience" (Sanders \& Stappers, 2014). In other words, despite being trained professionals, designers must recognize that other people may be more knowledgeable in certain situations. Sanders is an expert in co-creation or participatory 
design, which is a method of designing with users. Participatory design can be defined as "any act of collective creativity, i.e., creativity that is shared by two or more people" (Sanders \& Stappers, 2014). Design with Users suggests that subject matter experts and target users become co-designers, offering expertise throughout key stages in the design process (Carlson et al., 2014). Participatory design can be achieved through workshops or generative sessions that include subject matter experts and target users in creative activities using materials provided by designers and researchers. Designing with subject matter experts and target users can contribute to more appropriate and usable outcomes.

\subsection{Motivations for Accessibility}

To clarify why accessibility is of value to skiing, the literature highlights motivations for the implementation of accessibility. According to a 2016 survey by the Angus Reid Institute, $95 \%$ of Canadians believe that accessibility is an "important" consideration when planning for new design (Angus Reid Institute, 2016). Ironically, many buildings and public spaces in Canada continue to exclude a significant number of persons with disabilities (Rick Hansen Foundation, 2017). In the case of Canadian ski areas, accessibility is not consistently or thoroughly implemented.

Accessibility is a necessity for inclusion and is not only of benefit to persons with disabilities. The literature explores the following motivations for implementing accessible design, which are described in more detail below:

1) The Skier Experience

2) Human Rights 
3) Social

4) Health and Wellness

5) Standards

6) Economies

\subsubsection{The Skier Experience}

The skier experience may be different for everyone, but skiers frequently discuss the sense of the freedom that they feel when skiing, physically, emotionally, and mentally. In the words of Warren Miller, a prolific skiing filmmaker, "a pair of skis are the ultimate transportation to freedom" (Powder White, 2020). Physically, skiing can offer the exhilaration of speed and controlled turns. Even Oprah Winfrey famously said, "skiing is the next best thing to having wings" (Powder White, 2020). Emotionally, a spectrum of feelings can be used to describe the skier experience - bliss, fear, and accomplishment. Upon developing a technical skill or completing a challenging run, one may feel a sense of pride. Mentally, many describe skiing as a meditative or therapeutic activity. The skier experience can shift ones focus from daily stresses, feelings, or thoughts to the present moment in order to react to the environment. Skiing can offer a connection to nature and excites people to spend time outdoors during the winter.

Words cannot do the skier experience justice. Anyone who is interested, should have the opportunity to experience the joys of skiing. Insufficient accessibility on behalf of skier areas can obstruct access to the skier experience. 


\subsubsection{Human Rights}

According to the Universal Declaration of Human Rights, the United Nations recognizes 30 universal human rights. In essence, "all human beings are entitled to all rights and freedoms without distinction of any kind, such as race, colour, sex, language, religion, political or other opinion, national or social origin, property, birth or other status" (Puybaret, 2008). Persons with disabilities, just like anyone else, have the right to equality, dignity, and to participate fully in society. Similarly, the United Nations also adopted the Convention on the Rights of Persons with Disabilities (CRPD) in 2006. Article 30 in the CRPD points to the right of persons with disabilities to take part on an equal basis with others in cultural life, recreation, leisure and sport (United Nations, 2016). Ski areas have a social responsibility to implement accessibility to avoid excluding or discriminating against persons with disabilities. Accessibility is a human right.

\subsubsection{Social}

Skiing can be a way for friends and families to spend quality time together, to meet new people, or belong to a community. Lape et al. (2017) conduct a qualitative focus group study to find factors that influence participation in adaptive sports programs. The findings emphasize that when people with disabilities participate in adaptive skiing, social inclusion increases. When people experience social inclusion, they are more likely to be happier and healthier. When excluded, people are more likely to experience poor health, loneliness, isolation, and poor self-esteem (Byrne, 2007). 
Fortunately, various adaptive ski programs in Canada aim to promote social inclusion and provide opportunities for persons with disabilities to ski. However, if persons with disabilities cannot access or use a ski area, the effectiveness of an adaptive ski program may be threatened. Barriers to accessibility for skiing may have varying levels of impact, such as:

1) A complete inability to participate in skiing

2) A lessened quality of experience of skiing, which may cause the overall experience to become negative

3) Inaccessibility for persons with disabilities may have adjacency effects on the participation of their families or friends

Ski areas have a social responsibility to address their barriers to accessibility to enable social inclusion and equitable experiences for persons with disabilities and their families and friends.

\subsubsection{Health and Wellness}

Designing for the inclusion of persons with disabilities can promote health and wellness. In a 2020 study, Ponti et al. highlight that adaptive skiing is "correlated with elevated levels of satisfaction ... and increases quality of life" (Ponti et al., 2020). Adaptive skiing may positively influence self-esteem, physical self-worth, standing balance, and gross motor function.

In terms of risks to health, Nasuti and Temple (2010) evaluate the benefits and the risk of 
injury of adaptive skiing for people with disabilities. The results point to no greater risks of engaging in adaptive skiing compared to traditional skiing. Nasuti and Temple (2010) view adaptive skiing as a therapeutic and rehabilitating sport. Similarly, Laskowski (1991) compares the injury rate of adaptive skiers to non-disabled skiers. The study indicates that there is not a significant difference in injury rates between the two populations. Skiers with disabilities appear to sustain less severe injuries.

In essence, an accessible ski area can empower a person with a disability to improve their health and wellness.

\subsubsection{Standards}

Standards are established requirements that aim to identify, eliminate, and prevent barriers (Government of Canada, 2021). According to the Rick Hansen Foundation (n.d.), accessibility standards are typically minimum measures that will address approximately $40 \%$ of the barriers. In response, more rigorous accessibility standards are beginning to emerge at federal, provincial, and municipal levels. For example, the City of Ottawa strives to attain a higher level of accessibility with its Accessibility Design Standards (ADS) (Newell, 2015). The ADS embraces universal design, the "design of products and environments to be usable by all people, to the greatest extent possible, without the need for adaptation or specialized design" (Mace et al., 1997). Universal design is a practical approach for creating inclusive environments (Steinfeld \& Maisel, 2012). 


\subsubsection{Economies}

The demographics of Canadians with disabilities continue to rise with the country's ageing populations. The market for accessible products and services is expected to continue growing (Portales, 2015). Canadians with disabilities have a disposable income of $\$ 55$ billion (eMarketer, 2014). Blue Mountain Resort (2018) estimates that if accessibility increases tourism by $3 \%$, the economy will gain an additional $\$ 750 \mathrm{M}$ in tourism spending. According to Curio Research, trying to retrofit accessible features after the fact can increase production cost by a factor of 10,000 (Isaacson, 2020).

\subsection{History of Skiing and Persons with Disabilities}

A look at the historical relationship between skiing and disability sets up the groundwork for understanding this area of interest. Huntford (2009), the author of "Two Planks and a Passion”, theorizes that skiing has a history of at least twenty-two millennia. Archaeological evidence suggests that humans invented skis to travel over snow and ice during the Paleolithic Ice Age as a mode of survival to enable hunters to track reindeer and elk across the tundra. Fast-forward to the 1760s, the Norwegian army held shooting competitions while skiing down slopes, around trees, and across level snowfields. These races were precursors to modern downhill skiing and Olympic winter events. According to Fry (2010) in “The Story of Modern Skiing”, alpine skiing began to attract civilians around the mid-1800s, especially in Norway and other parts of Europe. A rise in skiing as a recreational and competitive sport sparked a market for ski areas. Canada began to develop ski areas around the 1920s. Due to long winters and mountainous terrain, Canada's ski industry became recognized worldwide, attracting locals, tourists, and 
international athletes (Manry, 2001). Persons with disabilities were generally unable to participate in skiing due to a lack of adaptive ski equipment and accessible ski areas (Laskowski, 1991). Within the social and political context of the 1920s, persons with disabilities were seen to be incapable and dependent on others. Little policy or legislation existed to promote accessibility or inclusion (Galer, 2015).

The literature recognizes the Second World War as a catalyst in developing adaptive skiing (De Luigi, 2018). In 1942, Franz Wendel, a German war amputee, lost a leg, which impeded his ability to ski. In response, Wendel attached a pair of short skis to the bottom of his crutches and attached one ski to his foot to ski down a slope (Illustration 4). This technique is referred to as "three-track" skiing. Wendel's crutches led to the development of today's "outriggers" (as seen in section 2.7.2 in Illustration 6), a common type of adaptive ski equipment used for balance (Disabled Sports USA, n.d.). Wendel became the first person with a disability to enter a ski competition using outriggers (Mitch, 2016).

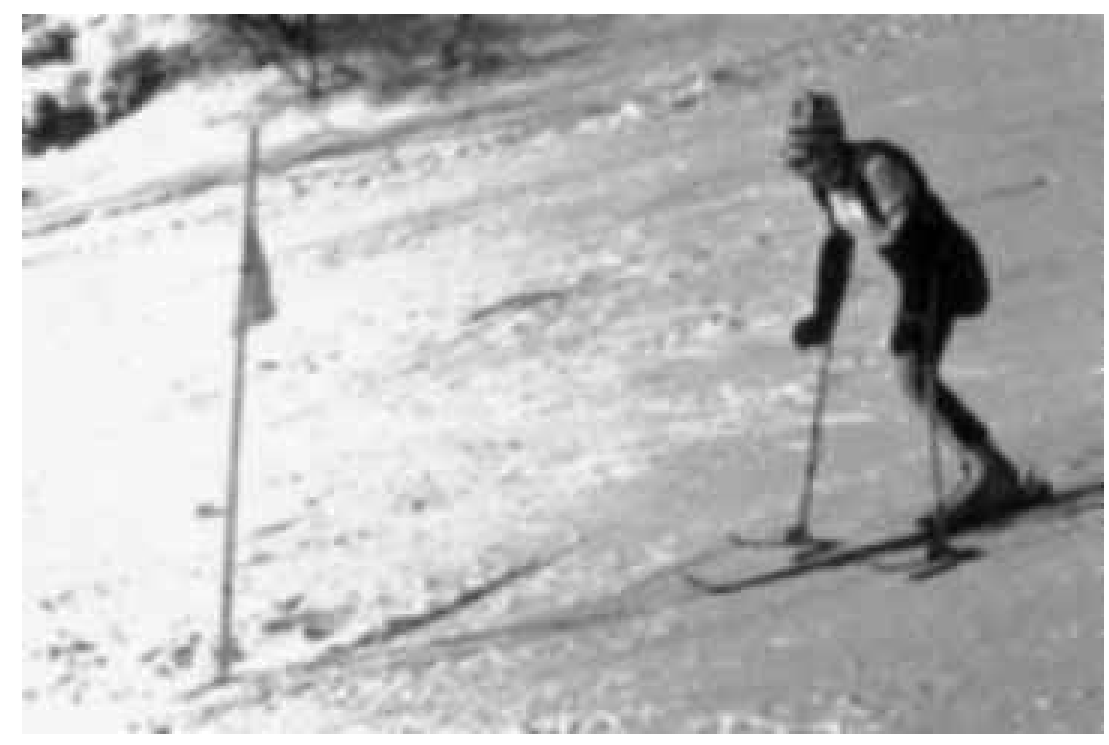




\section{Illustration 4 Three-Track Skiing (Mitch, 2016)}

Similarly, an Austrian veteran, Sepp Zwicknagl, lost both of his legs during the Second World War. Zwicknagl experimented with skiing prostheses and taught himself to ski again (Cross Country Ski de fond Canada, 2018). Eventually, Zwicknagl became a ski instructor and founded a division for disabled skiers within the Austrian Ski Association (Disabled World, 2017).

Over time, adaptive skiing gained popularity among civilians and expanded beyond physical disability to include sensory and cognitive conditions (De Luigi, 2018). Especially around the 1970s, interest in recreational and competitive skiing for persons with disabilities was echoed by programs such as Special Olympics International and Canadian Adaptive Snowsports (CADS), as well as a growing market for adaptive ski equipment. Despite the emergence of adaptive skiing, numerous ski areas have been slow to redevelop or construct accessible facilities and services to encompass the needs of persons with disabilities.

The literature points to large events and festivals, such as the Paralympic Winter Games and World Disabled Alpine Championships, as catalysts for inclusion. When put on a global stage, some ski areas recognized the necessity of accessibility for hosting paraathletes and increasing tourism. For example, in 2010, Whistler hosted the Olympic and Paralympic Winter Games. In preparation, Whistler installed an accessible athlete's lodge, 75 accessible rooms, and high-performance training gyms. Additionally, Whistler updated some of their existing facilities, such as accessible washrooms, stairs, ramps, and 
elevators, accessible entries, pathways, and transportation services (Whistler, 2017). As one of the results of preparing for the 2010 Olympic and Paralympic Winter Games, the Resort Municipality of Whistler adopted the Measuring Up program and began the process of developing an accessibility strategy that encompasses much more than a focus on just physical change to the environment, but also on inclusion (Whistler, 2020). Today, Whistler continues to set and achieve goals to "sustain ability" and inclusion.

Notably, Whistler is an exception. Not all ski areas in Canada have been designed or updated to accommodate persons with disabilities, potentially due to variance in the motivations or resources of the ski areas.

\subsection{Adaptive Ski Programs}

Adaptive ski programs provide persons with disabilities opportunities to participate in alpine skiing and snowboarding (Templeman, 2002). Adaptive ski programs are commonly volunteer-based. Volunteers are trained regularly, and some become certified ski instructors. The core mission of volunteers and instructors is to support persons with disabilities when skiing and to provide lessons to promote skill development (Canadian Adaptive Snowsports, 2019).

Adaptive ski programs typically serve children, youth, and adults with disabilities, such as physical, cognitive, and sensory impairments (CADS National, 2020). Persons with disabilities can enroll in adaptive ski programs as students and are typically required to pay a fee similar to a ski school program. The fee helps provide students with adaptive 
ski equipment for the ski season's duration, which takes place in January, February, and sometimes early to mid-March.

Notably, only select ski areas have adaptive ski programs. Over 79 ski area locations in Canada have an adaptive ski program (Hancock, 2016; Canadian Ski Council, 2021). To put this into perspective, Canada has approximately 291 ski areas (Ski Resort Info, 2021). Appendix A provides a list of nearly all the adaptive ski programs in Canada. The list is not exhaustive because some ski areas may have smaller programs or private schools or lessons. Some ski areas offer certified ski instructors for skiers with disabilities, independent of an adaptive ski program.

\subsection{Skiing with a Disability}

Most adaptive ski programs will either work with a specific type of impairment or serve a broad spectrum of persons with disabilities. For example, some adaptive ski programs, such as Ski Hawks, specialize in supporting persons with visual impairments or who are blind (CADS-NCD, 2020). Additionally, programs such as the Canadian Veterans Winter Sports Clinic specialize in supporting veterans (CADS-NCD, 2020). Veterans in adaptive ski programs commonly include amputees, para or quadriplegic, visually impaired, or persons with cognitive impairments (Canadian Adaptive Snowsports, 2019).

Meanwhile, adaptive ski programs, such as divisions of CADS and BC Adaptive Snowsports, aim to encompass a larger range of disabilities. Adaptive ski students may have physical, cognitive, and/or sensory impairments. The following is a non-exhaustive 
list of common disabilities that CADS supports:

1) Cerebral palsy

2) Spina bifida

3) Spinal cord injuries

4) Multiple sclerosis

5) Muscular dystrophy

6) Visual impairments

7) Amputation

8) Autism Spectrum Disorders \& Cognitive Impairments

9) Hemiplegics, Paraplegics \& Quadriplegics

McKercher and Darcy (2018) discuss this type of disaggregation, where people with disabilities are frequently seen as a homogenous group. However, "in reality, they are a heterogeneous cohort who face the same types of barriers as everyone, some barriers that are common to all people with disabilities, those that are unique to each disability dimension and specific impairment effects that are individualistic" (McKercher \& Darcy, 2018).

\subsection{Adaptive Ski Equipment}

A breadth of adaptive ski equipment has been designed to support skiers with disabilities (Canadian Ski Council, 2021). The following subsections highlight common types of adaptive ski equipment. 


\subsubsection{Sit Ski}

Illustration 5 shows two common types of sit skis: a bi-ski and a mono-ski. A bi-ski consists of a molded seat mounted to a frame above two skis. The two skis give a wider base and better balance than a mono-ski. A mono-ski consists of a molded seat mounted to a frame above one ski.

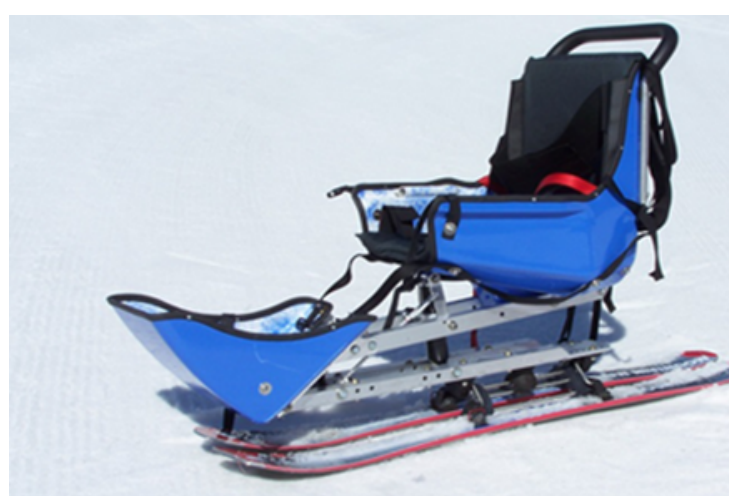

Bi-Ski

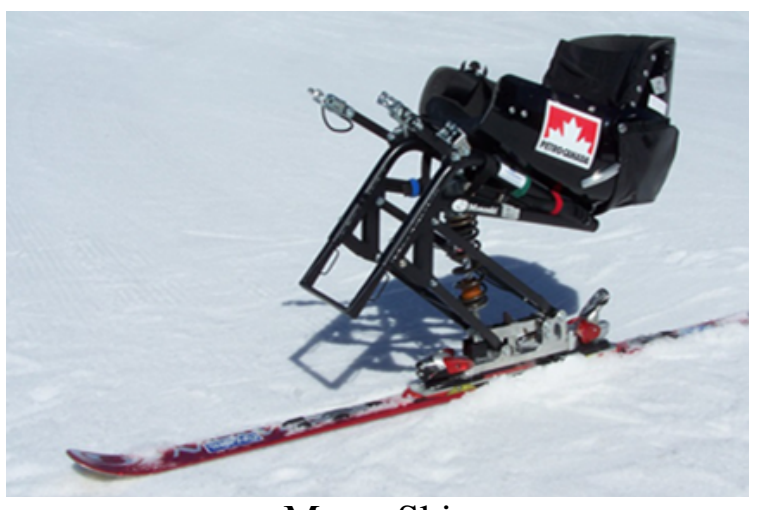

Mono-Ski

Illustration 5 Sit Ski

\subsubsection{Outrigger Poles}

Outriggers are used primarily for balance. As seen in Illustration 6 , the outrigger is a forearm crutch with a short ski attached to the bottom of the crutch and takes the place of ski poles. Outriggers are commonly used with a sit ski or standing (track skiing).

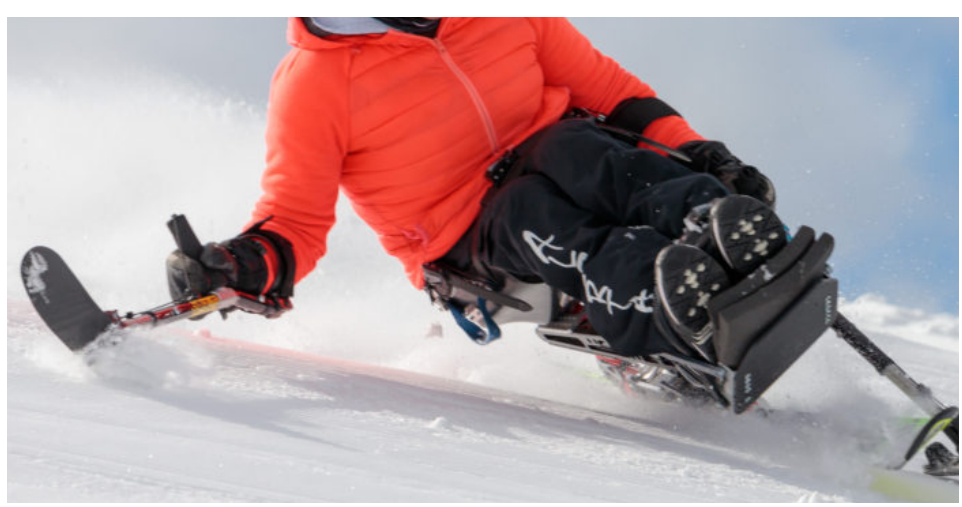

Outriggers \& Sit Ski

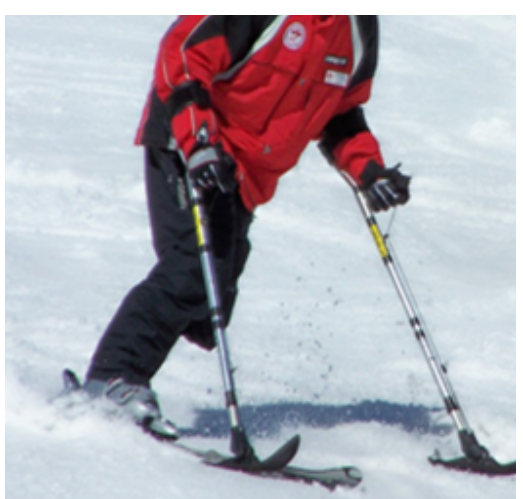

Outriggers \& Standing 


\section{Illustration 6 Outriggers}

\subsubsection{Snow Slider}

A snow slider is a frame with forearm rests and skis attached to the bottom. They can support weight and assist with balance (Illustration 7).
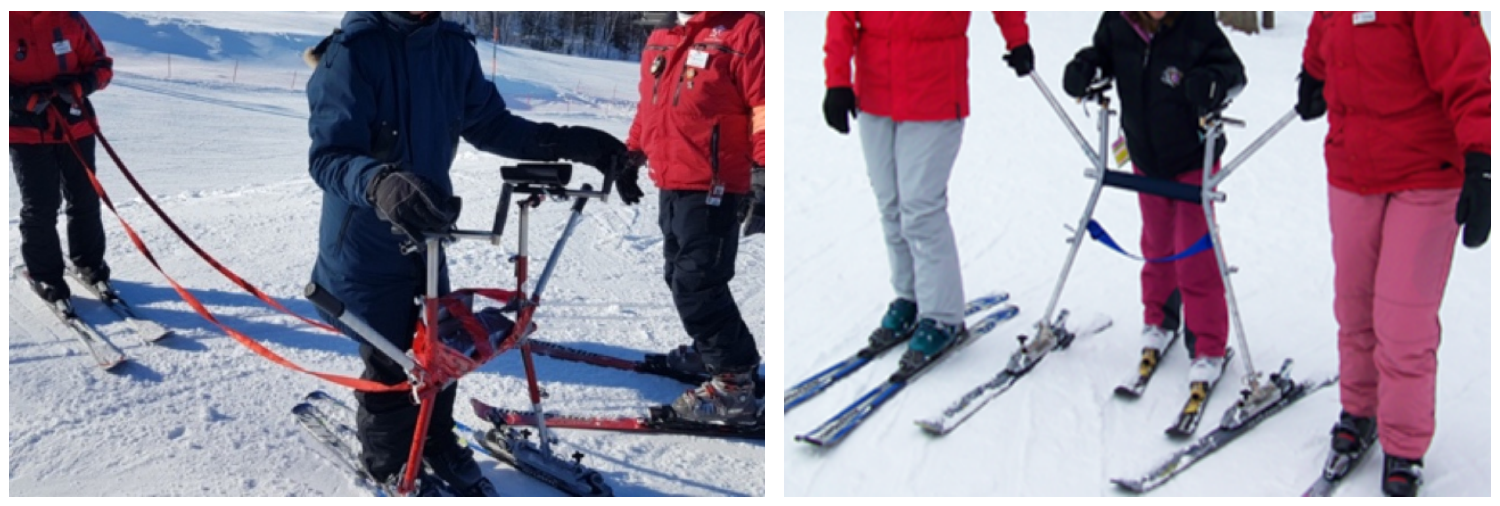

Illustration 7 Snow Slider

\subsubsection{Tethers}

Tethers can be attached to adaptive skiers and/or most types of adaptive ski equipment (Illustration 8). A tetherer (usually a ski instructor or volunteer) can control the tethers to assist with steering and maintaining control.
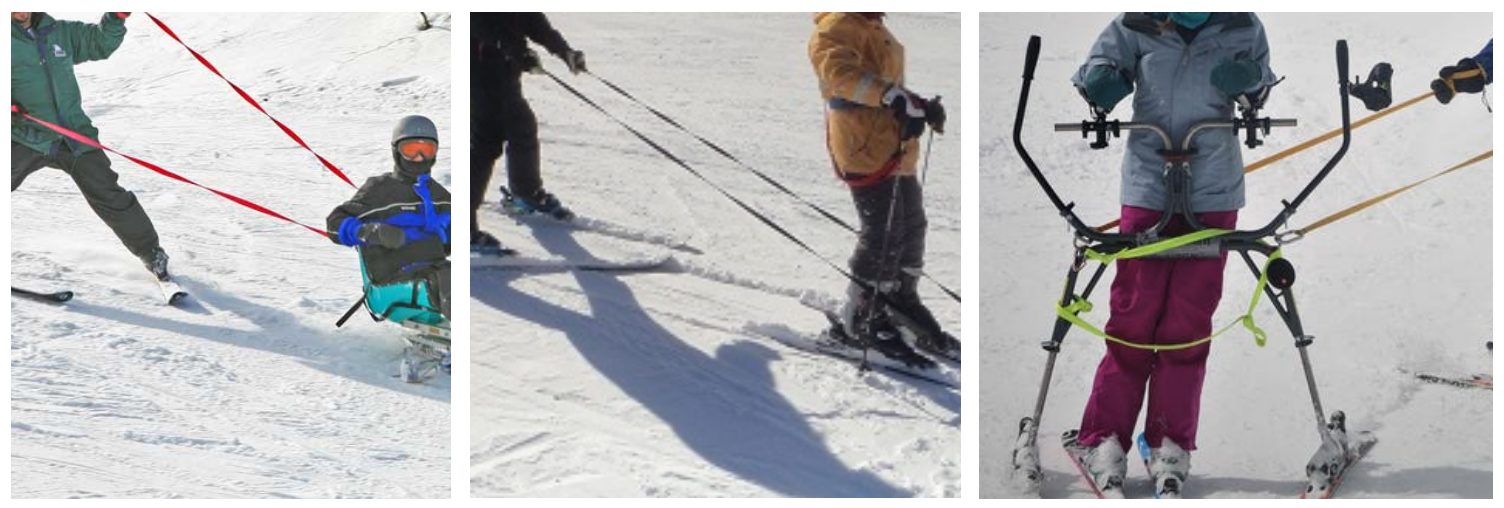

Illustration 8 Tethers 


\subsubsection{Adaptability and Modifications}

Barreda (n.d.) points out that adaptive ski equipment is typically designed to be adjustable. Popular sit skis, such as the Mountain Man and Dynamique, offer various setup options to enhance the fit based on the skier's dimensions (Barreda, n.d.). To serve a breadth of abilities and performance levels, adjustability of adaptive ski equipment is an important design consideration to help optimize safety, human wellbeing, and overall system performance (Woodson, 1981). Similar to a ski boot, adaptive ski equipment should be snug and comfortable. To increase fit and comfort, sit-ski manufacturers like Tessier offer custom-made seats that are molded to the skier's contours (Tessier, 2019). In other cases, foam, gel, or cushion inserts may be used (Cooper, 1995). Due to equipment availability and costs, fitting each adaptive ski student with custom-made equipment or molded features is often unattainable for adaptive ski programs. Chris Moden is an experienced sit-ski tetherer and instructor with CADS, the Canadian Veterans Winter Sports Clinic, and the American National Disabled Veterans Winter Sports Clinic. Moden is the author of the Sit Ski Blog, where he shares insights and ideas for adaptive skiing. According to Moden (2019), CADS makes temporary modifications to adaptive ski equipment with found materials, such as duct tape, foam, and pool noodles (Illustration 9).
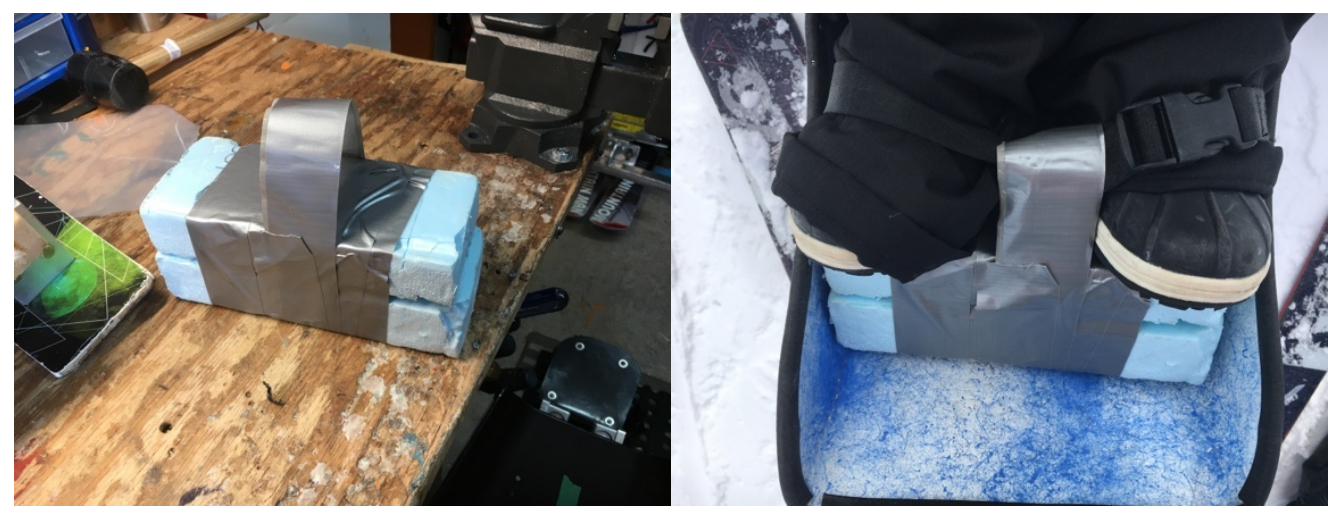


\section{Illustration 9 Temporary Modifications of Adaptive Ski Equipment (Moden, 2019)}

McCauley and Frankel (2020) discuss temporary modifications of adaptive ski equipment in relation to a paradox of inclusivity and individualism, where designers must consider the collective needs of many and the exceptional needs of individuals. In the instance of designing a sit ski, a designer may want to aim to develop a device that is inclusive, accessible, and usable for as many people as possible. In contrast, a designer applying an individualized approach may want to create a sit ski that acknowledges the problem of designing for everyone's unique differences. Essentially, no two adaptive skiers are alike. The paradox of inclusivity and individualism encourages the design of barrier-free systems, but also the integration of customized supports to ensure that people of all abilities gain equal opportunities to participate in adaptive skiing.

\subsection{Barriers to Accessibility for Skiing}

Accessibility allows people with diverse abilities to navigate, understand, and use a product, service, or environment (Erlandson, 2008). In Canada, organizations, including ski areas, are subject to provincial laws and accessibility standards (Government of Canada, 2021). For example, ski areas in Ontario are within the jurisdiction of the Accessibility for Ontarians with Disabilities Act (AODA), a law that sets out a process for developing and enforcing accessibility standards (Government of Ontario, 2021). Laws and accessibility standards can vary significantly from province to province. Most provincial standards point to minimal accessibility requirements, which are insufficient (Rick Hansen Foundation, 2017). 
In 2019, the Accessible Canada Act was introduced to realize a Canada without barriers by 2040 (Naef \& Perez-Leclerc, 2019). In the upcoming years, ski areas across Canada, regardless of provincial jurisdictions, are being encouraged by the Accessible Canada Act to identify and address their barriers to accessibility. The Accessible Canada Act defines a barrier as anything "that hinders the full and equal participation in society of persons with an impairment, including a physical, mental, intellectual, cognitive, learning, communication or sensory impairment or a functional limitation" (Legislative Services Branch, 2020). Architectural and physical barriers are commonly associated with barriers to accessibility. However, according to the Council of Ontario Universities (2013), there are five identified barriers to accessibility for persons with disabilities:

1) Architectural and physical barriers are elements of buildings or outdoor spaces that create barriers to persons with disabilities. For example: sidewalks and doorways that are too narrow for a wheelchair, scooter, or walker; tables that are too high for a person who is using a wheelchair, or other mobility devices; poor lighting that makes it difficult to see for a person with low vision or a person who lip-reads; doorknobs that are difficult to grasp for a person with arthritis.

2) Attitudinal barriers are behaviours, perceptions, and assumptions that discriminate against persons with disabilities. For example: assuming a person with a disability is inferior; assuming that someone with a speech impairment cannot understand you; forming ideas about a person because of stereotypes or a lack of knowledge; making a person feel as though you are doing them a "special favour" by accommodating their needs.

3) Organizational and systemic barriers are policies, procedures, or practices that 
unfairly discriminate and prevent individuals from participating fully in a situation. For example: offering customer services in person only, or not allowing users to access services by phone, e-mail, or other means of communication; having poorly defined or a lack of accessibility plans; requiring users to accomplish a task in only one way.

4) Informational and communicational barriers occur when sensory disabilities, such as hearing, seeing, or learning disabilities, have not been considered. These barriers relate to both the sending and receiving of information. For example: electronic documents that are not properly formatted and cannot be read by a screen reader; language that is not clear; print that is too small or in a font that is difficult to read; videos that are not captioned and do not have transcriptions.

5) Technological barriers occur when a device or technological platform is not accessible to its intended audience and cannot be used with an assistive device. For example: electronic documents without accessibility features, such as alternative (alt) text, that screen readers read to describe an image; books that are available only in hard copies; requiring skiers to use a website that does not meet accessibility standards; websites that cannot be accessed using screen-reading software.

According to Disabled World (2019), "the biggest barriers that people with disabilities encounter are other people" (Disabled World, 2019). Limited disability awareness and public knowledge about persons with disabilities propel attitudinal barriers. McGrattan (2001) recognizes the value of educating people regarding disabilities and giving people 
the knowledge needed to separate good practice from poor (Disabled World, 2019). Teaching disability etiquette to children and adults can provide guidelines for treating persons with disabilities appropriately and with common courtesy.

In the context of skiing, barriers to accessibility refer to obstacles that impede persons with disabilities from fully participating in skiing. A barrier to accessibility can occur at any time throughout the experience of skiing; for example, when a person with a disability is planning to visit a ski area, when traveling to the ski area, when parking, when navigating the lodge, skiing, and so on. Ultimately, the entire chain of events leading up to, and following, the physical act of skiing can contribute to barriers to accessibility for skiing.

The literature highlights a practical example of a ski area that is attempting to address barriers to accessibility for skiing. In Ontario, Blue Mountain Resort (BMR), the province's largest mountain village resort, is a leader in accessibility. BMR recognizes the five types of barriers to accessibility and is "committed to promoting an inclusive environment by preventing and removing barriers for persons with disabilities and allowing all guests the equal opportunity to access our goods and services in the same place and in the same way" (Blue Mountain Resorts LP, 2019). In 2018, BMR published a Multi-Year Accessibility Plan with the objective of preventing and removing barriers to accessibility for persons with disabilities. The Multi-Year Plan outlines the requirements for accessibility, including information and communication, the design of public spaces, and customer service standards. Like Whistler, BMR is an exception in terms of 
accessibility. These ski areas are committed to addressing barriers to accessibility to include persons with disabilities. Unfortunately, it appears that many other ski areas in Canada are ineffectively offering accessible facilities and services.

\subsection{Information Provision}

A common excuse to forgo accessibility is cost (Younes, 2019). In the long-run, implementing accessibility from the ground up can be more cost effective than adding it on as an after-thought or potentially dealing with a lawsuit. The literature highlights a trend of allocating resources to information provision, rather than addressing more complex barriers, such as physical and architectural accessibility. In the context of accessibility, information provision refers to the process of sharing information, usually online, with target users about the accessibility of a specific product, service, or environment. This can allow users to make individual judgment in an informed manner. For instance, Blair-Goldensohn and LoCoco (2018) argue that navigating public spaces can be one of the most challenging problems for people who have disabilities. A common way to combat the unpredictability of the physical world is to rely on technology for the information provision of accessibility information.

The following subsections describe examples of resources that aim to address barriers to accessibility through information provision.

\subsubsection{Example 1: Whistler's Accessibility Map}

Accessibility is built into Whistler Village with its pedestrian-only streets, paved 
pathways, and proximity to transportation. Whistler has developed an accessibility map as part of their strategy to encompass much more than a focus on just physical change to the environment, but also on inclusion. Illustration 10 provides a section of Whistler's accessibility map, showing parking spaces, barrier-free routes, slopes with gradients, accessible washrooms and more. The top of the map shows a legend symbolizing some of the architectural and physical features in the Whistler Village that may vary in degree of accessibility. For example, green lines on the map indicate barrier-free routes that are accessible. Areas marked with a green and white triangle indicate percentage of slope, which may be challenging for some people to navigate. A red circle with a diagonal white line indicates stairs or dead ends, which are not fully accessible.

Whistler's Accessibility Map is a method of information provision that allows people to make their own informed judgments about the barriers to accessibility at Whistler Village that may impact their experience of skiing. 


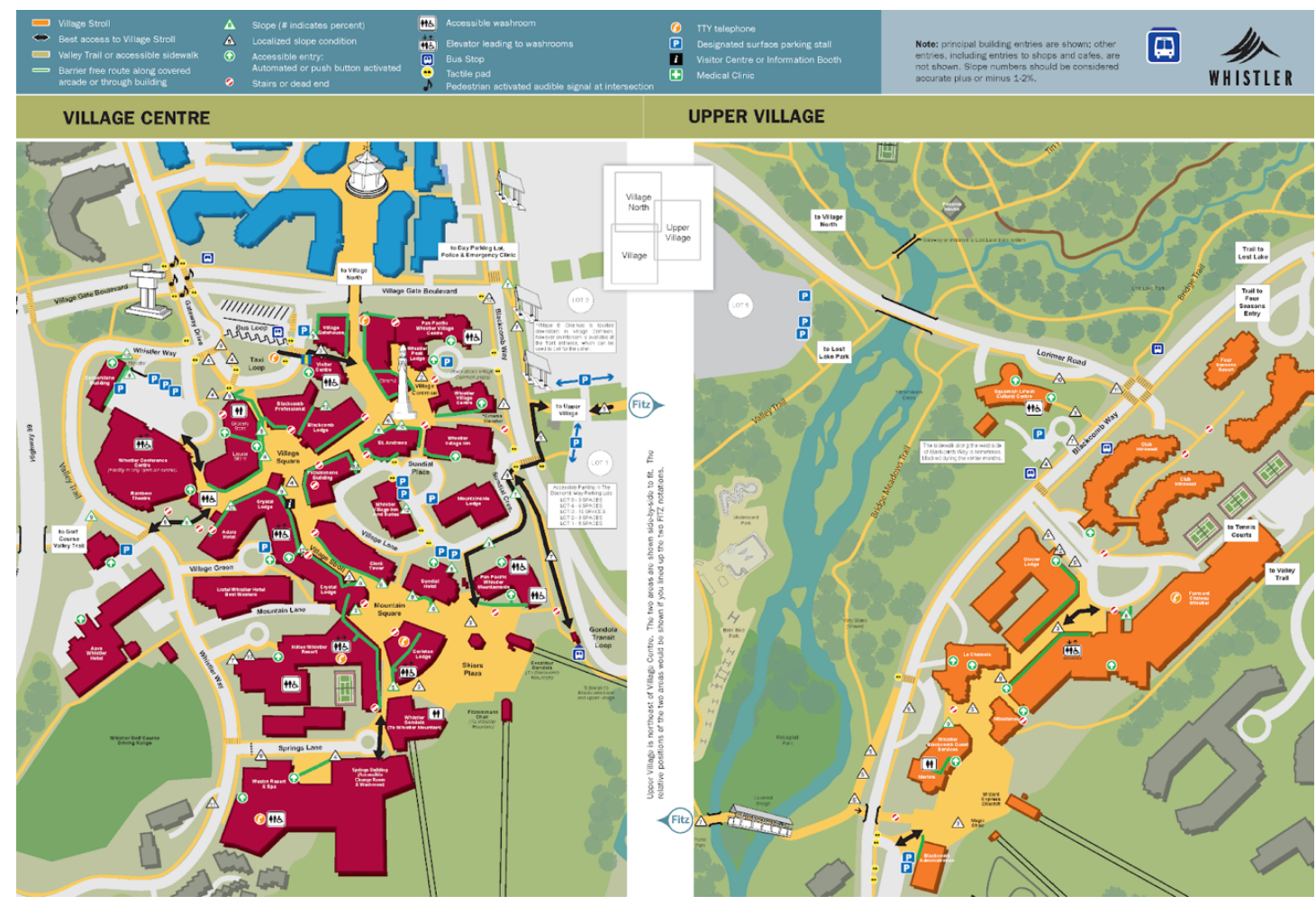

Illustration 10 Whistler's Accessibility Map (Resort Municipality of Whistler, n.d.)

\subsubsection{Example 2: Google Local Guides}

Local Guides is a program on Google Maps that allows the global community to write reviews, share photos, answer questions, add or edit places, and check facts (Illustration 11). Users can input accessibility information to help others navigate their environment (Thiagarajan, 2017). Local Guides is not targeted toward accessibility; however, Google has been using this platform as best they can to supply accessibility information. There is no evidence that Local Guides has been used for accessibility for ski areas in Canada. 


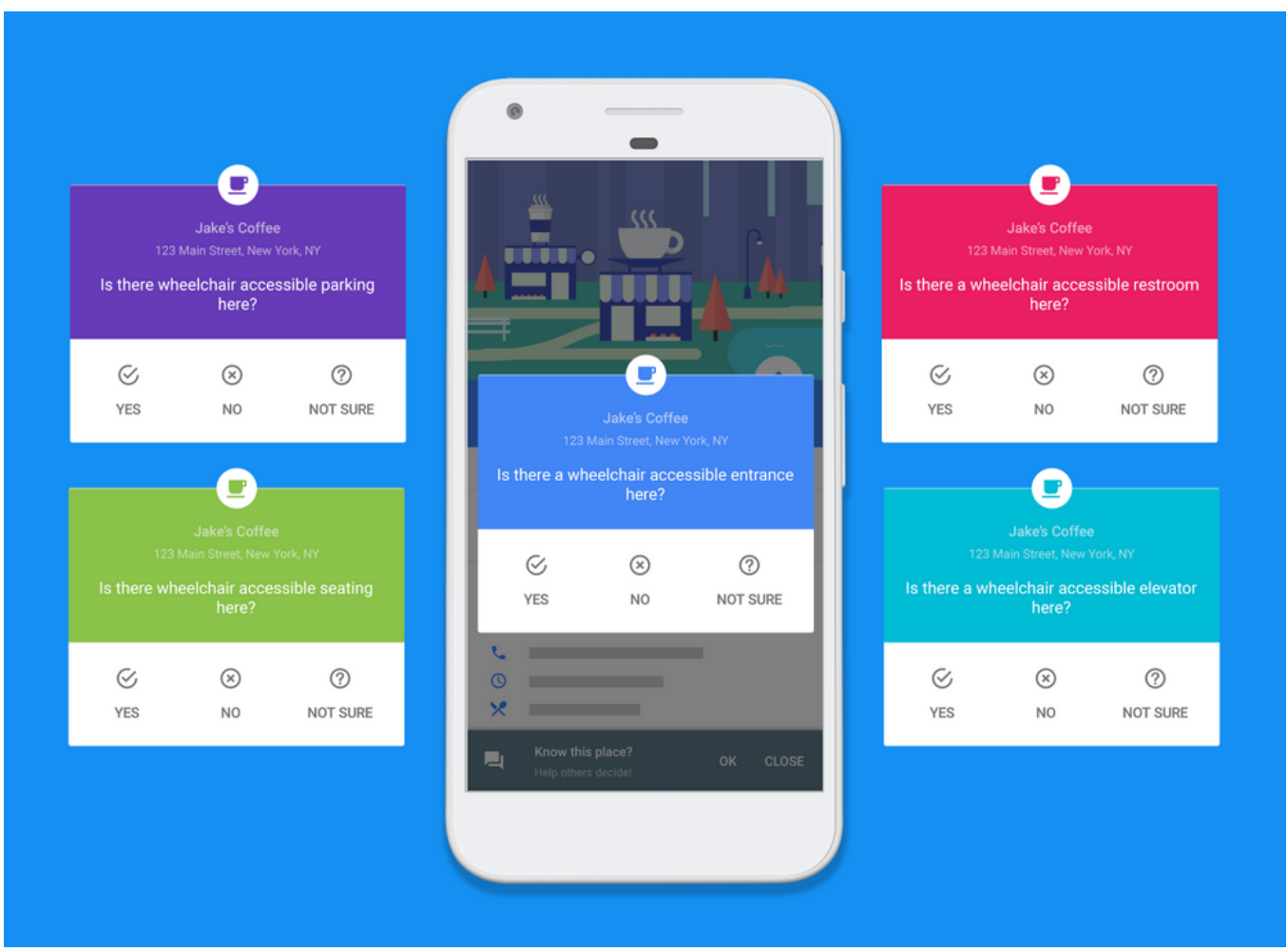

Illustration 11 Google Local Guides User Interface (TraciC, 2017)

\subsubsection{Example 3: AccessNow}

AccessNow is a crowdsourced map that rates the accessibility of locations. Users of the application can rate storefronts and businesses around the globe (Illustration 12). The interface shows an interactive map with coded pinpoints. A green pin represents a wheelchair accessible location, a yellow pin is a caution, while a red pin means not accessible (AccessNow, 2020). There is no evidence that AccessNow has been used for accessibility for ski areas in Canada. 


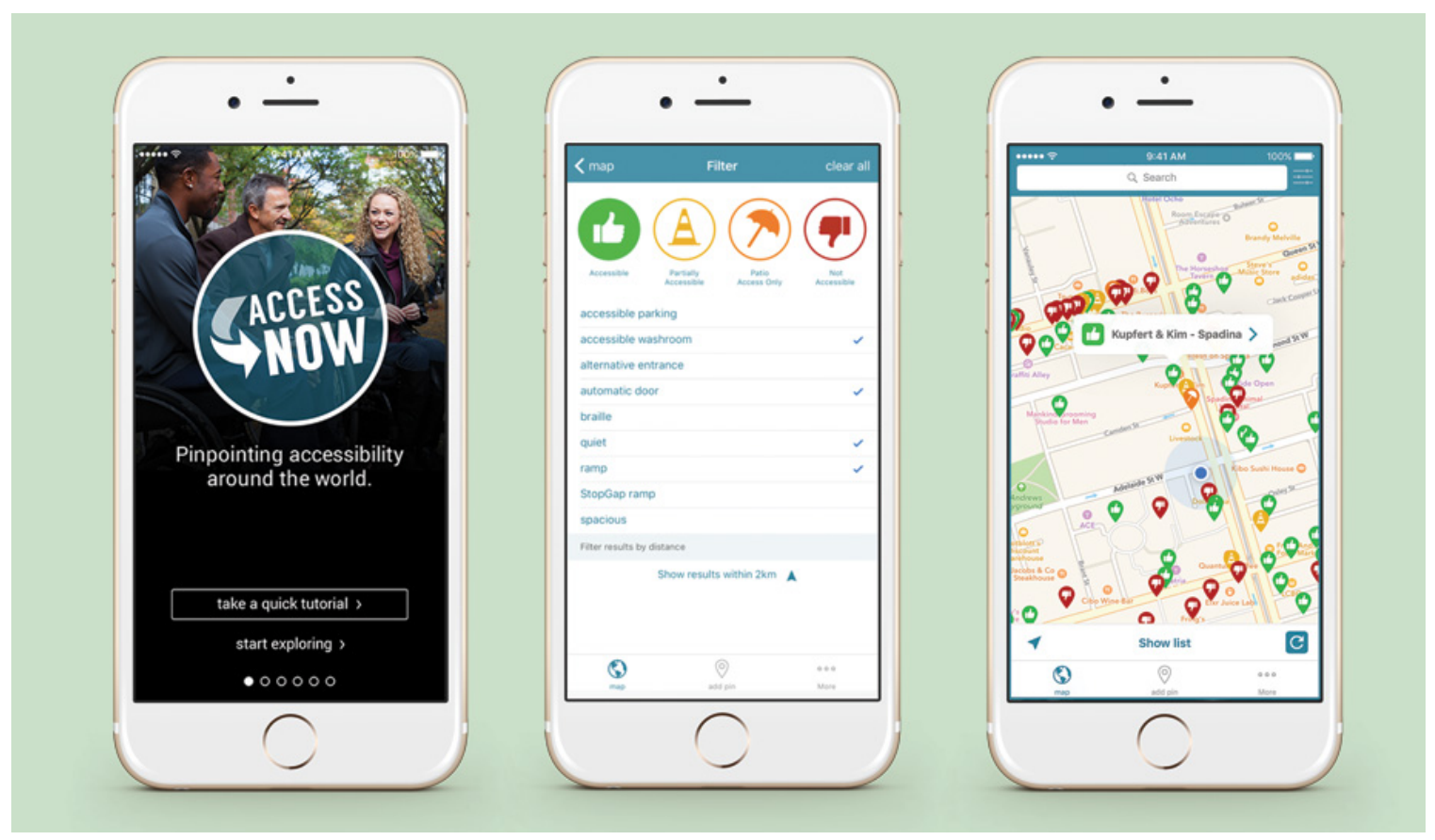

Illustration 12 AccessNow rating system and pin-point map (AccessNow, 2016)

\subsection{Summary of Literature Review Findings}

The literature indicates that accessibility is a relatively new design consideration for ski areas (Whistler, 2017; Fernie, 2015). Large ski areas in Canada, such as Whistler and Blue Mountain Resort, publicize their commitments to removing barriers to accessibility. However, there is limited evidence that all ski areas in Canada identify or address barriers to accessibility that occur during the experience of skiing. By 2040, ski areas will need to become barrier-free to meet the objectives of the Accessible Canada Act.

Five types of barriers to accessibility are discussed in the literature: architectural and physical, attitudinal, organizational and systemic, informational and communicational, and technological barriers. Some barriers can be complex or require more resources than others to be addressed. A trend highlighted in the literature is to use information 
provision to identify barriers to accessibility, to allow users to make individual judgment about a product, service, or environment. Information provision for skiing may provide an opportunity for ski areas to inform users of the accessibility of their facilities and services.

The literature highlights factors that contribute to the experience of adaptive skiing, including adaptive ski equipment and programs. Aside from that, there appears to be limited existing research literature on skiing and persons with disabilities. Thus, the need arises for a deeper exploration of the experience of adaptive skiing, in search of one or more areas that require improvement. 


\section{Chapter 3: Research Design}

The research design of this thesis is structured using an exploratory sequential approach.

The literature review indicates that limited research has been conducted on the experience of adaptive skiing. As a result, the researcher recognizes the value in conducting an initial, qualitative phase to inform the thesis direction by understanding the overall nature of the experience of adaptive skiing.

\subsection{Exploratory Sequential Design}

The research design of this thesis employs an exploratory sequential approach. Creswell and Plano Clark (2018) characterize exploratory sequential design as a mixed-methods approach, combining qualitative and quantitative data collection and analysis into a sequence of phases. Exploratory sequential design begins with a qualitative phase of inquiry, which promotes an initial exploration of a topic. Collecting and analyzing the qualitative data helps identify what needs to be studied in the next phase. A second phase emerges; its study intent and method(s) are informed by the previous phase. Selecting a quantitative method, such as a survey or questionnaire, can be useful for investigating the transferability of the previous qualitative findings (Curry \& Nunez-Smith, 2015; Plano Clark \& Ivankova, 2015; Watkins \& Gioia, 2015). For instance, a researcher might want to know if a broader sample of people has similar experiences to the initial sample. Onwuegbuzie et al. (2010) refer to the sequential development of research phases as building. Building occurs when the results from one data collection procedure inform the data collection approach of the other procedure (Fetters et al., 2013). 


\subsection{Overview of Sequential Phases}

This thesis consists of three sequential phases of data collection and analysis (Illustration 13). Phase 1 serves as the initial, qualitative phase. Due to the limited existing research literature on the experience of adaptive skiing, Phase 1 provides an opportunity to discover the experience of adaptive skiing. Thus, Phase 1 consists of a preliminary field study, which takes place at a ski area with participants involved in adaptive skiing. The study aims to explore the question, "What is the experience of adaptive skiing?" (subresearch question 1), to identify problem areas. Methods for data collection include:

1) Participant Observations

2) Photographs \& Video-Recordings

3) Semi-Structured Conversations

Upon analyzing the data from Phase 1, insights about multiple problem areas within adaptive skiing emerge. Skiing accessibility arguably cannot be thought of as one element, since if any part of the ski experience chain is inaccessible, that makes skiing inaccessible. Thus, the researcher identifies a thesis direction: barriers to accessibility within the entire experience of skiing.

Phase 2 further defines the barriers that are experienced skiing. A qualitative and quantitative questionnaire is developed, which asks participants, "Have you ever experienced or witnessed someone else experience a barrier to accessibility for skiing?" (sub-research question 2). Phase 2 provides insights from a larger sample size, which is valuable for putting the findings of Phase 1 into perspective and for providing more 
supporting information (Plano Clark \& Ivankova, 2015). The questionnaire sheds light on a breadth of barrier types. To organize these barriers, the need arises to identify the specific stages of skiing in which they occur and impact the most.

Phase 3 is developed to map out the barriers to accessibility within the entire chain of experiences related to skiing. For example, finding a ski area online, preparing at home, travelling, getting equipment, skiing, eating, and so on. The objective of Phase 3 is to generate a comprehensive picture of the experience of skiing with or as persons with disabilities. Phase 3 consists of directed storytelling, which is a qualitative research method that uses prompts and questions to encourage participants to share personal stories about their lived experiences (Martin \& Hanington, 2012). This method asks each participant, "What are your past experiences and future dreams for skiing with or as persons with disabilities?" (sub-research question 3). To clarify, a future dream is a want or need that could positively impact the future. This study question prompts a discussion of what might be or what could be in the future for the accessibility for skiing. Ultimately, directed storytelling generates user journey maps that highlight challenges during the experiences of skiing and proposes recommendations for improvement. User journey maps are visualizations of the user experiences of interacting with a product, service, or environment so that each moment can be individually evaluated and improved (Martin \& Hanington, 2012). 
Research Question:

How can design research be used to identify and address barriers to accessibility for skiing?

\begin{tabular}{|c|c|c|}
\hline Phase 1: Discovery & Phase 2: Definition & Phase 3: Design \\
\hline $\begin{array}{l}\text { Research Question Aim: } \\
\text { Identify ("What is?") }\end{array}$ & $\begin{array}{l}\text { Research Question Aim: } \\
\text { Identify ("What is?") }\end{array}$ & $\begin{array}{l}\text { Research Question Aim: } \\
\text { Address ("What could be?") }\end{array}$ \\
\hline $\begin{array}{l}\text { Sub-Research Question 1: } \\
\text { "What is the experience of adaptive } \\
\text { skiing?" }\end{array}$ & $\begin{array}{l}\text { Sub-Research Question 2: } \\
\text { "Have you ever experienced or } \\
\text { witnessed someone else experience } \\
\text { a barrier to accessibility for skiing?" }\end{array}$ & $\begin{array}{l}\text { Sub-Research Question 3: } \\
\text { "What are your past experiences and } \\
\text { future dreams for skiing for persons } \\
\text { with disabilities?" }\end{array}$ \\
\hline $\begin{array}{l}\text { Method: } \\
\text { Preliminary Field Study }\end{array}$ & $\begin{array}{l}\text { Method: } \\
\text { Questionnaire }\end{array}$ & $\begin{array}{l}\text { Method: } \\
\text { Directed Storytelling }\end{array}$ \\
\hline
\end{tabular}

\section{Illustration 13 Research Phases}

In summary, Phase 1 and Phase 2 focus on "what is", which is the current experience of skiing with or as persons with disabilities. Phase 3 aims to bridge the gap to "what could be". A key outcome of the three research phases is to triangulate the findings to develop design recommendations for reducing the barriers to accessibility for skiing. These research phases are cleared by Carleton University Research Ethics Board-B; CUREB-B Clearance \# 111989. Please refer to Appendix B for the approved ethics protocols.

Due to the exploratory sequential design of this thesis, the following sections will not structure "Methods" and "Findings" as separate sections, which is a conventional format for thesis documents. The findings from each phase are important in determining the next phase. Therefore, the following sections are organized based on the sequential phases; each section includes the "Methods" and "Findings" per phase. Chapter 7 triangulates the three research phases and offers further analysis and synthesis. 


\section{Chapter 4: Phase 1: Discovery}

\subsection{Overview}

The literature review indicates that there is limited pre-existing research related to the experience of adaptive skiing. This gap provides a compelling argument for the researcher to pursue adaptive skiing as a research area. Without sufficient literature, the exact research problem remains unclear, creating a need for an initial exploration of adaptive skiing. Thus, Phase 1 conducts a preliminary field study to discover the experience of adaptive skiing.

A preliminary field study is a qualitative method of data collection that aims to observe, interact with, and understand people while they are in their natural environment (Creswell \& Creswell, 2018). A preliminary field study constitutes the first phase of an exploratory sequential research design (Creswell \& Plano Clark, 2018). In relation to this thesis, a preliminary field study is used to conduct a broad exploration of the nature of adaptive skiing. The intended outcome is to identify one or more areas that could be improved, to develop a research problem, and to inform the next phase.

Another argument for the importance of the preliminary field study is seasonality. Adaptive skiing is a seasonal sport that is reliant on the snowy winter months. In relation to the timeline of this thesis, the ski season occurs prior to the beginning of the thesis. Thus, the researcher uses the ski season as an opportunity to start collecting data. In hindsight, this is fortunate because most adaptive ski programs had to suspend their 2021 ski season due to COVID-19 protocols. 


\subsection{Setting}

The preliminary field study is conducted at a ski area located in Québec, Canada. To respect the identity of the ski area, this thesis will change the ski area's name and use the alias, Snow Mountain. Snow Mountain is a family-oriented ski area that consists of mostly beginner and intermediate terrain. It has a summit elevation of approximately 1150 feet (about the height of the Empire State Building), with 20 trails and four lifts that can serve 7,500 skiers per hour. Since 1979, Snow Mountain has permitted a division of CADS to use the ski area to run their adaptive ski program each January and February. CADS provides adaptive ski equipment, volunteers, and instructors to support their students who ski with disabilities; this includes physical, cognitive, and/or sensory impairments. Accordingly, CADS facilitates the adaptive ski program on Saturdays and Sundays. Adaptive students, volunteers, and instructors typically select one of the days to enroll for the duration of the season at Snow Mountain.

In December 2019, the researcher is trained as a CADS volunteer, which permits the researcher to join the program during the 2020 ski season. Based on availability, the researcher enrols as a volunteer with the Sunday group. For seven Sundays throughout January and February 2020, the researcher skis with CADS students, volunteers, and instructors. Concurrent to volunteering with CADS, the researcher conducts the Phase 1 preliminary field study.

\subsection{Method Design}

The Phase 1 preliminary field study aims to explore "what is the experience of adaptive 
skiing?". This sub-research question (\#1) facilitates an initial exploration of various aspects of adaptive skiing, such as the design of equipment, the effectiveness of communication between ski instructors/volunteers and adaptive students, and gaps in accessibility and inclusivity at ski areas.

Three methods are developed for the preliminary field study:

1) Participant Observations

2) Photographs \& Video-Recordings

3) Semi-Structured Conversations

Participant observations are selected as an immersive method to learn about adaptive skiing, as well as from the perspectives of individual participants. Participant observations entail active participation and observations, including observations of people, behaviours, interactions, artifacts, and the environment (Creswell \& Creswell, 2013). Given the exploratory nature of Phase 1, the participant observations are casual and semi-structured. Semi-structured observations are a form of ethnographic research, which occurs in the field to provide rich insights into the participants' world. The intention of ethnographic observations "is to collect baseline information through immersion, particularly in territory that is new to the [researcher]" (Martin \& Hanington, 2012). Thus, ethnographic observations are used to sample the experience of adaptive skiing.

Photographs and video-recordings are selected to document and capture the participant observations. At Snow Mountain, one could expect crowds of people and a variety of 
activities to happen simultaneously. The researcher feels that it would be challenging to notice and retain all the observations, especially while balancing volunteer work.

Therefore, the researcher plans to wear a Go-Pro camera to capture photographs and video-recordings that could be analyzed later.

Semi-structured conversations are also selected to support the participant observations.

The objective of this method is to ask (1) clarifying questions and (2) who, what, when, where, why, how questions (Table 2 and Table 3) while observing participants in the field. In comparison to formal interviews, semi-structured conversations enable organic dialogue and interactions. Questions are only asked when needed.

Table 2 Examples of Questions to Ask Adaptive Ski Students

\begin{tabular}{|c|c|c|c|c|c|}
\hline Who & What & When & Where & Why & How \\
\hline $\begin{array}{l}\text { Do you require } \\
\text { assistance at } \\
\text { the ski hill? } \\
\text { From whom? } \\
\text { For what? }\end{array}$ & $\begin{array}{l}\text { What is your } \\
\text { experience } \\
\text { with CADS? } \\
\text { Please } \\
\text { describe. }\end{array}$ & $\begin{array}{l}\text { When did you } \\
\text { first start } \\
\text { skiing? }\end{array}$ & $\begin{array}{l}\text { Where do you } \\
\text { get your } \\
\text { equipment? }\end{array}$ & $\begin{array}{l}\text { Why do you } \\
\text { use this } \\
\text { specific type of } \\
\text { adaptive ski } \\
\text { equipment? }\end{array}$ & $\begin{array}{l}\text { How many } \\
\text { consecutive } \\
\text { runs do you } \\
\text { typically do? }\end{array}$ \\
\hline \multirow[t]{2}{*}{$\begin{array}{l}\text { Who do you } \\
\text { ski with? } \\
\text { Why? }\end{array}$} & $\begin{array}{l}\text { What is your } \\
\text { favourite part } \\
\text { about skiing? }\end{array}$ & $\begin{array}{l}\text { When is your } \\
\text { favourite time } \\
\text { to ski? (i.e., } \\
\text { time of day, } \\
\text { weather } \\
\text { conditions) }\end{array}$ & $\begin{array}{l}\text { Where do you } \\
\text { like to ski at } \\
\text { Snow } \\
\text { Mountain? } \\
\text { (i.e., terrain, } \\
\text { level of } \\
\text { difficulty) }\end{array}$ & $\begin{array}{l}\text { Why do you } \\
\text { ski with } \\
\text { CADS? }\end{array}$ & $\begin{array}{l}\text { How do you } \\
\text { feel while } \\
\text { skiing? }\end{array}$ \\
\hline & $\begin{array}{l}\text { What is your } \\
\text { least favourite } \\
\text { part about } \\
\text { skiing? }\end{array}$ & $\begin{array}{l}\text { Can you } \\
\text { describe a time } \\
\text { when you } \\
\text { experienced a } \\
\text { challenge } \\
\text { while skiing? }\end{array}$ & & & \\
\hline
\end{tabular}

Table 3 Examples of Questions to Ask Adaptive Ski Volunteers/Instructor

\begin{tabular}{|l|l|l|l|l|l|}
\hline Who & What & When & Where & Why & How \\
\hline
\end{tabular}




\begin{tabular}{|c|c|c|c|c|c|}
\hline $\begin{array}{l}\text { Who do you } \\
\text { ski with? }\end{array}$ & $\begin{array}{l}\text { What is your } \\
\text { experience } \\
\text { with CADS? } \\
\text { Please } \\
\text { describe. }\end{array}$ & $\begin{array}{l}\text { When did you } \\
\text { first start } \\
\text { skiing? }\end{array}$ & $\begin{array}{l}\text { Where does } \\
\text { CADS source } \\
\text { their } \\
\text { equipment? } \\
\text { Where can } \\
\text { modifications } \\
\text { be made? }\end{array}$ & $\begin{array}{l}\text { Why do you do } \\
\text { that action } \\
\text { and/or } \\
\text { behaviour } \\
\text { while skiing? }\end{array}$ & $\begin{array}{l}\text { How do you } \\
\text { support the } \\
\text { students? }\end{array}$ \\
\hline \multirow[t]{2}{*}{$\begin{array}{l}\text { Who do you } \\
\text { enjoy working } \\
\text { with the most? }\end{array}$} & $\begin{array}{l}\text { What is your } \\
\text { favourite part } \\
\text { about skiing } \\
\text { with CADS? }\end{array}$ & $\begin{array}{l}\text { Can you } \\
\text { describe a time } \\
\text { when you } \\
\text { experienced a } \\
\text { challenge while } \\
\text { skiing with } \\
\text { CADS? }\end{array}$ & $\begin{array}{l}\text { Where are the } \\
\text { skiers allowed } \\
\text { to ski on the } \\
\text { hill? Are } \\
\text { certain areas } \\
\text { off-limits? }\end{array}$ & $\begin{array}{l}\text { Why do you } \\
\text { ski with } \\
\text { CADS? }\end{array}$ & $\begin{array}{l}\text { How do you do } \\
\text { that action } \\
\text { and/or } \\
\text { behaviour } \\
\text { while skiing? }\end{array}$ \\
\hline & $\begin{array}{l}\text { What is your } \\
\text { least favourite } \\
\text { part about } \\
\text { skiing with } \\
\text { CADS? }\end{array}$ & $\begin{array}{l}\text { Was there ever } \\
\text { a time when a } \\
\text { skier was not } \\
\text { allowed to join } \\
\text { in CADS } \\
\text { activities? } \\
\text { Why? }\end{array}$ & & $\begin{array}{l}\text { Why are some } \\
\text { students } \\
\text { teamed up with } \\
\text { more } \\
\text { volunteers than } \\
\text { others? }\end{array}$ & $\begin{array}{l}\text { How would } \\
\text { you react if a } \\
\text { skier got } \\
\text { injured? }\end{array}$ \\
\hline
\end{tabular}

\subsection{Participants}

Participants for the preliminary field study are recruited from the CADS Sunday group at Snow Mountain, which include CADS students, volunteers, and instructors. Each season, CADS at Snow Mountain serves approximately 60 students and has over 100 volunteers and instructors (CADS, n.d.). From the Sunday group, the researcher recruits approximately 25 students and 25 volunteers and instructors. This sample size allows the researcher to witness a breadth of ability levels and skiing experiences.

CADS at Snow Mountain welcomes students of all ages and experience-levels with physical, cognitive, and/or sensory impairments. Each student is outfitted with adaptive ski equipment, if required. Typically, two volunteers and/or instructors are assigned to one student for the duration of the season to provide support while skiing. 
Volunteers receive basic training to support the students in terms of skills, knowledge, and safety requirements. Volunteers are required to be at least 15 years old and ski at an intermediate level or higher (CADS, 2019).

Instructors are experienced volunteers who have completed courses to become a certified CADS ski instructor and from the Canadian Ski Instructors' Alliance. CADS instructors coach and support students and volunteers.

\subsection{Recruitment}

Participant recruitment is carried out in two stages (Illustration 14). The first stage of recruitment is informative, while the second stage directly recruits participants in person at Snow Mountain.

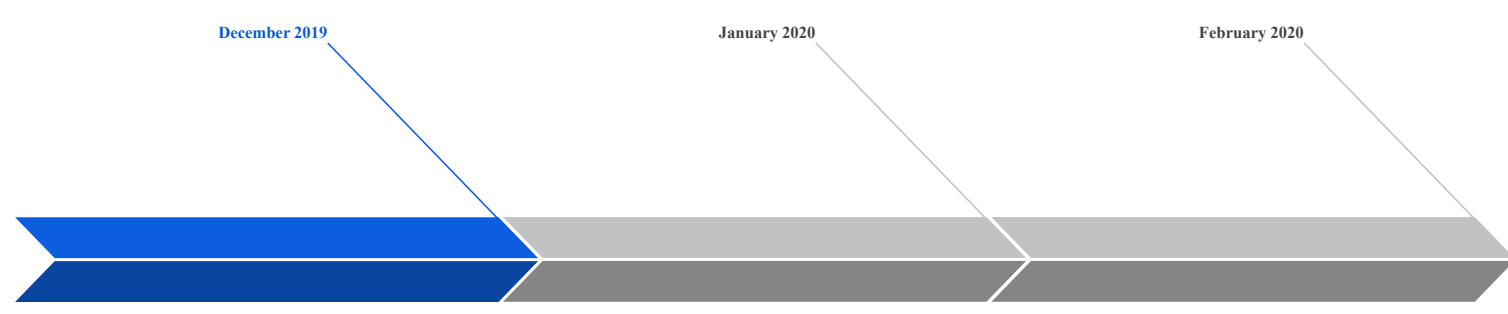

1st Stage of Recruitment

2nd Stage of Recruitment

Make announcement to members of CADS Edelweiss

regarding upcoming study.

Recruit members of CADS Edelweiss in-person to participate

in study.

\section{Illustration 14 Two Stages of Participant Recruitment}

In the first stage of recruitment, the program coordinator of CADS at Snow Mountain shares an announcement with the program on behalf of the researcher. The announcement is communicated via email and the program's Google Groups message boards. The 
announcement occurs prior to the 2020 ski season, with the goal of informing students, volunteers, and instructors about the upcoming study with CADS at Snow Mountain. The researcher uses the opportunity to introduce herself, her research, and outline the details of participation. Contact information is provided, and those who are interested or who have questions regarding the study are encouraged to email the researcher.

The researcher feels that the first stage of recruitment is important in order to provide advance notice. Typically, ski areas can be busy with people and activities. Thus, the intention of the announcement is to reduce the challenge of tracking down individual members of CADS at Snow Mountain. Another intention of the announcement is to make the information accessible, especially since the study recruits persons with disabilities. The announcement is shared in a written format and provides ample time for participants to consider joining the study. If a participant is a member of a vulnerable population (i.e., unable to provide consent on their own), a parent or guardian provides consent instead and must be present during the study. In this case, prior communication can provide sufficient time to prepare accordingly.

The second stage of recruitment occurs at Snow Mountain throughout the ski season. Members of CADS are recruited in-person by the researcher, which involves the participant providing oral consent to participate in the study, to be photographed, and/or video-recorded. Upon obtaining consent, data gathering begins. 


\subsection{Data Gathering}

Three methods are used for data gathering:

1) Participant Observations

2) Photographs \& Video-Recordings

3) Semi-Structured Conversations

The researcher participates with and observes participants from CADS over the course of seven Sundays. Each Sunday during the ski season, CADS operates from 9:30 AM until 3:00 PM. The participant observations focus on the experience of adaptive skiing and follows participants during various stages of skiing at Snow Mountain. For instance, the researcher observes participants in the parking lot, in the lodge, putting on gear and equipment, riding the chairlift, skiing, and so on. CADS students, volunteers, and instructors are observed in order to learn about different roles and experiences within adaptive skiing.

The participant observations are documented through notes, sketches, photographs, and video-recordings. When convenient, a notebook is used to mark observations. A notebook is not particularly conducive while skiing; thus, a Go-Pro camera is also used to capture photographs and video-recordings of the participant observations. The Go-Pro footage focuses on various stages of skiing, adaptive ski equipment, the facilities and services at Snow Mountain, and participant interactions and behaviours. Photographs and video-recordings are gathered with the intention of further analysis to identify problems areas within the experience of adaptive skiing. 
The participant observations also provide a source to engage in informal, semi-structured conversations with the participants. During each ski day, the researcher asks participants questions as they arise. For instance, if an observation is unclear, the researcher asks for clarification. The researcher also asks who, what, when, where, why, how questions. This allows the researcher to prompt conversations about individual experiences. Participants share their opinions and challenges during various stages of skiing.

\subsection{Exploration of Adaptive Ski Equipment}

The researcher has a background in Industrial Design. In accordance with her education, the researcher initially thought that the preliminary field study would point to a productfocused topic, such as the design of adaptive ski equipment. CADS at Snow Mountain has a collection of adaptive ski equipment (Illustration 15) that is shared between the Saturday and Sunday students. Each student has a unique set of abilities that often requires their equipment to be modified for reasons of ergonomics, fit, comfort, or performance. However, since equipment is shared, modifications must be temporary. 


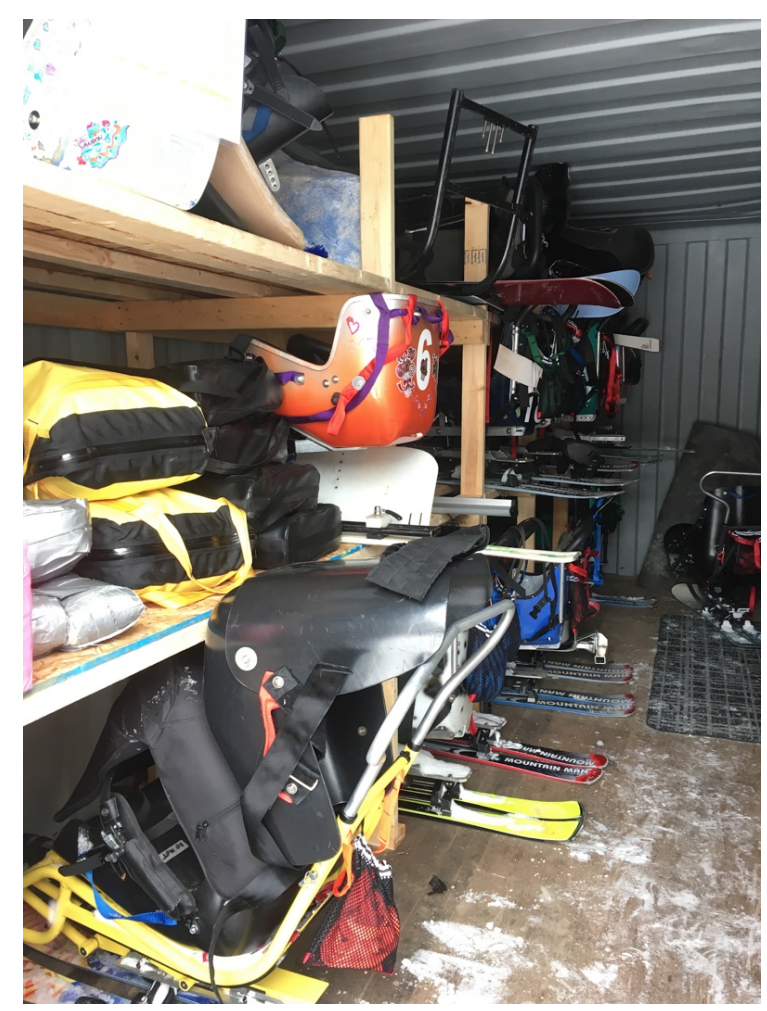

\section{Illustration 15 CADS Adaptive Ski Equipment at Snow Mountain}

Given the student's unique needs, a "one-size-fits-all" approach does not apply to adaptive ski equipment. Hence, CADS at Snow Mountain temporarily modifies the adaptive ski equipment for students with materials including foam blocks, duct tape and electrical tape, pool noodles, zip ties, shoelaces, and Velcro. Illustration 16 shows a sitski on the left that is modified with a piece of foam wrapped in duct tape to shorten the length of the foot bucket. A store-bought blue strap is added to secure the student's feet. On the right, Illustration 16 shows a snow slider with foam and tape to create a rest to support the student's knees and improve comfort. 

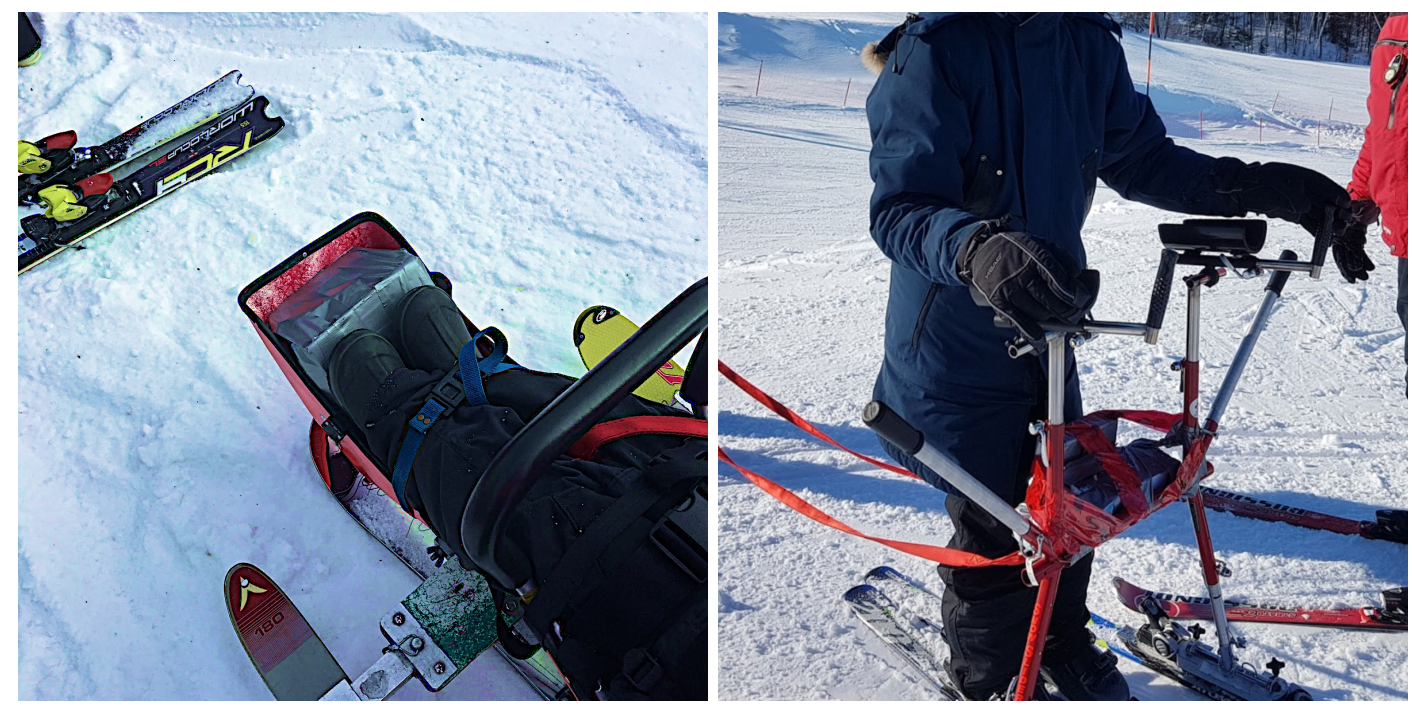

\section{Illustration 16 Modified Adaptive Ski Equipment}

Findings about the need to modify adaptive ski equipment indicate that there might be issues surrounding the design of adaptive ski equipment. However, CADS at Snow Mountain implements an individualized approach to provide unique equipment solutions to accommodate its students. Since CADS at Snow Mountain is working to overcome this challenge, the researcher feels that there are more pressing and deep-rooted issues that should be addressed first.

\subsection{Exploration of Ski Areas}

One area that captures the researcher's attention, is the design of the ski lodge. While conducting the preliminary field study, the researcher constantly observes participants having difficulties using various facilities and services at Snow Mountain. For example, one ski day the researcher sat by a set of doors entering a new section of the lodge (Illustration 17) from 12:00 PM until 12:30 PM. The flooring throughout the lodge is cement, which gets particularly wet from melting snow. The researcher counted a total of 
36 people slip and fall by the doors during a half hour period. The wet floors pose a hazard to all persons and additionally so to those with mobility impairments or disabilities.

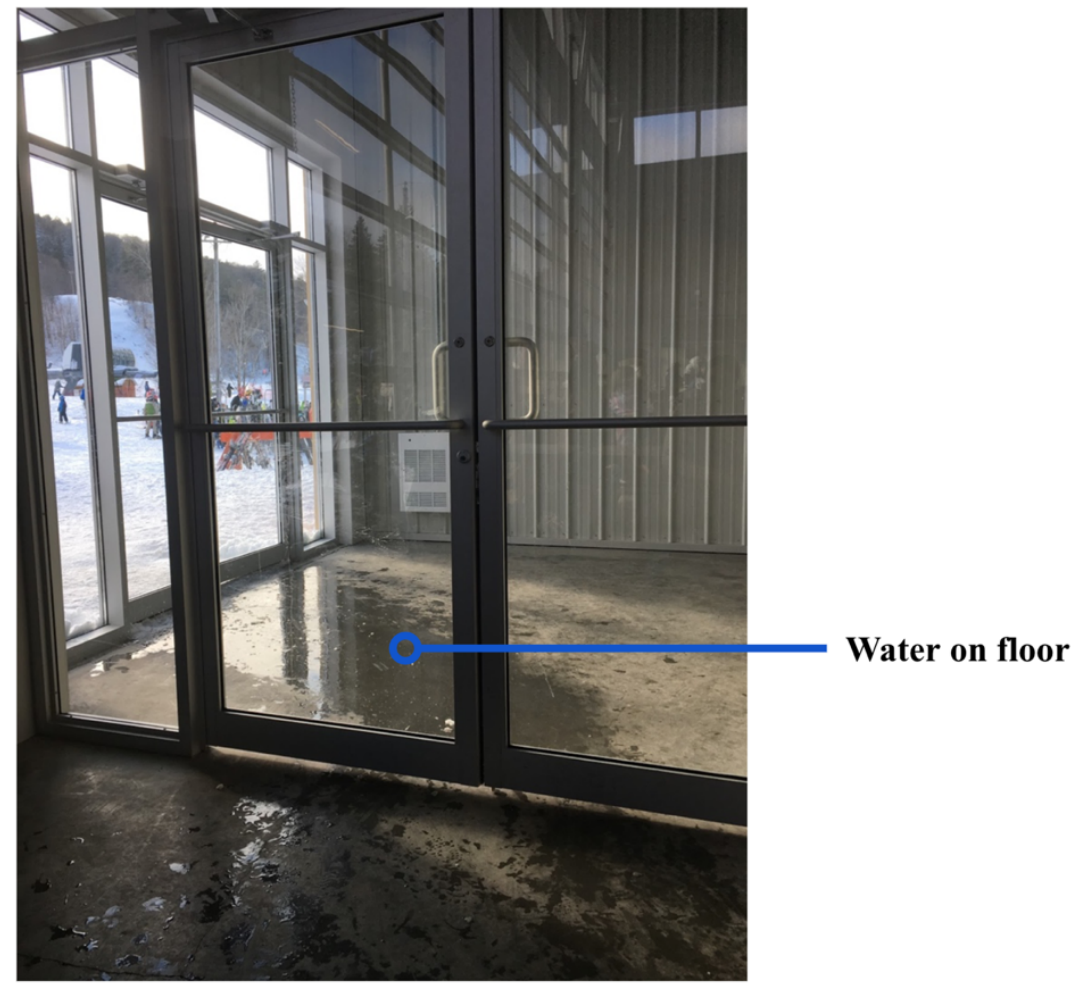

\section{Illustration 17 Wet Floors}

The doors within the new section of the lodge do not have push-to-open buttons, which are a necessity for some persons with disabilities. Moreover, the threshold to enter the doors is a few inches higher than the ground. People who use wheelchairs or who have limited mobility experience difficulties crossing the threshold. Illustration 18 shows a CADS instructor shoveling snow to create a ramp to help people enter through the doors. 


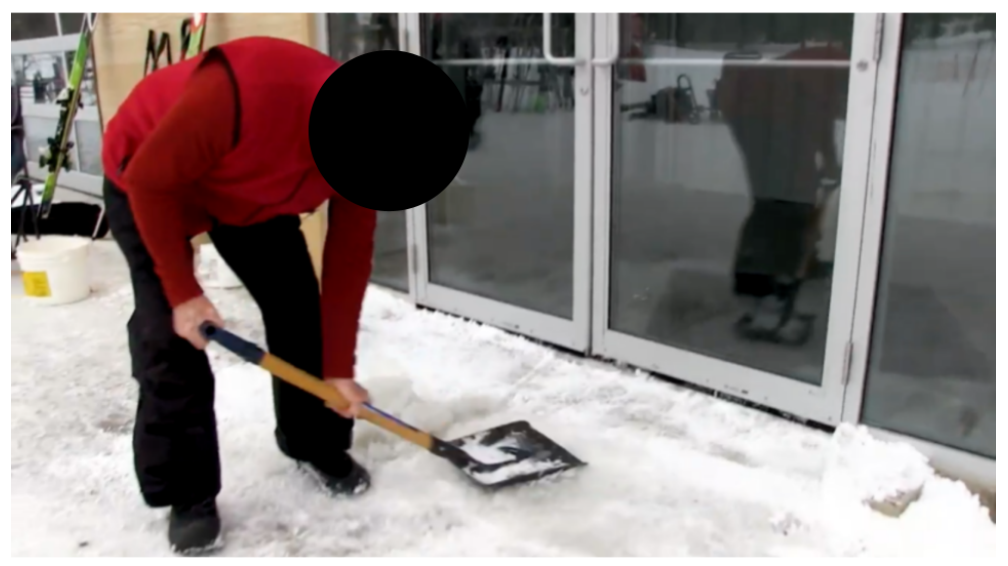

Illustration 18 Shoveling snow to create a ramp into the lodge

Another example of poor accessibility at the ski area can be seen in Illustration 19, which shows a new section of the lodge at Snow Mountain. The tables are arranged closely together and have fixed stools, which restrict movement and use for some persons with mobility issues or who use mobility aids (e.g., wheelchairs, scooters, walkers, rollators, crutches, canes). Additional obstacles are created because the lodge lacks sufficient storage space for personal belongings. People have to leave their items on the ground or the tables. On the right side of the image in Illustration 19 a second floor in the lodge can be seen. The second floor is only accessible by stairs. 


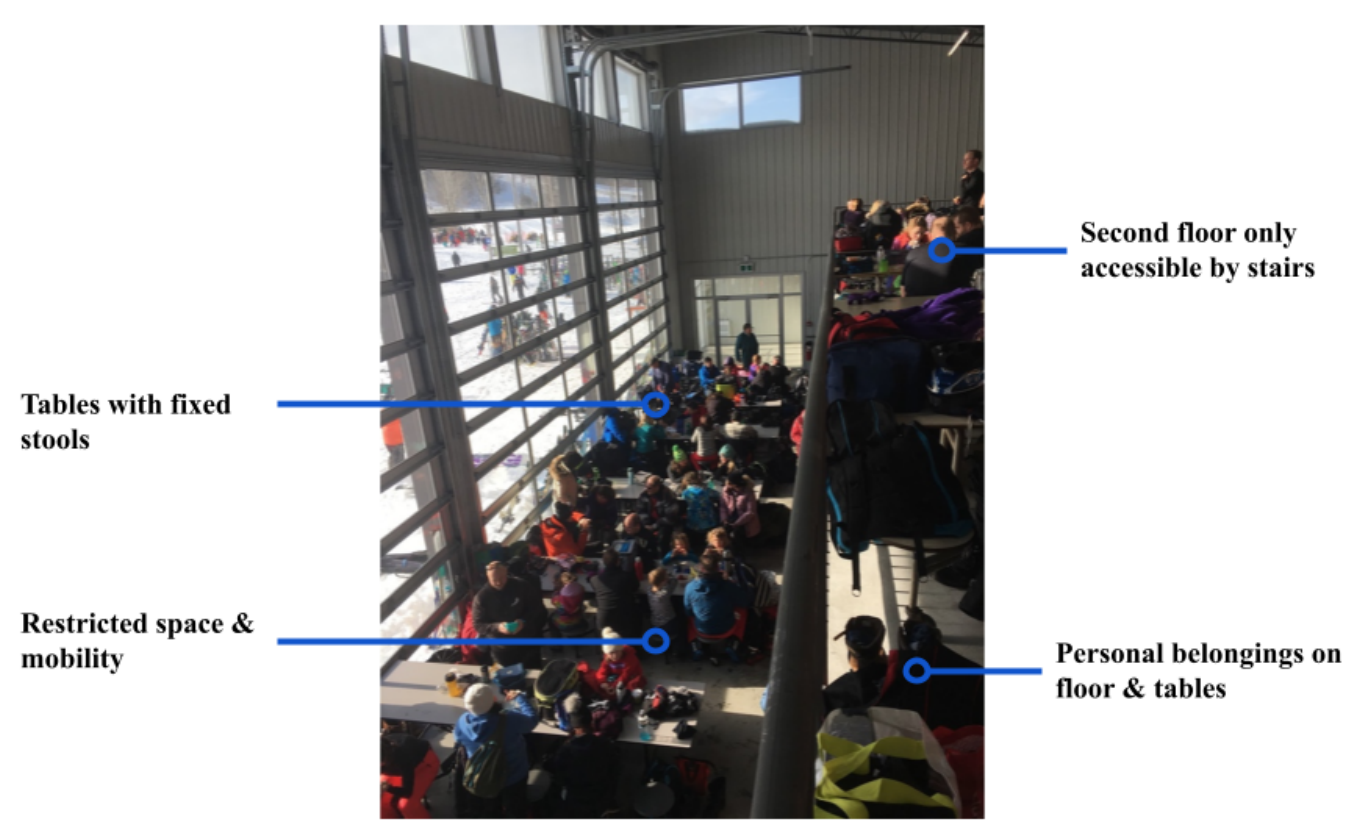

\section{Illustration 19 Accessibility Challenges in the Lodge}

These observations are surprising because they are conducted in a new section of the lodge that is brand-new and opened in 2020. Snow Mountain appears to have missed an opportunity to improve their facilities by implementing accessibility from the ground up. This prompts a question: if there are accessibility issues in the lodge, what other aspects of the skiing experience have barriers to accessibility?

Initially, the researcher set out in search of factors within the experience of adaptive skiing that could be improved. However, the findings demonstrate that the entire experience of adaptive skiing is contingent on a ski area's implementation of accessibility. If any part of the ski experience chain is inaccessible, skiing becomes inaccessible. 
This fuels the need to identify other barriers to improve the experience of adaptive skiing. As a result, further analysis of the preliminary field study data focuses on identifying other barriers to accessibility for skiing.

\subsection{Analysis}

Coding is used to analyze the notes, sketches, photographs, and video-recordings from the preliminary field study. Saldaña (2013) describes coding as assigning a summative word or short phrase to language-based or visual data. A first cycle of coding is conducted to begin interpreting the data in search of patterns and to identify the following elements within the data:

1) Information: what is the data showing?

2) Key Concept: what is of importance in the data?

3) Value: how significant is the data to the thesis?

4) Opinion: what is the researcher's informed opinion about the data?

Next, a second cycle of coding further filters the data. During the second cycle of coding, the researcher revises the data to assign a:

1) Theme: a summative word or short phrase to capture the essence of the data

2) Type of Barrier to Accessibility: architectural and physical, attitudinal, organizational and systemic, informational and communicational, or technological barriers

Tables 4 to 8 provide descriptions of the themes that emerge for each type of barrier to 
accessibility. The number in brackets beside each theme indicates the frequency that it is

coded.

Table 4 Barrier Type \#1: Architectural/Physical Barriers

\begin{tabular}{|c|c|c|}
\hline Theme & Description & Footage Sample \\
\hline Snow (7) & $\begin{array}{l}\text { Ski areas inherently have snow, but the snow } \\
\text { between the parking lot and the lodge caused } \\
\text { mobility issues for some participants, especially } \\
\text { people using mobility aids. }\end{array}$ & \\
\hline $\begin{array}{l}\text { Other Skiers } \\
\text { (7) }\end{array}$ & $\begin{array}{l}\text { CADS shared the ski area with other skiers, } \\
\text { which occasionally created obstacles on the hill. } \\
\text { There were racing groups, ski lessons, children, } \\
\text { teenagers, and adults. }\end{array}$ & \\
\hline Doors (6) & $\begin{array}{l}\text { The doors to the new section of the lodge did } \\
\text { not have push-to-open buttons. There was a gap } \\
\text { between the ground and doors preventing some } \\
\text { mobility aids from entering the lodge. }\end{array}$ & \\
\hline
\end{tabular}




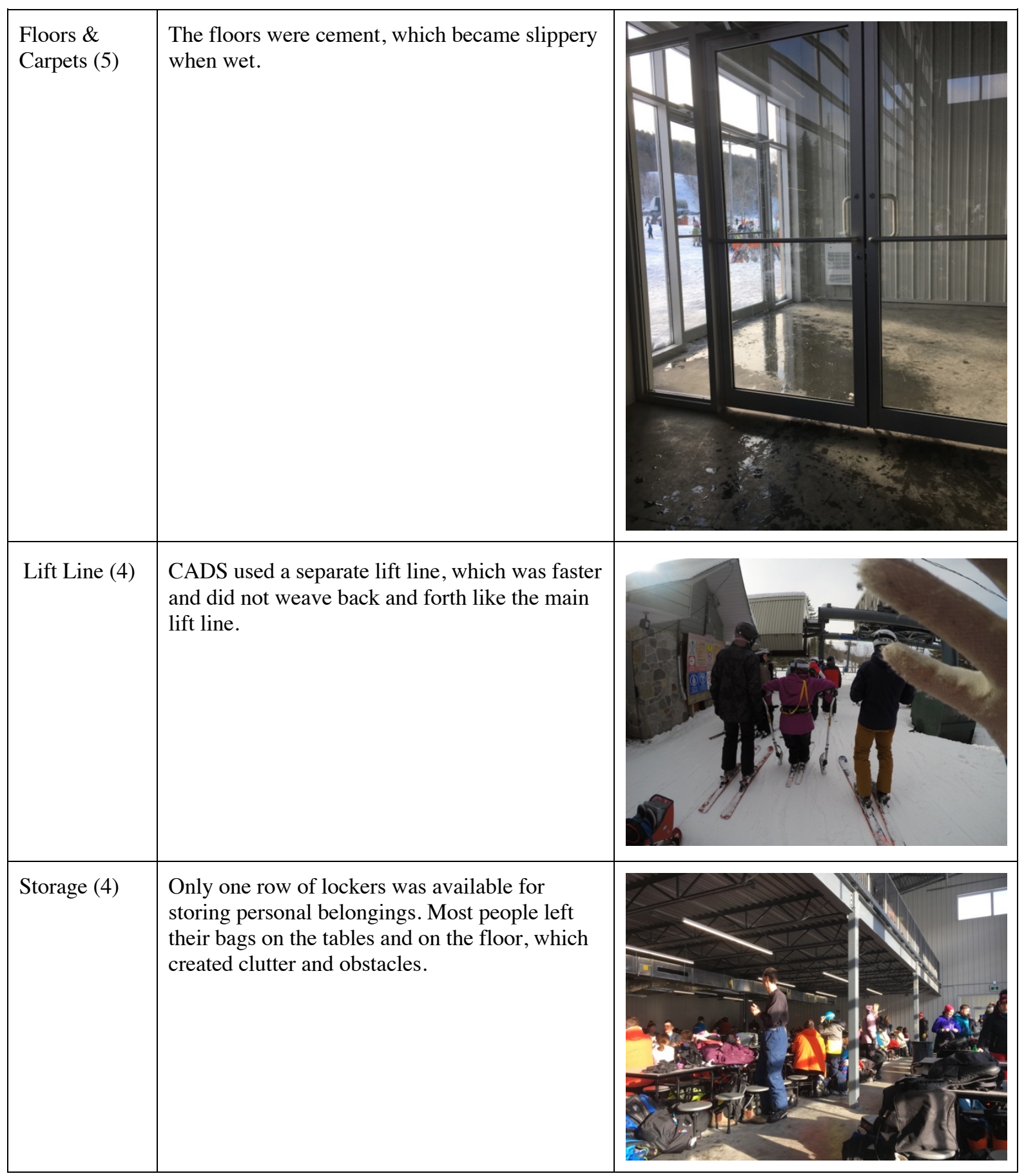




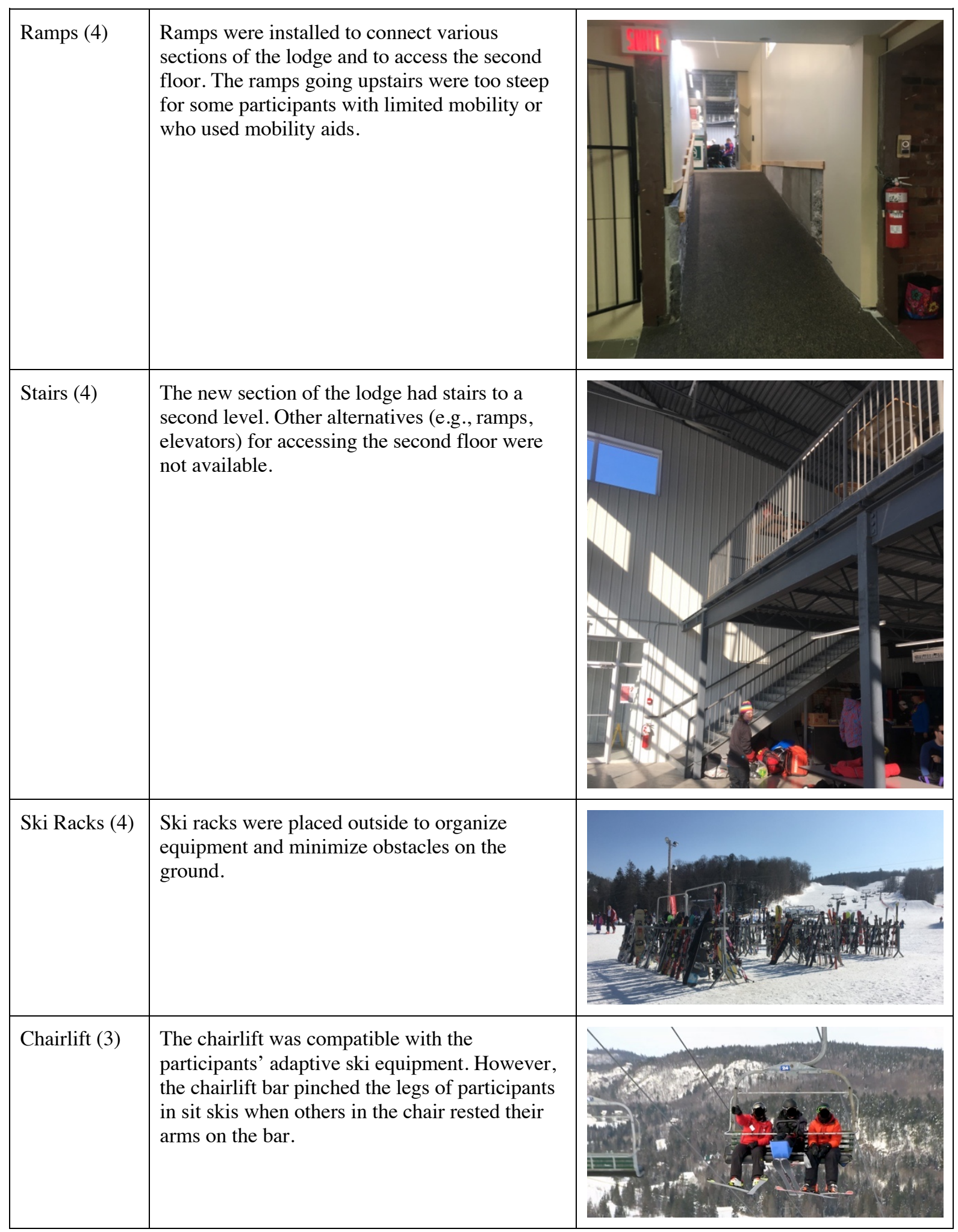




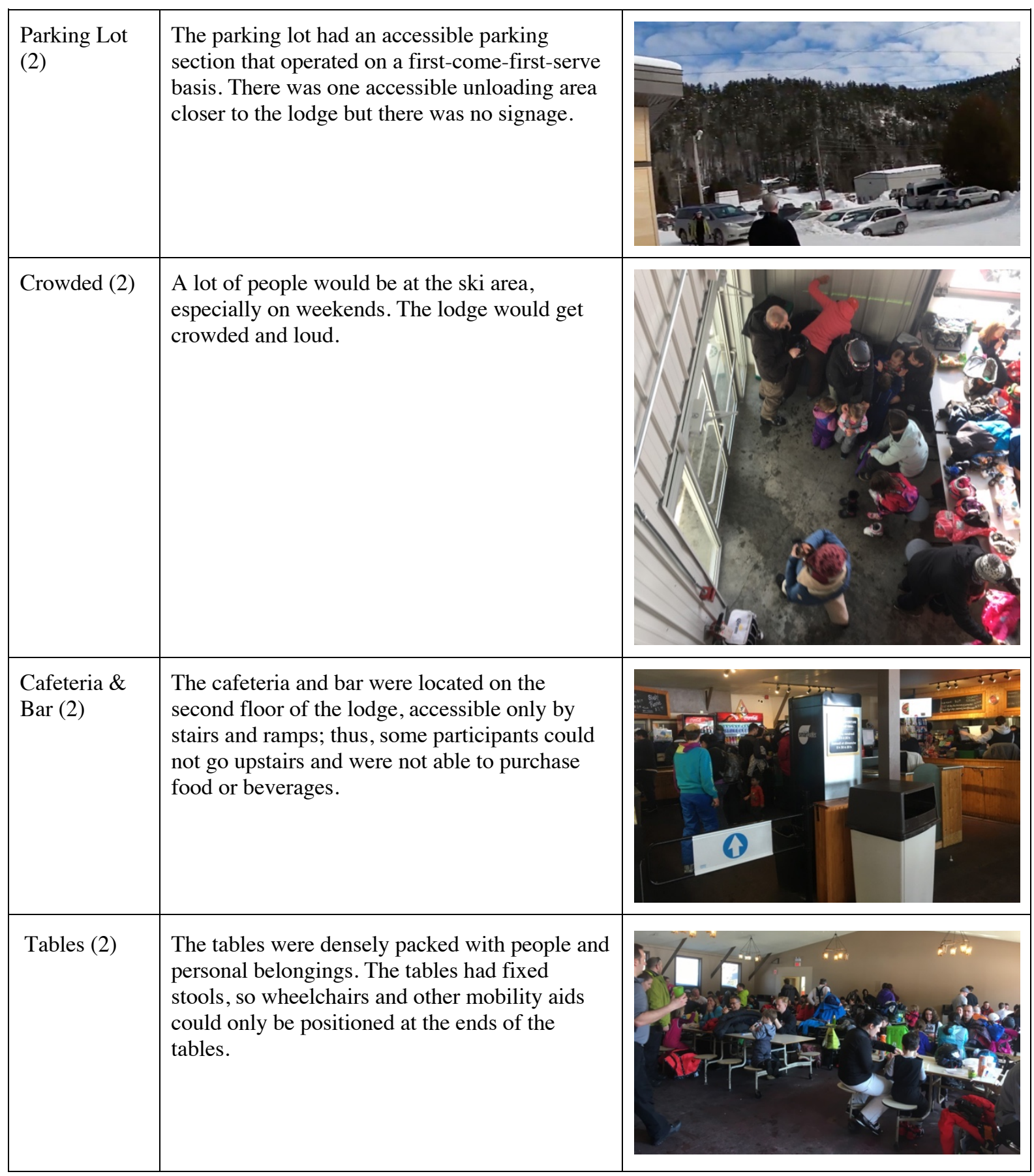




\begin{tabular}{|c|c|c|}
\hline $\begin{array}{l}\text { Vending } \\
\text { Machine (1) }\end{array}$ & $\begin{array}{l}\text { A vending machine selling snack foods and } \\
\text { beverages was located on the main floor of the } \\
\text { lodge. It provided an alternative to going to the } \\
\text { cafeteria or bar on the second floor. }\end{array}$ & \\
\hline $\begin{array}{l}\text { Washroom } \\
\text { (1) }\end{array}$ & $\begin{array}{l}\text { The washrooms had accessible stalls. The } \\
\text { washrooms were located on the first floor of the } \\
\text { lodge in the back corner, which was too far for } \\
\text { some people to walk. }\end{array}$ & N/A \\
\hline $\begin{array}{l}\text { Ticket Booth } \\
\text { (1) }\end{array}$ & $\begin{array}{l}\text { The ticket booth was located outside and had a } \\
\text { cleared area on the ground. The height of the } \\
\text { counter was wheelchair accessible. }\end{array}$ & \\
\hline $\begin{array}{l}\text { Equipment } \\
\text { Storage (1) }\end{array}$ & $\begin{array}{l}\text { Adaptive ski equipment was stored in a } \\
\text { container outdoors. Ideally, equipment should } \\
\text { be stored at room temperature to prevent the } \\
\text { equipment from freezing and for ease of repair. }\end{array}$ & \\
\hline
\end{tabular}

Table 5 Barrier Type \#2: Attitudinal Barriers

\begin{tabular}{|l|l|l|}
\hline Theme & Description & Footage Sample \\
\hline
\end{tabular}




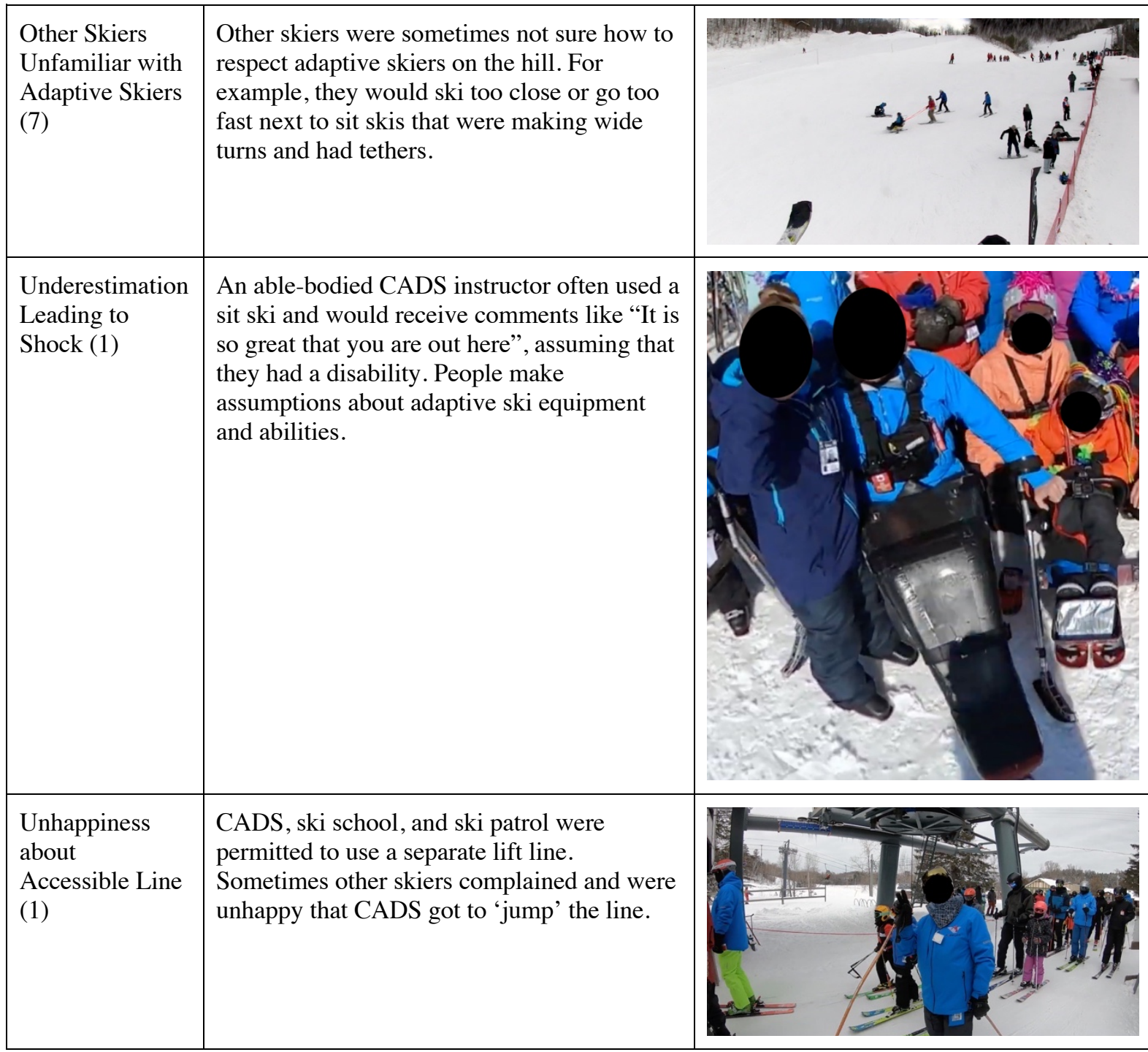

Table 6 Barrier Type \#3: Organizational/Systemic Barriers

\begin{tabular}{|l|l|l|}
\hline Theme & Description & Footage Sample \\
\hline $\begin{array}{l}\text { Accessible Lift } \\
\text { Line (2) }\end{array}$ & $\begin{array}{l}\text { Snow Mountain allowed CADS to use the } \\
\text { faster lift line to improve accessibility. }\end{array}$ \\
\hline
\end{tabular}




\begin{tabular}{|l|l|l|l|}
\hline $\begin{array}{l}\text { Lift Operators } \\
\text { (3) }\end{array}$ & $\begin{array}{l}\text { Most lift operators were aware of the adaptive } \\
\text { skiers and would help with loading or slow } \\
\text { down the lift if needed. }\end{array}$ \\
\hline Tickets (1) & $\begin{array}{l}\text { CADS provided volunteers and instructors } \\
\text { with lift tickets. }\end{array}$ \\
\hline
\end{tabular}

Table 7 Barrier Type \#4: Informational/Communicational Barriers

\begin{tabular}{|c|c|c|}
\hline Theme & Description & Footage Sample \\
\hline $\begin{array}{l}\text { Volunteer/Instructor } \\
\text { and Student } \\
\text { Communication (2) }\end{array}$ & $\begin{array}{l}\text { CADS volunteers and instructors were } \\
\text { constantly in communication with their } \\
\text { students to ensure safety. Some } \\
\text { students had challenges with } \\
\text { communicating due to their disability, } \\
\text { in which case CADS volunteers and } \\
\text { instructors had to apply various } \\
\text { techniques to foster effective } \\
\text { communication (e.g., communication } \\
\text { board) }\end{array}$ & 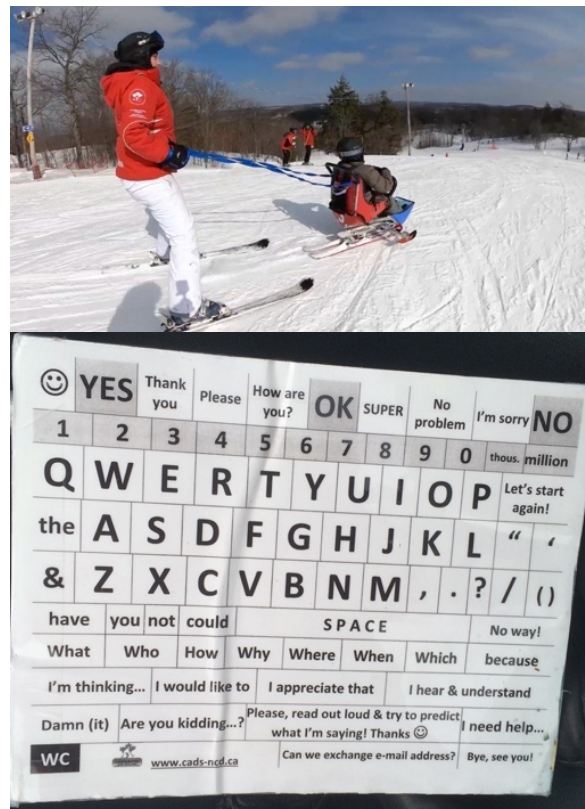 \\
\hline $\begin{array}{l}\text { Signage/Wayfinding } \\
\text { (1) }\end{array}$ & $\begin{array}{l}\text { Signs on the hill were brightly } \\
\text { coloured and identifiable. Some } \\
\text { adaptive skiers used high visibility } \\
\text { clothing and tethers for safety. }\end{array}$ & \\
\hline
\end{tabular}




\begin{tabular}{|l|l|l|}
\hline Information Desk (1) & $\begin{array}{l}\text { CADS had a designated information } \\
\text { desk, which served as a meeting point } \\
\text { and helped with organization. }\end{array}$
\end{tabular}

Table 8 Barrier Type \#5: Technological Barriers

\begin{tabular}{|l|l|l|}
\hline Theme & Description & Footage Sample \\
\hline $\begin{array}{l}\text { Individualized } \\
\text { Approach to } \\
\text { Equipment (1) }\end{array}$ & $\begin{array}{l}\text { CADS modified adaptive ski equipment } \\
\text { to meet individual needs because the } \\
\text { existing equipment did not fit all } \\
\text { students. }\end{array}$ & \\
\hline
\end{tabular}

\subsection{Content Analysis}

To explore the transferability and suitability of the themes and barriers to accessibility

that are identified above, a content analysis is employed. The content analysis explores whether other ski areas identify or address the barriers to accessibility that are encountered at Snow Mountain. Due to proximity to the researcher, ski areas in Ontario are studied. An online scan is conducted of the websites of the ski areas located in Ontario. The objective of the online scan is to identify what sorts of accessibility information ski areas are providing about their facilities and services on their website. Out of 57 Ontario ski areas, 39 of the websites do not provide accessibility information (Illustration 20). For a more comprehensive list of the ski areas in Ontario that do and do 
not provide accessibility information, please refer to Appendix C.

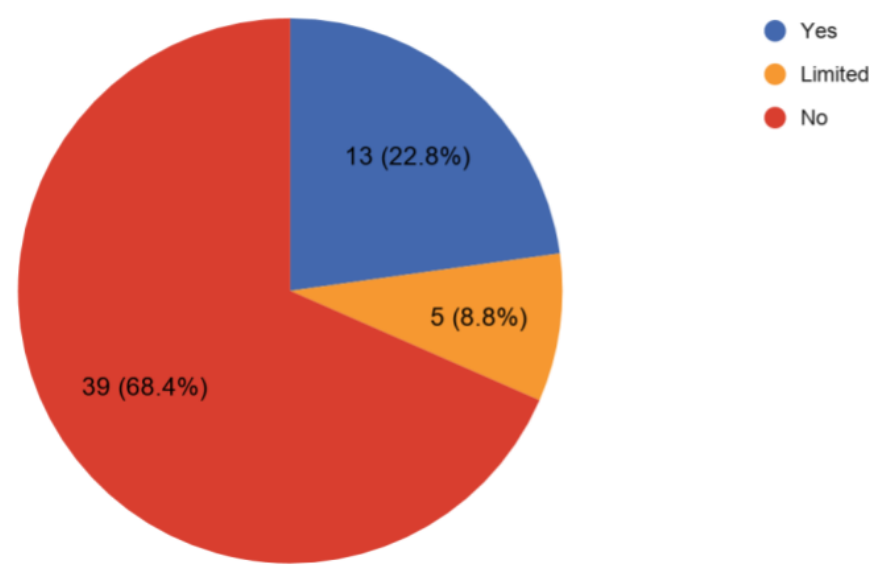

Illustration 20 Ontario ski areas that provide accessibility information on their website

The content analysis reveals that the ski areas that do provide accessibility information on their websites often identify the following facilities and services (Table 9):

Table 9 Accessible Facilities \& Services at Ontario Ski Areas

\begin{tabular}{|l|l|}
\hline Barrier Type & Ski Area Facility/Service \\
\hline Architectural \& Physical Barriers & Parking \\
\cline { 2 - 2 } & Lodging \& Accommodations \\
\cline { 2 - 2 } & Washrooms \\
\cline { 2 - 2 } & Restaurants \& Cafeterias \\
\cline { 2 - 2 } & Retail Stores \\
\cline { 2 - 2 } & Chairlifts \& Gondolas \\
\cline { 2 - 3 } & Resort Shuttles \\
\hline \multirow{2}{*}{ Attitudinal Barriers } & Employee Training \\
\hline \multirow{2}{*}{ Organizational \& Systemic Barriers } & Lift Lines \\
\cline { 2 - 2 } & Ski-Buddy Ticket \\
\cline { 2 - 2 } & Adaptive Ski Equipment Rentals \\
\hline
\end{tabular}




\begin{tabular}{|l|l|}
\hline \multirow{2}{*}{} & Adaptive Skiing Lessons \\
\cline { 2 - 2 } & Service Animals \\
\cline { 2 - 2 } & Support Persons \\
\hline Informational \& Communicational Barriers & Documentation \\
\cline { 2 - 2 } & Website \\
\hline Technological Barriers & Adaptive Devices \\
\hline
\end{tabular}

The content analysis gathers a list of facilities and services that are identified by some ski areas in Ontario that address barriers to accessibility. Notably, the content analysis also reveals a significant informational and communicational barrier - websites. $68 \%$ of Ontario ski areas do not provide accessibility information on their websites.

\subsection{Summary of Phase 1 Findings}

The following is a summary of the key insights from the Phase 1 findings:

1) There might be issues surrounding the design of adaptive ski equipment. However, CADS at Snow Mountain excels at modifying adaptive ski equipment to meet the unique needs of individuals.

2) Snow Mountain permits CADS to use their ski area to run an adaptive ski program. However, accessibility is not consistently and thoroughly implemented at the ski area. Barriers to accessibility for skiing include:
a. Architectural and Physical Barriers
b. Attitudinal Barriers
c. Organizational and Systemic Barriers 

d. Informational and Communicational Barriers
e. Technological Barriers

3) Some ski areas in Ontario identify good practices for accessibility.

4) $68 \%$ of Ontario ski areas do not provide accessibility information on their websites, which is an informational and communicational barrier for skiing.

Phase 1 discovers barriers to accessibility at Snow Mountain and at ski areas in Ontario via the content analysis; are barriers to accessibility experienced at other ski areas in Canada as well? 


\section{Chapter 5: Phase 2: Definition}

\section{$5.1 \quad$ Overview}

The findings from Phase 1 discover that participants experience barriers to accessibility for skiing at Snow Mountain. Phase 2 is developed to investigate whether similar issues are encountered at ski areas across Canada. A larger sample size than Phase 1 is recruited to define barriers to accessibility that are experienced when skiing. An additional motivation for Phase 2 is to introduce a new source of data, with the eventual goal of triangulation. Triangulation refers to the use of multiple methods or data sources to develop a robust understanding of phenomena (Patton, 1999).

Phase 2 consists of a questionnaire that gathers quantitative and qualitative data. The questionnaire relates to sub-research question 2 and asks participants, "Have you ever experienced or witnessed someone else experience a barrier to accessibility for skiing?".

Phase 1 also reveals that most ski areas in Ontario do not provide accessibility information about their ski area on their website. The questionnaire further investigates people's experiences with seeking accessibility information on the websites of ski areas and whether this causes informational and communicational barriers for skiing.

\subsection{Method Design}

A questionnaire is selected as a method for its ability to collect larger quantities of data (Gillham, 2007). Martin and Hanington (2012) describe questionnaires as being useful for collecting information about people's characteristics, thoughts, feelings, perceptions, 
behaviours, or attitudes. The aim of the questionnaire is to measure and collect written responses about people's experiences with barriers to accessibility for skiing across Canada. The questionnaire is structured to ask yes or no questions and includes space for participants to add their own examples and comments. A total of 26 questions are designed, which takes approximately 10 to 15 minutes to complete. Please refer to Appendix D for a copy of the Phase 2 questionnaire.

The questionnaire is constructed in Google Forms, a survey administration software offered by Google. Various software options are considered, however Google Forms is selected due to its accessibility. According to Google Accessibility, "you can create, edit, and navigate forms with a screen reader and keyboard shortcuts" (Google, 2021). Questionnaire accessibility is important because the researcher intends to recruit persons with disabilities who might use screen readers or assistive technologies to interact with computers.

The questionnaire is anonymous. Sharing information about personal disabilities or attitudes towards accessibility could be considered as sensitive topics. To that end, respondent anonymity is an important factor to help participants feel more open to discuss their experiences freely (Gillham, 2007).

In terms of analyzing the questionnaire responses, affinity diagramming is selected. Martin and Hanington (2012) describe affinity diagramming as a process of clustering and organizing data to identify underlying insights. To illustrate, one thought is written 
per sticky note, verbatim to the responses on the questionnaire. Next, the notes that share an affinity are clustered together, such as a similar intent, problem, or issue. Through the process of interpreting the notes, research-based themes emerge.

\section{$5.3 \quad$ Setting}

Phase 2 takes place during September and October 2020. Due to the COVID-19 pandemic, Phase 2 is conducted online. Nevertheless, the online format is effective for distributing the questionnaire across Canada and facilitates the recruitment of a larger sample size than Phase 1.

\subsection{Participants}

The questionnaire is distributed online to 19 adaptive ski programs across Canada, from Newfoundland and Labrador to British Columbia. While participation is anonymous, participants may be associated with CADS, BC Adaptive Snowsports, or independent programs at ski areas. Participant criteria includes having at least one experience with skiing as or with a person with a disability and being at least 18 years old.

\subsection{Recruitment}

Given the online format of the questionnaire, recruitment is also conducted online. An email containing detailed information about the study and a link to the questionnaire is sent to potential participants. The coordinators or administrators of various adaptive ski programs are recipients of the email. If the study is of interest to them, they are asked to share the email and questionnaire link with the members of their programs. 


\subsection{Data Gathering}

The questionnaire gathers data from participants in three parts:

1) General Information: Participants provide general information about their relationship to skiing, their disability and/or some of the disabilities of the skiers who they know. This data provides important context to the other information gathered. While the study does not disaggregate diverse types of disabilities, this part of the questionnaire is an opportunity to gain insight about the diversity of disability.

2) Barriers to Accessibility: For each of the five types of barriers to accessibility, participants indicate whether they have ever experienced or witnessed the barrier type when skiing. If yes, they describe a personal example and can add comments.

3) Ski Area Accessibility Information: The content analysis in Phase 1 reveals that $68 \%$ of Ontario ski areas do not provide accessibility information on their websites. To investigate whether this is an informational and communicational barrier, the questionnaire gathers data about participants' experiences with seeking accessibility information for ski areas.

\section{7 $\quad$ Findings}

76 participants have responded to the questionnaire. Illustration 21 shows the participants' relationships to adaptive skiing. $59.2 \%$ are volunteers or instructors; $28.9 \%$ are adaptive skiers; $19.7 \%$ are parents or guardians of adaptive skiers; and $2.6 \%$ are adaptive ski program coordinators. Notably, some participants have more than one 
relationship to adaptive skiing. For example, a participant may be a parent of an adaptive skier, in addition to a volunteer with an adaptive ski program. For this reason, Illustration 21 indicates a total of 84 responses when there are only 76 participants.

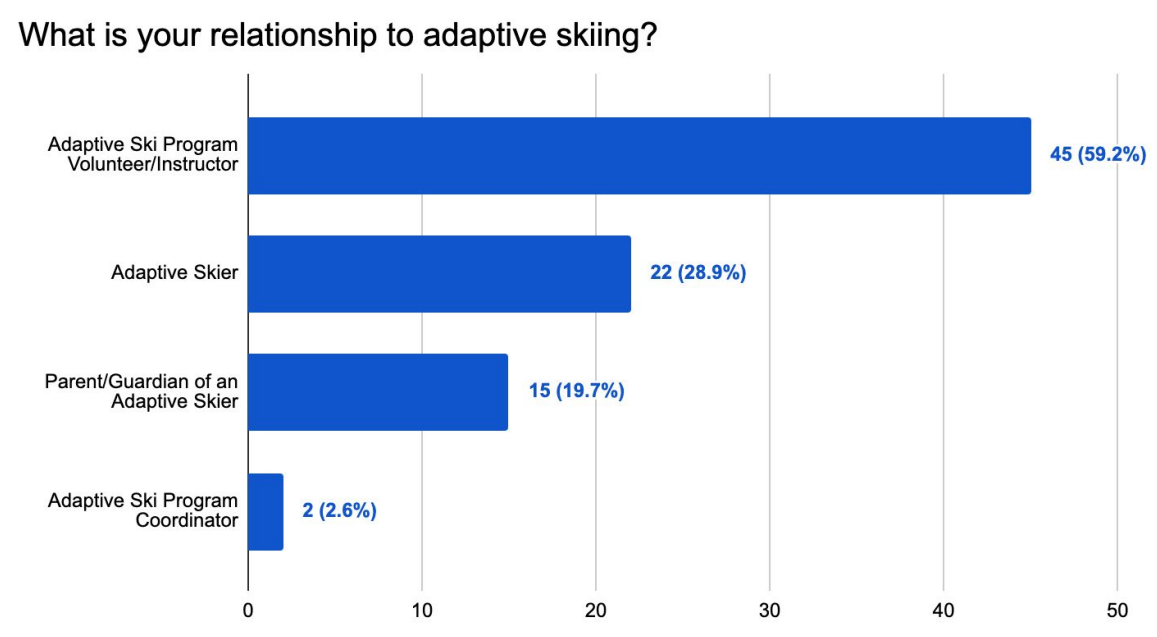

\section{Illustration 21 Participants' relationships to adaptive skiing}

Of the 76 participants, $25(32.9 \%)$ describe themself as a person with a disability (Illustration 22). Some of the disabilities that are reported in the questionnaire include:

1) Cerebral palsy

2) Visual impairment

3) Paraplegia or quadriplegia

4) Spina bifida

5) Multiple sclerosis

6) Documented learning disability

7) Amputation of a limb 


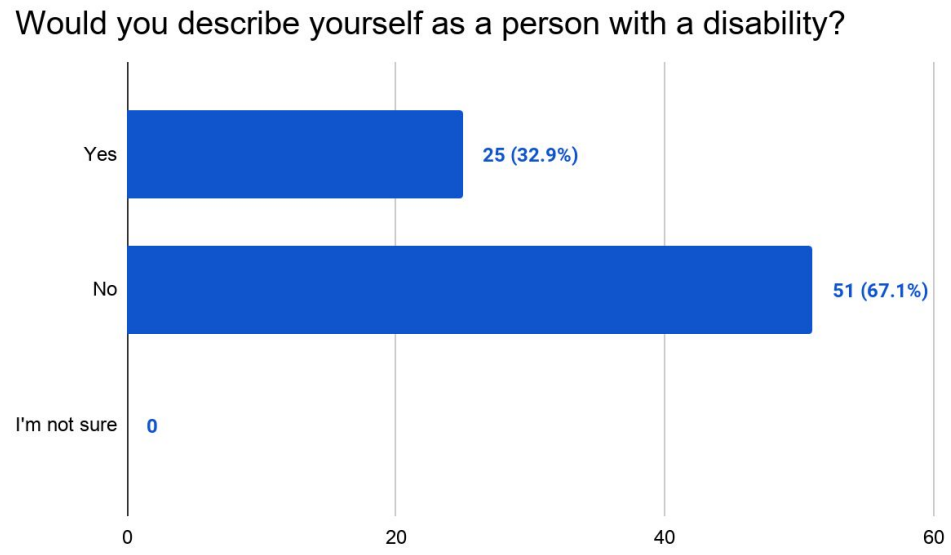

Illustration 2225 (32.9\%) participants described themselves as a person with a disability

\subsection{Analysis of Barriers to Accessibility}

Illustration 23 shows the percentage of participants who have reportedly experienced or witnessed each of the five types of barriers to accessibility for skiing. Each participant identifies at least one type of barrier. Architectural and physical barriers appear to be the most frequently experienced type of barrier to accessibility for skiing, followed by attitudinal, organizational and systemic, informational and communicational, then technological. 
"Have you ever experienced or witnessed someone else experience a barrier to accessibility for skiing?"

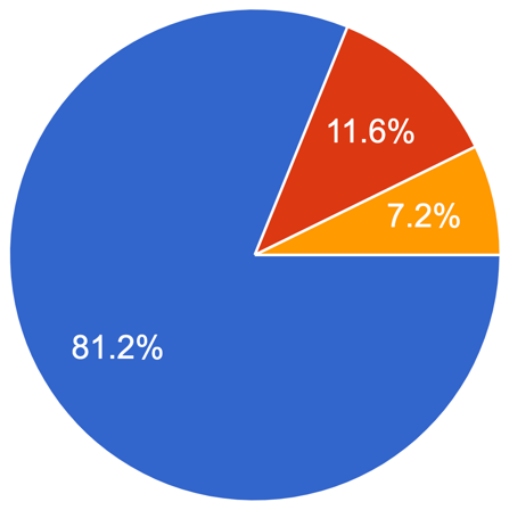

Architectural/Physical Barrier

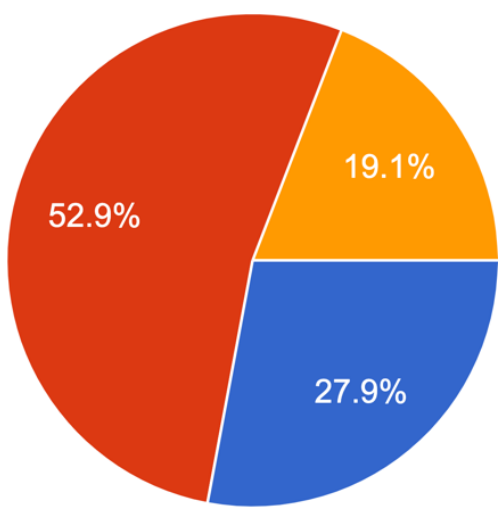

Informational/Communicational Barrier

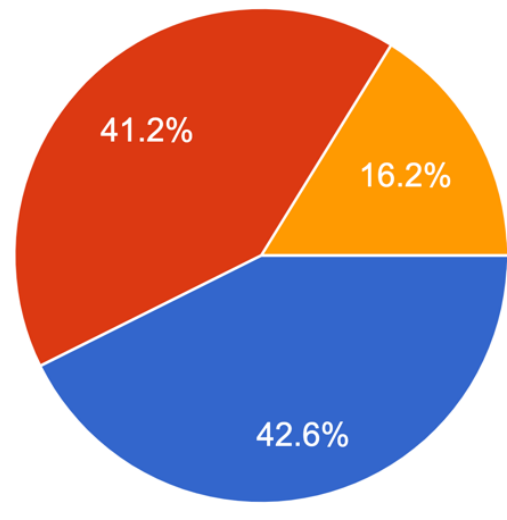

Attitudinal Barrier

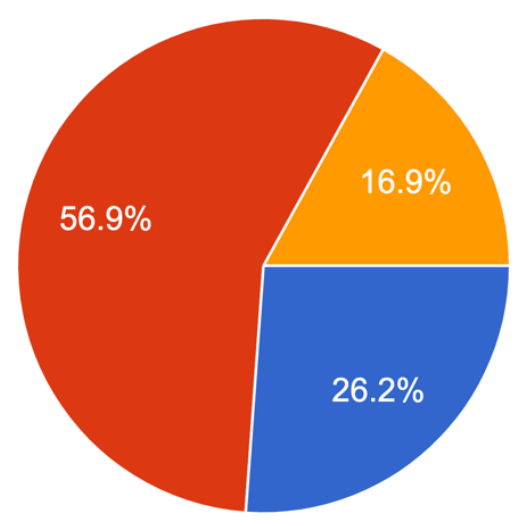

Technological Barrier

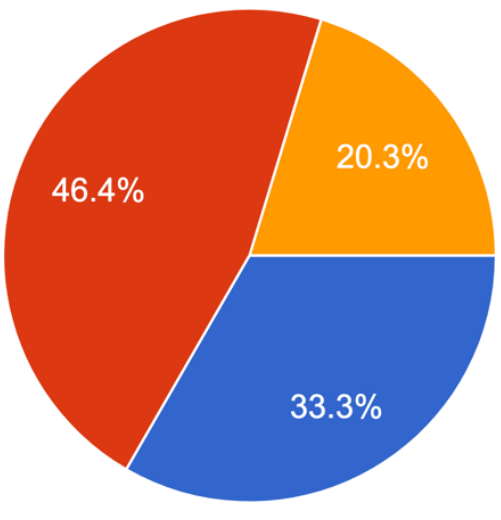

Organizational/Systemic Barrier

\section{Illustration 23 Barriers to Accessibility Experienced/Witnessed by Participants}

Tables 10 to 14 provide summaries of the themes that formed as a result of affinity diagramming for each of the five types of barriers to accessibility for skiing. The number in brackets beside each theme indicates the number of notes clustered within the theme.

\section{Table 10 Barrier Type \#1: Architectural/Physical Barriers}

\begin{tabular}{|l|l|}
\hline Theme & Examples of Barriers \\
\hline $\begin{array}{l}\text { Washrooms } \\
(12)\end{array}$ & $\bullet \quad$ Lack of proper wheelchair accessible washroom(s) \\
\hline
\end{tabular}




\begin{tabular}{|c|c|}
\hline & $\begin{array}{l}\text { - Lack of family washrooms for persons with disabilities and caretakers } \\
\text { - Narrow washroom doorways and stalls } \\
\text { - Washrooms were hard to access (e.g., must use stairs, ramps, or elevators to } \\
\text { - } \text { access) } \\
\text { - Sink and paper towel were out of reach } \\
\text { Washroom doors were too heavy and did not have push-to-open buttons }\end{array}$ \\
\hline Ramps (12) & $\begin{array}{l}\text { - Lack of ramps } \\
\text { - Some entrance doors were not level with the ground and did not use ramps } \\
\text { - Some ramps were too steep }\end{array}$ \\
\hline Doors (9) & $\begin{array}{l}\text { - All ski areas need automatic doors } \\
\text { - Some entrance doors were not level with the ground, making it difficult for } \\
\text { mobility aids and people with mobility issues to enter }\end{array}$ \\
\hline Stairs (9) & $\begin{array}{l}\text { - Stairs or even a single step created obstacles } \\
\text { - Some ski areas had external staircases leading to the lodge } \\
\text { - Other levels were inaccessible due to stairs } \\
\text { - Lack of alternatives to stairs }\end{array}$ \\
\hline Parking (7) & $\begin{array}{l}\text { - Insufficient accessible parking } \\
\text { - The distance from the wheelchair accessible parking spots to the lift or lodge } \\
\text { was too far } \\
\text { - Accessible parking spots were not enforced, therefore reducing the } \\
\text { availability to those who need it }\end{array}$ \\
\hline $\begin{array}{l}\text { Lift \& Lift } \\
\text { Line (6) }\end{array}$ & $\begin{array}{l}\text { - Some lifts moved too quickly to load } \\
\text { - } \text { Most gondolas are not compatible with wheelchairs and sit skis } \\
\text { - Narrow gates leading up to the lift } \\
\text { - Some ski areas had a dedicated lift line for skiers with disabilities } \\
\text { - If chairlift ramps and landings are much lower than the chairlift or too high, } \\
\text { people can have challenges unloading }\end{array}$ \\
\hline Tables (5) & $\begin{array}{l}\text { - Tables with fixed stools were hard to use for some persons in wheelchairs } \\
\text { - The aisles between tables were sometimes too narrow for mobility aids and } \\
\text { adaptive ski equipment }\end{array}$ \\
\hline Elevators (4) & $\begin{array}{l}\text { - Many lodges with multiple floors did not have elevators } \\
\text { - Some lodges allowed persons with disabilities to use the freight elevator }\end{array}$ \\
\hline $\begin{array}{l}\text { Cafeteria \& } \\
\text { Bar }(4)\end{array}$ & $\begin{array}{l}\text { - The cafeteria was located on the second floor but there was no elevator } \\
\text { - Difficulty reading the cafeteria menu due to font size and lighting }\end{array}$ \\
\hline Snow (4) & $\begin{array}{l}\text { - Inadequate infrastructure to support mobility aids on snow } \\
\text { - People in wheelchairs and with mobility issues had challenges on snow that } \\
\text { was not cleared or groomed properly }\end{array}$ \\
\hline Lighting (3) & $\begin{array}{l}\text { - The amount and quality of lights for night skiing were poor, which made } \\
\text { night skiing difficult for persons with visual impairments }\end{array}$ \\
\hline
\end{tabular}




\begin{tabular}{|l|ll|}
\hline Crowds (3) & $\begin{array}{l}\text { It could be difficult to find quiet places that were not crowded in the lodge } \\
\text { and cafeteria. Skiers with autism may not be able to handle excessive noise } \\
\text { and crowds } \\
\text { When the lodge was crowded, mobility aids and adaptive ski equipment did } \\
\text { not always fit }\end{array}$ \\
\hline $\begin{array}{l}\text { Ticket Booth } \\
(1)\end{array}$ & - The ticket window was on the second floor of a building without an elevator \\
\hline $\begin{array}{l}\text { Equipment } \\
\text { Room (1) }\end{array}$ & $\begin{array}{l}\text { An adaptive ski equipment room was installed down a flight of stairs and } \\
\text { was not accessible to those with mobility challenges }\end{array}$ \\
\hline
\end{tabular}

Table 11 Barrier Type \#2: Attitudinal Barriers

\begin{tabular}{|c|c|}
\hline Theme & Examples of Barriers \\
\hline $\begin{array}{l}\text { Underestimating } \\
\text { Adaptive Skiers (9) }\end{array}$ & $\begin{array}{l}\text { - Many people were shocked that persons with disabilities could ski } \\
\text { - Adaptive skiers often get comments such as "it is so inspirational to see } \\
\text { you out skiing", "wow, you can ski!" }\end{array}$ \\
\hline $\begin{array}{l}\text { Anti- } \\
\text { Accommodation (5) }\end{array}$ & $\begin{array}{l}\text { - Some people have said that adaptive skiers should not be allowed to } \\
\text { participate because they require accommodations } \\
\text { - Some people have said that sit skiers should not be permitted on the } \\
\text { same hills as the general public } \\
\text { - Some people assumed that it was dangerous to ski with a disability } \\
\text { (e.g., blind) } \\
\text { - Many people complained when adaptive skiers got to use the accessible } \\
\text { lift line and 'jump' the line } \\
\text { - Some school trips to ski areas excluded students with disabilities } \\
\text { because it was too much effort for the organizers to make } \\
\text { accommodations }\end{array}$ \\
\hline Belittlement (4) & $\begin{array}{l}\text { - Adaptive skiers have reported experiencing patronizing behaviours } \\
\text { - Racing and ski programs have reportedly singled out and belittled } \\
\text { skiers if they had a disability }\end{array}$ \\
\hline $\begin{array}{l}\text { Lack of Awareness } \\
\text { (4) }\end{array}$ & $\begin{array}{l}\text { - A person was walking down the stairs and began to complain because } \\
\text { the person in front of them did not move over. Once they noticed that } \\
\text { the person in front was wearing a vest that said, 'visually impaired', } \\
\text { they changed their attitude } \\
\text { - Judgments are often made about persons with disabilities } \\
\text { - Adaptive ski programs can expose the general public to disabilities and } \\
\text { increase awareness }\end{array}$ \\
\hline Self-Doubt (3) & $\begin{array}{l}\text { - Sometimes persons with disabilities doubt their own abilities } \\
\text { - "I am unable to do it" or "I am not capable of skiing as well or as fast } \\
\text { as someone who is able-bodied" } \\
\text { - Some parents/guardians of adaptive skiers were over-protective. This } \\
\text { can be in the form of trying to do everything for the child (e.g., Not }\end{array}$ \\
\hline
\end{tabular}


challenging them to overcome obstacles) or in the form of discouraging/not allowing the child to try new things (e.g., "You are not able to do that")

Table 12 Barrier Type \#3: Organizational/Systemic Barriers

\begin{tabular}{|c|c|}
\hline Theme & Examples of Barriers \\
\hline $\begin{array}{l}\text { Managing Other } \\
\text { Skiers (5) }\end{array}$ & $\begin{array}{l}\text { - Most adaptive ski programs have attempted to manage other skiers on } \\
\text { the hill to ensure safety. Some skiers did not know how adaptive skiing } \\
\text { worked and would ski too fast or too close to the adaptive skiers } \\
\text { Most adaptive ski programs have assigned volunteers to be "Assistant } \\
\text { Instructors" (also known as an "Uphill Assistant" or a "Blocker") to } \\
\text { manage other skiers on the hill. The primary mission of the assistant } \\
\text { instructor is to protect the adaptive skier from other hill users, by } \\
\text { positioning themselves uphill and slightly ahead of the athlete in order } \\
\text { to block other skiers } \\
\text { - When blocking for a visually impaired skier, the assistant instructor has } \\
\text { typically worn a special high visibility vest } \\
\text { When blocking for a skier using adaptive ski equipment (e.g., a sit ski), } \\
\text { the assistant instructor typically has not worn special high visibility } \\
\text { gear } \\
\text { Occasionally, assistant instructors have failed to block all other skiers } \\
\text { and an accident has occurred. When this happens, assistant instructors } \\
\text { have sometimes been blamed for having inadequate training }\end{array}$ \\
\hline $\begin{array}{l}\text { Accessible } \\
\text { Transportation } \\
\text { Services (5) }\end{array}$ & $\begin{array}{l}\text { - Public \& para transport were not offered at some ski areas } \\
\text { - } \quad \text { Ski trips, festivals, and events do not always use accessible busses }\end{array}$ \\
\hline $\begin{array}{l}\text { Access to Adaptive } \\
\text { Ski Programs \& } \\
\text { Equipment (5) }\end{array}$ & $\begin{array}{l}\text { - Not all ski areas have adaptive ski programs or adaptive ski equipment } \\
\text { rentals } \\
\text { Many adaptive ski programs had waitlists if there were not enough } \\
\text { volunteers or instructors for the students }\end{array}$ \\
\hline $\begin{array}{l}\text { Volunteer Training } \\
\text { (3) }\end{array}$ & $\begin{array}{l}\text { - Not all volunteers had the background to ski with persons with } \\
\text { disabilities and the observational or instructional skills to support } \\
\text { development } \\
\text { - Some volunteers lacked knowledge of adaptive ski equipment needs }\end{array}$ \\
\hline Staff Training (3) & $\begin{array}{l}\text { - Some lift operators have laughed at adaptive skiers } \\
\text { - Lift operators sometimes did not understand how adaptive ski } \\
\text { equipment could be used on chairlifts and sometimes avoided helping } \\
\text { - Ski area staff received limited training on how to help persons with a } \\
\text { disability to access their terrain }\end{array}$ \\
\hline Liability (2) & $\begin{array}{l}\text { - Some ski areas were reluctant to take on an adaptive ski program due to } \\
\text { concerns over liability } \\
\text { - Some persons with disabilities have been told that they are not allowed }\end{array}$ \\
\hline
\end{tabular}




\begin{tabular}{|l|l|}
\hline & \multicolumn{1}{|c|}{ to ski without disability insurance } \\
\hline $\begin{array}{l}\text { Skiing without an } \\
\text { Adaptive Ski }\end{array}$ & $\begin{array}{l}\text { Program (2) } \\
\text { to assist them on the hill. There were not many ski areas that offered } \\
\text { adaptive instructors in addition to regular ski instructors } \\
\text { If a skier were not part of an adaptive ski program, they would not have } \\
\text { access to appropriate signs, literature, coaching instructors, or adaptive } \\
\text { ski equipment }\end{array}$ \\
\hline Ski Lift Tickets (1) & $\begin{array}{l}\text { Some adaptive ski programs provided their volunteers and instructors } \\
\text { with free ski lift tickets, while some ski areas did not offer free or } \\
\text { discounted tickets to guides/support skiers }\end{array}$ \\
\hline
\end{tabular}

Table 13 Barrier Type \#4: Informational/Communicational Barriers

\begin{tabular}{|c|c|}
\hline Theme & Examples of Barriers \\
\hline Text Documents (4) & - Text documents excluded persons with visual impairments \\
\hline $\begin{array}{l}\text { Signage/Wayfinding } \\
\text { (7) }\end{array}$ & $\begin{array}{l}\text { - Signage at ski areas was often small or difficult to read } \\
\text { - Signage can be hard to see if it is poorly lit } \\
\text { - Small print font and poor contrast are not always readable }\end{array}$ \\
\hline Website (8) & $\begin{array}{l}\text { - Some websites and online forms were hard to navigate with screen } \\
\text { readers and assistive technologies (e.g., missing alternative text on } \\
\text { images or video captions and transcriptions) }\end{array}$ \\
\hline $\begin{array}{l}\text { Communication } \\
\text { Training (2) }\end{array}$ & $\begin{array}{l}\text { Ski area staff and adaptive ski program volunteers/instructors do not } \\
\text { always have an understanding of how to communicate with persons } \\
\text { with disabilities } \\
\text { When interacting with a person who is blind, people are not always } \\
\text { aware that they should avoid pointing, not giving clear directional } \\
\text { instruction and grabbing or pulling } \\
\text { - Communicating with a person who is non-verbal can be challenging }\end{array}$ \\
\hline Clear Language (1) & - Information that is being shared does not always use plain language \\
\hline Advance Notice (1) & $\begin{array}{l}\text { For those with autism, knowing exactly what is going to happen, } \\
\text { where it is going to happen, and when it is going to happen is } \\
\text { particularly important. Sometimes organizations do not communicate } \\
\text { soon enough, or make last minute changes with little advance notice }\end{array}$ \\
\hline
\end{tabular}

Table 14 Barrier Type \#5: Technological Barriers

\begin{tabular}{|l|l|}
\hline Theme & Examples of Barriers \\
\hline
\end{tabular}




\begin{tabular}{|l|l|}
\hline $\begin{array}{l}\text { Modifying Adaptive } \\
\text { Ski Equipment (1) }\end{array}$ & $\begin{array}{l}\text { Adaptive ski program volunteers/instructors were encouraged to } \\
\text { collaborate with the students to find appropriate modification solutions } \\
\text { for their equipment }\end{array}$ \\
\hline Management (1) & $\begin{array}{l}\text { Some adaptive ski programs have introduced an online management } \\
\text { software called Snowline. Other adaptive ski programs commonly use } \\
\text { a binder for management and record-keeping }\end{array}$ \\
\hline Lift Tickets (1) & $\begin{array}{l}\text { Lift tickets that need to be scanned can create a physical interaction } \\
\text { that is outside of the comfort zone of a person with a disability }\end{array}$ \\
\hline
\end{tabular}

\subsection{Analysis of Information Provision at Ski Areas}

The last part of the questionnaire gathers data about participants' experiences with retrieving accessibility information about ski areas. Over half of the participants indicate that they typically research the accessibility of a ski area's facilities and services prior to visiting (Illustration 24).
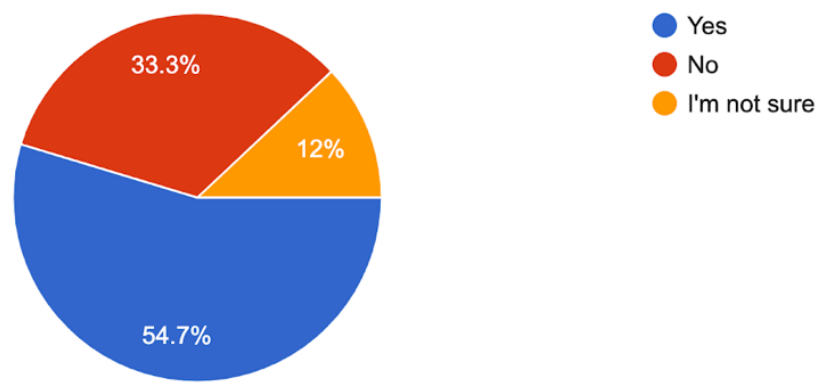

Illustration 24 "If you were planning to visit a ski area for the first time, would you seek information about the accessibility of the ski area?"

The most common way of seeking accessibility information is to go to the ski area's website (Illustration 25). 


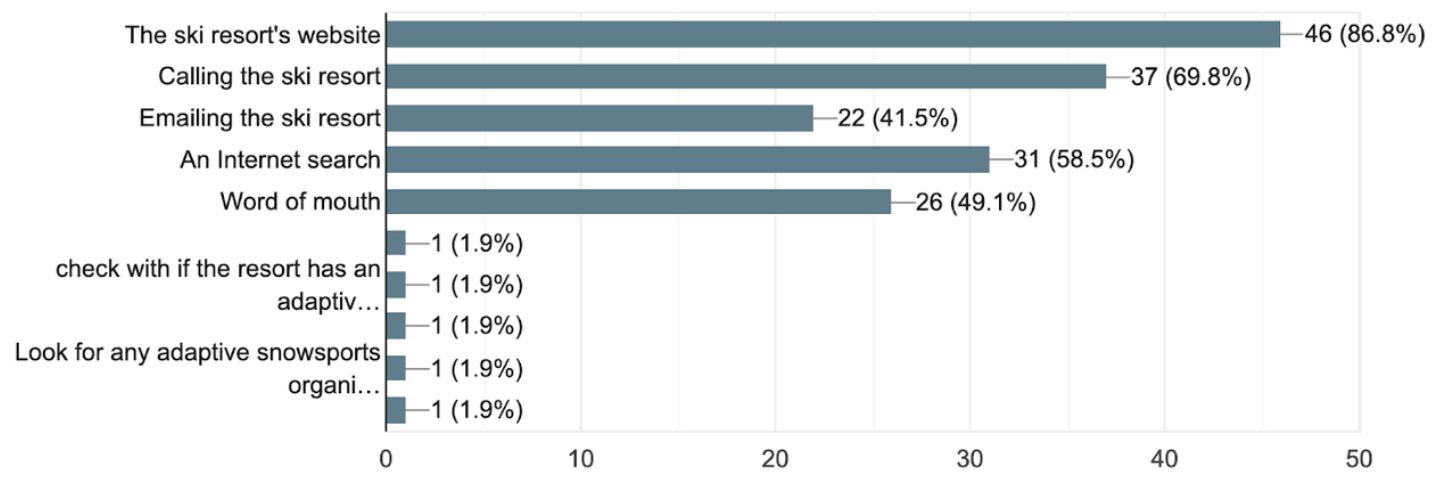

Illustration 25 'How would you seek the accessibility information?"

Approximately one third of participants report a time when they could not find accessibility information for a ski area (Illustration 26).
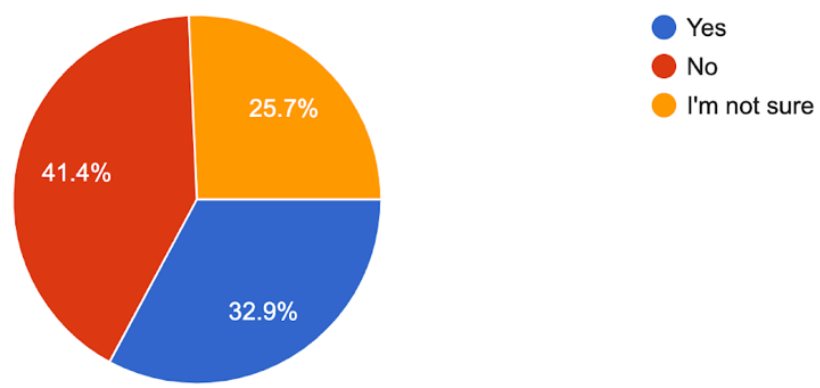

Illustration 26 'Has there ever been a time that you could not find accessibility information for a ski area?"'

The following is a list of accessibility information that some participants report not being able to find:

1) Is the ski area accessible? (e.g., wheelchair friendly)

2) Does the ski area permit adaptive skiers (sit skiers, visually impaired skiers) on the hill?

3) Can adaptive ski equipment be rented at the ski area?

4) Are ski lessons offered for adaptive skiers? What are the prices?

5) Is the chairlift or gondola compatible with adaptive ski equipment?

6) Is there accessible parking? 
7) Does the ski area have subsidized pricing for ski-buddy lift tickets?

This type of accessibility information is relatively basic and should not stand in the way of someone participating in skiing. Information provision appears to be an easy way to reduce barriers to accessibility for skiing.

\subsection{Summary of Phase 2 Findings}

The following is a summary of the key insights from the Phase 2 findings:

1) Accessibility issues are not isolated to Snow Mountain. It appears that ski areas across Canada do not implement accessible design consistently and thoroughly.

2) Participants report experiencing and/or witnessing barriers to accessibility for skiing in the following order of frequency:
a. Architectural \& Physical Barriers (81.2\%)
b. Attitudinal Barriers (42.6\%)
c. Organizational \& Systemic Barriers (33.3\%)
d. Informational \& Communicational Barriers (27.9\%)
e. Technological Barriers (26.2\%)

3) Although people can seek accessibility information for ski areas in several ways, inadequate provision of accessibility information on ski area websites appears to be an informational and communicational barrier for skiing.

4) Information provision appears to be an easy way to reduce barriers to accessibility for skiing. 
Now that a breadth of barriers to accessibility for skiing are identified, the need arises to seek ways to address these barriers. In essence, what should ski areas consider for offering accessible and inclusive facilities and services? Thus, the subsequent phase seeks to collaborate with participants. 


\section{Chapter 6: Phase 3: Design}

\subsection{Overview}

The findings from Phase 2 suggest that accessibility and inclusivity are not being implemented equally at all Canadian ski areas. Phase 3 arises in search of opportunities to minimize, and ideally remove, barriers to accessibility across Canadian ski areas. Phase 3 applies a participatory design approach to engage with subject matter experts and target users to generate desirable future scenarios and recommendations that may improve the experience of adaptive skiing.

Sanders and Stappers (2014) recognize people as "experts of their experiences". Design researchers can use tools, techniques, and procedures to help participants communicate their special knowledge. In the context of this thesis, the participants have an abundance of lived experience regarding skiing with/as persons with disabilities. There is value in collaborating with participants to learn about their past experiences to seek ways to reduce or remove barriers to accessibility for skiing.

\subsection{Method Design}

The design of Phase 3 is inspired by a participatory design framework proposed by Sanders and Stappers (2014) called the path of expression. The framework is a generative tool, which can help researchers develop a deeper understanding of user experiences in order to find opportunities for solutions and innovation research (Estes, 2020). Illustration 27 shows the path of expression, which asks participants to recall past experiences, in terms of memories and nightmares. Next, participants envision a future 
scenario by considering their dreams and fears. According to Sanders and Stappers (2014), the path of expression is a "process of sensitizing and awareness-building, by which design researchers guide participants to a deeper understanding of their needs, wants, hopes, and dreams in order to identify criteria and opportunities" (Sanders \& Stappers, 2014). Essentially, when researching the present situation, or "the moment", the path of expression framework is useful for guiding participants to think of what a desirable future situation would be based on previous good and bad experiences.

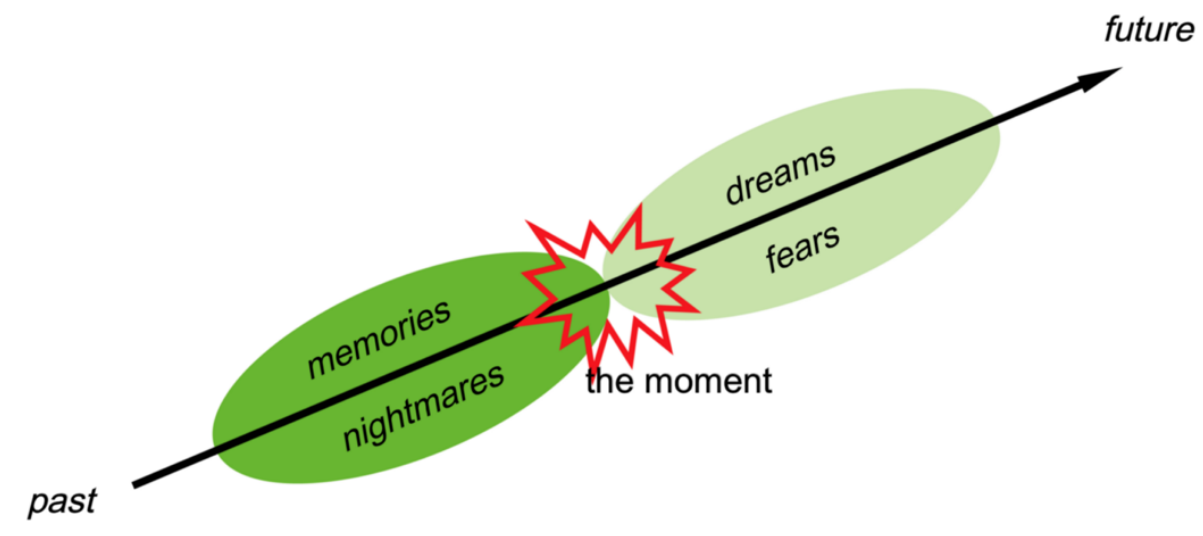

Illustration 27 The path of expression framework (Sanders \& Stappers, 2014)

To gather data using the path of expression framework, directed storytelling is selected as the method for Phase 3. Directed storytelling is an ethnographic qualitative research method that documents stories of lived experiences (Clandinin \& Connelly, 2000). Evenson (2006) explains that in a directed storytelling session, guiding and framing questions are used to prompt a participant to share personal stories and insights.

Directed storytelling is particularly useful when time or other factors prevent direct observation or longer forms of research inquiry (Martin \& Hanington, 2012). Given the 
seasonal nature of skiing and the restrictions of COVID-19, conducting more observations at a ski area is not feasible. Therefore, directed storytelling is optimal for learning about participants' lived experiences with accessibility during each stage of the experience of skiing.

During one-on-one directed storytelling sessions, each participant discusses their past experiences and future ideas for skiing with/as persons with disabilities. Given the online format, the sessions occur on Zoom, a video conferencing software program. Zoom uses audio and/or video, permits meetings to be recorded, and has a screen sharing feature. To promote collaboration, the researcher and the participant also use Miro, an online visual collaboration platform. On Miro, the researcher prepares three tasks containing prompts and questions for directed storytelling.

The tasks are reflective of the path of expression framework. Participants are asked to share stories of past experiences, which are then applied to guide thinking of what would be a desirable future for skiers with disabilities. Together, the researcher and the participant create visualizations of the storytelling using sticky notes, shapes, drawings, text, and images.

Task 1 is developed to ask screening questions. The purpose is to gather data that could help the researcher understand the participant's background with skiing with/as a person with a disability (Illustration 28). The questions include:

1) Would you describe yourself as having a disability? If yes, please define your 
disability.

2) What is your relationship to skiing?

Task 1: Screening Questions

1. Would you describe yourself as having a disability? If yes, please define your disability.

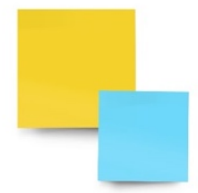

2. What is your relationship to skiing?

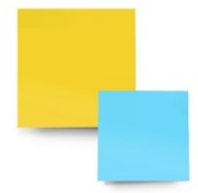

\section{Illustration 28 Phase 3, Task 1}

For Task 2, the researcher prepares a chart on Miro to facilitate storytelling about each participant's past experiences with skiing with/as a person with a disability (Illustration 29). Task 2 asks the participant to map out each stage of their typical skiing experience. A stage of skiing refers to one link in the chain of experiences while skiing. For instance, one might prepare and plan at home, commute to the ski area, find a parking spot, walk to the lodge, put on gear and equipment, ride the chairlift, ski, and so on. Ultimately, the stages occur before, during, and after the act of skiing and make up the overall experience. For each stage, the participant is asked to break down the activities and details, reflect on the positive and negative aspects of accessibility, and describe their mood during the stage. 
Let's map out each stage of your typical skiing experience:
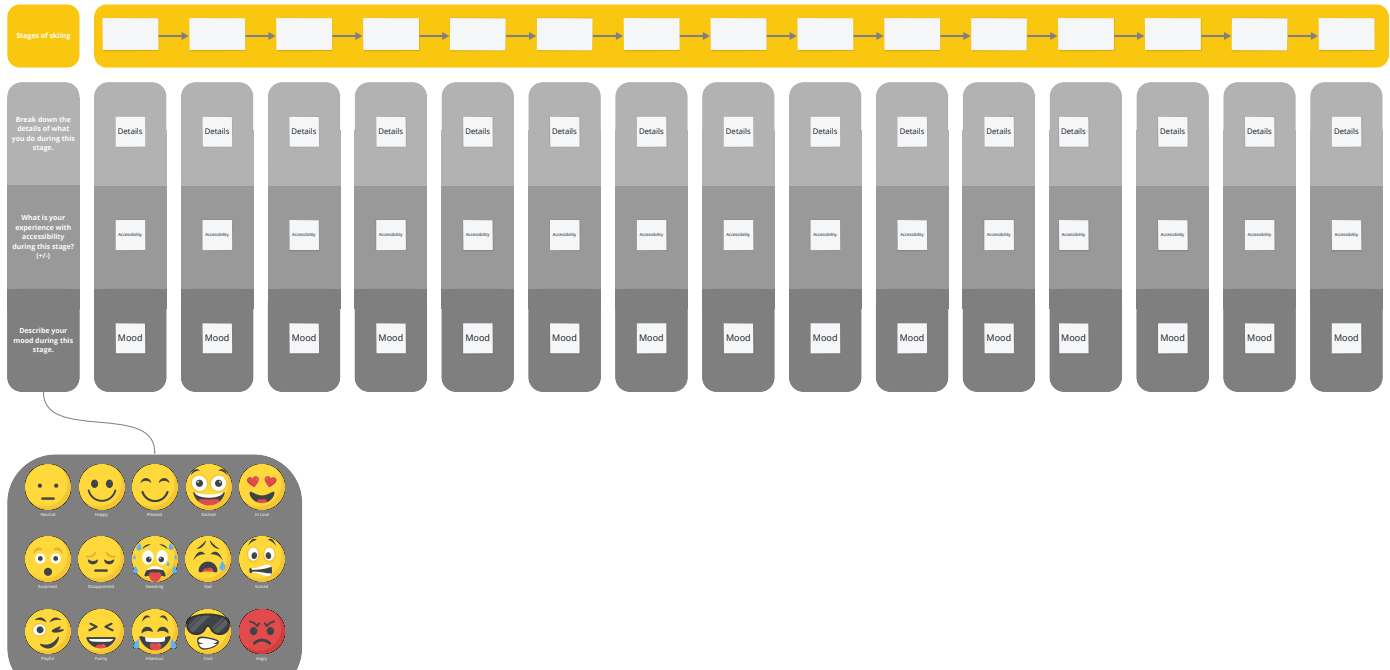

Illustration 29 Phase 3, Task 2

Task 2 is designed with three key objectives:

1) To examine if, when, and where barriers to accessibility occur during specific stages of the experience of skiing.

2) To compare each barrier to accessibility to the entire experience of skiing. For example, do factors from another stage within the experience influence a barrier to accessibility? Are the stages interconnected?

3) To prime the participant for Task 3 .

Task 3 asks the participant to reflect on the good and bad experiences from Task 2, to envision a desirable future for adaptive skiing. The researcher and the participant collaborate in Miro to create a collage.

An intended outcome of directed storytelling is to generate user journey maps. Martin 
and Hanington (2012) describe a user journey map as a visualization of a person's experiences while interacting with a product, service, or environment, so that each moment can be individually evaluated and improved. A user journey map can document a person's actions, feelings, perceptions, and frame of mind.

Another objective of Phase 3 is to continue identifying barriers to accessibility. An intended contribution of this thesis is to provide a list of barriers to accessibility that people experience when skiing, which might help ski areas gain awareness of their own shortcomings with accessibility. To analyze the data and identify barriers to accessibility, affinity diagramming is used. As previously mentioned, affinity diagramming is a process of writing data on sticky notes and clustering similar notes together to interpret the data and generate themes (Martin \& Hanington, 2012).

\subsection{Setting}

Phase 3 occurs during October 2020. Due to the COVID-19 pandemic, Phase 3 is conducted online.

\subsection{Participants}

Six participants complete a one-on-one directed storytelling session. The requirements for participation are to have at least one experience with skiing with a person with disability (subject matter expert) or as a person with a disability (target user) and to be at least 18 years old. 


\subsection{Recruitment}

Given the online format of the method, recruitment is also conducted online. In Phase 2, participants are recruited with an email, which contains detailed information about the study and a link to the questionnaire. In the same email from Phase 2, participants are also informed about the ensuing study: Phase 3 directed storytelling. The email outlines the purpose of the study and what participants are expected to do. If anyone has a question or is interested in participating in Phase 3, they are asked to contact the researcher via email. Likewise, the questionnaire in Phase 2 contains the same details to recruit participants for Phase 3.

When a participant indicates their interest in Phase 3, the researcher responds with a letter of information about the study and proceeds to schedule a time for the directed storytelling session.

\subsection{Data Gathering}

For each session, the researcher and participant meet on Zoom. The researcher shares their computer screen and reads the study consent form to the participant. With oral consent, the Zoom meeting is audio and/or video-recorded for the researcher's private use. Next, the researcher sends the participant a shareable link to Miro, where the three tasks are completed. If a participant cannot or chooses not to use Miro, the participant can still follow along on the shared computer screen and the researcher fills in the tasks.

The duration of each session is one hour long. Participant names are not used to ensure 
confidentiality.

The following is a list of the data that is gathered from each session:

1) A Zoom recording for the researcher's private use during analysis

2) Responses to the screening questions in Task 1

3) A completed chart with each stage of the participant's typical skiing experience in Task 2

4) A visualization of a desirable future for skiing in terms of accessibility in Task 3

\subsection{Findings}

The six participants represent subject matter experts and target users of adaptive skiing, and include four adaptive ski students, one program administrator, one instructor, and one volunteer. All participants are affiliated with CADS. Table 15 provides a breakdown of the six participants.

Table 15 Directed Storytelling Participants

\begin{tabular}{|l|l|l|l|l|}
\hline Participant \# & Age & $\begin{array}{l}\text { Relationship to Adaptive } \\
\text { Skiing }\end{array}$ & Skiing Experience & Disability \\
\hline Participant 1 & $40-50 \mathrm{y} / \mathrm{o}$ & $\begin{array}{l}\text { CADS Program } \\
\text { Administrator \& } \\
\text { Student/Skier }\end{array}$ & Advanced & Visual Impairment \\
\hline Participant 2 & $50-60 \mathrm{y} / \mathrm{o}$ & CADS Instructor & Advanced & N/A \\
\hline Participant 3 & $60-70 \mathrm{y} / \mathrm{o}$ & CADS Volunteer & Advanced & N/A \\
\hline Participant 4 & $20-30 \mathrm{y} / \mathrm{o}$ & CADS Student/Skier & Intermediate & Cerebral Palsy \\
\hline Participant 5 & $50-60 \mathrm{y} / \mathrm{o}$ & CADS Student/Skier & Beginner & Paraplegia \\
\hline Participant 6 & $30-40 \mathrm{y} / \mathrm{o}$ & CADS Student/Skier & Intermediate & Cerebral Palsy \\
\hline
\end{tabular}




\subsection{User Journey Maps}

User journey maps provide an opportunity to analyze and synthesize the data from each directed storytelling session. A total of six journey maps are created, one per participant. The raw data from each directed storytelling session is formatted into a user journey map. The goal is to showcase the participant's positive and negative experiences with accessibility during each stage of skiing, as well as their moods as an indication of the impact of each barrier to accessibility.

For each stage of the experience of skiing, the following information is identified:

1) What types of activities occur during the stage?

2) Are there positive or negative experiences with accessibility during the stage?

3) What is the participant's mood during each stage?

4) Does the participant have any recommendations to improve the stage?

The following subsections describe the findings from the six user journey maps.

\subsubsection{Participant 1}

Please refer to Illustration 30 for the user journey map that is developed with Participant 1. Participant 1 is 40 to 50 years old and is involved with a visually impaired ski program as an administrator and a student. Participant 1 says "I am visually impaired with about $10 \%$ vision. I function visually and live a very active life, but there are certain things that I can't do or need assistance with - skiing is one of them". 
Based on the evolution of Participant 1's feelings throughout the experience of skiing, the lodge appears to be one of their most significant barriers to accessibility. One issue with the lodge is that it is a chaotic and loud environment. They indicate that loud areas are not ideal for some persons with visual impairments because it can be challenging to distinguish essential information.

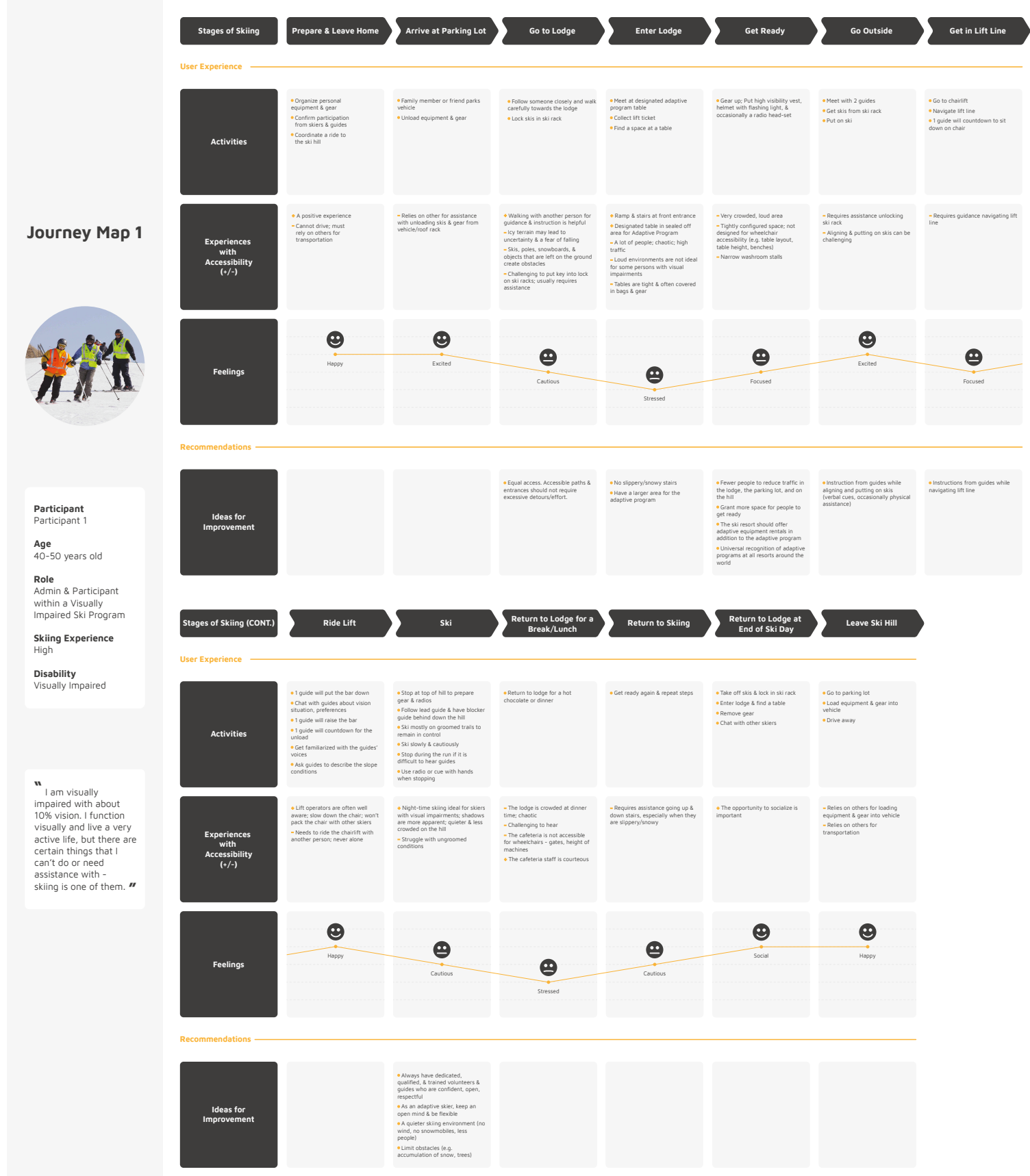

Illustration 30 Participant 1: User Journey Map 


\subsubsection{Participant 2}

Please refer to Illustration 31 for the user journey map that is developed with Participant 2. Participant 2 is 50 to 60 years old and is involved with an adaptive ski program as an instructor. Participant 2 speaks about the importance of instructors maintaining positive attitudes while working with students with disabilities. Participant 2 says, "You have to be flexible because no two rides could be the same. Be prepared to have those things in your back pocket to avoid negative situations and clashing. We can goof around with our students and make them feel comfortable, not embarrassed".

Based on Participant 2's feelings throughout the experience of skiing, their mood remains relatively consistent. This could reflect their statement that instructors should keep a positive attitude, be flexible, and adapt to challenges to promote a better experience for the adaptive ski students. The positive attitude could also be in recognition that Participant 2 has the knowledge that their attitude could be reflected upon the people they are working with; if they are not positive, their students are less likely to be positive. Lastly, Participant 2 does not identify as having a disability, therefore it is possible that they do not personally experience barriers to accessibility when skiing.

One area that Participant 2 would like to be improved would be training opportunities for:

1) Instructors and volunteers working with adaptive skiers: Training could help instructors and volunteers handle concerns and react to accessibility challenges appropriately. Ethical training, such as Sport for Life, could also promote an equal, respectful, and trusting partnership with adaptive ski students. 
2) Staff at ski areas: Staff at ski areas could partner with adaptive ski programs to do pre-season training to become more aware of the needs of adaptive skiers. For example, lift operators and ski patrol could become familiar with adaptive ski equipment, loading techniques, and evacuation procedures.

3) The public: Having better public education of persons with disabilities could improve safety and inclusivity on the hill. 


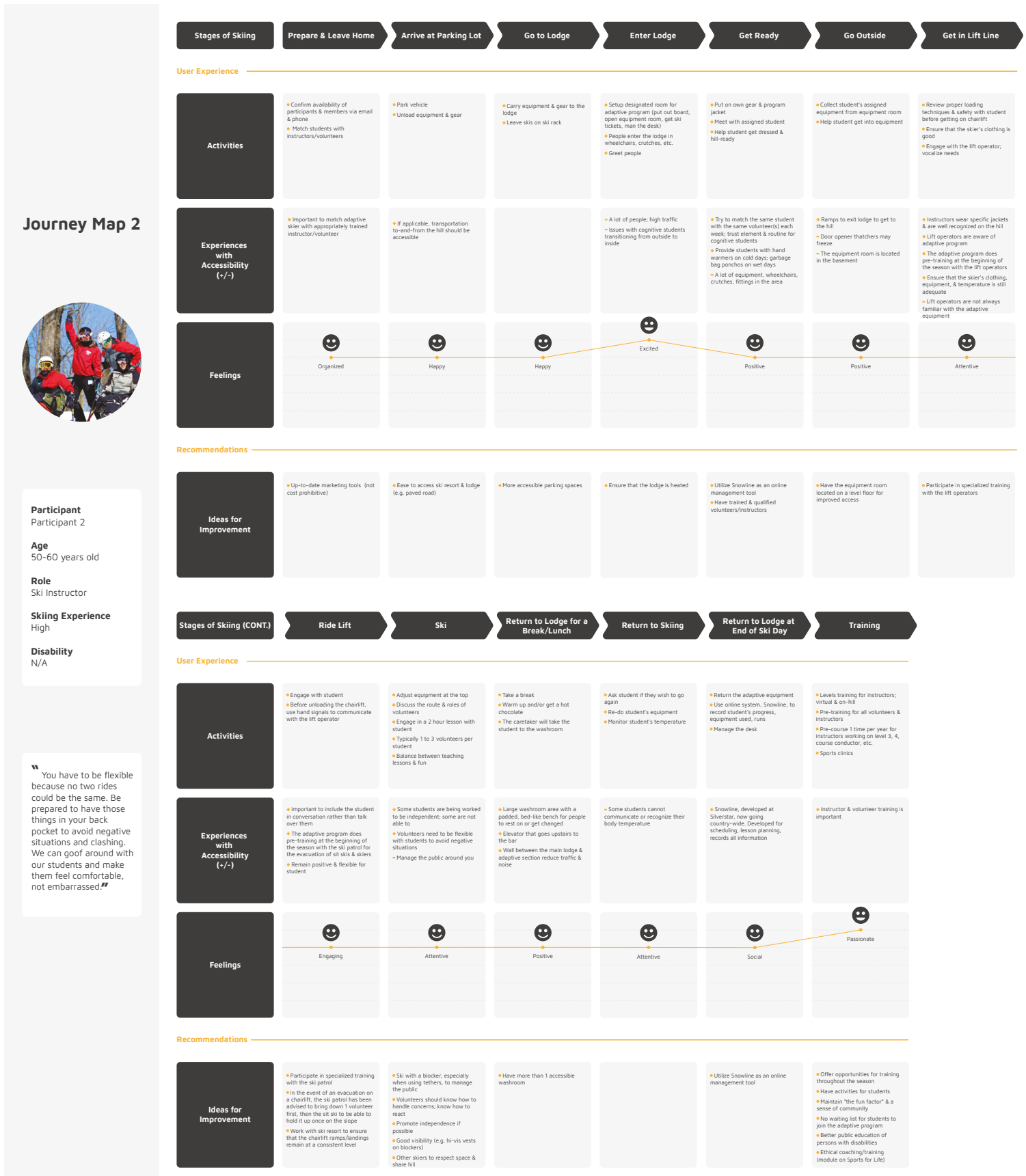

Illustration 31 Participant 2: User Journey Map 


\subsubsection{Participant 3}

Please refer to Illustration 32 for the user journey map that is developed with Participant 3. Participant 3 is 60 to 70 years old and is involved with an adaptive ski program as a volunteer. Participant 3 says "Money solves everything. Money provides more equipment, creates more space for the instructors, minimizes membership fees...whether it comes from the Government or corporate sponsorship. Some ski areas are very generous to adaptive ski programs". Essentially, Participant 3 indicates that some barriers to accessibility could be addressed if adaptive ski programs and ski areas had more money.

Based on Participant 3's feelings throughout the experience of skiing, their mood remains relatively consistent. This is similar to Participant 2 , who is an instructor and maintains a positive attitude for the adaptive ski students, which may be the same for Participant 3 . Likewise, Participant 3 does not identify as having a disability, therefore it is possible that they do not personally experience barriers to accessibility when skiing. 


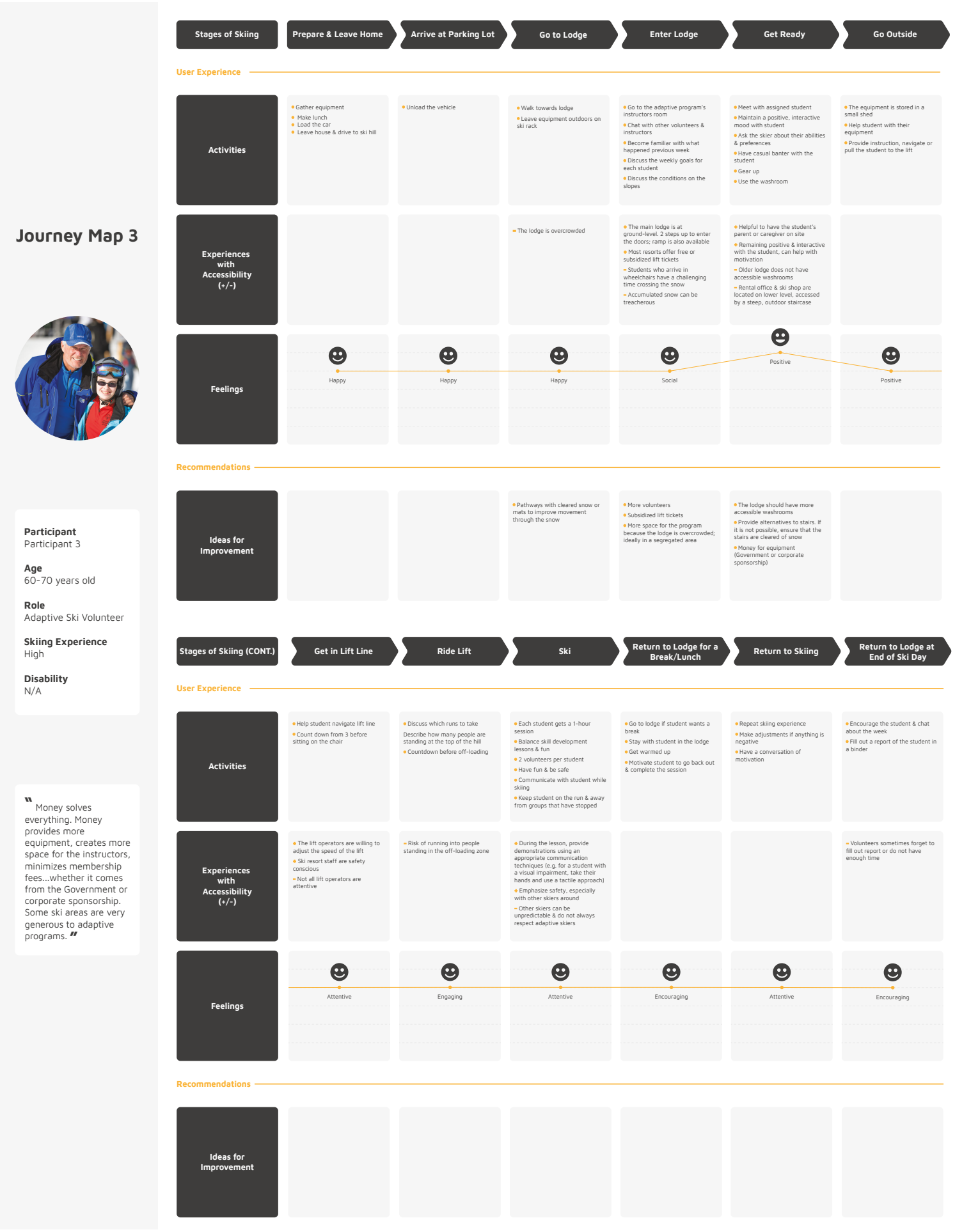

Illustration 32 Participant 3: User Journey Map 


\subsubsection{Participant 4}

Please refer to Illustration 33 for the user journey map that is developed with Participant

4. Participant 4 is 20 to 30 years old and is involved with an adaptive ski program as a student with cerebral palsy. Participant 4 says, "The lodge should have a universal design versus a 'wheelchair ramp'; so, designing the lodge with a ramp built in rather than having it as an after-thought, stuck outside because what's the point of a wheelchair ramp if it is covered in snow \& ice?".

Based on the evolution of Participant 4's feelings throughout the experience of skiing, getting ready in the lodge appears to be one of their most significant barriers to accessibility. They attribute this to the following negative experiences and offer recommendations, provided in Table 16.

\section{Table 16 Participant 4's negative experiences and recommendations}

\begin{tabular}{|l|l|}
\hline Negative Experience & Recommendations \\
\hline Limited places to store their belongings. & $\begin{array}{l}\text { Have more shelving, lockers, or storage for personal } \\
\text { belongings. }\end{array}$ \\
\hline $\begin{array}{l}\text { They avoid using washrooms because they are too } \\
\text { far of a walk. }\end{array}$ & $\begin{array}{l}\text { Make washrooms more central \& accessible (e.g., on } \\
\text { ground floor, close to main lodge). }\end{array}$ \\
\hline $\begin{array}{l}\text { They avoid going to the cafeteria because it is } \\
\text { upstairs and too far of a walk. }\end{array}$ & Cafeteria, restaurant, \& bar should be easier to access. \\
\hline $\begin{array}{l}\text { The second floor of the lodge is not accessible } \\
\text { because there are only stairs and ramps that are } \\
\text { too steep to use. }\end{array}$ & $\begin{array}{l}\text { Install ramps that are to code \& not steep with railings. } \\
\text { Install an elevator. }\end{array}$ \\
\hline
\end{tabular}

Other significant barriers include the parking lot and the snow. According to Participant 4, the accessible parking spots do not have enough room for their van's wheelchair ramp 
to open. As a result, they cannot use their electric wheelchair and have to walk with a cane instead. This makes them tired before skiing. Even if they could use their electric wheelchair, the snow would create issues.

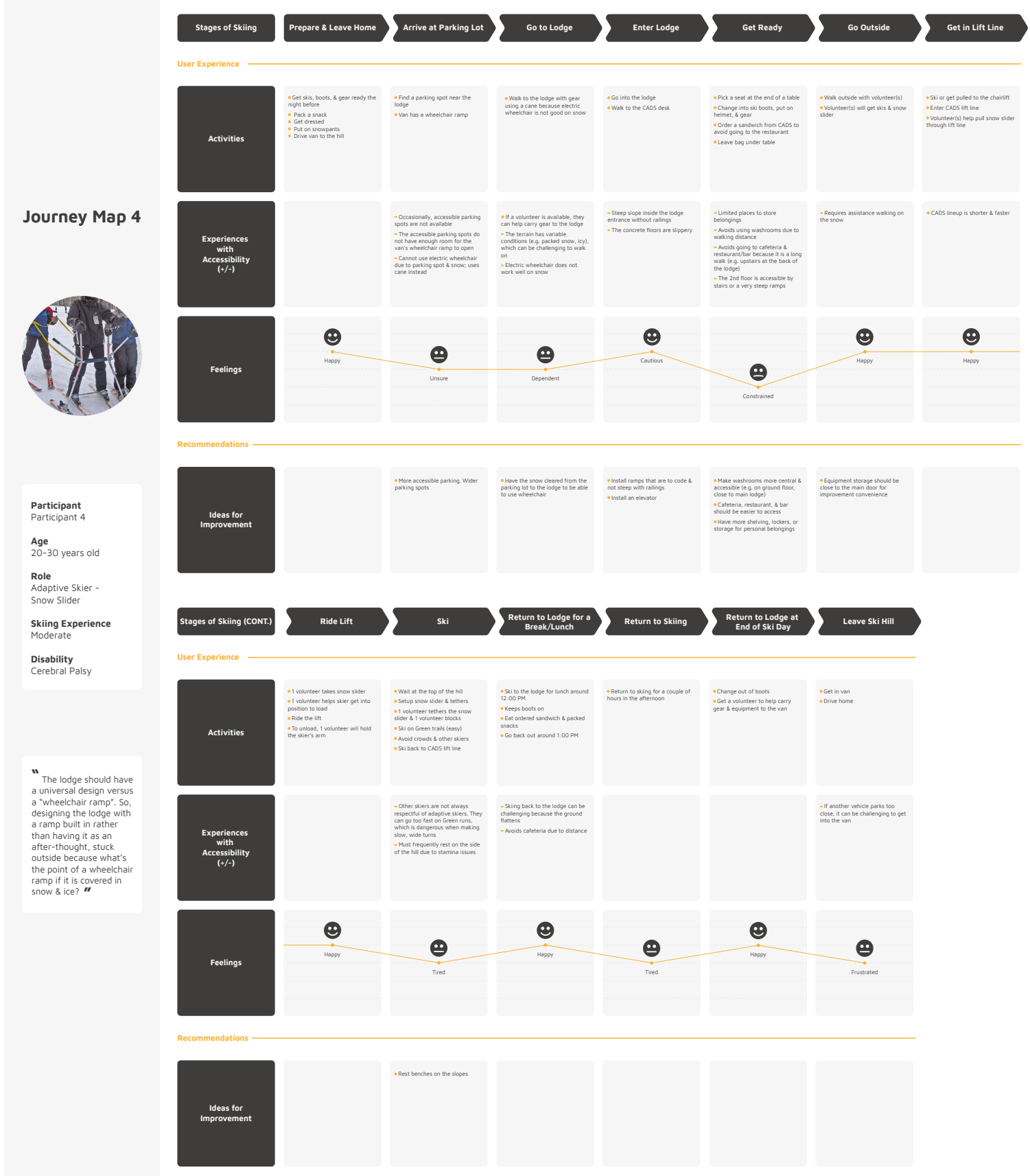

Illustration 33 Participant 4: User Journey Map 


\subsubsection{Participant 5}

Please refer to Illustration 34 for the user journey map that is developed with Participant 5. Participant 5 is 50 to 60 years old and is involved with an adaptive ski program as a sit ski student due to a spinal cord injury resulting in paraplegia. Participant 5 says, "I have to recruit other people to help me because I cannot be independent. Accessibility does not mean 'someone can push you up here'. Accessibility means you can get there yourself'.

Based on the evolution of Participant 5's feelings throughout the experience of skiing, using their wheelchair on the snow appears to be one of their most significant barriers to accessibility. For example, Participant 5 indicates that they have to rely on others to push them up a snow-covered incline from the parking lot to the lodge. The snow is not always flattened or cleared and creates challenges with traction when changing surfaces (e.g., moving from the snow to the lodge floor). 


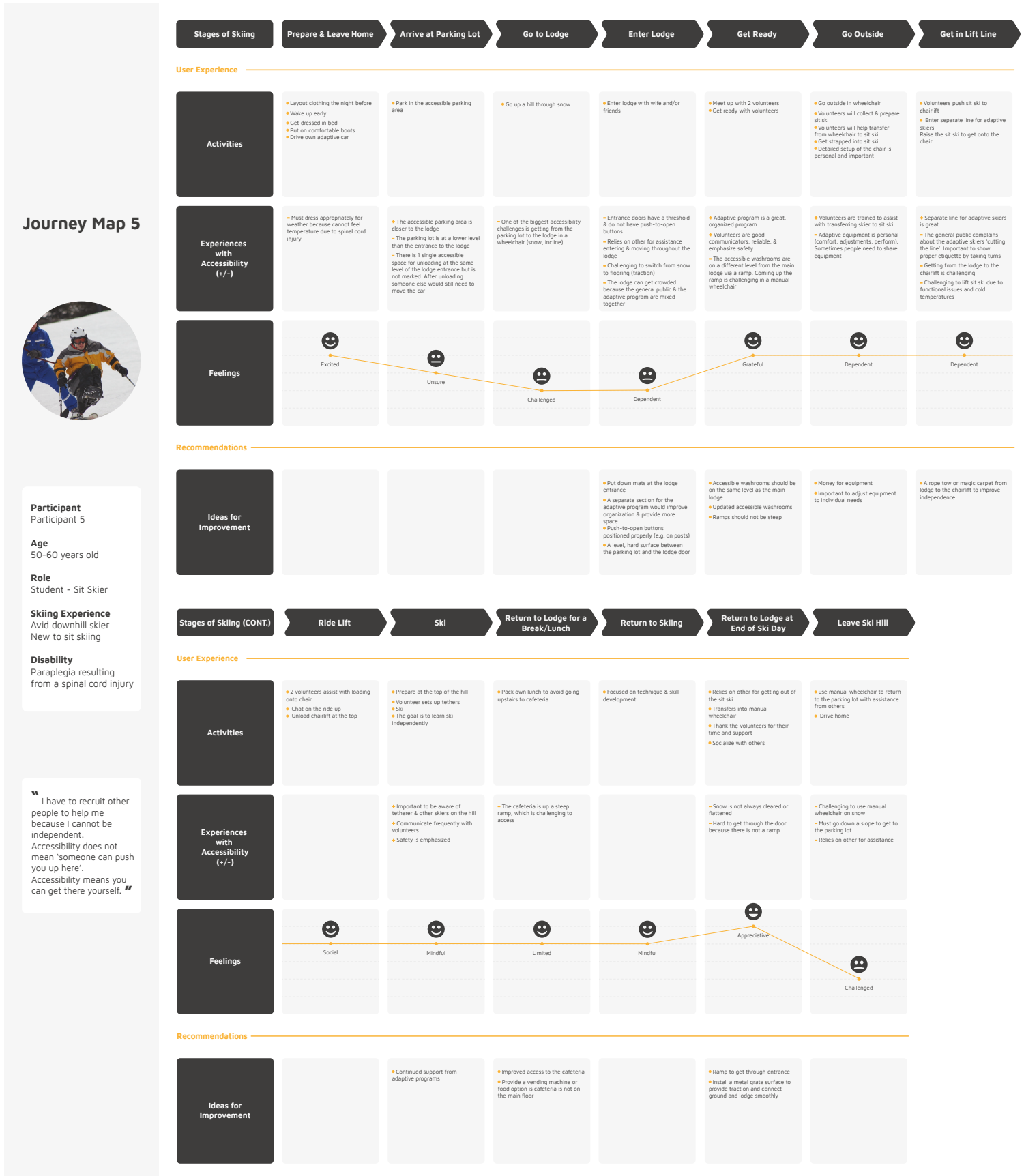

Illustration 34 Participant 5: User Journey Map 


\subsubsection{Participant 6}

Please refer to Illustration 35 for the user journey map that is developed with Participant 6. Participant 6 is 30 to 40 years old and is involved with an adaptive ski program as a student with cerebral palsy. Participant 6 says, "What some people don't know is if you make everything accessible, it would be good for everybody, not only for people with disabilities. Good accessible design means everybody can use it regardless of disability or ability".

Based on the evolution of Participant 6's feelings throughout the experience of skiing, the parking lot, the snow, and the lodge appear to be some of their most significant barriers to accessibility. For example, Participant 6 has challenges navigating the ski area with their wheelchair. If they are skiing with their brother, who does not have a disability, Participant 6 can use their manual wheelchair because their brother will push them. If their brother is not available to help, Participant 6 has to use their electric wheelchair, which is not ideal for crossing the snow and moving around in the busy lodge. 


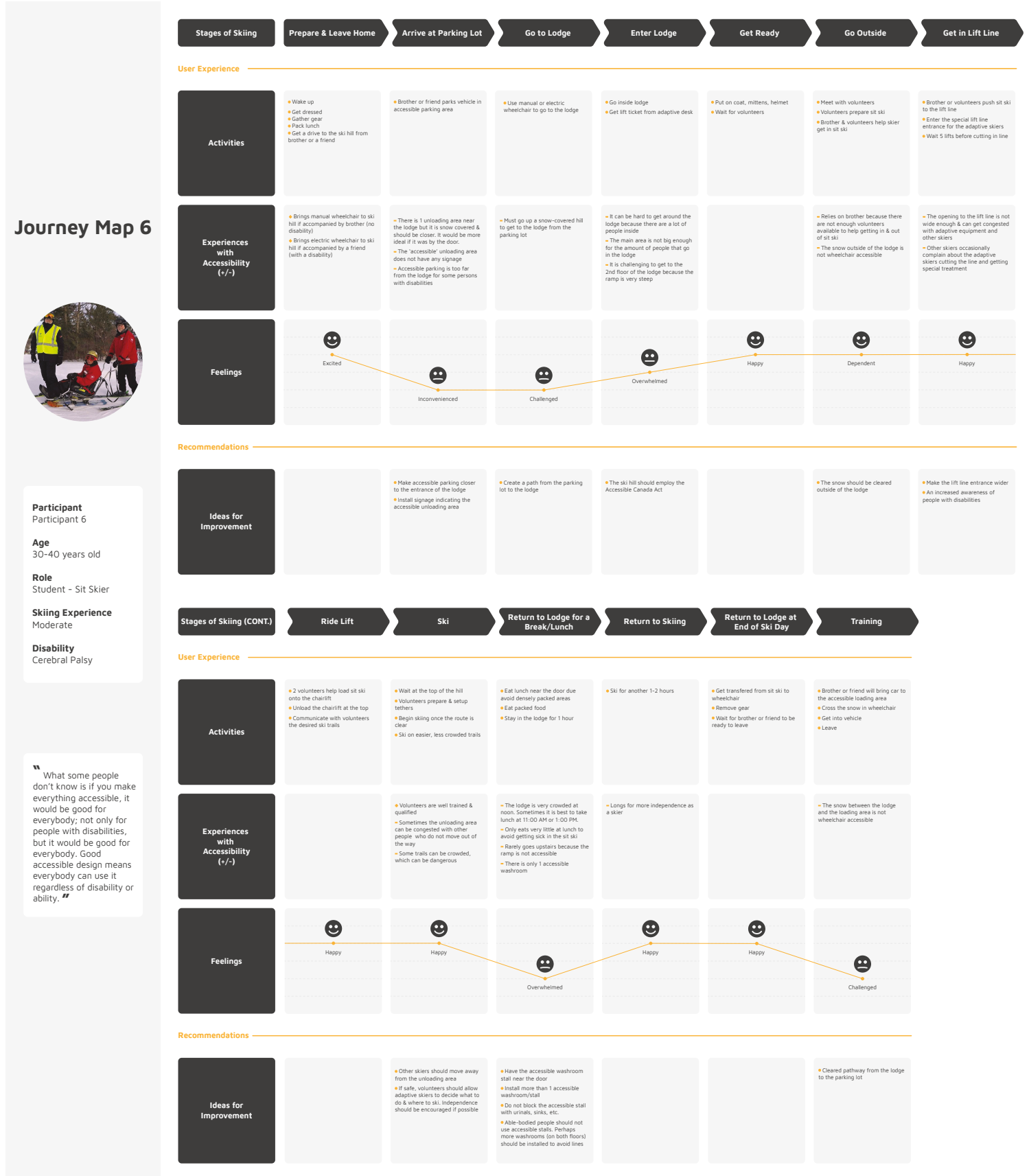

Illustration 35 Participant 6: User Journey Map 


\subsection{Analysis of Barriers to Accessibility}

One objective of Phase 3 is to continue identifying barriers to accessibility for skiing. A list of themes related to the five types of barriers to accessibility emerge from Phase 1 and Phase 2, thus Phase 3 aims to add to the list. Phase 3 also uses affinity diagramming for analysis. Analyzing data similarly across methods can facilitate the convergence of findings, to study methods from several different angles and to generate a more comprehensive list of barriers. Through affinity diagramming, the data from Phase 3 is analyzed to identify themes related to the five types of barriers to accessibility. The themes are provided in Tables 17 to 21 . The number in brackets beside each theme indicates the number of notes clustered within the theme.

Table 17 Barrier Type \#1: Architectural/Physical Barriers

\begin{tabular}{|c|c|}
\hline Theme & Examples of Barriers \\
\hline Lift (30) & $\begin{array}{l}\text { - Navigating a 'normal' lift line required guidance } \\
\text { - The opening to the lift line was not wide enough and could get } \\
\text { congested with adaptive ski equipment and other skiers } \\
\text { - Lift operators were not always familiar with loading adaptive ski } \\
\text { equipment } \\
\text { - Some skiers blocked the unloading area at the top of the hill } \\
\text { - Other skiers occasionally complained about the adaptive skiers cutting } \\
\text { the line and getting special treatment } \\
\text { When chairlifts were located far from the lodge or up an incline, } \\
\text { adaptive skiers often struggled to get to the lift independently }\end{array}$ \\
\hline Parking (29) & $\begin{array}{l}\text { - Occasionally, accessible parking spots were not available } \\
\text { - The accessible parking spots were too narrow to open a vehicle } \\
\text { wheelchair ramp } \\
\text { - The parking lot was at a lower level than the entrance to the lodge } \\
\text { - There was one accessible space for unloading at the same level of the } \\
\text { lodge entrance, but it was not marked. After unloading someone else } \\
\text { would still need to move the car to the parking lot } \\
\text { - Accessible parking was too far from the lodge for some persons with } \\
\text { disabilities }\end{array}$ \\
\hline Washrooms (19) & - Narrow washroom stalls \\
\hline
\end{tabular}




\begin{tabular}{|c|c|}
\hline & $\begin{array}{l}\text { - Lack of or limited accessible washrooms } \\
\text { The accessible washrooms were on a different level from the main lodge } \\
\text { via a ramp. Coming up the ramp was challenging in a manual } \\
\text { wheelchair } \\
\text { - One participant avoided using the washroom because it was too far to } \\
\text { walk } \\
\text { - Sometimes persons without disabilities would use accessible stall }\end{array}$ \\
\hline Lodge (18) & $\begin{array}{l}\text { - Older lodges are typically not accessible } \\
\text { - The lodge was high traffic, chaotic, and loud } \\
\text { - Tightly configured space; not designed for wheelchair accessibility (e.g., } \\
\text { table layout, table height, benches) } \\
\text { - There was limited storage space for personal belongings } \\
\text { - The concrete floors were slippery }\end{array}$ \\
\hline Skiing (17) & $\begin{array}{l}\text { - Sometimes the unloading area could be congested with other people } \\
\text { who did not move out of the way } \\
\text { - Some trails could be crowded, which could be dangerous } \\
\text { - Other skiers were not always respectful of adaptive skiers. They would } \\
\text { go too fast on Green runs, which was dangerous when making slow, } \\
\text { wide turns } \\
\text { - Instructors and volunteers had to manage the public }\end{array}$ \\
\hline Snow (15) & $\begin{array}{l}\text { - Students who arrived in mobility aids had a challenging time crossing } \\
\text { the snow } \\
\text { - The terrain had variable conditions (e.g., packed snow, icy), which } \\
\text { could be challenging to walk on } \\
\text { - Accumulated snow could be treacherous }\end{array}$ \\
\hline $\begin{array}{l}\text { Stairs \& Ramps } \\
(10)\end{array}$ & $\begin{array}{l}\text { - It was challenging to get to the second floor of the lodge because the } \\
\text { ramp was very steep }\end{array}$ \\
\hline Cafeteria (7) & $\begin{array}{l}\text { - The cafeteria was not accessible for wheelchairs (e.g., gates, height of } \\
\text { machines) } \\
\text { - The cafeteria was up a steep ramp, which was challenging to access } \\
\text { - Some people used vending machines because they could not access the } \\
\text { cafeteria }\end{array}$ \\
\hline $\begin{array}{l}\text { Ski Racks \& } \\
\text { Equipment Storage } \\
\text { (7) }\end{array}$ & $\begin{array}{l}\text { - Skis, poles, snowboards, and objects that were left on the ground created } \\
\text { obstacles } \\
\text { - Challenging for persons with visual impairments to put the key into the } \\
\text { lock on the ski racks } \\
\text { - Equipment storage should be on the main level }\end{array}$ \\
\hline Doors (4) & - Entrance doors had a threshold and did not have push-to-open buttons \\
\hline Access to Hill (3) & $\begin{array}{l}\text { - Some persons with disabilities relied on others for transportation } \\
\text { - Transportation to-and-from the hill should be accessible } \\
\text { - } \quad \text { Ease to access ski area and lodge (e.g., paved road) }\end{array}$ \\
\hline
\end{tabular}


- Rental office and ski shop were located on lower level, accessed by a steep, outdoor staircase

Table 18 Barrier Type \#2: Attitudinal Barriers

\begin{tabular}{|l|c|}
\hline Theme & Examples of Barriers \\
\hline $\begin{array}{l}\text { Awareness of } \\
\text { Disabilities (4) }\end{array}$ & $\begin{array}{l}\text { Other skiers were not always aware of different disabilities and did not } \\
\text { always know how respect adaptive skiers on the hill } \\
\text { Lift operators were not always familiar with disabilities and adaptive } \\
\text { ski equipment }\end{array}$ \\
\hline Safety (3) & - $\begin{array}{l}\text { Above all, adaptive ski programs aimed to maintain safety for students } \\
\text { and other skiers on the hill }\end{array}$ \\
\hline $\begin{array}{l}\text { Goal of } \\
\text { Independence (3) }\end{array}$ & $\begin{array}{l}\text { Accessible design should help promote user independence } \\
\text { Persons with disability should not always have to rely on others for } \\
\text { assistance }\end{array}$ \\
\hline $\begin{array}{l}\text { Instructor/Volunteer } \\
\text { Mentality (3) }\end{array}$ & $\begin{array}{l}\text { Instructors and volunteers should be flexible to adapt to challenges } \\
\text { To help students have an enjoyable time, instructors and volunteers } \\
\text { should remain positive and incorporate a 'fun factor' when appropriate }\end{array}$ \\
\hline
\end{tabular}

Table 19 Barrier Type \#3: Organizational/Systemic Barriers

\begin{tabular}{|l|l|}
\hline Theme & Examples of Barriers \\
\hline Training (11) & $\begin{array}{l}\text { Volunteers and instructors could benefit from more training to work with } \\
\text { persons with disabilities } \\
\text { Ski area staff (e.g., lift operators) could partner with adaptive ski } \\
\text { programs for training }\end{array}$ \\
\hline $\begin{array}{l}\text { Adaptive Skiing } \\
\text { (7) }\end{array}$ & $\begin{array}{l}\text { Adaptive ski programs function on a volunteer basis. If there were not } \\
\text { enough volunteers, students could not join the program and were placed } \\
\text { on a waitlist } \\
\text { There was a lack of adaptive skiing opportunities for persons who were } \\
\text { not members of a program } \\
\text { Most ski areas did not rent adaptive ski equipment }\end{array}$ \\
\hline $\begin{array}{l}\text { Design for } \\
\text { Inclusivity (6) }\end{array}$ & $\begin{array}{l}\text { Equal access should be considered. For example, accessible paths \& } \\
\text { entrances should not require excessive detours/effort } \\
\text { The design of ski areas should include persons with disabilities }\end{array}$ \\
\hline Money (4) & $\begin{array}{l}\text { If ski areas and adaptive ski programs had more money, some barriers to } \\
\text { accessibility could be fixed more quickly }\end{array}$ \\
\hline
\end{tabular}




\begin{tabular}{|l|ll|}
\hline Marketing (1) & $\bullet$ & There was a need for up-to-date marketing tools (not cost prohibitive) \\
\hline Ski Lift Ticket (1) & $\bullet \begin{array}{l}\text { Some ski areas did not offer tickets for persons accompanying adaptive } \\
\text { skiers }\end{array}$ \\
\hline
\end{tabular}

Table 20 Barrier Type \#4: Informational/Communicational Barriers

\begin{tabular}{|l|c|}
\hline Theme & Examples of Barriers \\
\hline $\begin{array}{l}\text { Management } \\
\text { System (3) }\end{array}$ & $\begin{array}{l}\text { Instructors and volunteers had to file a report each ski day in a binder } \\
\text { (management system) }\end{array}$ \\
- $\begin{array}{l}\text { Instructors and volunteers sometimes forgot to fill out report or did not } \\
\text { have enough time }\end{array}$ \\
$\begin{array}{l}\text { Some adaptive ski programs used an online management system } \\
\text { (Snowline), which meant instructors and volunteers could file the report } \\
\text { from home if they forgot }\end{array}$ \\
\hline $\begin{array}{l}\text { Lift Operator (2) } \\
\text { Communication } \\
(2)\end{array}$ & $\begin{array}{l}\text { If lift operators are unsure, they should adaptive skiers if they could help } \\
\text { and how }\end{array}$ \\
\hline $\begin{array}{l}\text { Volunteers and instructors should not talk over or ignore the adaptive ski } \\
\text { student, rather include them in the conversation }\end{array}$ \\
$\begin{array}{l}\text { People should always communicate with a person with a disability } \\
\text { before entering their personal space of adjusting their adaptive ski } \\
\text { equipment } \\
\text { Some adaptive skiers cannot feel temperature or cannot communicate } \\
\text { whether they are cold or uncomfortable. Volunteers and instructors need } \\
\text { to frequently check in with the students }\end{array}$ \\
\hline
\end{tabular}

Table 21 Barrier Type \#5: Technological Barriers

\begin{tabular}{|l|l|}
\hline Theme & Examples of Barriers \\
\hline $\begin{array}{l}\text { Bluetooth Radios } \\
(2)\end{array}$ & $\begin{array}{l}\text { Some skiers with visual impairments use Bluetooth radios to } \\
\text { communicate with their guide. Bluetooth radios do not always work well } \\
\text { with wind, loud noises like snowmobiles, and when radio towers are } \\
\text { blocked }\end{array}$ \\
\hline $\begin{array}{l}\text { Online } \\
\text { Management (1) }\end{array}$ & $\begin{array}{l}\text { Snowline is an online management system for adaptive ski programs. It } \\
\text { was developed at Silverstar and is beginning to be adopted country wide. } \\
\text { It is useful for scheduling, lesson planning, and information records }\end{array}$ \\
\hline
\end{tabular}

\subsection{Summary of Phase 3 Findings}

The following is a summary of the key insights from the Phase 3 findings: 
1) It appears that participants who do not identify as having a disability might not experience barriers to accessibility themselves when skiing. Participants with disabilities report experiencing barriers to accessibility and more negative feelings.

2) The findings from Phase 3 appear to share similarities to the barriers to accessibility that are identified in Phase 1 and Phase 2. This informs the next step: triangulation of findings to determine similarities, differences, and potential outliers that may be relevant. Comparing and combining the findings from all three research phases can result in a rich depth of information about the participants' perspectives about their experiences when skiing.

3) Participants, which include subject matter experts (volunteers, instructors, parents, guardians) and target users (adaptive students) of adaptive skiing, contribute insights and recommendations for improving the experience of adaptive skiing. 


\section{Chapter 7: Analysis Methods and Findings}

The methods of Phase 1, Phase 2, and Phase 3 are triangulated to integrate their findings and support the development of insights. Webb et al. (1966) explain that triangulation is the convergence of multiple methods to review the findings from several different angles. Triangulation can be used "to ensure accuracy of information, by combining sources and mitigating the weaknesses of any single method or source" (Martin \& Hanington, 2012). Denzin (1970) adds that triangulation can increase the breadth and robustness of a study's findings.

\subsection{Overview}

Triangulation is an opportunity to integrate the findings from the three research phases to produce an in-depth account of the barriers to accessibility that are encountered during the experience of skiing. The research phases use mixed methods, to gather quantitative and qualitative data, and to ultimately triangulate the findings to examine different perspectives. When the same issues emerge from various mixed methods, findings are reinforced (Creswell, 2018). To elaborate, the findings from the three research phases can be compared to identify similarities, differences, and outlying information. When the findings are similar across all methods, they confirm the importance of the results; when the findings are different, they warrant examining closer for reasons why; when the findings have outlying information, they may provide unique insights.

\subsection{Methods}

Multiple rounds of analysis and synthesis are conducted for triangulation. The process of 
affinity diagramming is utilized to examine the barriers to accessibility that have emerged from the three research phases. The themes from Phase 1 (Tables 4 to 8), Phase 2 (Tables 10 to 14), and Phase 3 (Tables 17 to 21) are gathered. Each theme is written on an individual sticky note that is colour-coded based on the method. The preliminary field study uses red notes; the questionnaire uses green notes; the directed storytelling uses blue notes. Colour-coding helps with the organization and traceability of the information. Next, the sticky notes are clustered. Similar themes typically form larger clusters, while less common themes form smaller clusters or do not belong in a cluster at all. A summative theme title can be assigned to each cluster.

Illustration 36 provides an example of the initial round of triangulation using affinity diagramming. The clusters of sticky notes are organized into the five types of barriers to accessibility. Two themes in particular, "Universal Design" and "Design for Disability", could be applied to all five types of barriers. Thus, a sixth category, labelled "Other Barriers", is created for sticky notes that cannot be assigned to only one type of barrier. Please refer to Appendix E.1 for a larger version of Illustration 36. 


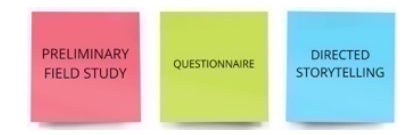

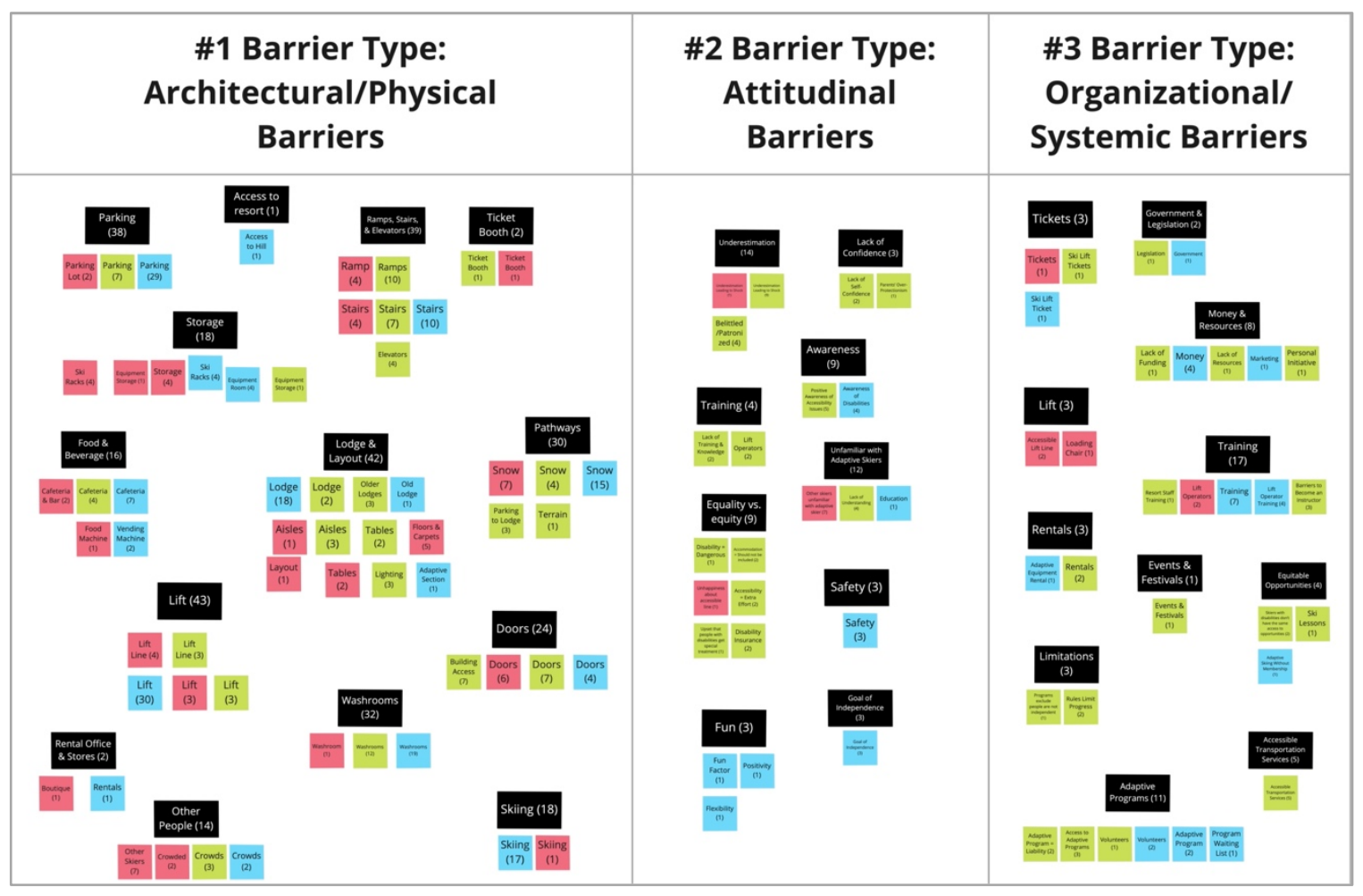

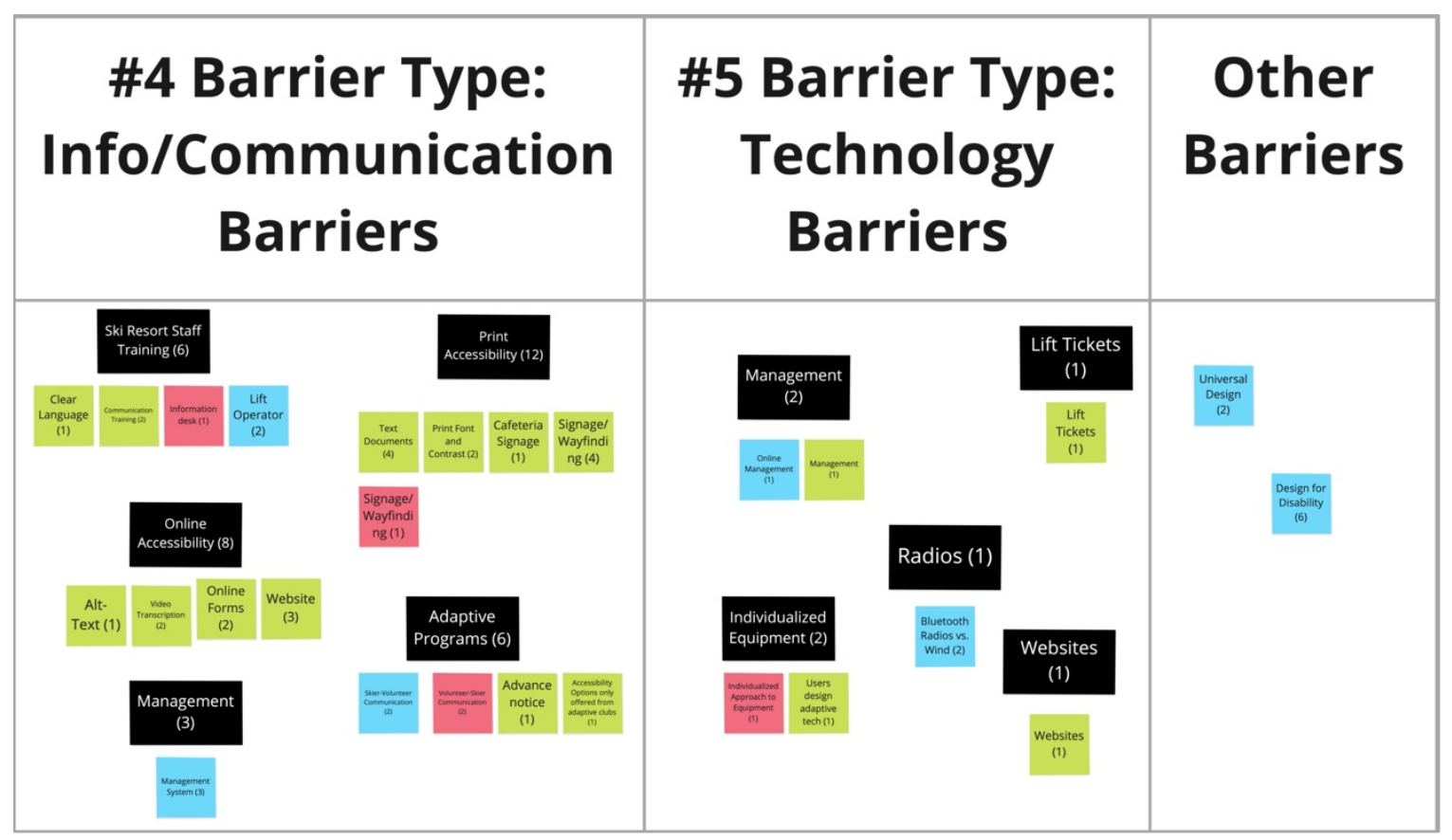

Illustration 36 Initial Round of Triangulation using Affinity Diagramming 
The initial round of triangulation using affinity diagramming demonstrates overlap between the three research phases. Participants from all three research phases report barriers to accessibility at distinctive stages throughout the experience of skiing, including on the slopes, at the ski area, and outside of the ski area.

Phase 1 focuses predominantly on barriers to accessibility that occur:

1) On the slopes: engaging in skiing (e.g., lift line, riding the lift, skiing)

2) At the ski area: navigating and interacting with facilities and services on the premises (e.g., parking lot, lodge)

Phase 2 focuses predominantly on barriers to accessibility that occur:

1) On the slopes: engaging in skiing (e.g., lift line, riding the lift, skiing)

2) At the ski area: navigating and interacting with facilities and services on the premises (e.g., parking lot, lodge)

3) Outside of the ski area: no on the premises (e.g., at home, on the Internet, or other external factors)

Phase 3 focuses predominantly on barriers to accessibility that occur:

1) On the slopes: engaging in skiing (e.g., lift line, riding the lift, skiing)

2) At the ski area: navigating and interacting with facilities and services on the premises (e.g., parking lot, lodge)

3) Outside of the ski area: no on the premises (e.g., at home, on the Internet, or other external factors) 
This point is most clearly illustrated in Phase 3's user journey maps where participants indicate where and when they encounter specific barriers to accessibility for skiing.

Illustration 37 highlights where and when each stage of skiing takes place relative to the entire experience. Understanding the context of barriers can provide insights into how accessibility can be addressed for skiing.

Outside of the Ski Area

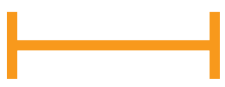

At the

Ski Area

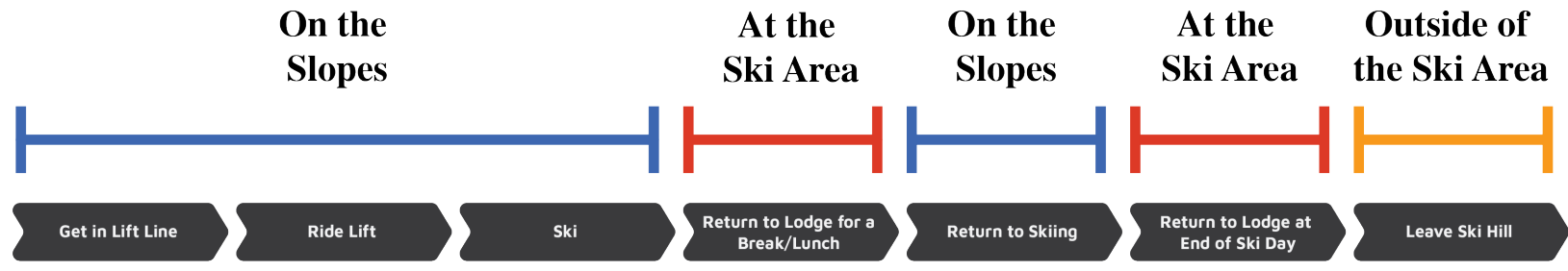

Illustration 37 Where barriers to accessibility are encountered

Considering where and when barriers occur, the initial round of triangulation using affinity diagramming can be restructured. A second round of triangulation using affinity diagramming (Illustration 38) is conducted to further organize the sticky notes based on where they occur: on the slopes, at the ski area, outside of the ski area. Please refer to Appendix E.2 for a larger version of the second round of triangulation using affinity diagramming. 


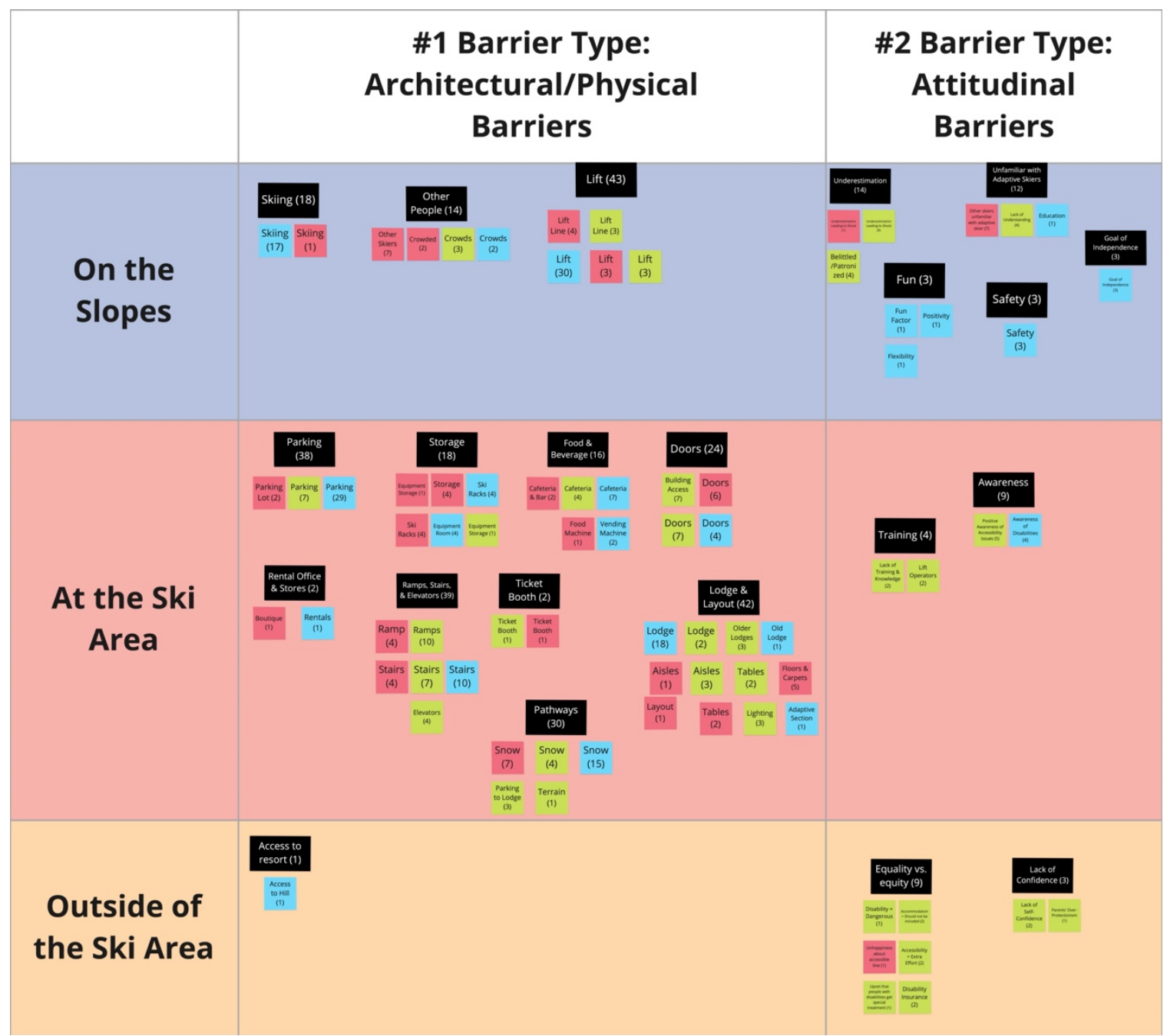




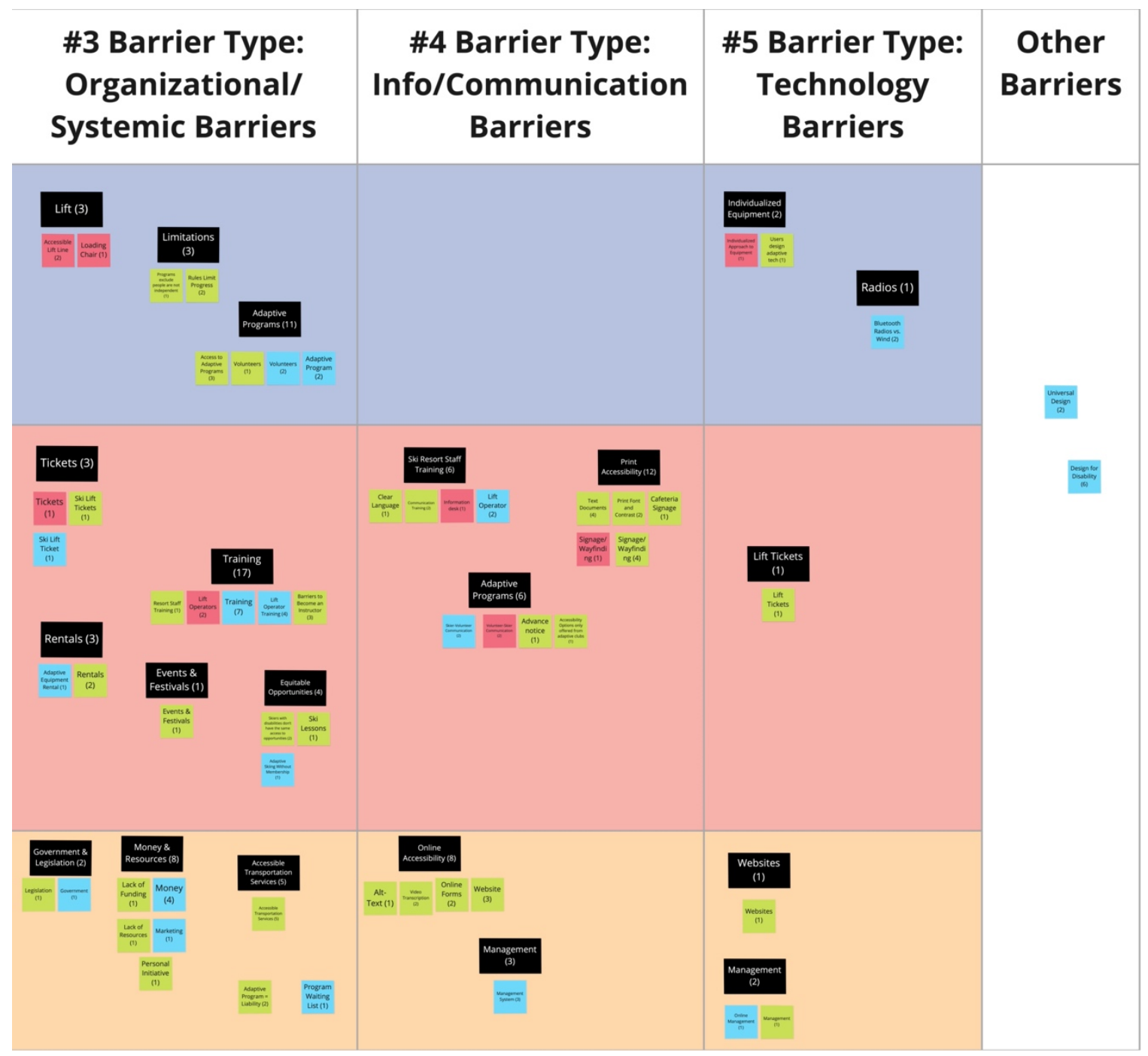

Illustration 38 Second Round of Triangulation Using Affinity Diagramming

Holtzblatt and Beyer (1995) describe affinity diagramming as a rigorous process.

Researchers typically iterate and rearrange the sticky notes in search of underlying significance or new interpretations. After several rounds of restructuring and fine-tuning the sticky notes, summative themes (black sticky notes in Illustration 38) are identified.

The researcher feels that affinity diagramming traditionally has controlled conditions.

The sticky notes and summative themes are abstractions of lived experience and offer 
limited context. Isolating experiences from the influences and richness of their surroundings may cause key insights to be overlooked. An opportunity arises to further analyze and synthesize the sticky notes and summative themes in the context of a ski area. The researcher has created a map resembling a hypothetical ski area (Illustration 39), since the three research phases study various ski areas across Canada. The ski area map visualizes the same three contexts as the second affinity diagram: on the slopes, at the ski area, and outside of the ski area. Next, the sticky notes and summative themes are reorganized on the ski area map based on where they occur. The ski area map exercise is the researcher's invention, which is essentially a variation of affinity diagramming by facilitating further clustering, analysis, and synthesis. Triangulation using the ski area map helps visualize the interrelatedness and context of the barriers to accessibility for skiing. 


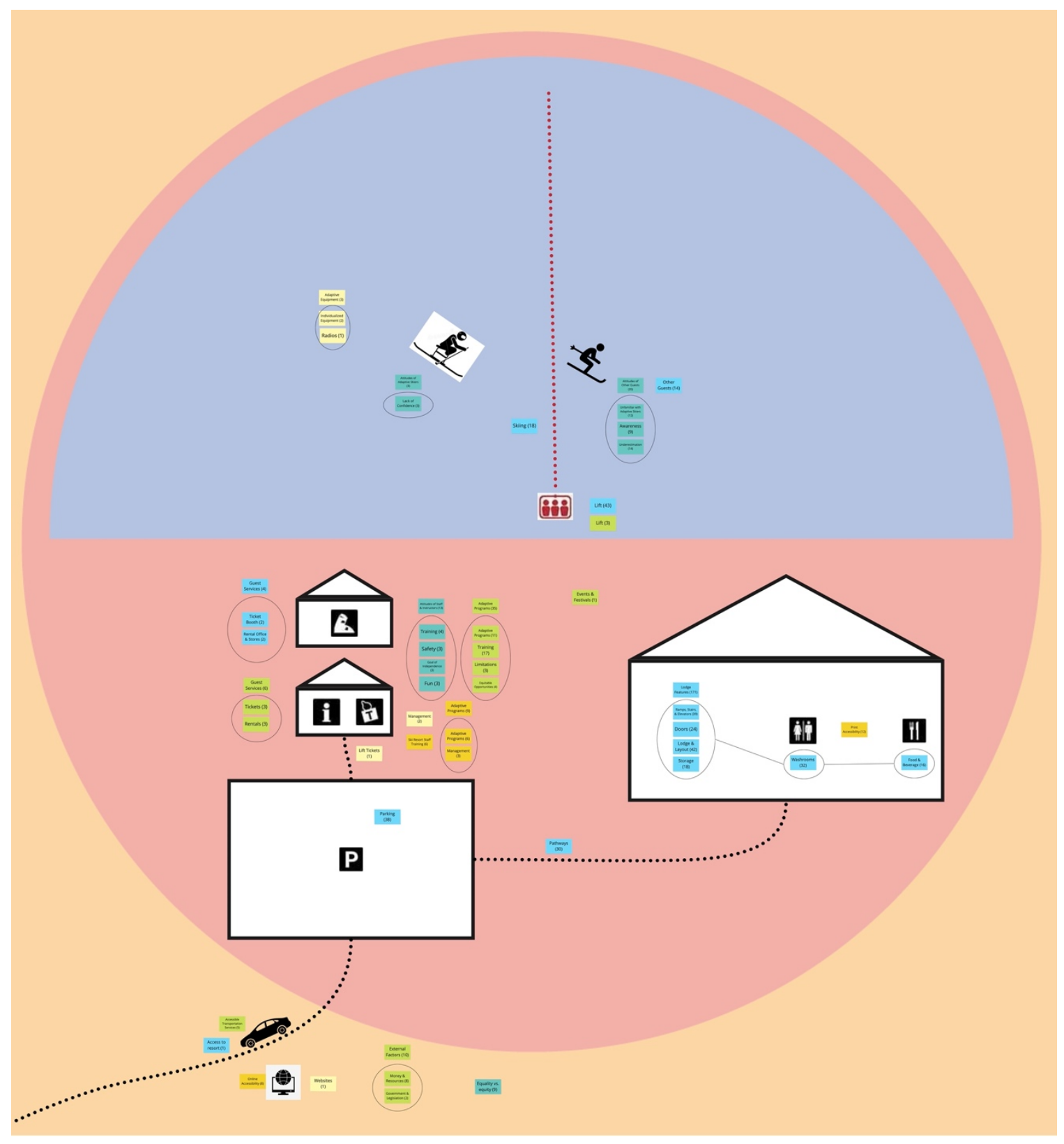

On the Slopes

At the Ski Area

Outside of the Ski Area

\section{Illustration 39 Triangulation: Ski Area Map Exercise}




\subsection{Findings}

\subsubsection{Affinity Diagramming and Ski Area Map Exercise}

The outcomes of triangulation using two rounds of affinity diagramming and the ski area map exercise are presented in Illustration 40 and Tables 22 (On the Slopes), 23 (At the

Ski Area), and 24 (Outside of the Ski Area).

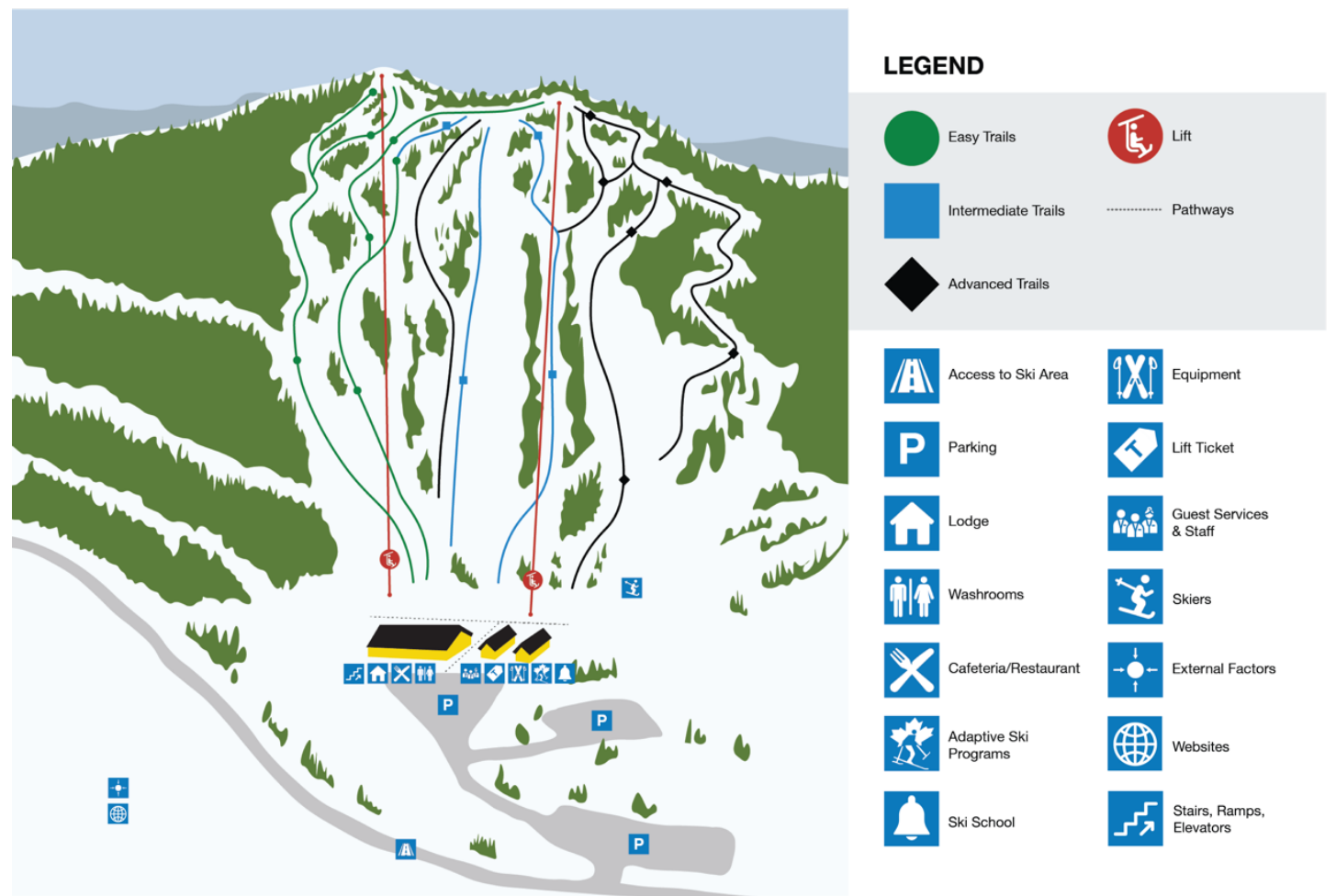

\section{Illustration 40 Findings: Ski Area Map Exercise}

Table 22 Findings: On the Slopes

\begin{tabular}{|l|l|l|}
\hline Theme & Barrier Type & Findings \\
\hline Lift & $\begin{array}{l}\text { Architectural and } \\
\text { Physical }\end{array}$ & $\begin{array}{l}\text { CADS at Snow Mountain used a separate lift line, which was } \\
\text { faster and did not weave back and forth like the main lift line }\end{array}$ \\
& $\begin{array}{l}\text { - Some lifts moved too quickly to load } \\
\text { - }\end{array}$ \\
& $\begin{array}{l}\text { Most gondolas are not compatible with wheelchairs and sit } \\
\text { - }\end{array}$ \\
& $\begin{array}{l}\text { Narrow gates leading up to the lift } \\
\text { - Some ski areas had a dedicated lift line for skiers with } \\
\end{array}$ \\
& $\begin{array}{l}\text { disabilities } \\
\text { - If chairlift ramps and landings are much lower than the } \\
\text { chairlift or too high, people can have challenges unloading } \\
\end{array}$ \\
& Navigating a 'normal' lift line required guidance \\
\hline
\end{tabular}




\begin{tabular}{|c|c|c|}
\hline & & $\begin{array}{l}\text { - The opening to the lift line was not wide enough and could } \\
\text { get congested with adaptive ski equipment and other skiers } \\
\text { - Some skiers blocked the unloading area at the top of the hill } \\
\text { - When chairlifts were located far from the lodge or up an } \\
\text { incline, adaptive skiers often struggled to get to the lift } \\
\text { independently } \\
\text { - Sometimes the unloading area could be congested with other } \\
\text { people who did not move out of the way }\end{array}$ \\
\hline & Attitudinal & $\begin{array}{l}\text { - CADS, ski school, and ski patrol were permitted to use a } \\
\text { separate lift line. Sometimes other skiers complained and } \\
\text { were unhappy that CADS got to 'jump' the line. } \\
\text { - Many people complained when adaptive skiers got to use the } \\
\text { accessible lift line and 'jump' the line } \\
\text { - Other skiers occasionally complained about the adaptive } \\
\text { - } \quad \text { Skiers cutting the line and getting special treatment } \\
\text { - } \quad \text { Some lift operators have laughed at adaptive skiers }\end{array}$ \\
\hline & $\begin{array}{l}\text { Organizational } \\
\text { and Systemic }\end{array}$ & $\begin{array}{l}\text { - Snow Mountain allowed CADS to use the faster lift line to } \\
\text { improve accessibility } \\
\text { Most lift operators were aware of the adaptive skiers and } \\
\text { would help with loading or slow down the lift if needed } \\
\text { - Lift tickets that need to be scanned can create a physical } \\
\text { interaction that is outside of the comfort zone of a person } \\
\text { with a disability } \\
\text { - Lift operators were not always familiar with loading adaptive } \\
\text { ski equipment }\end{array}$ \\
\hline & $\begin{array}{l}\text { Informational } \\
\text { and } \\
\text { Communicational }\end{array}$ & $\begin{array}{l}\text { - If lift operators are unsure, they should adaptive skiers if they } \\
\text { could help and how }\end{array}$ \\
\hline & Technological & $\begin{array}{l}\text { The chairlift was compatible with the participants' adaptive } \\
\text { ski equipment. However, the chairlift bar pinched the legs of } \\
\text { participants in sit skis when others in the chair rested their } \\
\text { arms on the bar. }\end{array}$ \\
\hline Ski Trails & $\begin{array}{l}\text { Architectural and } \\
\text { Physical }\end{array}$ & $\begin{array}{l}\text { The amount and quality of lights for night skiing were poor, } \\
\text { which made night skiing difficult for persons with visual } \\
\text { impairments } \\
\text { - Some trails could be crowded, which could be dangerous }\end{array}$ \\
\hline & Attitudinal & $\begin{array}{l}\text { Other skiers were not always respectful of adaptive skiers. } \\
\text { They would go too fast on Green runs, which was dangerous } \\
\text { when making slow, wide turns }\end{array}$ \\
\hline & $\begin{array}{l}\text { Informational } \\
\text { and } \\
\text { Communicational }\end{array}$ & $\begin{array}{l}\text { - Signs on the hill were brightly coloured and identifiable. } \\
\text { - Some adaptive skiers used high visibility clothing and tethers } \\
\text { for safety. } \\
\text { - Visual trail maps and text trail signs should be large for }\end{array}$ \\
\hline
\end{tabular}




\begin{tabular}{|c|c|c|}
\hline & & persons with visual impairments \\
\hline \multirow[t]{3}{*}{$\begin{array}{l}\text { Adaptive } \\
\text { Skiers }\end{array}$} & $\begin{array}{l}\text { Organizational } \\
\text { and Systemic }\end{array}$ & $\begin{array}{l}\text { - Most adaptive ski programs have assigned volunteers to be } \\
\text { "Assistant Instructors" (also known as an "Uphill Assistant" or } \\
\text { a "Blocker") to manage other skiers on the hill. The primary } \\
\text { mission of the assistant instructor is to protect the adaptive } \\
\text { skier from other hill users, by positioning themselves uphill } \\
\text { and slightly ahead of the athlete in order to block other skiers } \\
\text { - When blocking for a visually impaired skier, the assistant } \\
\text { instructor has typically worn a special high visibility vest } \\
\text { - When blocking for a skier using adaptive ski equipment (e.g., } \\
\text { a sit ski), the assistant instructor typically has not worn special } \\
\text { high visibility gear } \\
\text { Occasionally, assistant instructors have failed to block all } \\
\text { other skiers and an accident has occurred. When this happens, } \\
\text { assistant instructors have sometimes been blamed for having } \\
\text { inadequate training }\end{array}$ \\
\hline & $\begin{array}{l}\text { Informational } \\
\text { and } \\
\text { Communicational }\end{array}$ & $\begin{array}{l}\text { - CADS volunteers and instructors were constantly in } \\
\text { communication with their students to ensure safety. Some } \\
\text { students had challenges with communicating due to their } \\
\text { disability, in which case CADS volunteers and instructors had } \\
\text { to apply various techniques to foster effective communication } \\
\text { (e.g., communication board) } \\
\text { - Volunteers and instructors should not talk over or ignore the } \\
\text { adaptive ski student, rather include them in the conversation } \\
\text { - Some adaptive skiers cannot feel temperature or cannot } \\
\text { communicate whether they are cold or uncomfortable. } \\
\text { Volunteers and instructors need to frequently check in with the } \\
\text { students }\end{array}$ \\
\hline & Technological & $\begin{array}{l}\text { - Some skiers with visual impairments use Bluetooth radios to } \\
\text { communicate with their guide. Bluetooth radios do not always } \\
\text { work well with wind, loud noises like snowmobiles, and when } \\
\text { radio towers are blocked }\end{array}$ \\
\hline \multirow[t]{2}{*}{ Other Guests } & $\begin{array}{l}\text { Architectural and } \\
\text { Physical }\end{array}$ & $\begin{array}{l}\text { - CADS shared the ski area with other skiers, which } \\
\text { occasionally created obstacles on the hill. There were racing } \\
\text { groups, ski lessons, children, teenagers, and adults. }\end{array}$ \\
\hline & Attitudinal & $\begin{array}{l}\text { Other skiers were sometimes not sure how to respect adaptive } \\
\text { skiers on the hill. For example, they would ski too close or go } \\
\text { too fast next to sit skis that were making wide turns and had } \\
\text { tethers. } \\
\text { - An able-bodied CADS instructor often used a sit ski and } \\
\text { would receive comments like "It is so great that you are out } \\
\text { here", assuming that they had a disability. People make } \\
\text { assumptions about adaptive ski equipment and abilities. } \\
\text { - Many people were shocked that persons with disabilities could }\end{array}$ \\
\hline
\end{tabular}




\begin{tabular}{|c|c|}
\hline & $\begin{array}{l}\text { ski } \\
\text { - Adaptive skiers often get comments such as "it is so } \\
\text { inspirational to see you out skiing", "wow, you can ski!" } \\
\text { - Some people have said that adaptive skiers should not be } \\
\text { allowed to participate because they require accommodations } \\
\text { - Some people have said that sit skiers should not be permitted } \\
\text { on the same hills as the general public } \\
\text { - Some people assumed that it was dangerous to ski with a } \\
\text { disability (e.g., blind) } \\
\text { - Adaptive skiers have reported experiencing patronizing } \\
\text { behaviours } \\
\text { - Able-bodied racing and ski programs have reportedly singled } \\
\text { out and belittled skiers if they had a disability } \\
\text { - Other skiers were not always aware of different disabilities } \\
\text { and did not always know how respect adaptive skiers on the } \\
\text { hill } \\
\text { Lift operators were not always familiar with disabilities and } \\
\text { adaptive ski equipment }\end{array}$ \\
\hline $\begin{array}{l}\text { Organizational } \\
\text { and Systemic }\end{array}$ & $\begin{array}{l}\text { Most adaptive ski programs have attempted to manage other } \\
\text { skiers on the hill to ensure safety. Some skiers did not know } \\
\text { how adaptive skiing worked and would ski too fast or too } \\
\text { close to the adaptive skiers }\end{array}$ \\
\hline
\end{tabular}

Table 23 Findings: At the Ski Area

\begin{tabular}{|c|c|c|}
\hline Theme & Barrier Type & - $\quad$ Findings \\
\hline \multirow[t]{3}{*}{ Parking } & $\begin{array}{l}\text { Architectural and } \\
\text { Physical }\end{array}$ & $\begin{array}{l}\text { - The parking lot had an accessible parking section that } \\
\text { operated on a first-come-first-serve basis. } \\
\text { - Insufficient accessible parking } \\
\text { The distance from the wheelchair accessible parking } \\
\text { spots to the lift or lodge was too far } \\
\text { Occasionally, accessible parking spots were not } \\
\text { available } \\
\text { - The accessible parking spots were too narrow to open } \\
\text { a vehicle wheelchair ramp } \\
\text { - The parking lot was at a lower level than the entrance } \\
\text { to the lodge } \\
\text { There was one accessible space for unloading at the } \\
\text { same level of the lodge entrance, but it was not } \\
\text { marked. After unloading someone else would still } \\
\text { need to move the car to the parking lot } \\
\text { Accessible parking was too far from the lodge for } \\
\text { some persons with disabilities }\end{array}$ \\
\hline & $\begin{array}{l}\text { Organizational and } \\
\text { Systemic }\end{array}$ & $\begin{array}{l}\text { - Accessible parking spots were not enforced, therefore } \\
\text { reducing the availability to those who need it }\end{array}$ \\
\hline & $\begin{array}{l}\text { Informational and } \\
\text { Communicational }\end{array}$ & $\begin{array}{l}\text { - There was one accessible unloading area closer to the } \\
\text { lodge but was not marked. }\end{array}$ \\
\hline
\end{tabular}




\begin{tabular}{|c|c|c|}
\hline Pathways & $\begin{array}{l}\text { Architectural and } \\
\text { Physical }\end{array}$ & $\begin{array}{l}\text { - Ski areas inherently have snow, but the snow between } \\
\text { the parking lot and the lodge caused mobility issues for } \\
\text { some participants, especially people using mobility } \\
\text { aids. Some participants said that they would prefer for } \\
\text { the snow to be shoveled, packed down, or covered with } \\
\text { a grate or mat. } \\
\text { - Inadequate infrastructure to support mobility aids on } \\
\text { snow } \\
\text { - People in wheelchairs and with mobility issues had } \\
\text { challenges on snow that is not cleared or groomed } \\
\text { properly } \\
\text { - Students who arrived in mobility aids had a challenging } \\
\text { time crossing the snow } \\
\text { - The terrain had variable conditions (e.g., packed snow, } \\
\text { icy), which could be challenging to walk on } \\
\text { - Accumulated snow could be treacherous } \\
\text { - Skis, poles, snowboards, and objects that were left on } \\
\text { the ground created obstacles }\end{array}$ \\
\hline $\begin{array}{l}\text { Lodge/ } \\
\text { Buildings }\end{array}$ & $\begin{array}{l}\text { Architectural and } \\
\text { Physical }\end{array}$ & $\begin{array}{l}\text { The doors to the new section of the lodge did not have } \\
\text { push-to-open buttons. There was a gap between the } \\
\text { ground and doors preventing some mobility aids from } \\
\text { entering the lodge. } \\
\text { - } \\
\text { - Sll ski areas need automatic doors } \\
\text { making it difficult for mobility aids and people with } \\
\text { mobility issues to enter } \\
\text { The floors were cement, which became slippery when } \\
\text { wet. Mats or carpets might reduce the amount of } \\
\text { people slipping and falling. } \\
\text { Only one row of lockers was available for storing } \\
\text { personal belongings. Most people left their bags on the } \\
\text { tables and on the floor, which created clutter and } \\
\text { obstacles. } \\
\text { A lot of people would be at the ski area, especially on } \\
\text { weekends. The lodge would get crowded and loud. } \\
\text { The tables were densely packed with people and } \\
\text { personal belongings. The tables had fixed stools, so } \\
\text { wheelchairs and other mobility aids could only be on } \\
\text { the ends. } \\
\text { - Tables with fixed stools were hard to use for some } \\
\text { persons in wheelchairs } \\
\text { The aisles between tables were sometimes too narrow } \\
\text { for mobility aids and adaptive ski equipment } \\
\text { - It could be difficult to find quiet places that were not } \\
\text { crowded in the lodge and cafeteria. Skiers with autism } \\
\text { may not be able to handle excessive noise and crowds } \\
\text { - When the lodge was crowded, mobility aids and } \\
\text { adaptive ski equipment did not always fit } \\
\text { - Ther lodges are typically not accessible } \\
\text { Tightly configured space; not designed for wheelchair } \\
\text { accessibility (e.g., table layout, table height, benches) }\end{array}$ \\
\hline
\end{tabular}




\begin{tabular}{|c|c|c|}
\hline & & $\begin{array}{l}\text { - There was limited storage space for personal } \\
\text { belongings } \\
\text { - The concrete floors were slippery }\end{array}$ \\
\hline & $\begin{array}{l}\text { Informational and } \\
\text { Communicational }\end{array}$ & $\begin{array}{l}\text { - Text wayfinding and signage exclude persons with } \\
\text { visual impairments }\end{array}$ \\
\hline \multirow[t]{8}{*}{$\begin{array}{l}\text { Ramps, } \\
\text { Stairs, } \\
\text { Elevators }\end{array}$} & \multirow[t]{7}{*}{$\begin{array}{l}\text { Architectural and } \\
\text { Physical }\end{array}$} & \multirow{7}{*}{$\begin{array}{l}\text { - Ramps were installed to connect various sections of } \\
\text { the lodge and to access the second floor. The ramps } \\
\text { going upstairs were too steep for some participants } \\
\text { with limited mobility or who were used mobility aids } \\
\text { to use. } \\
\text { - The new section of the lodge had stairs to a second } \\
\text { level. Other alternatives (e.g., ramps, elevators) for } \\
\text { accessing the second floor were not available. } \\
\text { - Lack of ramps } \\
\text { - Some entrance doors were not level with the ground } \\
\text { and should have a ramp } \\
\text { - Some ramps were too steep } \\
\text { - Stairs or even a single step created obstacles } \\
\text { - Some ski areas had external staircases leading to the } \\
\text { lodge } \\
\text { - Lther levels were inaccessible due to stairs } \\
\text { - Many of alternatives to stairs } \\
\text { - } \text { elevators } \\
\text { - } \text { Some lodges allowed persons with disabilities to use } \\
\text { the freight elevator } \\
\text { It was challenging to get to the second floor of the } \\
\text { lodge because the ramp was very steep }\end{array}$} \\
\hline & & \\
\hline & & \\
\hline & & \\
\hline & & \\
\hline & & \\
\hline & & \\
\hline & Attitudinal & $\begin{array}{l}\text { A person was walking down the stairs and began to } \\
\text { complain because the person in front of them did not } \\
\text { move over. Once they noticed that the person in front } \\
\text { was wearing a vest that said, 'visually impaired', they } \\
\text { changed their attitude }\end{array}$ \\
\hline Washrooms & \multirow{2}{*}{$\begin{array}{l}\text { Architectural and } \\
\text { Physical }\end{array}$} & \multirow[b]{2}{*}{$\begin{array}{l}\text { - The washrooms had accessible stalls. } \\
\text { - The washrooms were located on the first floor of the } \\
\text { lodge in the back corner, which was too far for some } \\
\text { people to walk } \\
\text { - Lack of proper wheelchair accessible washroom } \\
\text { - Lack of family washrooms for persons with disabilities } \\
\text { and caretakers } \\
\text { - Narrow washroom doorways and stalls } \\
\text { - Washrooms were hard to access (e.g., must use stairs, } \\
\text { - } \quad \text { Sink and paper towel were out of reach } \\
\text { - Washroom doors were too heavy are did not have } \\
\text { - } \quad \text { push-to-open buttons } \\
\text { - Lack of or limited accessible washrooms }\end{array}$} \\
\hline & & \\
\hline
\end{tabular}




\begin{tabular}{|c|c|c|}
\hline & & $\begin{array}{l}\text { The accessible washrooms were on a different level } \\
\text { from the main lodge via a ramp. Coming up the ramp } \\
\text { was challenging in a manual wheelchair } \\
\text { One participant avoided using the washroom because } \\
\text { it was too far to walk } \\
\text { - Sometimes persons without disabilities would use } \\
\text { accessible stall }\end{array}$ \\
\hline \multirow[t]{2}{*}{$\begin{array}{l}\text { Cafeteria/ } \\
\text { Restaurant }\end{array}$} & $\begin{array}{l}\text { Architectural and } \\
\text { Physical }\end{array}$ & $\begin{array}{l}\text { - The cafeteria and bar were located on the second floor } \\
\text { of the lodge, accessible only by stairs and ramps; thus, } \\
\text { some participants could not go upstairs and would } \\
\text { have to pack their own food } \\
\text { - A vending machine selling snack food and beverages } \\
\text { was located on the main floor of the lodge, which } \\
\text { provided an alternative to going to the cafeteria or bar } \\
\text { on the second floor } \\
\text { - The cafeteria was located on the second floor but there } \\
\text { was no elevator } \\
\text { - Difficulty reading the cafeteria menu due to font size } \\
\text { and lighting } \\
\text { - The cafeteria was not accessible for wheelchairs (e.g., } \\
\text { gates, height of machines) } \\
\text { The cafeteria was up a steep ramp, which was } \\
\text { challenging to access } \\
\text { - Some people used vending machines because they } \\
\text { could not access the cafeteria }\end{array}$ \\
\hline & $\begin{array}{l}\text { Informational and } \\
\text { Communicational }\end{array}$ & - Menus and signage were not always readable \\
\hline \multirow[t]{2}{*}{$\begin{array}{l}\text { Adaptive Ski } \\
\text { Program }\end{array}$} & Attitudinal & $\begin{array}{l}\text { - Sometimes persons with disabilities doubt their own } \\
\text { abilities } \\
\text { "I am unable to do it" or "I am not capable of skiing as } \\
\text { well or as fast as someone who is able-bodied" } \\
\text { - Some parents/guardians of adaptive skiers were over- } \\
\text { protective. This can be in the form of trying to do } \\
\text { everything for the child (e.g., not challenging them to } \\
\text { overcome obstacles) or in the form of discouraging/not } \\
\text { allowing the child to try new things (e.g., "You are not } \\
\text { able to do that") }\end{array}$ \\
\hline & $\begin{array}{l}\text { Organizational and } \\
\text { Systemic }\end{array}$ & $\begin{array}{l}\text { Many adaptive ski programs had waitlists if there were } \\
\text { not enough volunteers or instructors for the students } \\
\text { Not all volunteers had the background to ski with } \\
\text { persons with disabilities and the observational or } \\
\text { instructional skills to support development } \\
\text { - Some volunteers lacked knowledge of adaptive ski } \\
\text { equipment needs } \\
\text { - Instructors and volunteers had to file a report each ski } \\
\text { day in a binder (management system) } \\
\text { Instructors and volunteers sometimes forgot to fill out } \\
\text { report or did not have enough time } \\
\text { - Some adaptive ski programs used an online }\end{array}$ \\
\hline
\end{tabular}




\begin{tabular}{|c|c|c|}
\hline & & $\begin{array}{l}\text { management system (Snowline), which meant } \\
\text { instructors and volunteers could file the report from } \\
\text { home if they forgot }\end{array}$ \\
\hline & $\begin{array}{l}\text { Informational and } \\
\text { Communicational }\end{array}$ & $\begin{array}{l}\text { For those with autism, knowing exactly what is going } \\
\text { to happen, where it is going to happen, and when it is } \\
\text { going to happen is particularly important. Sometimes } \\
\text { organizations do not communicate soon enough, or } \\
\text { make last minute changes with little advance notice } \\
\text { - CADS had a designated information desk, which } \\
\text { served as a meeting point and helped with organization }\end{array}$ \\
\hline Ski School & & $\begin{array}{l}\text { Most adaptive skiers relied on programs to access } \\
\text { qualified personnel to assist them on the hill. There } \\
\text { were not many ski areas that offered adaptive } \\
\text { instructors in addition to regular ski instructors } \\
\text { - If a skier were not part of an adaptive ski program, } \\
\text { they would not have access to appropriate signs, } \\
\text { literature, coaching instructors, or adaptive ski } \\
\text { equipment } \\
\text { There was a lack of adaptive skiing opportunities for } \\
\text { persons who were not members of a program }\end{array}$ \\
\hline \multirow[t]{3}{*}{ Equipment } & $\begin{array}{l}\text { Architectural and } \\
\text { Physical }\end{array}$ & $\begin{array}{l}\text { - Ski racks were placed outside to organize equipment } \\
\text { and minimize obstacles on the ground. } \\
\text { - Adaptive ski equipment was stored in a container } \\
\text { outdoors. Ideally, equipment should be stored at room } \\
\text { temperature to prevent the equipment from freezing } \\
\text { and for ease of repair. } \\
\text { - An adaptive ski equipment room was installed down a } \\
\text { flight of stairs and was not accessible to those with } \\
\text { mobility challenges } \\
\text { - Rental equipment and ski shop were located on lower } \\
\text { level, accessed by a steep, outdoor staircase }\end{array}$ \\
\hline & $\begin{array}{l}\text { Organizational and } \\
\text { Systemic }\end{array}$ & $\begin{array}{l}\text { - Most ski area did not offer adaptive ski programs or } \\
\text { adaptive ski equipment rentals }\end{array}$ \\
\hline & Technological & $\begin{array}{l}\text { CADS modified adaptive ski equipment to meet } \\
\text { individual needs because the existing equipment was } \\
\text { not compatible with all students and had issues with } \\
\text { safety, comfort, or performance. } \\
\text { Adaptive ski program volunteers/instructors were } \\
\text { encouraged to collaborate with the students to find } \\
\text { appropriate modification solutions for their equipment }\end{array}$ \\
\hline \multirow[t]{2}{*}{ Lift Tickets } & $\begin{array}{l}\text { Architectural and } \\
\text { Physical }\end{array}$ & $\begin{array}{l}\text { - One ticket booth was located outside and had a cleared } \\
\text { pathway. The height of the counter was wheelchair } \\
\text { accessible. } \\
\text { - One ticket booth was on the second floor of a building } \\
\text { without an elevator }\end{array}$ \\
\hline & Organizational and & - CADS provided volunteers and instructors with lift \\
\hline
\end{tabular}




\begin{tabular}{|c|c|c|}
\hline & Systemic & $\begin{array}{l}\text { tickets. } \\
\text { Some adaptive ski programs provided their volunteers } \\
\text { and instructors with free ski lift tickets, while some ski } \\
\text { areas did not offer free or discounted tickets to } \\
\text { guides/support skiers } \\
\text { - Lift tickets that need to be scanned at times created a } \\
\text { physical interaction that was outside of the comfort } \\
\text { zone of a person with a disability }\end{array}$ \\
\hline \multirow[t]{3}{*}{$\begin{array}{l}\text { Guest } \\
\text { Services \& } \\
\text { Staff }\end{array}$} & $\begin{array}{l}\text { Organizational and } \\
\text { Systemic }\end{array}$ & \multirow{2}{*}{$\begin{array}{l}\text { - Lift operators sometimes did not understand how } \\
\text { adaptive ski equipment could be used on chairlifts and } \\
\text { sometimes avoided helping the students load } \\
\text { - Ski area staff received limited training on how to help } \\
\text { persons with a disability access their terrain }\end{array}$} \\
\hline & & \\
\hline & $\begin{array}{l}\text { Informational and } \\
\text { Communicational }\end{array}$ & $\begin{array}{l}\text { - Ski area staff did not always have an understanding of } \\
\text { how to communicate with persons with disabilities } \\
\text { - Communicating with a person who is non-verbal can } \\
\text { be challenging }\end{array}$ \\
\hline
\end{tabular}

Table 24 Findings: Outside of the Ski Area

\begin{tabular}{|c|c|c|}
\hline Theme & Barrier Type & Findings \\
\hline $\begin{array}{l}\text { Access to Ski } \\
\text { Area }\end{array}$ & $\begin{array}{l}\text { Architectural } \\
\text { and Physical }\end{array}$ & $\begin{array}{l}\text { - Some persons with disabilities relied on others for } \\
\text { transportation }\end{array}$ \\
\hline & $\begin{array}{l}\text { Organizational } \\
\text { and Systemic }\end{array}$ & $\begin{array}{l}\text { - Public \& para transport were not offered at some ski areas } \\
\text { - Ski trips, festivals, and events do not always use accessible } \\
\text { busses }\end{array}$ \\
\hline Websites & Technological & $\begin{array}{l}\text { - Some websites and online forms were hard to navigate with } \\
\text { screen readers and assistive technologies }\end{array}$ \\
\hline \multirow{2}{*}{ 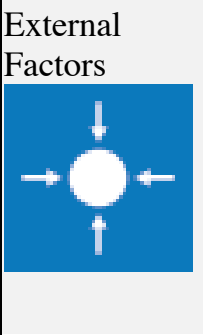 } & Attitudinal & $\begin{array}{l}\text { - Some school trips to ski areas excluded students with } \\
\text { disabilities because it was too much effort for the organizers to } \\
\text { make accommodations }\end{array}$ \\
\hline & $\begin{array}{l}\text { Organizational } \\
\text { and Systemic }\end{array}$ & $\begin{array}{l}\text { - Some ski areas were reluctant to take on an adaptive ski } \\
\text { program due to concerns over liability } \\
\text { - Some persons with disabilities have been told that they are not } \\
\text { allowed to ski without disability insurance }\end{array}$ \\
\hline
\end{tabular}

\subsubsection{Similarities, Differences, and Outlying Information}

Most themes are similar across the three research phases, which confirm the importance 
of the results. Table 25 organizes the themes of barriers to accessibility in order of frequency that they are reported by participants, from most to least.

Table 25 Frequency of Themes of Barriers to Accessibility

\begin{tabular}{|c|c|c|c|c|c|}
\hline $\begin{array}{l}\text { Architectural/ } \\
\text { Physical } \\
\text { Barriers }\end{array}$ & $\begin{array}{l}\text { Attitudinal } \\
\text { Barriers }\end{array}$ & $\begin{array}{l}\text { Organizational/ } \\
\text { Systemic } \\
\text { Barriers }\end{array}$ & $\begin{array}{l}\text { Informational/ } \\
\text { Communicational } \\
\text { Barriers }\end{array}$ & $\begin{array}{l}\text { Technological } \\
\text { Barriers }\end{array}$ & $\begin{array}{l}\text { Other } \\
\text { Barriers }\end{array}$ \\
\hline Lodge (171) & $\begin{array}{l}\text { Attitudes of } \\
\text { Other Guests } \\
\text { (35) }\end{array}$ & $\begin{array}{l}\text { Adaptive } \\
\text { Programs (35) }\end{array}$ & $\begin{array}{l}\text { Print Accessibility } \\
\text { (12) }\end{array}$ & $\begin{array}{l}\text { Adaptive ski } \\
\text { equipment (3) }\end{array}$ & $\begin{array}{l}\text { Design } \\
\text { for } \\
\text { Disability } \\
(6)\end{array}$ \\
\hline Lift (43) & $\begin{array}{l}\text { Attitudes of } \\
\text { Staff \& } \\
\text { Instructors } \\
\text { (13) }\end{array}$ & $\begin{array}{l}\text { External Factors } \\
\text { (10) }\end{array}$ & $\begin{array}{l}\text { Adaptive Programs } \\
\text { (9) }\end{array}$ & $\begin{array}{l}\text { Management } \\
\text { (2) }\end{array}$ & $\begin{array}{l}\text { Universal } \\
\text { Design } \\
(2)\end{array}$ \\
\hline Parking (38) & $\begin{array}{l}\text { Equality vs. } \\
\text { equity (9) }\end{array}$ & $\begin{array}{l}\text { Guest Services } \\
\text { (6) }\end{array}$ & $\begin{array}{l}\text { Online } \\
\text { Accessibility (8) }\end{array}$ & Websites (1) & \\
\hline Pathways (30) & $\begin{array}{l}\text { Attitudes of } \\
\text { Adaptive } \\
\text { Skiers (3) }\end{array}$ & $\begin{array}{l}\text { Accessible } \\
\text { Transportation } \\
\text { Services (5) }\end{array}$ & $\begin{array}{l}\text { Ski Area Staff } \\
\text { Training (6) }\end{array}$ & & \\
\hline Skiing (18) & & Lift (3) & & & \\
\hline $\begin{array}{l}\text { Other Guests } \\
\text { (14) }\end{array}$ & & $\begin{array}{l}\text { Events \& } \\
\text { Festivals (1) }\end{array}$ & & & \\
\hline \multicolumn{6}{|l|}{$\begin{array}{l}\text { Guest Services } \\
\text { (4) }\end{array}$} \\
\hline $\begin{array}{l}\text { Access to Ski } \\
\text { Area (1) }\end{array}$ & & & & & \\
\hline
\end{tabular}

The findings demonstrate that architectural and physical barriers in the lodge are the most encountered barrier to accessibility during the experience of skiing. 171 architectural and physical barriers are reportedly associated with the lodge, including:

1) Ramps, Stairs, and Elevators (39) 
2) Floorplan \& Layout (33)

3) Washrooms (32)

4) Doors (24)

5) Storage (18)

6) Cafeteria and Bar (16)

7) Floors and Carpets (5)

8) Tables and Seating (4)

A few themes only emerge once or twice because they are not discussed in all research phases. For example, “Access to Ski Area (1)", "Events \& Festivals (1)”, or "Websites (1)". This does not necessarily devalue the occurrence or significance of these barriers, however they could be further examined to determine why they do not emerge from all three research phases.

In terms of outlying information, organized under "Other Barriers", "Design for Disability (6)" and "Universal Design (2)" are identified. Participants from separate research phases highlight the need for accessible design approaches to encompass all five types of barriers to accessibility.

\subsection{Summary of Analysis Methods and Findings}

The following is a summary of the key insights from the triangulation:

1) Triangulation is used as an analysis method to integrate the findings from the three research phases and search for similarities, differences, and outliers within 
the information

2) This thesis conducts triangulation through two rounds of affinity diagramming and a ski area map exercise that is created by the researcher

3) The themes of barriers to accessibility are organized into three contexts based on where they are most likely to be encountered: (1) On the Slopes, (2) At the Ski Area, (3) Outside of the Ski Area

4) Architectural and physical barriers in the lodge are the most reported barrier to accessibility

5) Barriers to accessibility that are reported the least do not necessarily occur less or are less significant, however they could be further examined to determine why they do not emerge from all three research phases. 


\section{Chapter 8: Discussion}

\subsection{Interpretation of Findings}

Chapters 4 to 7 present the raw data, analysis, and synthesis of the three research phases. The next step is to interpret these findings into a reasonable answer to the research question, sub-research questions, and in relation to the literature.

\subsubsection{Evaluation of Main Research Question}

This thesis seeks to answer, "How can design research be used to identify and address the barriers to accessibility for skiing?". This chapter begins by exploring how the findings from the three research phases and sub-research questions contribute to answering the main research question.

The exploratory sequential design of the research methods enables Phase 1 to inform Phase 2, and Phase 2 to inform Phase 3. The organic nature of exploratory sequential design is reflective of the design process. The design process is not linear and often begins with the "fuzzy front end" where the direction is undefined (Illustration 41). The fuzzy front end is an insight-driven process that seeks to understand user needs, collect insights, and identify opportunities. The three research phases represent the fuzzy front end of the design process, as they navigate uncertainty and search for emerging patterns. Likewise, the analysis and triangulation represent the end of the design process where clarity and focus emerge to enable the development of design outcomes. The design outcomes of this thesis include: 
1) The identification of barriers to accessibility that are experienced in adaptive skiing

2) Design recommendations and practical approaches that may be of value for addressing the barriers to accessibility for skiing

3) The suggestion of a novel method that might promote information provision and reduce the impact of barriers to accessibility for skiing

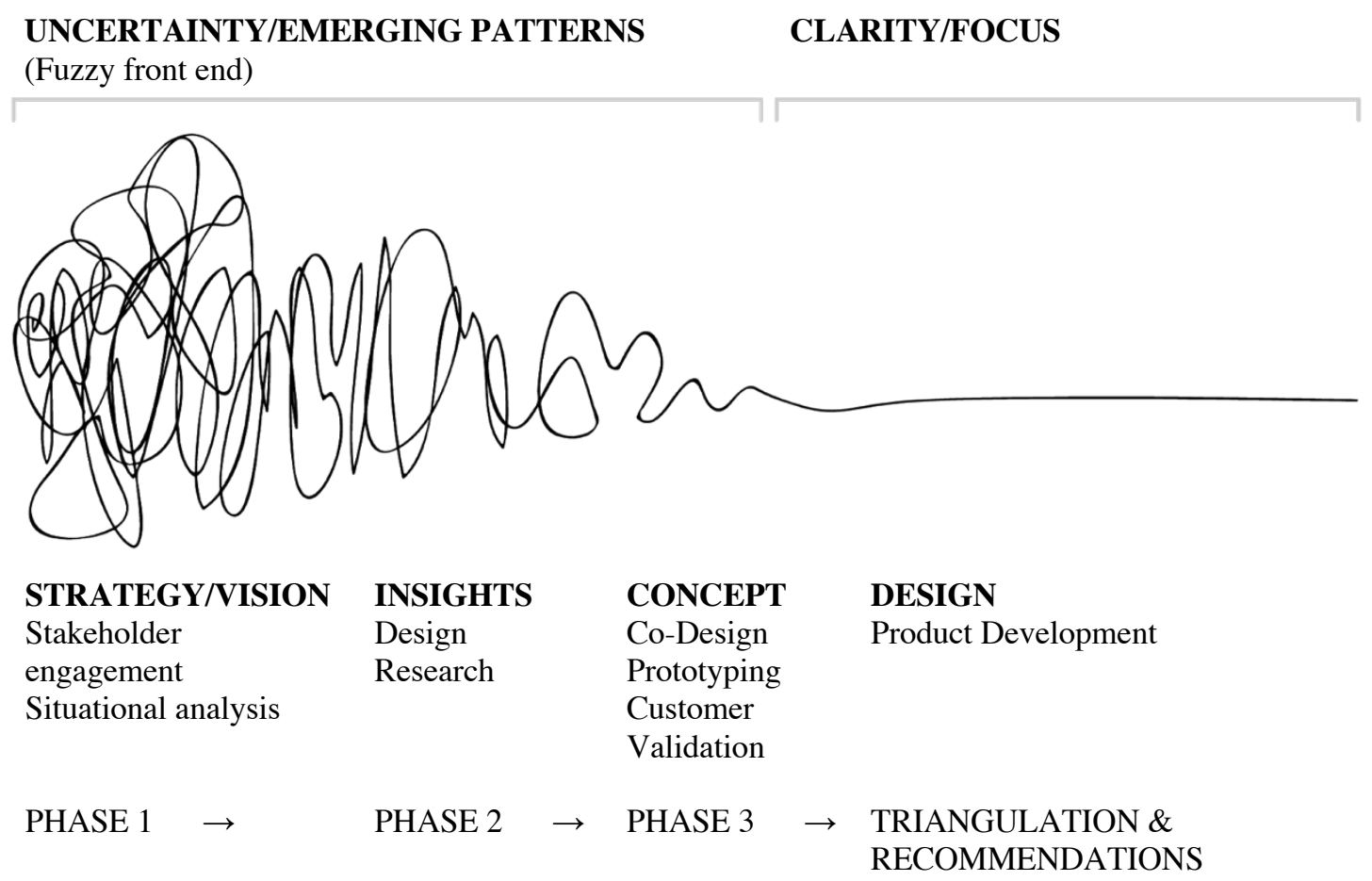

Illustration 41 Fuzzy Front End

Approaching research through the lens of design is an effective technique for navigating the fuzzy front end. The exploratory sequential design provides a foundation for creativity and informs intuition.

\subsubsection{Evaluation of Sub-Research Question 1}


In answer to sub-research question 1, Phase 1 explores "What is the experience of adaptive skiing?" to discover a thesis direction. Based on the literature review, several key factors that contribute to the experience of adaptive skiing are highlighted. For example, the literature review highlights the importance of adaptive ski equipment and adaptive ski programs, which empower skiers with disabilities (Laskowski, 1991; De Luigi, 2018; Disabled World, 2017; McCauley \& Frankel, 2020). Findings from Phase 1 support these factors, but unexpectedly identify that the experience of adaptive skiing is most negatively impacted by the accessibility and inclusivity of ski areas. In part, the experience of adaptive skiing, equipment, and programs are contingent on ski areas' circumstances. This insight can be deduced to three core reasons:

1) Accessibility and Inclusivity: When ski areas have barriers to accessibility, the experience of adaptive skiing may be impeded. As discussed in the literature review, barriers to accessibility may have varying levels of impact, such as: a complete inability to participate in skiing; a lessened quality of experience of skiing; adjacency effects on the participation of the families or friends of persons with disabilities (Lape et al., 2017; Byrne 2007).

2) Partnerships: When a ski area partners with or permits an adaptive ski program to operate at their ski area, adaptive ski opportunities are likely to increase. Phase 2 reports that some ski areas are reluctant to take on an adaptive ski program due to concerns over liability. Additionally, due to limited resources, some adaptive ski programs cannot serve all students who apply to the program and must create a waitlist.

3) Willingness or ability to offer adaptive ski options: The findings highlight a 
desire for ski areas to offer adaptive ski options, such as the rental of adaptive ski equipment and adaptive ski schools or lessons, for adaptive skiers who are not enrolled in an adaptive ski program.

\subsubsection{Evaluation of Research Question 2}

In answer to sub-research question 2, Phase 2 explores "Have you ever experienced or witnessed someone else experience a barrier to accessibility for skiing?" to further define barriers. Questionnaire responses indicate that all participants have experienced or witnessed at least one barrier to accessibility for skiing. As shown in section 5.8, Illustration 23, the most reported barrier to accessibility for skiing is architectural and physical, followed by attitudinal, organizational and systemic, informational and communicational, then technological. This finding is consistent with the literature review, which discusses how people generally associate accessibility with architectural and physical design more often than the other types of barriers (Legislative Services Branch, 2020; Council of Ontario Universities, 2013).

Another potential influence on the reported order of barriers to accessibility for skiing, could be availability biases. An availability bias is a mental shortcut that relies on immediate examples that come to one's mind. The availability bias operates on the notion that if something can be recalled, it must be important, or at least more important than alternative solutions, which are not as readily recalled (Welsh, 2018). For some, it may be easier to recall architectural and physical barriers than other barriers, which may be harder to recall or less familiar. As a result, the consequences of architectural and 
physical barriers may be perceived as greater. All to say, people experience barriers to accessibility for skiing. Regardless of the recognizability of a barrier, all barriers carry the potential to negatively impact the experience of adaptive skiing and should not be overlooked.

\subsubsection{Evaluation of Research Question 3}

In answer to sub-research question 3, Phase 3 explores "What are your past experiences and future dreams for skiing for persons with disabilities?" to seek design recommendations. In terms of past experiences, Phase 3 contributes insight into the participants' moods during each stage of the experience of skiing. Accordingly, four out of the six participants (P1, P4, P5, P6) in the directed storytelling study identify as having a disability. As visualized in the user journey maps (Illustration 42), their moods are less positive throughout the experience of skiing, compared to the other two participants $(\mathrm{P} 2$, P3) who do not identify as having a disability.

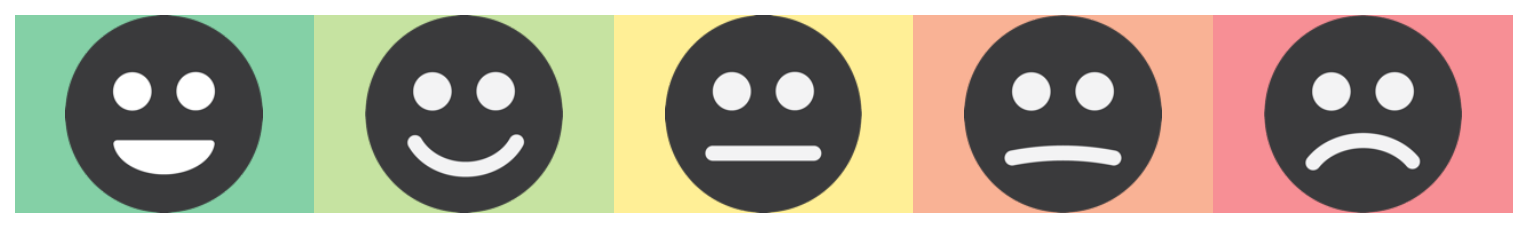




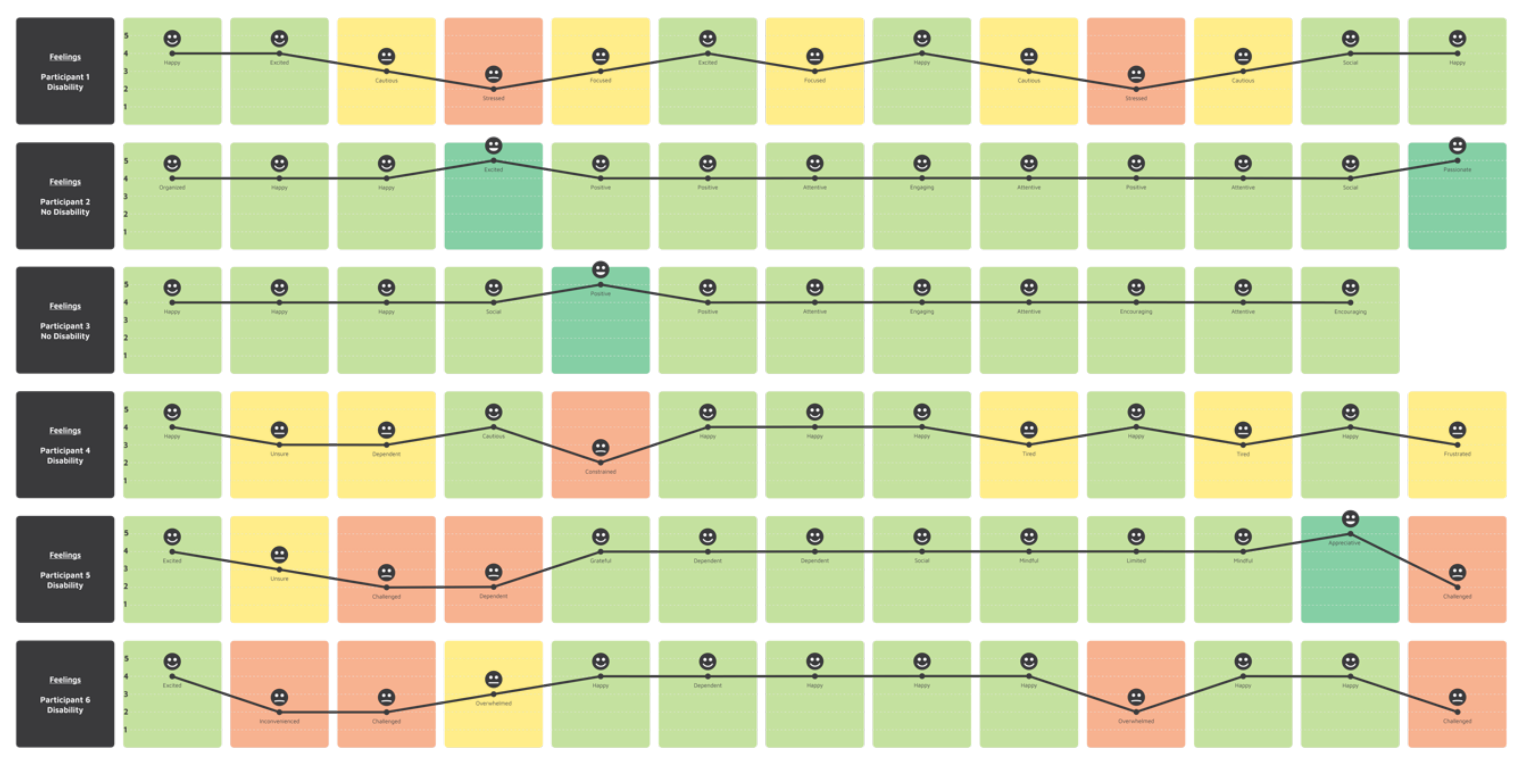

Illustration 42 Participant Moods Throughout User Journey Maps

Illustration 43 rates from 1 to 5 each participant's average mood throughout the experience of skiing. The four participants who identify as having disabilities experience fewer positive moods than the two participants who do not identify as having a disability.

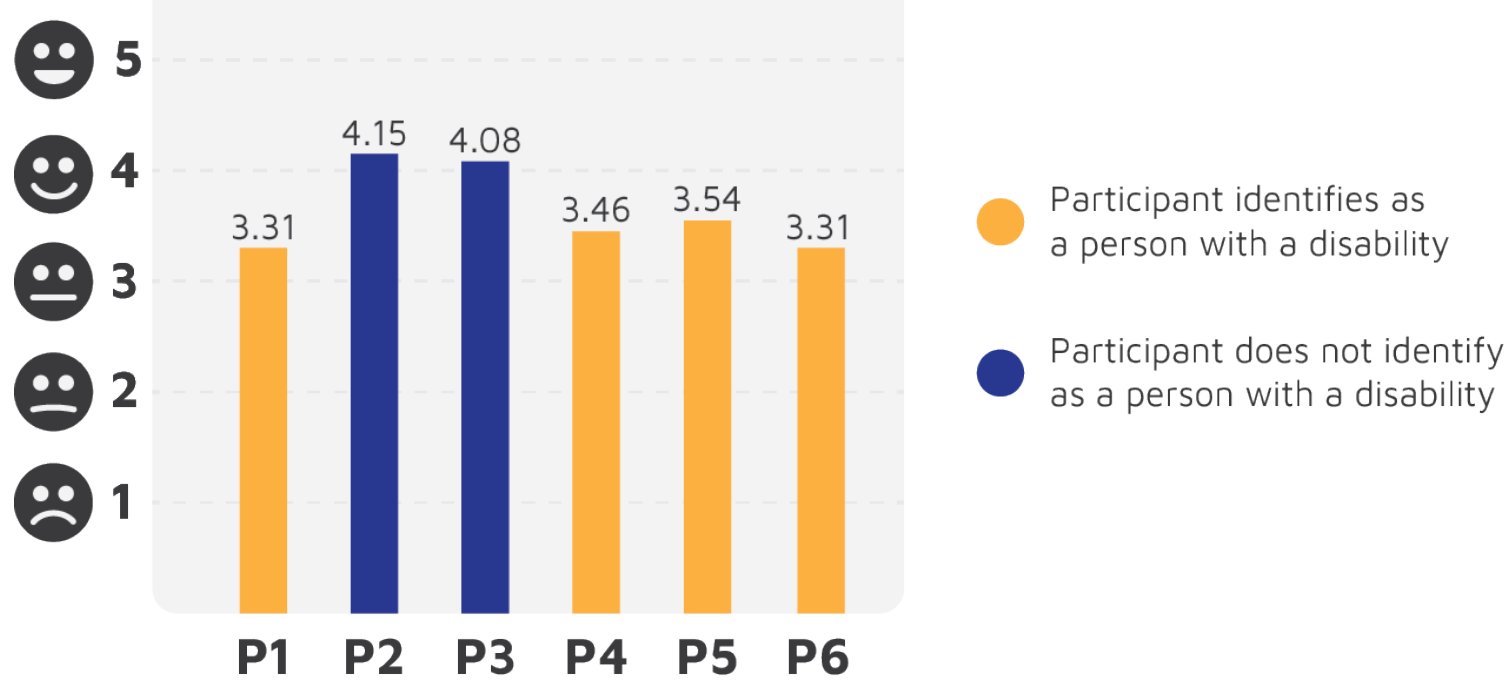

Illustration 43 Participants' Average Moods Throughout User Journey Maps 
In reflection, it is possible that people who do not identify as having a disability do not personally experience barriers to accessibility when skiing. Further research could explore the transferability and validity of this insight. Nevertheless, this insight highlights a need for ski areas to consider the experiences of persons with disabilities, which are often different from what non-disabled people take for granted. Ski areas should be designed to provide equal opportunities and experiences to all users.

In terms of desires for the future of adaptive skiing, participants in Phase 3 generate ideas that may improve their experiences of skiing. Table 26 is developed in collaboration with the subject matter experts and target users to offer recommendations for addressing barriers to accessibility for skiing.

Table 26 Recommendations

\begin{tabular}{|c|c|}
\hline Theme & Participant Ideas for Improvement \\
\hline $\begin{array}{l}\text { Access to Ski } \\
\text { Area }\end{array}$ & $\begin{array}{l}\text { - Ski areas should be easy to access } \\
\text { - Ski areas should consider having paved roads and sufficient signage leading } \\
\text { up to the ski area } \\
\text { - Ski areas should consider providing accessible transportation services }\end{array}$ \\
\hline Parking & $\begin{array}{l}\text { - Ski areas should consider implementing more accessible parking spaces } \\
\text { - Accessible parking spaces or unloading areas should be wide enough for a } \\
\text { vehicle's mobility aid ramp to open } \\
\text { - Accessible parking should be as close to the lodge entrance as possible } \\
\text { - Unloading areas and accessible parking spaces should be clearly marked } \\
\text { - Snow should be cleared from the parking lot, especially for people using } \\
\text { mobility aids }\end{array}$ \\
\hline Pathways & $\begin{array}{l}\text { - Accessible pathways should not require excessive detours or effort } \\
\text { - Pathways should be cleared of snow and/or use platforms, mats, or grates to } \\
\text { improve ease of walking and using mobility aids } \\
\text { - Pathways should not be steep. If they are, there should be an indication of the } \\
\text { slope percentage }\end{array}$ \\
\hline Lodge & $\begin{array}{l}\text { - Entrances should be universally accessible. They should not require excessive } \\
\text { detours or effort }\end{array}$ \\
\hline
\end{tabular}




\begin{tabular}{|c|c|}
\hline & 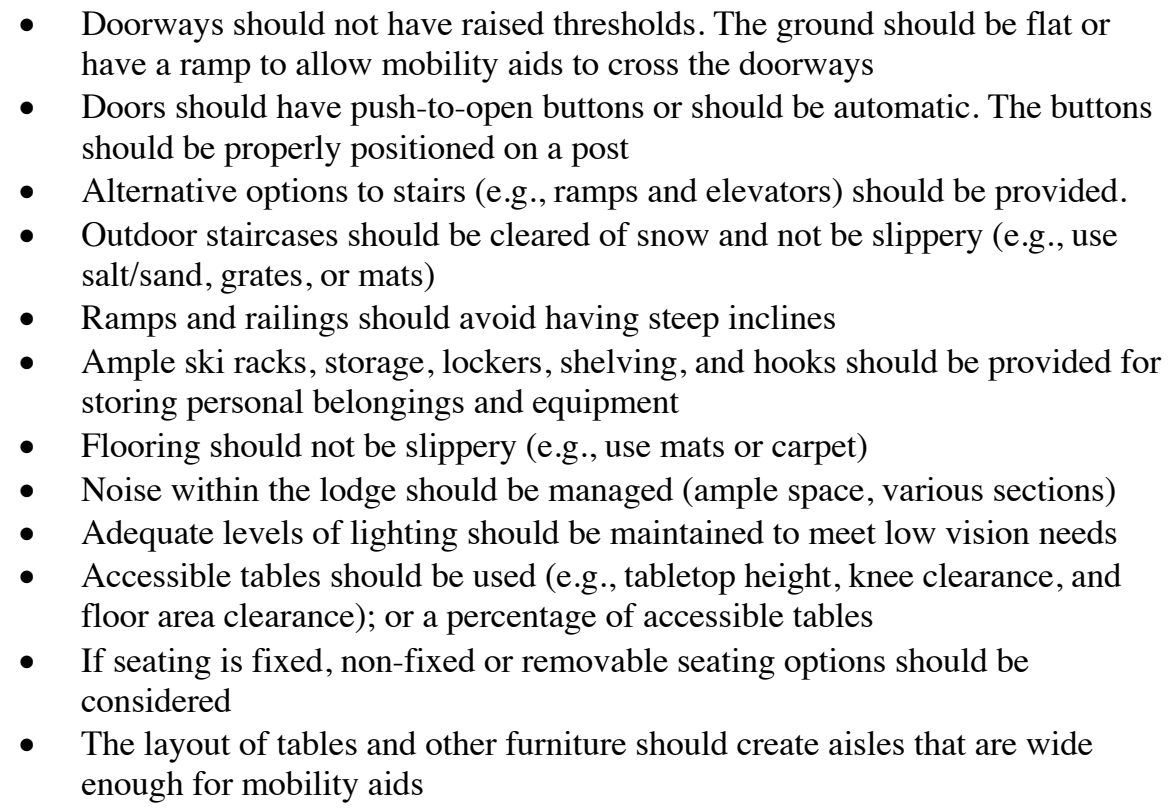 \\
\hline Washrooms & $\begin{array}{l}\text { - Ski areas should consider having multiple accessible washrooms } \\
\text { - Family washrooms/single-use washrooms would benefit some skiers with } \\
\text { disabilities. Some ski areas have installed washrooms with padded benches } \\
\text { and changing tables } \\
\text { - Washrooms should be central and easy to access (e.g., no stairs or ramps) } \\
\text { - Accessible washroom stalls should not be blocked by urinals, sinks, or other } \\
\text { - } \quad \text { elements } \\
\text { To deter persons without disabilities from using accessible stalls, more } \\
\text { 'regular' stalls should be available }\end{array}$ \\
\hline $\begin{array}{l}\text { Cafeteria/ } \\
\text { Restaurant }\end{array}$ & $\begin{array}{l}\text { - The cafeteria, restaurant, or bar should be easy to access } \\
\text { - If the cafeteria is not located on the main floor, an elevator or accessible ramp } \\
\text { should be installed } \\
\text { - If the cafeteria is not easy to access (e.g., not on the main level, far distance } \\
\text { for the centre of lodge), other food options, such as vending machines, should } \\
\text { be available } \\
\text { - Navigation of the cafeteria should be wheelchair accessible } \\
\text { - Signage and menus should be designed with an accessible font and have good } \\
\text { contrast }\end{array}$ \\
\hline $\begin{array}{l}\text { Adaptive Ski } \\
\text { Program }\end{array}$ & $\begin{array}{l}\text { - All volunteers and instructors should have access to an adaptive ski program } \\
\text { manual to which they can refer for guidance } \\
\text { - If possible, adaptive ski programs should have a designated space at the ski } \\
\text { area to minimize crowds, noise, and obstacles } \\
\text { - More ski areas should consider partnering with adaptive ski programs } \\
\text { - } \quad \text { Adaptive ski programs and ski areas should have up-to-date marketing tools } \\
\text { to inform the public about adaptive skiing opportunities (e.g., customer } \\
\text { relationship management, online advertising, social media, etc.) } \\
\text { - Ensure that volunteers and instructors are trained and qualified to ski with } \\
\text { persons with disabilities } \\
\text { Volunteers and instructors should know how to react to and handle challenges } \\
\text { with skiers with disabilities to promote a safe and enjoyable experience }\end{array}$ \\
\hline
\end{tabular}




\begin{tabular}{|c|c|}
\hline & $\begin{array}{l}\text { - Adaptive ski programs should consider offering training throughout the ski } \\
\text { season } \\
\text { - Volunteers and instructors should consider ethical coaching training, such as } \\
\text { modules on Sports for Life } \\
\text { - Members of adaptive ski programs should maintain a positive and flexible } \\
\text { attitude. The "fun-factor" can improve the user experience of adaptive skiing } \\
\text { - To improve internal communication, adaptive ski programs should consider } \\
\text { adopting Snowline, an online management system } \\
\text { - In an ideal world, adaptive ski programs should have more volunteers so } \\
\text { adaptive skiers do not have to be put on a waitlist } \\
\text { - Adaptive ski programs should provide members with accessible information } \\
\text { and provide advance notice about changes to the program }\end{array}$ \\
\hline Equipment & $\begin{array}{l}\text { - Ski areas should consider renting out adaptive ski equipment and offering } \\
\text { adaptive ski lessons in addition to having an adaptive ski program } \\
\text { Equipment rentals and equipment storage for adaptive ski programs should be } \\
\text { located on ground level to improve ease of access } \\
\text { - Equipment storage for adaptive ski programs should be in a heated space to } \\
\text { improve comfort and function. Students could be properly fitted to their } \\
\text { equipment in the space, and the equipment could be repaired } \\
\text { - Adaptive ski equipment should be modified and adjusted based on the unique } \\
\text { needs of each skier }\end{array}$ \\
\hline Lift Tickets & $\begin{array}{l}\text { - Ski area should consider subsidizing lift tickets for people providing support } \\
\text { to adaptive skiers } \\
\text { - If lift tickets must be scanned, lift operators should be aware that some people } \\
\text { do not feel comfortable when another person enters their personal space } \\
\text { - Point of purchase for tickets should be wheelchair accessible }\end{array}$ \\
\hline $\begin{array}{l}\text { Guest Services } \\
\text { \& Staff }\end{array}$ & $\begin{array}{l}\text { - Consider participating in specialized training with adaptive ski programs (e.g., } \\
\text { lift operators handling adaptive ski equipment, snow patrol performing } \\
\text { evacuations with adaptive skiers) } \\
\text { - Ski area staff should be trained to properly communicate with and assist } \\
\text { persons with disabilities } \\
\text { - Ski areas should design accessible information (e.g., physical signs and } \\
\text { documents, websites) }\end{array}$ \\
\hline Lift & $\begin{array}{l}\text { - Lift operators should be aware of adaptive skiers and adaptive ski equipment } \\
\text { - Chairlift ramps and landings should be kept at a consistent level because if } \\
\text { they are too high or too low, people may have challenges loading/unloading } \\
\text { - The placement of lifts should aim to allow adaptive skiers to access the lifts } \\
\text { independently } \\
\text { - The entrance the lift lines should be wide enough for adaptive ski equipment } \\
\text { - If possible, adaptive skiers should be permitted to use accessible lift lines } \\
\text { (e.g., a line that do not weave back and forth or that are easier to enter and } \\
\text { navigate) } \\
\text { - Skiers should be encouraged to move away from the unloading area }\end{array}$ \\
\hline Ski Trails & $\begin{array}{l}\text { - Noise should be limited on the ski hill (e.g., reduce the amount of snowmobile } \\
\text { traffic) } \\
\text { - A variety of trails should be offered (e.g., groomed trails, wide trails) } \\
\text { - Landings and rest spots should be designed into the hill to allow skiers to take } \\
\text { breaks }\end{array}$ \\
\hline
\end{tabular}




\begin{tabular}{|l|ll|}
\hline Other Guests & $\begin{array}{l}\text { Increased public education about persons with disabilities could improve } \\
\text { accessibility and inclusivity }\end{array}$ \\
- $\begin{array}{l}\text { Other skiers should be made aware of adaptive skiers and to provide them } \\
\text { with adequate space on the hill }\end{array}$ \\
- $\begin{array}{l}\text { Adaptive ski programs should consider assigning volunteers to ski as } \\
\text { "Blockers" to manage the other guests on the hill and protect the adaptive } \\
\text { student. Blockers should have special high visibility clothing }\end{array}$ \\
\hline $\begin{array}{l}\text { External } \\
\text { Factors }\end{array}$ & $\begin{array}{l}\text { External funding (e.g., from the Government or corporate sponsorship) could } \\
\text { increase opportunities for adaptive skiing }\end{array}$ \\
& $\begin{array}{l}\text { Ski areas should employ the Accessible Canada Act or other standards to } \\
\text { create universal inclusion } \\
\text { Disability insurance should not impede a person with a disability from skiing }\end{array}$ \\
\hline
\end{tabular}

These recommendations discuss all five types of barriers to accessibility but are most concentrated on architectural and physical barriers at ski areas. As visualized in the user journey maps, the poor design of parking lots, pathways, and lodges contribute to a significant decrease in the user experiences for adaptive skiing. The architectural and physical barriers associated with these areas demonstrate the adjacency of effects. To elaborate, in Phase 3, Participant 4 discusses how they need to go through numerous obstacles to ski. Consequently, the obstacles take away from the experience of skiing. To illustrate, Participant 4, who has cerebral palsy, arrives at their ski area in a wheelchairaccessible van. Unfortunately, the "accessible" parking spots are not wide enough to open the van's ramp and unload their electric wheelchair. As a result, Participant 4 must use their cane to walk to the lodge. Walking on snow requires increased effort and makes Participant 4 tired before skiing and makes the remaining experience more challenging than normal.

The experiences of Participant 4 speak to the need for ski areas to recognize the diverse needs of skiers to promote equal access. As discussed in the literature review, not all 
people can use the same systems (Hawranik, 2020). Equitable treatment, such as installing a ramp can be helpful; however, removing the need for the ramp can be ideal. In the words of Participant 6 from Phase 3, “What some people don't know is if you make everything accessible, it would be good for everybody, not only for people with disabilities. Good accessible design means everybody can use it regardless of disability or ability". Accessible design can be achieved through universal design, which facilitates the design of products, services, and environments that are usable by as many people as possible. The next section will provide an example of how universal design can be applied to skiing.

\subsection{Design Recommendations and Opportunities}

The following design recommendations discuss useful approaches for addressing barriers to accessibility for skiing.

\subsubsection{Universal Design}

All three research phases identify significant physical and architectural barriers for skiing. At ski areas, adaptive skiers may experience barriers in the parking lot, on the snow and terrain, in the lodge, using the chairlift, and so on. The literature review remarks that universal design is a practical approach for creating inclusive environments (Steinfeld \& Maisel, 2012) and can help achieve a higher standard of accessibility (Newell, 2015). Thus, the 7 Principles of Universal Design are used to organize the recommendations to help promote a higher level of accessibility. Table 27 below demonstrates the application of the 7 Principles of Universal Design for skiing. 
Table 277 Principles of Universal Design for Skiing

\begin{tabular}{|c|c|c|}
\hline Principle & Guidelines & Examples of Applications to Skiing \\
\hline \multirow[t]{4}{*}{$\begin{array}{l}\text { Principle 1: } \\
\text { Equitable Use } \\
\text { The design is useful and } \\
\text { marketable to people with } \\
\text { diverse abilities. }\end{array}$} & $\begin{array}{l}\text { Provide the same means of } \\
\text { use for all users: identical } \\
\text { whenever possible; } \\
\text { equivalent when not. }\end{array}$ & $\begin{array}{l}\text { Entrances and doors should be usable by as } \\
\text { many people as possible, including mobility } \\
\text { aids (e.g., level automatic doors), if not } \\
\text { alternative entrances (e.g., ramps) should not } \\
\text { require added effort. }\end{array}$ \\
\hline & $\begin{array}{l}\text { Avoid segregating or } \\
\text { stigmatizing any users. }\end{array}$ & $\begin{array}{l}\text { Never belittle or patronize persons with } \\
\text { disabilities. }\end{array}$ \\
\hline & $\begin{array}{l}\text { Provisions for privacy, } \\
\text { security, and safety should } \\
\text { be equally available to all } \\
\text { users. }\end{array}$ & $\begin{array}{l}\text { Evacuation procedures should include } \\
\text { everyone. Ski patrol and lift operators should } \\
\text { consider partnering with adaptive ski } \\
\text { programs to learn how to properly handle and } \\
\text { evacuate adaptive ski equipment from the lift. }\end{array}$ \\
\hline & $\begin{array}{l}\text { Make the design appealing } \\
\text { to all users. }\end{array}$ & $\begin{array}{l}\text { Designs for persons with disabilities should } \\
\text { not appear blatantly different from "regular" } \\
\text { designs. Designs should appear integrated and } \\
\text { appealing rather than as an afterthought. For } \\
\text { example, it is not ideal to make persons with } \\
\text { disabilities use freight elevators or segregated } \\
\text { entrances. }\end{array}$ \\
\hline \multirow{4}{*}{$\begin{array}{l}\text { Principle 2: } \\
\text { Flexibility in Use } \\
\text { The design accommodates a } \\
\text { wide range of individual } \\
\text { preferences and abilities. }\end{array}$} & $\begin{array}{l}\text { Provide choice in methods of } \\
\text { use. }\end{array}$ & $\begin{array}{l}\text { Consider installing stairs, ramps, and elevators } \\
\text { to access other levels in a building. } \\
\text { Ski trails should vary in terrain and difficulty. }\end{array}$ \\
\hline & $\begin{array}{l}\text { Accommodate right- or left- } \\
\text { handed access and use. }\end{array}$ & $\begin{array}{l}\text { Adaptive ski equipment or other products } \\
\text { should be usable by right- or left-handed } \\
\text { users. }\end{array}$ \\
\hline & $\begin{array}{l}\text { Facilitate the user's accuracy } \\
\text { and precision. }\end{array}$ & $\begin{array}{l}\text { Consider modifying adaptive ski equipment to } \\
\text { provide better fit, comfort, and safety to the } \\
\text { user. }\end{array}$ \\
\hline & $\begin{array}{l}\text { Provide adaptability to the } \\
\text { user's pace. }\end{array}$ & $\begin{array}{l}\text { Consider installing detachable lifts that } \\
\text { slowdown in the loading and unloading areas. } \\
\text { Alternatively, lift operators should be } \\
\text { prepared to manually slow down or stop the } \\
\text { lift to accommodate individual preferences } \\
\text { and abilities. }\end{array}$ \\
\hline \multirow{3}{*}{$\begin{array}{l}\text { Principle 3: } \\
\text { Simple and Intuitive Use } \\
\text { Use of the design is easy to } \\
\text { understand, regardless of } \\
\text { the user's experience, } \\
\text { knowledge, language skills, }\end{array}$} & $\begin{array}{l}\text { Eliminate unnecessary } \\
\text { complexity. }\end{array}$ & Pathways and entrances should be direct. \\
\hline & $\begin{array}{l}\text { Be consistent with user } \\
\text { expectations and intuition. }\end{array}$ & $\begin{array}{l}\text { The gap between the lift and the ground } \\
\text { should always be the same height. }\end{array}$ \\
\hline & Accommodate a wide range & Signage, information, and communication \\
\hline
\end{tabular}




\begin{tabular}{|c|c|c|}
\hline \multirow[t]{3}{*}{$\begin{array}{l}\text { or current concentration } \\
\text { level. }\end{array}$} & $\begin{array}{l}\text { of literacy and language } \\
\text { skills. }\end{array}$ & $\begin{array}{l}\text { should be clear. Best practices say to aim for } \\
\text { the reading level of a } 12 \text {-year-old }\end{array}$ \\
\hline & $\begin{array}{l}\text { Arrange information } \\
\text { consistent with its } \\
\text { importance. }\end{array}$ & $\begin{array}{l}\text { Consider using headings to create a hierarchy } \\
\text { of information. }\end{array}$ \\
\hline & $\begin{array}{l}\text { Provide effective prompting } \\
\text { and feedback during and } \\
\text { after task completion. }\end{array}$ & $\begin{array}{l}\text { Automatic or push-to-open doors should } \\
\text { respond promptly. }\end{array}$ \\
\hline \multirow{5}{*}{$\begin{array}{l}\text { Principle 4: } \\
\text { Perceptible Information } \\
\text { The design communicates } \\
\text { necessary information } \\
\text { effectively to the user, } \\
\text { regardless of ambient } \\
\text { conditions or the user's } \\
\text { sensory abilities. }\end{array}$} & $\begin{array}{l}\text { Use different modes } \\
\text { (pictorial, verbal, tactile) for } \\
\text { redundant presentation of } \\
\text { essential information. }\end{array}$ & $\begin{array}{l}\text { Signage, wayfinding, documents, and online } \\
\text { content should consider using different modes } \\
\text { of presenting information. }\end{array}$ \\
\hline & $\begin{array}{l}\text { Provide adequate contrast } \\
\text { between essential } \\
\text { information and its } \\
\text { surroundings. }\end{array}$ & $\begin{array}{l}\text { Flooring, transitions, signage, wayfinding, } \\
\text { documents, and online content should use high } \\
\text { contrast colours. }\end{array}$ \\
\hline & $\begin{array}{l}\text { Maximize "legibility" of } \\
\text { essential information. }\end{array}$ & $\begin{array}{l}\text { Font type, size, and contrast should be } \\
\text { considered to maximize legibility and } \\
\text { readability. }\end{array}$ \\
\hline & $\begin{array}{l}\text { Differentiate elements in } \\
\text { ways that can be described } \\
\text { (i.e., make it easy to give } \\
\text { instructions or directions). }\end{array}$ & $\begin{array}{l}\text { Provide sufficient directions and maps of the } \\
\text { ski area. }\end{array}$ \\
\hline & $\begin{array}{l}\text { Provide compatibility with a } \\
\text { variety of techniques or } \\
\text { devices used by people with } \\
\text { sensory limitations. }\end{array}$ & $\begin{array}{l}\text { Ski areas should be designed to support } \\
\text { mobility aids and adaptive ski equipment. }\end{array}$ \\
\hline \multirow[t]{3}{*}{$\begin{array}{l}\text { Principle 5: } \\
\text { Tolerance for Error } \\
\text { The design minimizes } \\
\text { hazards and the adverse } \\
\text { consequences of accidental } \\
\text { or unintended actions. }\end{array}$} & $\begin{array}{l}\text { Arrange elements to } \\
\text { minimize hazards and errors: } \\
\text { most used elements, most } \\
\text { accessible; hazardous } \\
\text { elements eliminated, } \\
\text { isolated, or shielded. }\end{array}$ & $\begin{array}{l}\text { Identify hazards and reduce consequences of } \\
\text { elements that have low tolerances for error. } \\
\text { For example, wet floors should be clearly } \\
\text { marked and should use mats or carpets to } \\
\text { avoid the number of people who slip. }\end{array}$ \\
\hline & $\begin{array}{l}\text { Provide warnings of hazards } \\
\text { and errors. }\end{array}$ & $\begin{array}{l}\text { Some members of adaptive ski programs } \\
\text { should consider using high visibility to } \\
\text { provide warnings of hazards to other skiers. } \\
\text { For example, high visibility tethers; assistant } \\
\text { instructor should wear high visibility when } \\
\text { blocking }\end{array}$ \\
\hline & Provide fail safe features. & $\begin{array}{l}\text { In the event of a lift evacuation, adaptive ski } \\
\text { equipment should have the appropriate } \\
\text { elements (e.g., straps and clips) to be } \\
\text { evacuated. Ski patrol/lift operators should } \\
\text { know how to properly evacuate adaptive ski } \\
\text { equipment. }\end{array}$ \\
\hline
\end{tabular}




\begin{tabular}{|c|c|c|}
\hline & $\begin{array}{l}\text { Discourage unconscious } \\
\text { action in tasks that require } \\
\text { vigilance. }\end{array}$ & The lift should be easy to load and unload. \\
\hline \multirow{4}{*}{$\begin{array}{l}\text { Principle 6: } \\
\text { Low Physical Effort } \\
\text { The design can be used } \\
\text { efficiently and comfortably } \\
\text { and with a minimum of } \\
\text { fatigue. }\end{array}$} & $\begin{array}{l}\text { Allow user to maintain a } \\
\text { neutral body position. }\end{array}$ & $\begin{array}{l}\text { A portion of, or all of the tables should be } \\
\text { accessible without fixed seating to allow } \\
\text { persons in mobility aids to maintain a neutral } \\
\text { body position. }\end{array}$ \\
\hline & $\begin{array}{l}\text { Use reasonable operating } \\
\text { forces. }\end{array}$ & Doors should not be too heavy. \\
\hline & Minimize repetitive actions. & $\begin{array}{l}\text { Traveling long distances to access the lodge or } \\
\text { the lift should be minimized. }\end{array}$ \\
\hline & $\begin{array}{l}\text { Minimize sustained physical } \\
\text { effort. }\end{array}$ & $\begin{array}{l}\text { The accessible parking lot should be close to } \\
\text { the lodge. Accessible pathways should reduce } \\
\text { the amount of sustained physical effort. Slopes } \\
\text { should be minimized. }\end{array}$ \\
\hline \multirow{4}{*}{$\begin{array}{l}\text { Principle 7: } \\
\text { Size and Space for } \\
\text { Approach and Use } \\
\text { Appropriate size and space } \\
\text { is provided for approach, } \\
\text { reach, manipulation, and } \\
\text { use, regardless of user's } \\
\text { body size, posture, or } \\
\text { mobility. }\end{array}$} & $\begin{array}{l}\text { Provide a clear line of sight } \\
\text { to important elements for } \\
\text { any seated or standing user. }\end{array}$ & $\begin{array}{l}\text { Signage and wayfinding should be visible } \\
\text { from different lines on sight. }\end{array}$ \\
\hline & $\begin{array}{l}\text { Make reach to all } \\
\text { components comfortable for } \\
\text { any seated or standing user. }\end{array}$ & $\begin{array}{l}\text { Push-to-open buttons should be placed on a } \\
\text { post rather than behind a door to allow for } \\
\text { ease of use. }\end{array}$ \\
\hline & $\begin{array}{l}\text { Accommodate variations in } \\
\text { hand and grip size. }\end{array}$ & $\begin{array}{l}\text { Handles should be usable by persons of all } \\
\text { ages and abilities. }\end{array}$ \\
\hline & $\begin{array}{l}\text { Provide adequate space for } \\
\text { the use of assistive devices } \\
\text { or personal assistance. }\end{array}$ & $\begin{array}{l}\text { The layout of the lodge (e.g., tables and } \\
\text { seating) should provide adequate space for } \\
\text { mobility aids and adaptive ski equipment }\end{array}$ \\
\hline
\end{tabular}

\subsubsection{Ability-Based Design}

Historically, ski areas have not been designed to include persons with disabilities. The literature review discusses that Canada began to develop ski areas in the 1920s (Fry, 2010). Ski areas were established with the ableist values of the 1920s that believed that persons with disability did not have the ability to ski. Ableism refers to the discrimination and social prejudice against people with disabilities and characterizes people with disabilities as inferior to the non-disabled. Fortunately, as described in this thesis, adaptive skiing emerged through factors such as adaptive ski equipment and programs to 
accommodate users' abilities, which both apply the concept of ability-based design (Wobbrock et al., 2011).

Ability-based design is a practical approach that could contribute to the accessibility and inclusivity of skiing. All the same, this thesis reveals that the application of ability-based design to skiing might conflict with existing perspectives. It is possible that the societal and political attitudes about persons with disabilities in the 1920 s, a time when many ski areas were founded, still play a role in skiing today. Ableist perspectives arise in the findings, including persons with disabilities are less capable or cannot or should not participate in skiing. For example, the theme of underestimating adaptive skiers emerges from Phase 1 and Phase 2. Participants report that as adaptive skiers, they often receive comments such as "it is so inspirational to see you out skiing" or "wow, you can ski!". These types of comments have condescending undertones and suggest that a disability makes a skier less capable than skiers without disabilities. Participants in Phase 2 recount times when other guests at ski areas have said that adaptive skiers should not be permitted to participate in skiing if they require special accommodation. For instance, Phase 1 remarks how other guests at Snow Mountain frequently complain about CADS using an accessible entrance to the lift, which merges with the front of the main lift line. Additionally, Phase 2 reports that adaptive skiers have been told that they should not be allowed to use the same ski areas as the general public, mainly due to the belief that skiing with a disability, such as blindness is dangerous.

Examples of ableism within the findings are not only directed from other guests at ski 
areas. Phase 2 reports that some parents or guardians of adaptive skiers can be overprotective. This can be in the form of trying to do everything for the child (e.g., not challenging them to overcome obstacles) or in the form of not allowing the child to try new things (e.g., "You are not able to do that"). By the same token, adaptive skiers can doubt their own abilities. According to participants in Phase 2, adaptive skiers might say "I am unable to do it" or "I am not capable of skiing as well or as fast as someone who is non-disabled".

The literature review highlights that "the biggest barriers that people with disabilities encounter are other people" (Disabled World, 2019). When members of society, including persons with disabilities, are surrounded by products, services, and environments that are designed in favour of people without disabilities, ableist attitudes are perpetuated and can be internalized. To enhance inclusion and treatment of persons with disabilities, ability-based design is a practical approach to shift the focus from disability to ability.

\subsubsection{Design with Users}

This thesis advocates for the application of "Design with Users". The literature review discusses that designing with users can add value to the design process by generating appropriate and usable outcomes (Carlson et al., 2014). Phase 3 applies a "Design with Users" approach to collaborate with subject matter experts and target users of adaptive skiing. Phase 3 is inspired by Sanders and Stappers' (2014) participatory design framework, the path of expression, to involve users in design research. The path of 
expression is a valuable generative tool that guides the design researcher, subject matter experts, and target users in the development of recommendations (section 8.1.4, Table 26) for improving the experience of adaptive skiing. These recommendations may offer more desirable outcomes, as they are grounded in real findings and lived experiences. The participatory design approach of Phase 3 is a practical example of the application of "Design with Users".

\subsection{Novel Method}

This thesis touches on the importance of information provision. In Phase 1, the content analysis determined that $68 \%$ of Ontario ski areas do not provide accessibility information on their websites. Phase 2 further explores how people retrieve accessibility information. Although people can seek accessibility information for ski areas in several ways (e.g., calling or emailing a ski area, an Internet search, word of mouth), the limited accessibility information provided by ski areas on their websites appears to be an informational and communicational barrier for skiing.

Existing information provision tools are discussed in the literature review. Whistler's Accessibility Map, Google Local Guides, and AccessNow are resources that aim to reduce or remove barriers by making accessibility information readily available. The opportunity arises to adopt or adapt a similar information provision tool for ski areas.

As a contribution, the researcher invents the use of a ski area map for triangulation in section 7.3.1 (Illustration 44). Future research and design could transform the ski area 
map for triangulation into a tool for information provision.
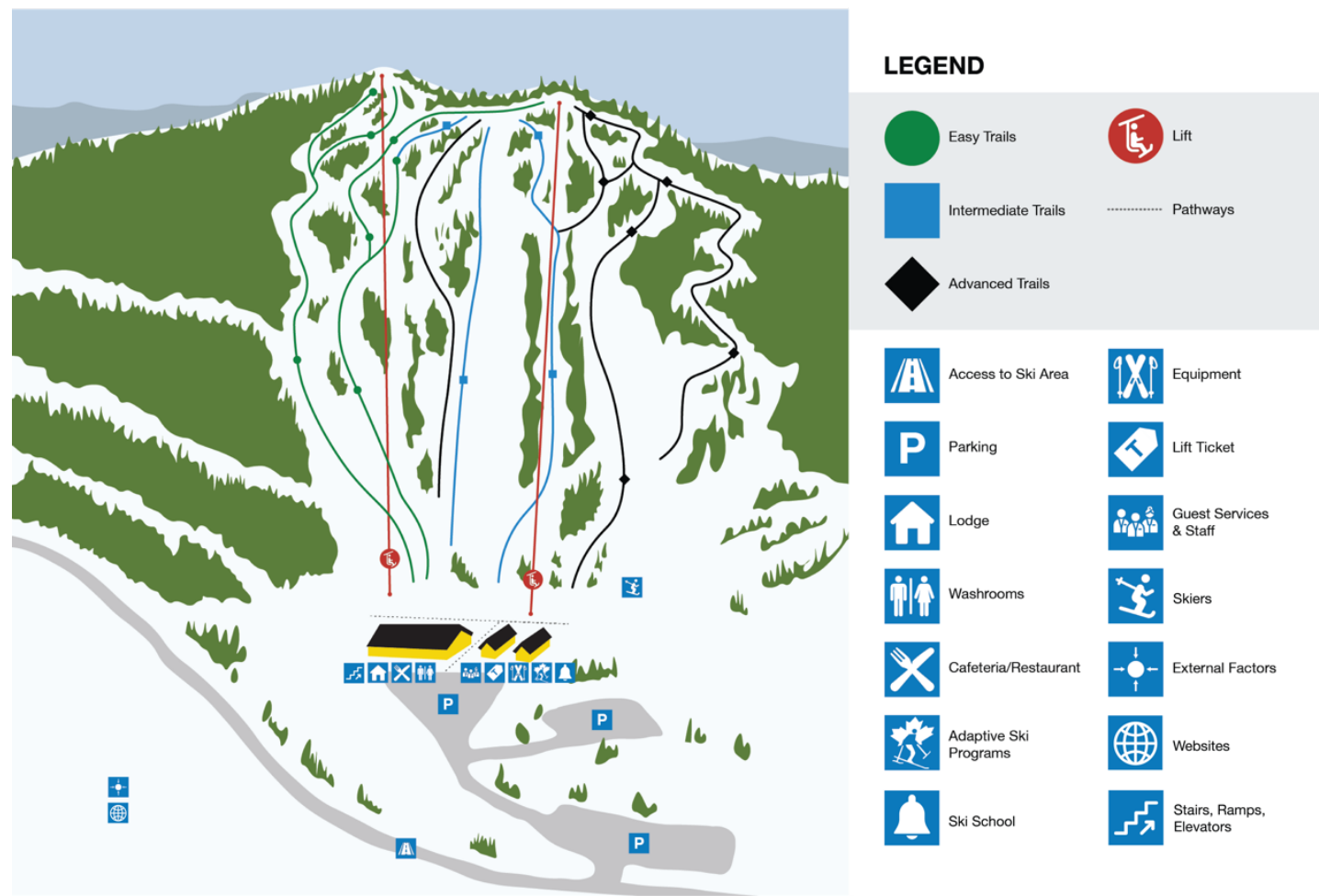

Illustration 44 Ski area map for triangulation from section 7.3.1

Currently, all ski areas use maps to show ski trails, facilities, and services. There may be opportunities for utilizing existing maps to provide accessibility information. To reach more people, the map could be offered online as an interactive accessibility map. The interactive accessibility map could identify where barriers to accessibility might exist, on the slopes, at the ski area, and outside of the ski area. For example, as seen in Illustration 45 , if a user were to select the "Parking" icon, layers of information could expand.

General accessibility information could be outlined, as well as user experiences, photographs, or reviews. The user journey maps from section 6.8 highlight the participants' feelings during each stage of their skiing experiences. As an added layer of information provision, the interactive accessibility map could show these types of user 
emotions. For a larger version of Illustration 45, please refer to Appendix F.
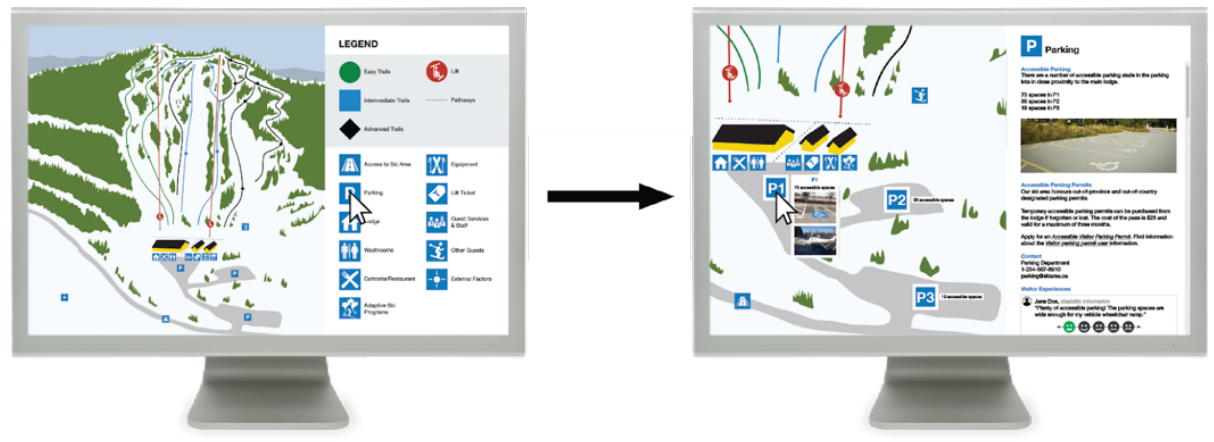

\section{Illustration 45 Interactive Accessibility Map}

As a result of the Accessible Canada Act, ski areas will experience a period of transition while working toward a barrier-free Canada by 2040 . Some barriers may take more time or resources than others to be addressed. In the meantime, the interactive accessibility map could reduce the impact of the remaining barriers to accessibility. Ski areas could use the interactive ski map to identify their barriers to accessibility and enable skiers to make informed decisions based on their individual abilities and disabilities. This interactive accessibility map is a concept. Further research is required, and the map would need to meet accessibility requirements.

\subsection{Limitations}

There are several limitations to this thesis. The first limitation is related to sample bias. All the participants recruited in Phase 1 and Phase 3 are affiliated with CADS. Additionally, Phase 2 includes participants who are also affiliated with CADS or other adaptive ski programs in Canada. Since many of the participants are from the same organization, it is hard to say whether their responses are representative of the attitudes 
and opinions of all adaptive ski programs in Canada. However, due to the range of the participants' relationships to adaptive skiing, there seems to be a diversity of perspectives and experiences with barriers to accessibility for skiing. For example, in the Phase 3 directed storytelling, two out of six of the participants do not identify as having a disability. This sample bias also includes persons with disabilities who have not skied before. The barriers to accessibility may be different for someone starting the sport versus someone who is already participating in it.

The second limitation is related to the accessibility of the questionnaire in Phase 2. The questionnaire is constructed and distributed using Google Forms because it is reportedly compatible with assistive computer devices and software. However, one participant shares the following comment in the questionnaire:

“This survey is not completely keyboard accessible, can't always see the focus when tabbing through this survey; for example, I don't know when the focus is on the 'Next' button, etc.”.

Despite the researcher's efforts, the questionnaire is not entirely accessible. This finding is ironic because the thesis focuses on barriers to accessibility, yet the questionnaire contains a barrier to accessibility. To mitigate issues with accessibility in the future, piloting a questionnaire may be useful in identifying problems with usability. For this study, which recruits persons with diverse abilities, it may have been beneficial to pilot the questionnaire with persons who use assistive computer devices and software, such as 
screen readers, adapted keyboards, voice recognition, wands and sticks, joysticks, sipand-puff systems, trackballs, and much more. Testing a questionnaire with all types of users of assistive computer devices and software may not be feasible. However, there is something to be said about the value of working with users to develop more effective outcomes.

Another limitation emerges from the directed storytelling in Phase 3 and the use of Miro, the online visual collaboration platform. During each directed storytelling session, the researcher shares a link to the Miro board with the participant to enable collaboration and simultaneous editing. Most participants do not end up using Miro as intended. For instance, one participant has a visual impairment and has difficulty seeing the computer screen. Multiple participants use assistive computer devices, such as a stick worn on the head to press keys on the keyboard. Prior to each directed storytelling session, the researcher does not have any knowledge of the participant's abilities and is not able to prepare ahead of time. In addition, some participants join the session on a mobile device rather than a computer. As a result, they have challenges using Zoom and Miro simultaneously. In hindsight, the researcher should have specified in the recruitment email that having access to a computer is recommended for the session.

These unintended experiences encourage the researcher to remain flexible and adapt to accommodate each participant's abilities. For each session, the researcher shares their computer screen so that the participant can follow along on Miro. The researcher types and then orally repeats the participant's responses. This way, the participant can still 
provide input and expand on thoughts or correct the researcher if there is a misunderstanding.

Ultimately, Miro has limitations to accessibility since it is a virtual and visual experience. However, conducting directed storytelling online gathers invaluable information and allows people from across Canada to participate from the comfort of their own homes.

\subsection{Effects of COVID-19 Pandemic on Thesis}

Due to restrictions from the COVID-19 pandemic, some of the research in this thesis is unable to be conducted in-person. Fortunately, the Phase 1preliminary field study takes place in January and February 2020 before the pandemic and is conducted in-person. As a result, the preliminary field study offers rich, contextual, insights that inform and guide the subsequent research phases.

The Phase 2 questionnaire occurs during the pandemic, in September and October 2020 and is conducted online. Even without restrictions, the online format is ideal for recruiting participants across Canada.

The Phase 3 directed storytelling also takes place during the pandemic, in September and October 2020, and is online using Zoom and Miro. Traditionally, participatory design approaches, like directed storytelling are conducted in-person to facilitate collaboration and hands-on design tasks. In-person participatory design can be an immersive sensory experience, while Miro mainly focuses on the visual experience. As a result, some 
persons with disabilities or sensory impairments are unable collaborate in Miro, as intended. Conducting the directed storytelling online is convenient and allows people to participate from the comforts of their own homes. Nevertheless, in an ideal world, inperson participatory design might be easier for a design researcher to accommodate diverse participant abilities.

\subsection{Recommendations for Future Research}

The following sections offer recommendations for future research.

\subsubsection{Evaluation of Design Recommendations}

The design recommendations offered in this thesis are currently ideas for improving accessibility and the experience of skiing. Future research could test and evaluate the effectiveness of the recommendations. Future research may consider studying the recommendations at select ski areas, before expanding to other Canadian ski areas, and examining the application to other countries. There may be value in using the design recommendations to develop guidelines or best practices for addressing barriers to accessibility. In doing so, including more stakeholders in the research and design process may be beneficial for understanding how accessibility is regarded and implemented by ski areas. To elaborate, this thesis studies participants involved in adaptive skiing. Future research could also include ski area owners, management, staff, and operators to further understand the application of the recommendations. More stakeholders may reveal insights about if and how the recommendations could be implemented, and discussions of affordability may be crucial. For example, private sector (ski clubs) and public sector (ski 
resorts) ski areas may have differences in financial resources. Private sector ski areas are often funded by exclusive memberships, while public ski hills and resorts often receive support from the government and various associations, and also benefit from tourism. There is an opportunity in future research to disaggregate private sector and public sector ski areas to understand the affordability and application of the recommendations.

\subsubsection{Severity of Barriers}

This thesis contributes to the identification of barriers to accessibility for skiing. The themes that emerged from the three research phases indicate the number of occurrences in brackets: for example, lodge (171), parking (38), access to ski area (1). This number of occurrences measures the number of times the theme is identified or discussed and is not correlated with severity. Future research may consider studying the importance or the severity of each barrier to prioritize which accessibility issues require the most attention. For example, a research questionnaire could include parameters for asking how important or severe an issue is, not just if it exists.

\subsubsection{Generalizability}

This thesis focuses on ski areas in Canada due to the researcher's skiing experience and proximity. This thesis may be of benefit to the global skiing community, in other countries, such as the United States or Europe. Future research could compare Canada to other countries, such as the United States or Europe, to learn about how they address these accessibility issues. There may be opportunities to identify and examine countries that are leading in accessibility. There may be some limitations in generalization, 
including different contexts, which may have differences in culture or legislative requirements.

Additionally, there may be future research opportunities in exploring this thesis's applications to other areas, outside of alpine skiing. For example, the exploratory sequential design used in this thesis could be generalized to identify and address barriers to accessibility for other adaptive sports, such as cross-country skiing, water skiing, swimming, or basketball.

This thesis is not only of benefit to adaptive athletes. Accessibility can improve the user experience for many people. For example, impairments can be temporary, like a broken bone or a pregnancy; they can also be episodic, like fatigue or difficulties seeing when the environment is too bright or poorly lit. As the literature review points out, Canada has an ageing population. Addressing barriers to accessibility for any environment, product, or services, can benefit a significant portion of the population.

\subsubsection{Disaggregation of Impairments}

This thesis does not focus on a specific type of disability. Subsequent studies could consider a disaggregation based on impairments, which might provide greater focus. Some barriers to accessibility may be unique to specific disabilities or individuals (McKercher and Darcy, 2018). 


\subsubsection{Novel Method: Interactive Accessibility Map}

Another recommendation for future research includes the interactive accessibility map. There may be opportunities for design researchers to develop an interactive accessibility map in collaboration with ski areas to provide accessibility information about facilities and services. Usability testing would be required, as well as the evaluation of the effectiveness of information provision. Above all, the interactive accessibility map would need to be accessible. Ultimately, ski areas across Canada or in other countries could offer interactive accessibility maps to reduce informational and communicational barriers. 


\section{Chapter 9: Conclusion}

Accessible design is a relatively new consideration for ski areas. As a result, skiers with disabilities are experiencing challenges regarding access and inclusion. This research explores how design can be used to identify and address barriers to accessibility for skiing. Three research phases are employed to answer the research question. Phase 1 consists of a preliminary field study that explores the nature of adaptive skiing. Phase 2 consists of a mixed, qualitative, and quantitative questionnaire that gathers insights and examples of lived experiences concerning barriers to accessibility for skiing. Finally, Phase 3 uses directed storytelling to facilitate participatory design. Significant outcomes of Phase 3 include the development of user journey maps, which visualize the user experiences of six participants for skiing. In addition, participants contribute to recommendations for improving the experience of adaptive skiing.

This thesis contributes to the literature in four major ways:

\section{1) Design Recommendations and Practical Approaches:}

The first major research contributions of this thesis are the design recommendations and practical approaches. They are ideas for ski areas to potentially improve accessibility and inclusivity for skiers . With further testing and evaluation, the design recommendations and practical approaches could be implemented across Canada or be recognized by the global skiing community.

\section{2) Identification of Barriers to Accessibility for Skiing:}

The next contribution of this thesis is an overview of barriers to accessibility that people experience when skiing in Canada. This research contribution is provided 
in Tables 4 to 8,10 to 14 , and 17 to 21 . A list of barriers to accessibility for skiing emerges from Phase 1, Phase 2, and Phase 3. This list is important for bringing awareness to accessibility issues and encourages ski areas to consider their own barriers and the experiences of adaptive skiers.

\section{3) Identification of a Novel Method:}

Another contribution is the proposal to develop a novel method: an interactive accessibility map for information provision. While all five types of barriers to accessibility need to be addressed, information provision could lessen the impact of some barriers at ski areas by allowing users to create their own informed decisions. The interactive accessibility map offers opportunities for future design research.

\section{4) Importance of Collaboration:}

The last contribution that this thesis makes to the literature is the importance of collaboration. This thesis applies a design research lens and is guided by usercentered design and participatory design approaches. Design researchers are not always the experts of a topic. Target users and subject matter experts should be included in research and the design process to develop usable and appropriate outcomes.

Accessible and inclusive ski areas will hopefully become a norm in Canada. The removal of barriers to accessibility is being encouraged at federal, provincial, and municipal levels. Predominantly larger ski areas in Canada have begun to consider the experiences of persons with disabilities; the remaining ski areas will need to follow suit. This thesis 
hopes to contribute design recommendations and practical approaches that identify and address barriers to accessibility for skiing. If ski areas across Canada can consistently and thoroughly implement accessibility, skiing can genuinely become a sport for all. 


\section{References}

AccessNow. (2016). AccessNow named Best Product for Social Good by Azure Magazine. Retrieved August 5, 2020, from https://accessnow.ca/blog/accessnownamed-best-product-social-good-azure-magazine/

AccessNow. (2020). Pin pointing accessibility around the world. Retrieved May 26, 2020, from https://accessnow.com/

Angus Reid Institute. (2016, December 2). Disability in Canada: Does closing the accessibility gap literally start from the ground up? Retrieved July 12, 2020, from http://angusreid.org/disability-in-canada/

Barreda, K. (n.d.). Adaptive Skiing. https://adaptiveskiing.net/

Blair-Goldensohn, S., \& LoCoco, K. (2018, October 23). Building a more accessible map thanks to Local Guides from around the world. Retrieved July 18, 2020, from https://www.blog.google/outreach-initiatives/accessibility/accessible-map-localguides-around-world/

Blue Mountain Resorts LP. (2018, May). Multi Year Accessibility Plan. Retrieved January 29, 2021, from https://www.bluemountain.ca/-/media/bluemountain/pdf/aoda_multiyear_accessibility_plan_may2018.ashx

Bradshaw, E. (2019). Disabilities. UWIRE Text. p. 1. Gale Academic OneFile. Retrieved February 2020, from https://linkgalecom.proxy.library.carleton.ca/apps/doc/A582478960/AONE?u=ocul_carleton\&si $\mathrm{d}=\mathrm{AONE} \& \mathrm{xid}=1086 \mathrm{ba} 06$

Byrne, D. (2007). Social Exclusion (2nd ed.). McGraw-Hill Education.

CADS National. (2020). CADS Ski Level 1 Study Guide. Retrieved from 
https://cads.ski/system/education_resources/docs/000/000/024/original/CADS_Sk i_Lv1_Study_Guide_2020.pdf?1610637985

CADS-NCD. (2020, December 03). Winter sports Clinic. Retrieved April 14, 2021, from https://www.cads-ncd.ca/contact-cads-ncd/winter-sports-clinic/

CADS-NCD. (2020, December 08). Ski Hawks Ottawa. Retrieved March 14, 2021, from https://www.cads-ncd.ca/contact-cads-ncd/welcome-to-ski-hawks/

Canadian Adaptive Snowsports. (2019). CADS. Retrieved May 4, 2020, from https://www.cads.ski/

Canadian Institute for Health Information. (2017). Infographic: Canada's seniors population outlook: Uncharted territory. CIHI.

https://www .cihi.ca/en/infographic-canadas-seniors-population-outlookuncharted-

territory\#: :text=Over\%20the\%20next\%2020\%20years, expected\%20to\%20grow $\% 20$ by $\% 2068 \% 25$.\&text=Between\%201977\%20and\%201997\%2C\%20the, expect ed\%20to\%20number\%2010.4\%20million.

Canadian Ski Council. (2021, March 25). Accessible skiing Information: CANADIAN Adaptive Snowsports (CADS): Go SKIING go snowboarding. Retrieved February 14, 2021, from https://www.skicanada.org/ready/accessible-skiing-information/

Carlson, C., Peake, W., Joiner, J. (2014). Letting context speak. Commun. Des. Q. Rev. 2, 34-39

Clandinin, D., \& Connelly, F. (2000). Narrative inquiry: experience and story in qualitative research ( $1^{\text {st }}$ ed.). Jossey-Bass Publishers.

Conference Board of Canada, The. (2018). The Business Case to Build Physically 
Accessible Environments. Ottawa: The Conference Board of Canada.

Cooper, R.A. (1995). Rehabilitation Engineering Applied to Mobility and Manipulation. Institute of Physics Pub.

Council of Ontario Universities. (2013). Understanding Barriers to Accessibility. Retrieved May 22, 2020, from https://www.uottawa.ca/respect/sites/www.uottawa.ca.respect/files/accessibilitycou-understanding-barriers-2013-06.pdf

Creswell, J., \& Creswell, J. (2013). Qualitative inquiry \& research design: choosing among five approaches (3rd ed.). SAGE Publications.

Creswell, J., \& Creswell, J. (2018). Research design: qualitative, quantitative, and mixed methods approaches (Fifth edition.). SAGE Publications, Inc.

Creswell, J., \& Plano Clark, V. (2018). Designing and conducting mixed methods research (Third Edition.). SAGE.

Cross Country Ski de fond Canada. (2018). Paralympic Winter Games. Retrieved November 14, 2019, from https://www .cccski.com/About/History/OurParalympians/Canada-s-Paralympic-History-1976-1998(1).aspx\#.XeRxXpNKgfF

Curry, L., Nunez-Smith, M. (2015). Mixed methods in health sciences research: A practical primer. SAGE.

De Luigi, A. J. (2018). Adaptive sports medicine: a clinical guide. Cham: Springer.

Denzin, N. (1970). Sociological methods: a sourcebook. Aldine Pub. Co. 
Disabled Sports USA. (n.d.). Early History. Retrieved November 14, 2019, from https://www.disabledsportsusa.org/about/our-mission/early-history/

Disabled World. (2017, December 24). Adaptive Skiing: General Overview. Retrieved November 14, 2019, from https://www.disabled-world.com/sports/snow/as.php

Disabled World. (2019, January 05). Disability awareness: Information, programs and dates. Retrieved May 05, 2020, from https://www.disabledworld.com/disability/awareness/

EMarketer. (2014, October 23). Immigrants in Canada: Just How Big Is Their Spending Power? Retrieved July 23, 2020, from https://www.emarketer.com/Article/Immigrants-Canada-Just-How-Big-TheirSpending-Power/1011356

Erlandson, R. (2008). Universal and accessible design for products, services, and processes. CRC Press.

Evenson, S. (2006). Directed Storytelling: Interpreting Experience for Design. In A. Bennett (ed.), Design Studies - Theory and Research in Graphic Design (pp. 231240). Princeton Architectural Press.

Fernie, R. M. (2015). Retrieved from City of Fernie Resort Development Strategy: https://fernie.civicweb.net/document/42950

Fetters, M. D., Curry, L. A., Creswell, J. W . (2013). Achieving integration in mixed methods designs: Principles and practice. Health Care Research, 48(6, Pt. 2), 2134-2156. https://doi-org.proxy.library.carleton.ca/10.1111/1475-6773.12117

Fry, J. (2010). The story of modern skiing. Hanover: University Press of New England. 
Fulton Suri, J. (2013). INFORMING OUR INTUITION: DESIGN RESEARCH FOR RADICAL INNOVATION. In Rotman on Design (p. 110-). University of Toronto Press. https://doi.org/10.3138/j.ctt5hjvq9.23

Galer, D. (2015). Disability Rights Movement in Canada. Retrieved May 15, 2020, from https://www.thecanadianencyclopedia.ca/en/article/disability-rights-movement

Gillham, B. (2007). Developing a questionnaire (2 $2^{\text {nd }}$ ed.). Continuum.

Google. (2021). Google workspace user guide to accessibility. Retrieved March 3, 2021, from https://support.google.com/accessibility/answer/1631886?hl=en

Government of Canada. (n.d.). Justice Laws Website. Retrieved July 2, 2020, from https://laws-lois.justice.gc.ca/eng/Const/page-15.html

Government of Canada. (2021, January 11). Accessibility standards Canada. Retrieved January 13, 2021, from https://accessible.canada.ca/

Government of Ontario. (2021). About accessibility laws. Retrieved February 25, 2021, from https://www.ontario.ca/page/about-accessibility-laws

Hawranik, M. (2020, January 21). Equity or equality? Retrieved January 29, 2021, from https://canadianequality.ca/equity-or-equality/

Holtzblatt, K., \& Beyer, H. (1995). Contextual design. Conference Companion on Human Factors in Computing Systems - CHI ‘95. Doi:10.1145/223355.223737

Huntford, R. (2009). Two planks and a passion: the dramatic history of skiing. London: Continuum.

Isaacson, L. (2020, March 30). Why Make Research Accessible to People with 
Disabilities. Retrieved August 5, 2020, from https://www.curioresearch.net/newsnotes/whyaccessibleresearch

Kouprie, M., \& Visser, F. (2009). A framework for empathy in design: stepping into and out of the user's life. Journal of Engineering Design, 20(5), 437-448. https://doi.org/10.1080/09544820902875033

Laskowski, E.R. (1991). Snow Skiing for the Physically Disabled. Mayo Clinic Proceedings. 66, 160-172

Lape, E. C., Katz, J. N., Losina, E., Kerman, H. M., Gedman, M. A., \& Blauwet, C. A. (2017). Participant-Reported Benefits of Involvement in an Adaptive Sports Program: A Qualitative Study. 10(5), 507-515. Doi: 10.1016/j.pmrj.2017.10.008

Laurel, B. (2003). Design research: methods and perspectives. MIT Press.

Legislative Services Branch. (2020, May 28). Consolidated federal laws of Canada, Accessible Canada Act. Retrieved June 1, 2020, from https://awslois.justice.gc.ca/eng/acts/A-0.6/

Mace, R., Connell, B. R., Jones, M., Mueller, J., Mullick, A., Ostroff, E., . . . Vanderheiden, G. (1997). The center for universal design - universal design principles. Retrieved April 29, 2020, from https://projects.ncsu.edu/ncsu/design/cud/about_ud/udprinciplestext.htm

Manry, K. (2001). Skoki beyond the passes: the story of Western Canada's first backcountry ski lodge. Rocky Mountain Books.

Martin, B., \& Hanington, B. (2012). Universal methods of design 100 ways to research complex problems, develop innovative ideas, and design effective solutions ( $1^{\text {st }}$ edition). Rockport Publishers. 
Mayer, P. (2020, April 29). Wheelblades. Retrieved April 29, 2021, from https://wheelblades.shop

McCauley L., Frankel L. (2020) An Interdisciplinary Framework for Designing Adaptive Snowsports. In: Di Bucchianico G., Shin C., Shim S., Fukuda S., Montagna G., Carvalho C. (eds) Advances in Industrial Design. AHFE 2020. Advances in Intelligent Systems and Computing, vol 1202. Springer, Cham. https://doi.org/10.1007/978-3-030-51194-4_63

McKercher, B., \& Darcy, S. (2018). Re-conceptualizing barriers to travel by people with disabilities. Tourism Management Perspectives, 26, 59-66. https://doi.org/10.1016/j.tmp.2018.01.003

Mitch, W. (2016, September 07). History - sports medicine. Retrieved April 29, 2020, from https://www.mitchmedical.us/sports-medicine-3/history.html

Moden, C. (2019, March 02). Innovations in duct Tape engineering. Retrieved January 29, 2021, from https://sitskiblog.wordpress.com/2019/03/02/duct-tapeengineering/

Moden, C. (2020, November 09). The art of the single tether. Retrieved March 02, 2021, from https://sitskiblog.wordpress.com/2020/11/09/art-of-the-single-tether/

Naef, B., \& Perez-Leclerc, M. (2019). Bill C-81: An Act to Ensure a Barrier-Free Canada (Revised 27 June 2019.). Library of Parliament = Bibliothèque du Parlement.

Nasuti, G., \& Temple, V. A. (2010). The risks and benefits of snow sports for people with disabilities: a review of the literature. International journal of rehabilitation research. Internationale Zeitschrift fur Rehabilitationsforschung. Revue internationale de recherches de readaptation, 33(3), 193-198. 
https://doi.org/10.1097/MRR.0b013e32833638a5

Newell. (2015). Accessibility Design Standards (Second ed., Rep.). Ottawa, ON: City of Ottawa.https://documents.ottawa.ca/sites/documents/files/documents/accessibility _design_standards_en.pdf

Nielsen, L. (2019). Personas - User Focused Design (2nd ed. 2019.). Springer London. https://doi.org/10.1007/978-1-4471-7427-1

Null, R. (2014). Universal design: principles and models (Second edition.). CRC Press.

OECD. (n.d.). Economic Benefits of Improved Accessibility to Transport Systems. OECD Publishing.

Onwuegbuzie, A. J., Bustamante, R. M., Nelson, J. A. (2010). Mixed research as a tool for developing quantitative instruments. Journal of Mixed Methods Research, $4(1), 56-78$.

Patton M. Q. (1999). Enhancing the quality and credibility of qualitative analysis. Health services research, 34(5 Pt 2), 1189-1208.

Plano Clark, V. L., Ivankova, N. V. (2015). Mixed methods research: A guide to the field (Vol.3). SAGE.

Ponti, A. et al. (2020). "Quality of life, concern of falling and satisfaction of the sit-ski aid in sit-skiers with spinal cord injury: observational study." Spinal Cord Ser Cases 6, 8. https://doi.org/10.1038/s41394-020-0257-x

Portales, Rafael Cruces. (2015). "Removing "invisible" barriers: opening paths towards the future of accessible tourism." Journal of Tourism Futures. 
Powder White. (2020, July 7). 10 Inspirational Ski Quotes Of All Time!

https://www.powderwhite.com/expertise/blog/inspirational-ski-quotes/.

Puybaret, E. (2008). Universal declaration of human rights. United Nations.

Resort Municipality of Whistler. (n.d.). RMOW Accessibility Map. Retrieved February, 2021, from https://cdn.whistler.com/s3/pdf/maps/rmow-accessibility-map.pdf

Rick Hansen Foundation. (n.d.). Let's create a world where Everyone can go Everywhere. Retrieved July 20, 2020, from https://www.rickhansen.com/

Rick Hansen Foundation. (2017, April 26). Rick Hansen Foundation Spring 2017 Newsletter: Rick Hansen Foundation. Retrieved July 12, 2020, from https://www.rickhansen.com/news-stories/blog/rick-hansen-foundation-spring2017-newsletter

Saldaña, J. (2013). The coding manual for qualitative researchers ( $2^{\text {nd }}$ ed.). SAGE.

Sanders, E., Brandt, E., \& Binder, T. (2010). A framework for organizing the tools and techniques of participatory design. Proceedings of the $11^{\text {th }}$ Biennial Participatory Design Conference, 195-198. https://doi.org/10.1145/1900441.1900476

Sanders, E., \& Stappers, P. (2012). Convivial toolbox: generative research for the front end of design. BIS.

Sanders, L., \& Stappers, P. (2014). From designing to co-designing to collective dreaming: three slices in time. Interactions (New York, N.Y.), 21(6), 24-33. https://doi.org/10.1145/2670616

Ski Resort Info. (2021). Ski Resorts Canada - Skiing in Canada. Retrieved May 01, 2021, from https://www.skiresort.info/ski-resorts/canada/ 
Statistics Canada. (2017).: Infographic: Canadian Survey on Disability. Retrieved from https://www150.statcan.gc.ca/n1/pub/11-627-m/11-627-m2017008-eng.htm

Steinfeld, E., \& Maisel, J. (2012). Universal design creating inclusive environments. John Wiley \& Sons.

Still, B., \& Crane, K. (2017). Fundamentals of user-centered design: a practical approach. CRC Press.

Templeman, B. (2002). ADAPTIVE SKI PROGRAM. The Santa Fe New Mexican (Santa Fe, N.M.: 1988), W-40-. Whistler, C. f. (2017). WCS Engagement and Planning. Retrieved from http://www.whistlercentre.ca/

Tessier. (2019). Outdoor Adaptive Sports Equipment. http://www.dualski.com/en/

Thiagarajan, S. (2017, July 6). Building a map for everyone. Retrieved from https://www.blog.google/products/maps/building-map-everyone/

TraciC. (2017). How Local Guides can help millions in September. Retrieved from https://www.localguidesconnect.com/t5/Announcements/How-Local-Guides-canhelp-millions-in-September/ba-p/432069

United Nations. (2016). Convention on the rights of persons with Disabilities (CRPD) Enable. Retrieved April 29, 2020, from https://www.un.org/disabilities/documents/COP/cosp9_infographic.pdf

Visser, F., Stappers, P., van der Lugt, R., \& Sanders, E. (2005). Contextmapping: experiences from practice. CoDesign, 1(2), 119-149. https://doi.org/10.1080/15710880500135987 
Watkins, D., \& Gioia, D. (2015). Mixed Methods Research. Oxford University Press.

Webb, E. (1966). Unobtrusive measures: nonreactive research in the social sciences. Rand McNally.

Welsh, M. (2018). Bias in science and communication: a field guide. IOP Publishing. https://doi.org/10.1088/978-0-7503-1311-7

Wheelchair Traveling. (2011). USA and CANADA accessible snow skiing. Retrieved April 28, 2021, from https://www.wheelchairtraveling.com/accessible-adaptivesnow-skiing-usa-canada-wheelchairs-disabled-handicap/

Whistler. (2020, October 20). Accessibility. Retrieved March 12, 2021, from https://www.whistler.ca/services/accessibility

Wobbrock, J., Kane, S., Gajos, K., Harada, S., \& Froehlich, J. (2011). Ability-Based Design: Concept, Principles and Examples. ACM Transactions on Accessible Computing, 3(3), 1-27. https://doi.org/10.1145/1952383.1952384

Woodson, W.E. (1981). Human Factors Design Handbook: Information and Guidelines for the Design of Systems, Facilities, Equipment, and Products for Human Use. McGraw-Hill Book Company, New York.

Younes, D. (2019, February 21). Is accessibility really as expensive as we think? Retrieved February 12, 2021, from https://medium.com/@younesdian123/isaccessibility-really-as-expensive-as-we-think-3dca68456629 


\section{Appendices}

\section{Appendix A}

\section{A.1 Adaptive Ski Programs in Canada}

\begin{tabular}{|c|c|c|}
\hline Program & Division & Location \\
\hline \multirow[t]{10}{*}{ Canadian Adaptive Snowsports } & $\begin{array}{l}\text { National Capital } \\
\text { Division }\end{array}$ & $\begin{array}{ll}\text { 1. } & \text { Calabogie Peaks } \\
\text { 2. } & \text { Mont Cascades } \\
\text { 3. } & \text { Sommet Edelweiss } \\
\text { 4. } & \text { Mount Pakenham } \\
\text { 5. } & \text { Camp Fortune }\end{array}$ \\
\hline & Alberta & $\begin{array}{l}\text { 6. Alliance } \\
\text { 7. Calgary } \\
\text { 8. Cold Lake } \\
\text { 9. Crowsnest Pass } \\
\text { 10. Edmonton } \\
\text { 11. Grande Prairie } \\
\text { 12. Jasper } \\
\text { 13. Lethbridge } \\
\text { 14. Medicine Hat } \\
\text { 15. Red Deer } \\
\text { 16. Tawatinaw Valley }\end{array}$ \\
\hline & Ontario & $\begin{array}{l}\text { 17. Sir Sam's } \\
\text { 18. Horseshoe Resort } \\
\text { 19. Snow Valley Resort } \\
\text { 20. Heights of Horseshoe Ski Club } \\
\text { 21. Haliburton }\end{array}$ \\
\hline & Durham Region & 22. Brimacombe Ski Club \\
\hline & Nova Scotia & $\begin{array}{l}\text { 23. Ski Martock } \\
\text { 24. Ski Wentworth } \\
\text { 25. Ski Ben Eoi }\end{array}$ \\
\hline & $\begin{array}{l}\text { Newfoundland } \\
\text { and Labrador }\end{array}$ & $\begin{array}{l}\text { 26. White Hills Ski Resort } \\
\text { 27. Marble Mountain Resort } \\
\text { 28. Smokey Mountain Ski \& Snowboard } \\
\text { Club }\end{array}$ \\
\hline & New Brunswick & $\begin{array}{l}\text { 29. Poley Mountain } \\
\text { 30. Crabbe Mountain } \\
\text { 31. Sugarloaf Mountain }\end{array}$ \\
\hline & Québec & 32. Saint-Adolphe-d'Howard \\
\hline & Saskatchewan & N/A \\
\hline & Manitoba & N/A \\
\hline BC Adaptive Snowsports & $\mathrm{N} / \mathrm{A}$ & $\begin{array}{l}\text { 33. Kimberley Alpine Resort } \\
\text { 34. RED Mountain Resort } \\
\text { 35. Fernie Alpine Resort }\end{array}$ \\
\hline
\end{tabular}




\begin{tabular}{|c|c|c|}
\hline & & $\begin{array}{l}\text { 36. Panorama Resort } \\
\text { 37. Silver Star Mountain Resort } \\
\text { 38. Whistler Blackcomb } \\
\text { 39. East Kootenays } \\
\text { 40. Sasquatch Mountain Resort }\end{array}$ \\
\hline Adult Disabled Downhill Ski Club & N/A & 41. Mansfield Ski Resort \\
\hline No Limits Adaptive Ski Club & N/A & 42. Searchmont Resort \\
\hline Alpine Ontario Para Race Team & N/A & $\begin{array}{l}\text { 43. Panorama } \\
\text { 44. Tremblant } \\
\text { 45. Kimberly }\end{array}$ \\
\hline Laurentian Adaptive Sports & N/A & 46. Laurentian Ski Hill \\
\hline Ontario Track 3 & N/A & $\begin{array}{l}\text { 47. Alpine Ski Club } \\
\text { 48. Batawa Ski Hill } \\
\text { 49. Beaver Valley Ski Club } \\
\text { 50. Caledon Ski Club } \\
\text { 51. Craigleith } \\
\text { 52. Earl Bales Park } \\
\text { 53. Glen Eden } \\
\text { 54. Hockley Valley Resort } \\
\text { 55. Mt St Louis Moonstone }\end{array}$ \\
\hline Track 3 London & N/A & 56. Boler Mountain \\
\hline $\begin{array}{l}\text { Waterloo Regional Track } 3 \text { Ski } \\
\text { School }\end{array}$ & N/A & 57. Chicopee \\
\hline Ski Adapté Mauricie & N/A & 58. Vallée du Parc \\
\hline $\begin{array}{l}\text { Association du Ski Alpin Adapte en } \\
\text { Abitibi }\end{array}$ & N/A & 59. Mont-Vidéo \\
\hline $\begin{array}{l}\text { Le Massif de Charlevoix Adaptive } \\
\text { Skiing }\end{array}$ & N/A & 60. Le Massif de Charlevoix \\
\hline Rocky Mountain Adaptive & N/A & $\begin{array}{l}\text { 61. Sunshine Village Ski Resort } \\
\text { 62. Lake Louise } \\
\text { 63. Nakiska Ski Area }\end{array}$ \\
\hline Northern Adaptive Snowsports Club & N/A & 64. Hudson Bay Mountain \\
\hline People in Motion & N/A & $\begin{array}{l}\text { 65. Big White Ski Resort } \\
\text { 66. Baldy Mountain Resort }\end{array}$ \\
\hline $\begin{array}{l}\text { Saskatchewan Adaptive Snow Ski } \\
\text { Club }\end{array}$ & N/A & 67. Table Mountain Regional Park \\
\hline Regina Alpine Adaptive Ski Program & N/A & 68. Mission Ridge Winter Park \\
\hline Adaptive Sports at Sun Peaks & N/A & 69. Sun Peaks Mountain Resort \\
\hline Caledonia Adaptive Snowsports & N/A & 70. Prince George \\
\hline
\end{tabular}




\begin{tabular}{|c|c|c|}
\hline Society & & $\begin{array}{l}\text { 71. Purden } \\
\text { 72. Tabor } \\
\text { 73. Murray Ridge } \\
\text { 74. Troll } \\
\text { 75. Hart Highlands }\end{array}$ \\
\hline Vancouver Adaptive Snow Sports & N/A & $\begin{array}{l}\text { 76. Grouse Mountain } \\
\text { 77. Seymour Mountain } \\
\text { 78. Cypress Mountain }\end{array}$ \\
\hline $\begin{array}{l}\text { Vancouver Island Society for } \\
\text { Adaptive Snowsports }\end{array}$ & N/A & $\begin{array}{l}\text { 79. Mount Washington Alpine } \\
\text { Resort }\end{array}$ \\
\hline
\end{tabular}




\title{
Appendix B
}

\section{B.1 Research Ethics Protocol: Phase 1}

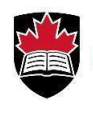

\author{
Office of Research Ethics
}

CARLETON UNIVERSITY

\section{Research Ethics Protocol Form}

This is the primary CUREB study submission form, to be used when none of the other submission forms, intended for more specialized categories of research, are suitable. If you have any doubt about which form to use, or for help in completing this form, please contact the Office of Research Ethics at ethics@carleton.ca or by phone: 6135202600 ext. 2517 (CUREB A) or ext. 4085 (CUREB B).

Please submit this form, and all accompanying documents, through cuResearch. For further instructions, go to https://carleton.ca/researchethics/submit-an-application/.

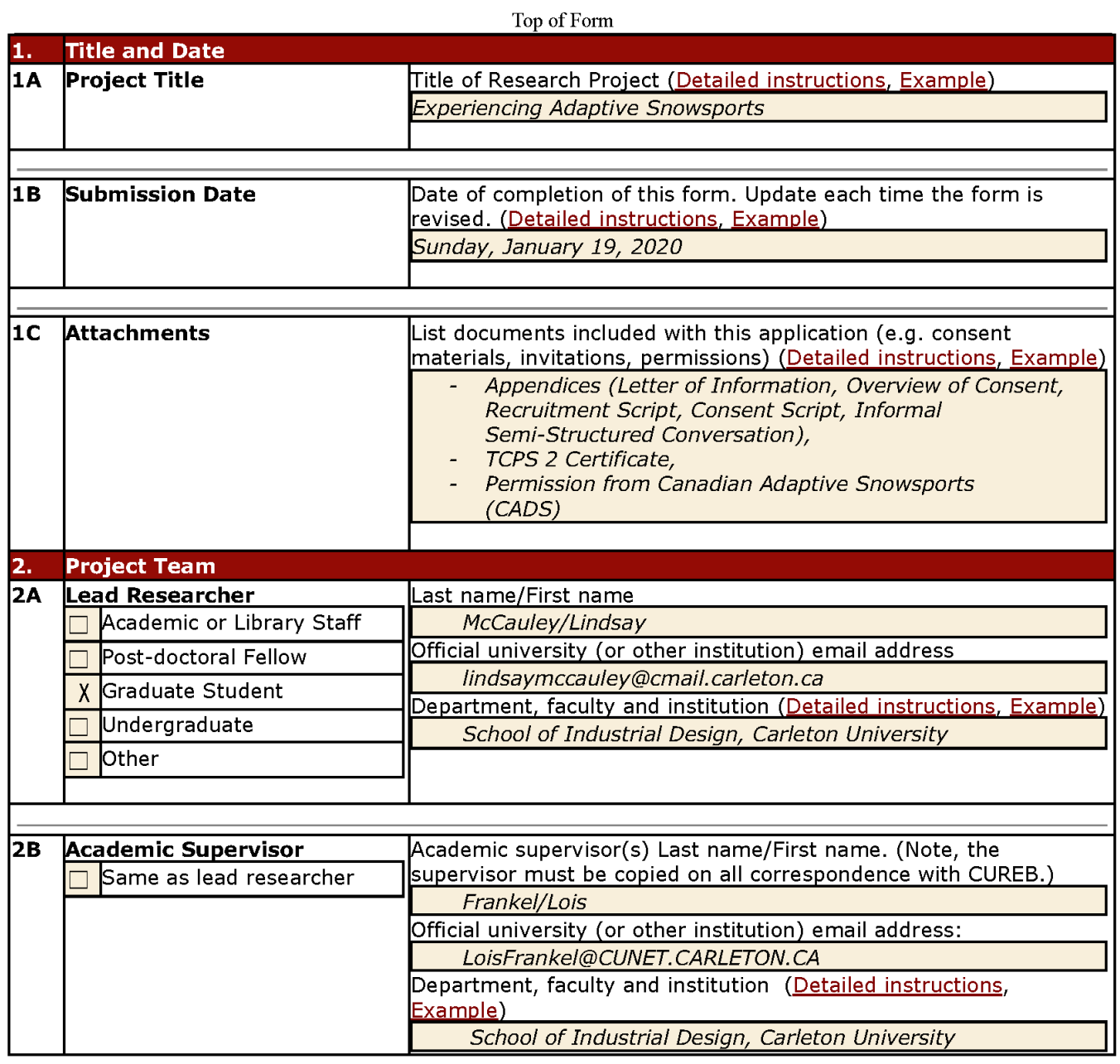

Form Version: April 2019 


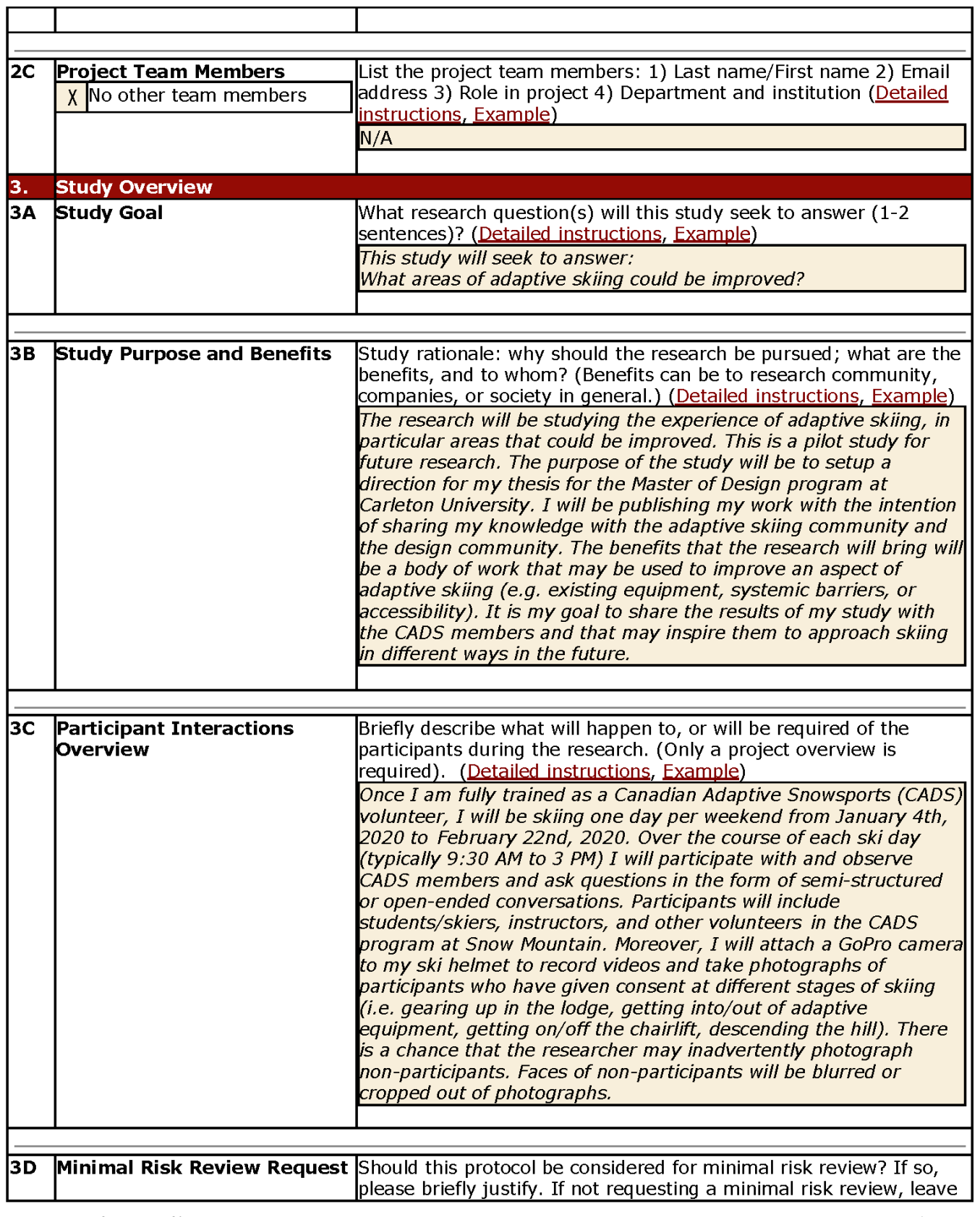

Form Version: April 2019 


\begin{tabular}{|c|c|c|}
\hline & \begin{tabular}{|l|l|}
$X$ & Yes, minimal risk review \\
$\square$ & No, not minimal risk \\
\end{tabular} & $\begin{array}{l}\text { this section blank. (CUREB will decide whether an application is } \\
\text { reviewed at full board or via a delegated process). (Detailed } \\
\text { instructions, Example) }\end{array}$ \\
\hline & & $\begin{array}{l}\text { Interaction phase: The participant group is not exposed to any } \\
\text { more risk than they would experience in participating in CADS } \\
\text { regularly. } \\
\text { Management phase: Data will only be accessible to the research. } \\
\text { Participant names will be stored securely separately from data. } \\
\text { Participant identifiers will include type of adaptive equipment and } \\
\text { disability. There are no anticipated risks to participants. } \\
\text { Interpretation phase: Video recordings and photographs will allow } \\
\text { me to crosscheck data analysis to ensure accuracy of } \\
\text { interpretation. There are no anticipated risks. }\end{array}$ \\
\hline $3 \mathrm{E}$ & $\begin{array}{l}\text { Dates of } \\
\text { Recruitment/Participant }\end{array}$ & $\begin{array}{l}\text { Estimated date when will you will start recruiting participants? } \\
\text { (YYYY-MM-DD) }\end{array}$ \\
\hline & Interaction & $2020-01-26$ \\
\hline & & $\begin{array}{l}\text { Estimated date when you will end participant interactions? } \\
\text { (YYYY-MM-DD) (Detailed instructions, Example) }\end{array}$ \\
\hline & & $2020-03-21$ \\
\hline $3 \mathbf{F}$ & Additional Reviews & Has this project been reviewed for academic merit? (not required, \\
\hline & \begin{tabular}{|l|l|}
$\mathrm{X}$ & No additional review \\
\end{tabular} & but for the Board's information) By whom? (e.g. a Tri-Council grant \\
\hline & \begin{tabular}{|l|l|} 
& Departmental review \\
\end{tabular} & tudent's thesis committee) (Detalled instructlons, \\
\hline & \begin{tabular}{|l|l} 
Grant council review \\
\end{tabular} & \\
\hline 4. & Methods: Participants & \\
\hline 4A & Description of Participants & $\begin{array}{l}\text { Describe the participants and any inclusion and exclusion criteria. If } \\
\text { using a separate sample of control participants, describe this } \\
\text { group. (Detailed instructions, Example) } \\
\text { Participants must be members of CADS, be located at Snow } \\
\text { Mountain, speak English or French, and be at least } 15 \text { years of age. } \\
\text { Participants will include: } \\
\text { 1) Student members: CADS students have physical and/or } \\
\text { cognitive impairments, thus use adaptive skiing equipment. } \\
\text { Students can be skiing at any level. } \\
\text { 2) Instructor members: CADS instructors can certified at any } \\
\text { level and can be new or experienced in the program } \\
\text { 3) Volunteer members: CADS volunteers must be trained and } \\
\text { can be new or experienced in the program }\end{array}$ \\
\hline 4B & $\begin{array}{l}\text { Number of Participants } \\
\text { (Sample size) }\end{array}$ & $\begin{array}{l}\text { How many participants will be recruited? If multiple groups of } \\
\text { participants are involved, breakdown by participant type. Provide a } \\
\text { justification including a statistical rationale if appropriate. (Detailed } \\
\text { instructions, Example) }\end{array}$ \\
\hline & & $\begin{array}{l}\text { Each season, CADS at Snow Mountain serves approximately } 60 \\
\text { students and has over } 100 \text { instructors/volunteers. I would like to }\end{array}$ \\
\hline
\end{tabular}

Form Version: April 2019 


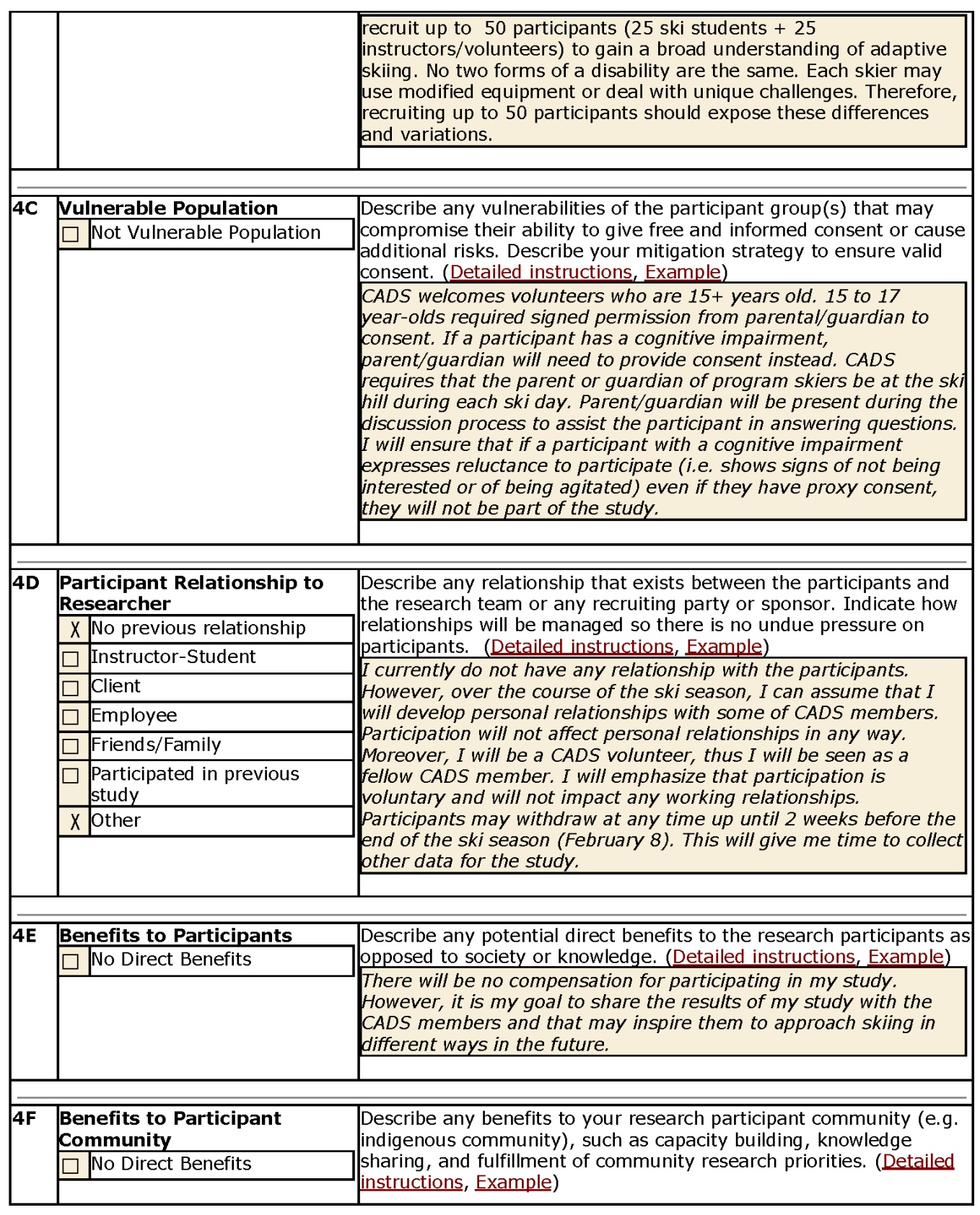

Form Version: April 2019 


\begin{tabular}{|c|c|c|}
\hline & & $\begin{array}{l}\text { Benefits to adaptive sking community: the end result of my } \\
\text { research will be a body of work that will attempt to improve an } \\
\text { aspect of the experience of adaptive skiing. My thesis will make a } \\
\text { contribution to the design of adaptive skiing and be accessible to } \\
\text { the public. } \\
\text { As a volunteer, I assume that I will build working relationships with } \\
\text { CADS members(i.e. cooperation between volunteer-student, } \\
\text { volunteer-volunteer, volunteer-instructor). We will only meet at Snow } \\
\text { Mountain I do not only want to be seen as a researcher. I want to } \\
\text { be trusted and have a relationship of reciprocity, where I will be } \\
\text { able to share the results of the study as a way to give back to the } \\
\text { CADS community. In addition, I would like to maintain a long term } \\
\text { working relationship with CADS, even once my research is } \\
\text { complete. }\end{array}$ \\
\hline \multirow[t]{5}{*}{$4 \mathbf{G}$} & Conflict of Interest & \multirow{5}{*}{$\begin{array}{l}\text { Describe any conflicts of interest, and indicate how they will be } \\
\text { managed. (Detailed instructions, Example) }\end{array}$} \\
\hline & \begin{tabular}{|l|l}
$\wedge$ & Financial benefit to \\
\end{tabular} & \\
\hline & researcher & \\
\hline & $\square$ Benefit to Corporation & \\
\hline & $\square$ Other & \\
\hline \multirow[t]{3}{*}{$4 \mathrm{H}$} & $\begin{array}{l}\text { Researcher Training with } \\
\text { Participant Group }\end{array}$ & \multirow{2}{*}{$\begin{array}{l}\text { In addition to the TCPS2 training, describe any additional training } \\
\text { the researcher(s) have (or will receive) to work with the proposed } \\
\text { participants (e.g. research with Indigenous communities). (Detailed } \\
\text { instructions, Example, TCPS2 Training) }\end{array}$} \\
\hline & \multirow[t]{2}{*}{\begin{tabular}{|l|l|}
$\square$ Not applicable \\
\end{tabular}} & \\
\hline & & $\begin{array}{l}\text { I am registered to be a CADS volunteer at Snow Mountain for the } \\
2020 \text { ski season. This will allow me to ski every weekend with } \\
\text { disabled skiers (individuals who have cognitive and physical } \\
\text { disabilities). On December 14, 2019, I will be attending a New } \\
\text { Volunteer Training session where I will be introduced to the } \\
\text { program and how CADS operates. On December } 28-29,2019 \text { I will } \\
\text { be attending a Sit Ski Tethering Training Clinic where I will receive } \\
\text { instruction and practical training for tethering a sit ski. }\end{array}$ \\
\hline 5. & \multicolumn{2}{|c|}{ Indigenous Peoples and Community Engagement } \\
\hline \multirow[t]{5}{*}{ 5A } & \multicolumn{2}{|c|}{$\begin{array}{l}\text { Research involving Indigenous / Aboriginal peoples } \\
\text { If none of the statements are applicable, skip this section (Detailed instructions, Example) }\end{array}$} \\
\hline & \multicolumn{2}{|c|}{\begin{tabular}{|l|l|l}
$\square$ & Recruitment criteria includes Indigenous identity as a significant factor \\
\end{tabular}} \\
\hline & \multicolumn{2}{|c|}{\begin{tabular}{|l|l}
$\square$ & Study will seek input from participants regarding Indigenous communities, cultures, artifacts, \\
traditional knowledge or unique characteristics
\end{tabular}} \\
\hline & \multicolumn{2}{|r|}{ 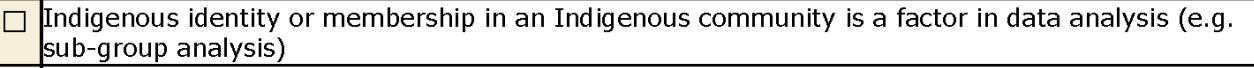 } \\
\hline & \multicolumn{2}{|c|}{\begin{tabular}{|l|l|}
$\square$ & $\begin{array}{l}\text { Interpretation of the research findings will refer to Indigenous communities, peoples, languages, } \\
\text { histories or cultures }\end{array}$ \\
\end{tabular}} \\
\hline
\end{tabular}




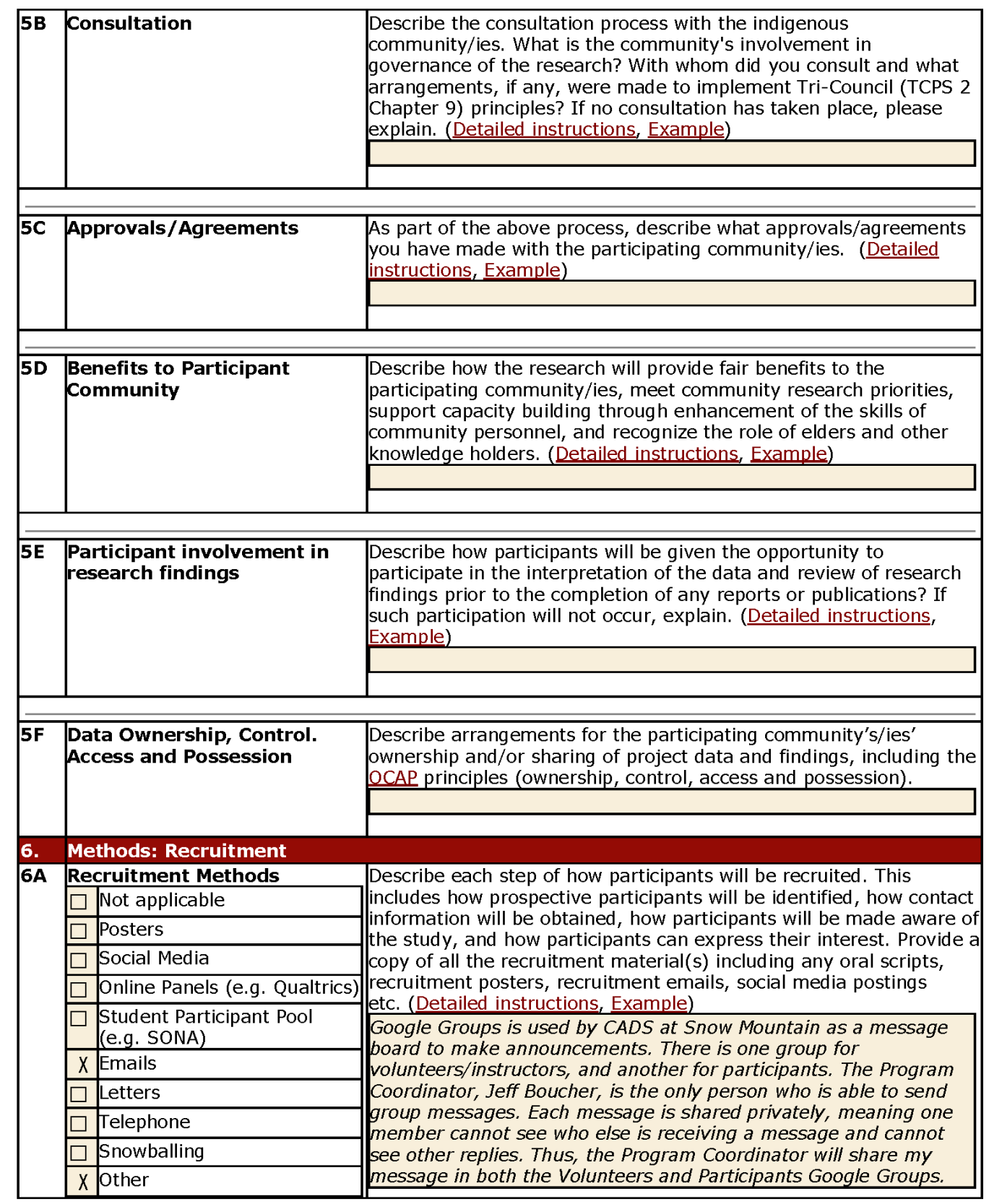

Form Version: April 2019 


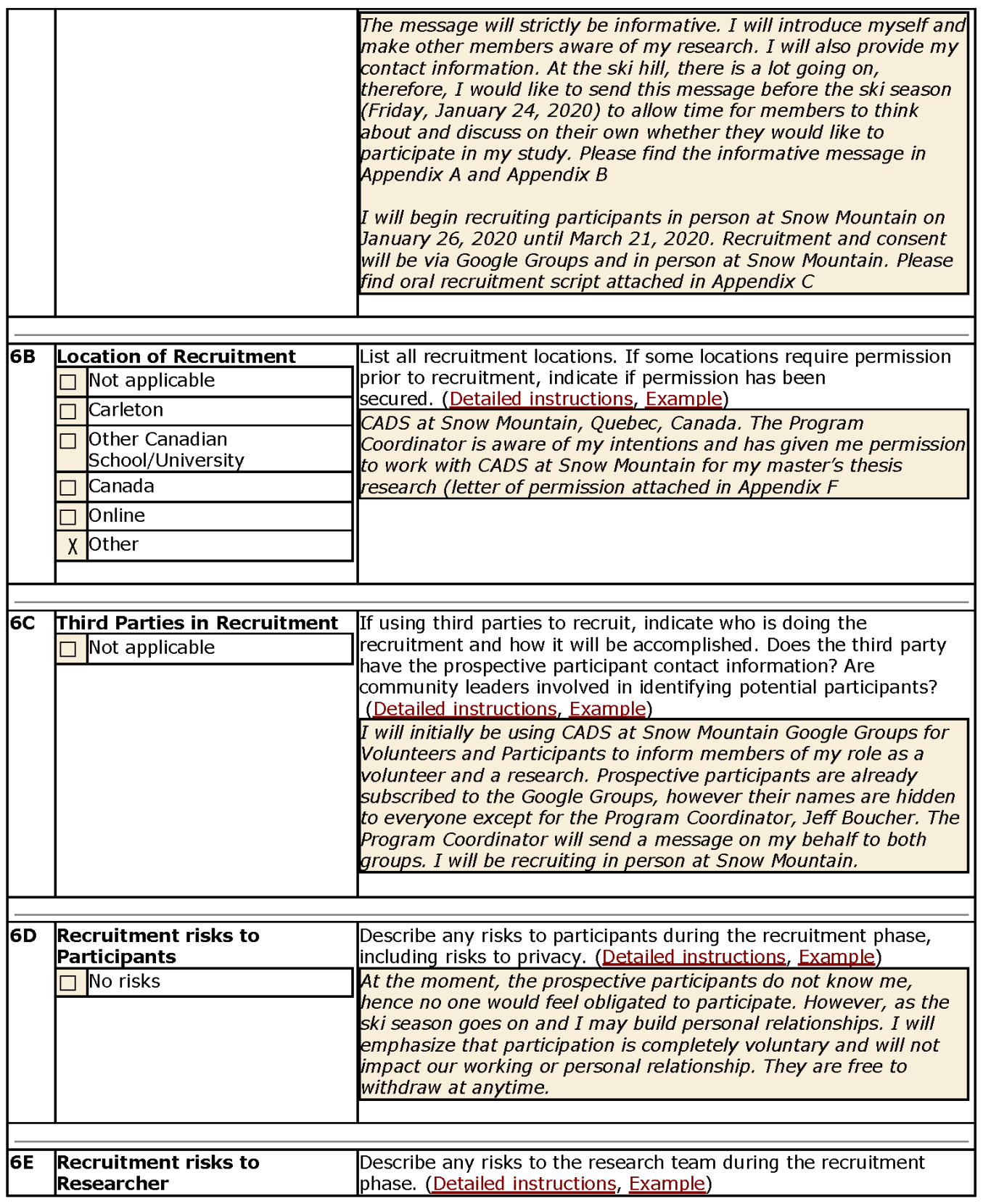

Form Version: April 2019 


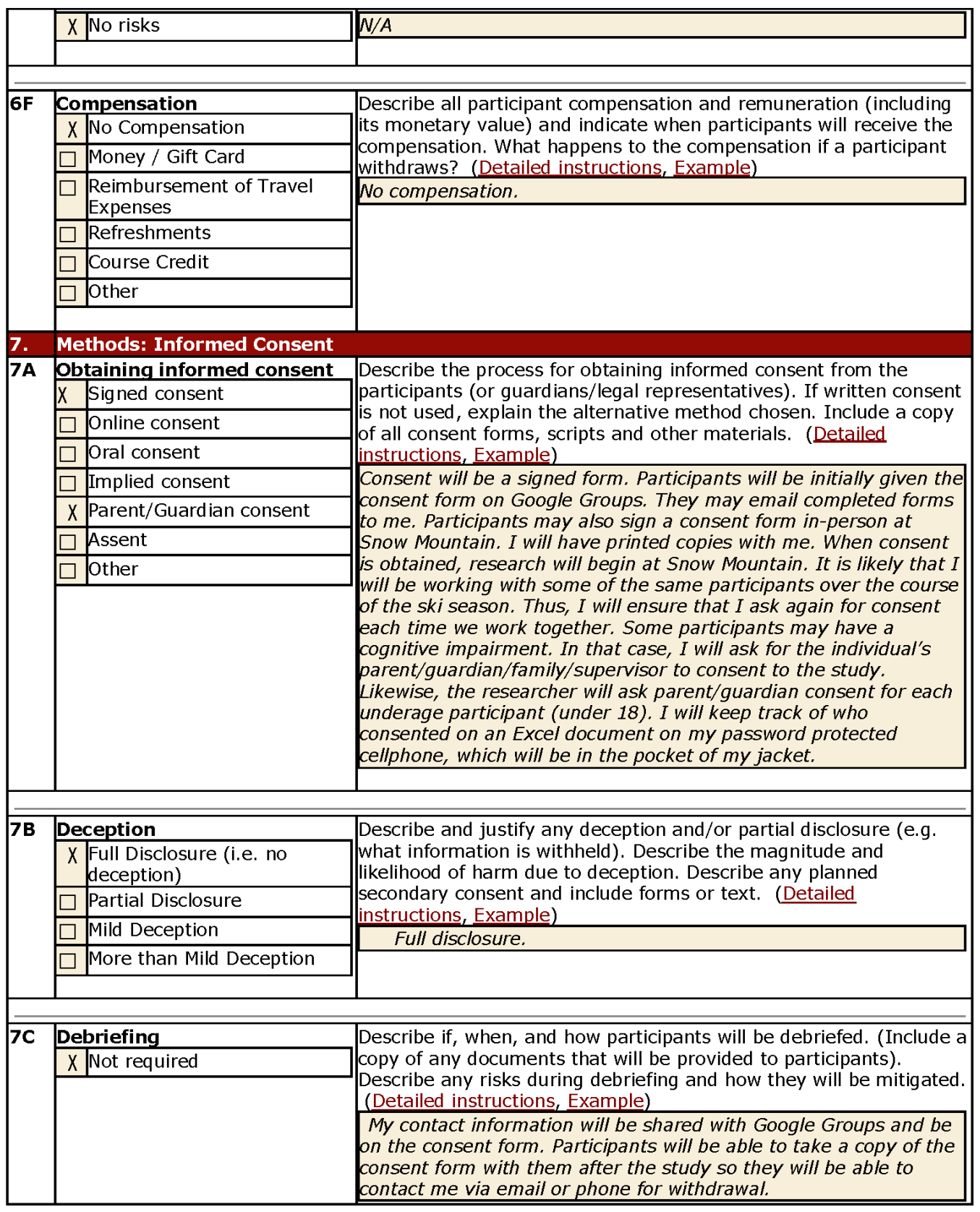

Form Version: April 2019 


\begin{tabular}{|c|c|c|}
\hline & & \\
\hline & & \\
\hline 7D & Withdrawal Procedures & Describe the procedures for a participant to withdraw. What will \\
\hline & \begin{tabular}{|l|l|}
$\square$ & Not applicable \\
\end{tabular} & happen to data from participants who withdraw? Describe any \\
\hline & \begin{tabular}{l|l}
$\mathrm{X}$ & Participants can withdraw
\end{tabular} & $\begin{array}{l}\text { deadlines and limitations on withdrawal, during the study or after } \\
\text { research participation is complete Explain if compensation amount }\end{array}$ \\
\hline & \begin{tabular}{|l|l}
$\square$ Participants can only \\
\end{tabular} & is affected by withdrawal. (Detailed instructions, Example) \\
\hline & \begin{tabular}{|l} 
withdraw during the study \\
session
\end{tabular} & $\begin{array}{l}\text { Participants can only withdraw up to February } 23,2020, \text { as this is } \\
\text { when data analysis begins. Participants can tell me in person, }\end{array}$ \\
\hline & \begin{tabular}{|l|l|}
$\square$ & $\begin{array}{l}\text { Special withdrawal } \\
\text { procedures }\end{array}$ \\
\end{tabular} & $\begin{array}{l}\text { email me, or call me if they wish to withdraw their semi-structured } \\
\text { interview, video-recording or photographs. In which case, I will }\end{array}$ \\
\hline & \begin{tabular}{|l|l|}
$\square$ & $\begin{array}{l}\text { Full compensation to } \\
\text { withdrawn participants }\end{array}$ \\
\end{tabular} & delete the data. \\
\hline & 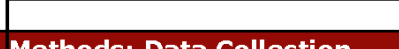 & \\
\hline 8. & Methods: Data Collection & \\
\hline $\mathbf{8 A}$ & Data Collection Methods & Describe in detail the method of data collection being used and \\
\hline & $\square$ Questionnaires / Surveys & provide details of any instruments used. Breakdown by phases, \\
\hline & \begin{tabular}{|l|l|}
$\mathrm{X}$ & Interviews \\
\end{tabular} & 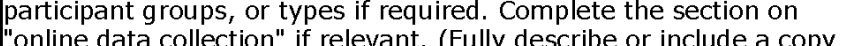 \\
\hline & \begin{tabular}{|l|l|}
$\square$ & Focus Groups \\
\end{tabular} & of any questionnaires, surveys, interview guides, or other data \\
\hline & \begin{tabular}{|l|l|}
$\square$ & Oral and/or Visual Stimuli \\
\end{tabular} & collection instruments). (Detailed instructions, Example) \\
\hline & \begin{tabular}{|l|l|}
$\square$ & $\begin{array}{l}\text { Equipment and/or software } \\
\text { testing }\end{array}$ \\
\end{tabular} & $\begin{array}{l}\text { 1) Informal, semi-structured conversations: the purpose of } \\
\text { this method is to ask (1) clarification questions, and (2) }\end{array}$ \\
\hline & \begin{tabular}{|l|l|}
$X$ & Other \\
\end{tabular} & conducting or setting up interviews, but rather talking with \\
\hline & & $\begin{array}{l}\text { participants during a ski day at Snow Mountain. Please find } \\
\text { questions attached in Appendix E } \\
\text { 2) Participant observation: the purpose of this method will be } \\
\text { to enhance my understanding of adaptive skiing as a whole, } \\
\text { as well as on the individual level. Observing will provide me } \\
\text { with a source of questions to engage in casual conversation } \\
\text { with participants. I will be using a Sensory framework for } \\
\text { guidelines for observations (Appendix G). I will also be } \\
\text { using the AEIOU structure to organize my observations } \\
\text { (please find attached in Appendix H). }\end{array}$ \\
\hline & & \\
\hline 8B & $\begin{array}{l}\text { Location of Participant } \\
\text { Interactions }\end{array}$ & $\begin{array}{l}\text { Where will the research procedures involving participants take } \\
\text { place? (Detailed instructions, Example) }\end{array}$ \\
\hline & $\square$ Carleton & Snow Mountain is a ski area located in Wakefield, QC and \\
\hline & \begin{tabular}{|l|l|}
$\square$ & Workplace \\
\end{tabular} & Saint-Sauveur/Avila, Piedmont, $Q C$ \\
\hline & \begin{tabular}{|l|l}
$\square$ & Public venue \\
\end{tabular} & \\
\hline & \begin{tabular}{|l|l|}
$\square$ & Online \\
\end{tabular} & \\
\hline & \begin{tabular}{|l|l|}
$\square$ & Outside Canada \\
\end{tabular} & \\
\hline & \begin{tabular}{l|l}
$\mathrm{x}$ & Other \\
\end{tabular} & \\
\hline $8 C$ & $\begin{array}{l}\text { Frequency and Duration of } \\
\text { Participant Interactions }\end{array}$ & $\begin{array}{l}\text { How many times will you interact with participants? How long will } \\
\text { each interaction take? (Detailed instructions, Example) }\end{array}$ \\
\hline
\end{tabular}

Form Version: April 2019 


\begin{tabular}{|c|c|c|}
\hline & & $\begin{array}{l}\text { Over the ski season, I will be interacting with a variety of } \\
\text { participants once a week from 9:30 AM to 3:00 PM. Participation } \\
\text { will be informal, as some participants may join and leave. }\end{array}$ \\
\hline \multirow[t]{7}{*}{ 8D } & Photography or Recordings & \multirow{5}{*}{$\begin{array}{l}\text { If the participant will be photographed, video-recorded or } \\
\text { audio-recorded, indicate how the data will be acquired and } \\
\text { protected. How will consent for recordings be obtained? If other } \\
\text { (e.g. fingerprints or eye-tracking) please describe. Can participants } \\
\text { opt out of recordings and still participate? (Detailed instructions, } \\
\text { Example) }\end{array}$} \\
\hline & \begin{tabular}{|l|l|}
$\square$ & Not applicable \\
\end{tabular} & \\
\hline & \begin{tabular}{|l|l|}
$\mathrm{X}$ & Photographs \\
\end{tabular} & \\
\hline & $\square$ Audio Recording & \\
\hline & \begin{tabular}{|l|l|}
$X$ & Video Recording \\
\end{tabular} & \\
\hline & \begin{tabular}{|l|l|}
$\square$ & Other (Please describe) \\
\end{tabular} & \multirow[b]{2}{*}{$\begin{array}{l}\text { Photographs: I will take photographs of adaptive equipment, } \\
\text { participant interactions, and overall skiing and related activities, } \\
\text { Participant consent will be obtained prior to taking any } \\
\text { photographs. Participants will be told in the consent that they may } \\
\text { still participate if they do not wish to be photographed. Photos will } \\
\text { be saved on my password protected personal, external harddrive. } \\
\text { Participant faces will be blurred in the photographs to conceal } \\
\text { identity. } \\
\text { Video-recording: Video-recording will be taken to analyze } \\
\text { participant behaviour. Participant consent will be obtained prior to } \\
\text { conducting any video recording. Participants will be told in the } \\
\text { consent that they may still participate if they do not wish to be } \\
\text { video recorded. All faces will be blurred in video-recordings. } \\
\text { Footage will be saved on my password protected personal, external } \\
\text { harddrive. Video will not be used in future publications. Edited } \\
\text { video footage will be kept for } 5 \text { years and destroyed at that time. } \\
\text { vidis }\end{array}$} \\
\hline & & \\
\hline & & \\
\hline \multirow[t]{5}{*}{$8 \mathrm{BE}$} & Translation or Transcription & \multirow{3}{*}{$\begin{array}{l}\text { If you require the services of a translator or transcriber, describe } \\
\text { what services you will use and how you will interact with the } \\
\text { translator and/or transcriber. If a confidentiality agreement will be } \\
\text { used, include a copy. (Detailed instructions, Example) }\end{array}$} \\
\hline & \begin{tabular}{|l|l|}
$\mathrm{X}$ & Not applicable \\
\end{tabular} & \\
\hline & \begin{tabular}{|l|l|}
$\square$ & Translation \\
\end{tabular} & \\
\hline & \begin{tabular}{|l|l}
$\square$ & Transcription \\
\end{tabular} & $N / A$ \\
\hline & \begin{tabular}{|l|l|}
$\square$ & $\begin{array}{l}\text { Researcher will translate or } \\
\text { transcribe }\end{array}$ \\
\end{tabular} & \\
\hline & & \\
\hline \multirow[t]{6}{*}{$\mathbf{8 F}$} & Online data collection & \multirow{3}{*}{$\begin{array}{l}\text { Describe the software platform used for online data collection, and } \\
\text { the security of data storage. Where will data be stored? Will } \\
\text { participant IP addresses be recorded? Are there any special } \\
\text { limitations on privacy? (Detailed instructions, Example) }\end{array}$} \\
\hline & \begin{tabular}{|l|l|}
$\mathrm{X}$ & Not applicable \\
\end{tabular} & \\
\hline & \begin{tabular}{|l|l} 
& Carleton-based server \\
\end{tabular} & \\
\hline & \begin{tabular}{|l|l|} 
Commercial server (based in \\
Canada)
\end{tabular} & \multirow[t]{3}{*}{$N / A$} \\
\hline & \begin{tabular}{|l|l|} 
& Canada) \\
$\square$ & $\begin{array}{l}\text { Commercial server (outside } \\
\text { Canada) }\end{array}$ \\
\end{tabular} & \\
\hline & \begin{tabular}{|l|l}
$\square$ & Other \\
\end{tabular} & \\
\hline $8 \mathbf{8 G}$ & \begin{tabular}{|l|l|} 
Biological specimens or fluids \\
$X$ & Not applicable \\
\end{tabular} & $\begin{array}{l}\text { Describe the apparatus and methods to collect biological specimens } \\
\text { or fluids (e.g., blood, saliva, tissue samples). How will specimens be } \\
\text { stored? If any will be retained or transferred to another }\end{array}$ \\
\hline
\end{tabular}

Form Version: April 2019 


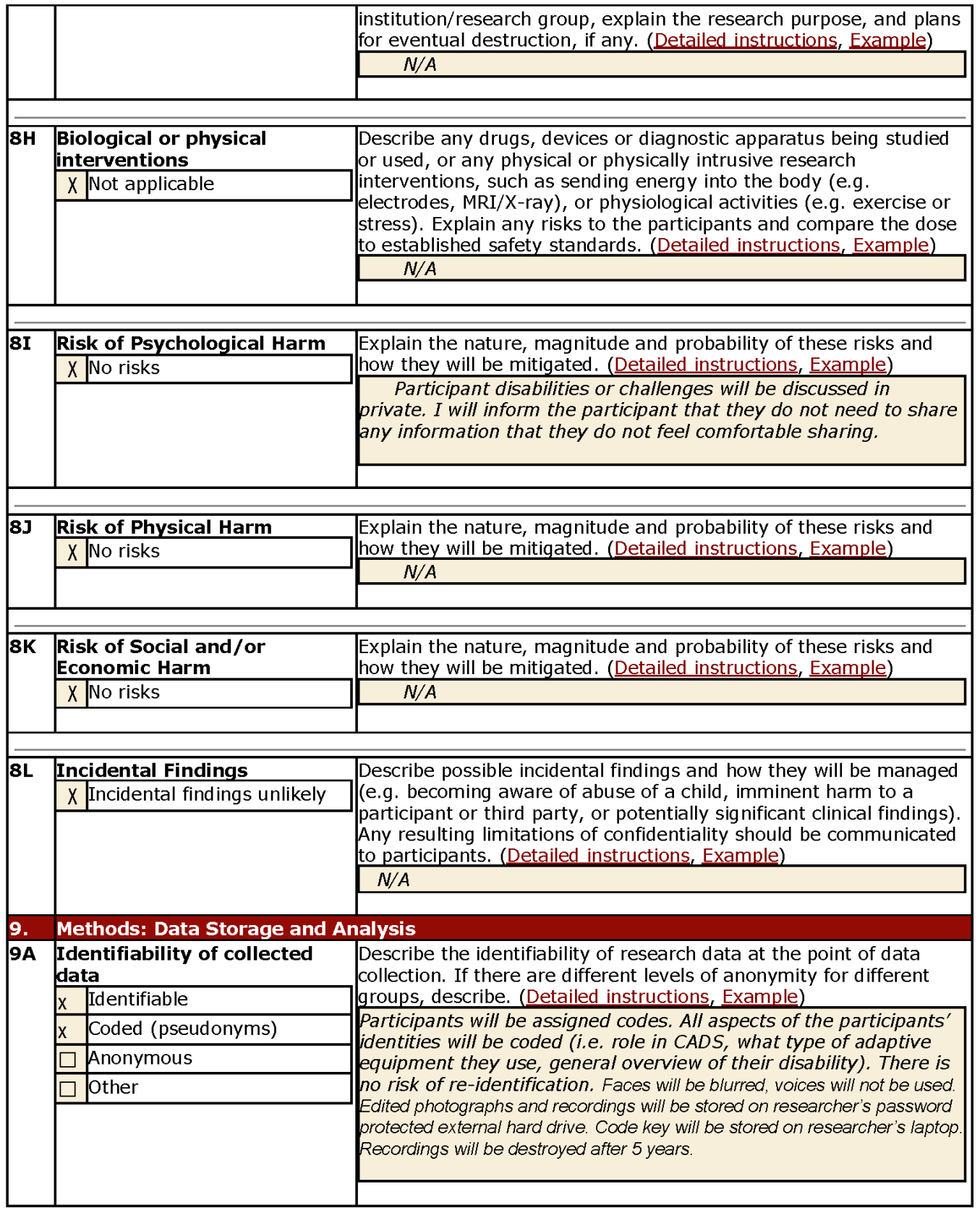

Form Version: April 2019 


\begin{tabular}{|c|c|c|}
\hline \multirow[t]{6}{*}{ 9B } & Identifiability of stored data & \multirow{4}{*}{$\begin{array}{l}\text { Describe the identifiability of stored research data. If a link to } \\
\text { participant identities is retained (e.g. to permit compensation or } \\
\text { withdrawal), also explain storage of linking data. Describe the } \\
\text { process of anonymization if applicable. (Detailed instructions, } \\
\text { Example) }\end{array}$} \\
\hline & \begin{tabular}{l|l}
$X$ & Identifiable \\
\end{tabular} & \\
\hline & \begin{tabular}{|l|l|}
$X$ & Coded (pseudonyms) \\
\end{tabular} & \\
\hline & $\square$ Anonymous/anonymized & \\
\hline & \begin{tabular}{|l|l} 
& Other \\
\end{tabular} & \multirow{2}{*}{$\begin{array}{l}\text { Each consent form/participant will be given a code. Consent forms and } \\
\text { codes will be stored on a password protected folder in the researcher's } \\
\text { personal, password protected laptop. Next, on the researcher's password } \\
\text { protected external hard drive, raw data will be de-identified an assigned a } \\
\text { corresponding participant code. Faces will be blurred in photographs and } \\
\text { videos. Raw data/original footage refers to unedited video recordings and } \\
\text { photographs. Raw data will not be saved and will be replaced with versions } \\
\text { with blurred faces. }\end{array}$} \\
\hline & & \\
\hline \multirow[t]{6}{*}{$9 \mathrm{C}$} & $\begin{array}{l}\text { Identifiability of published } \\
\text { data }\end{array}$ & \multirow{3}{*}{$\begin{array}{l}\text { Describe the identifiability of data that will appear in publications, } \\
\text { including how pseudonyms will be assigned, if applicable. If there } \\
\text { are different levels of anonymity for different groups, describe each } \\
\text { level here. (Detailed instructions, Example) }\end{array}$} \\
\hline & \begin{tabular}{l|l} 
\\
\end{tabular} & \\
\hline & \begin{tabular}{|l|l} 
& Aggregate data only \\
\end{tabular} & \\
\hline & \begin{tabular}{l|l}
$\mathrm{X}$ & Pseudonyms/Coded \\
\end{tabular} & \multirow{3}{*}{$\begin{array}{l}\text { Participants will be categorized either as a CADS Student, } \\
\text { Instructor, or Volunteer. In addition, I will need to identify which } \\
\text { type of adaptive equipment a student uses and a general overview } \\
\text { of their disability. I will not use names. If photographs are taken, } \\
\text { faces will be blurred. }\end{array}$} \\
\hline & \begin{tabular}{|l|l|}
$\square$ & $\begin{array}{l}\text { Real participant names with } \\
\text { data attributable }\end{array}$ \\
\end{tabular} & \\
\hline & $\square$ Other & \\
\hline \multirow[t]{6}{*}{ 9D } & Data Storage (during the & \multirow{6}{*}{$\begin{array}{l}\text { How will data be stored and kept safe? Provide details for each type } \\
\text { of data (e.g. raw data, contact lists, consent documents, } \\
\text { anonymized data, recordings and images, electronic data and paper } \\
\text { documents). (Detailed instructions, Example) } \\
\text { Notes, photographs, video-recordings, coded data will be stored on } \\
\text { my external, password protected, harddrive. Photographs and } \\
\text { videos will only be saved with blurred faces. The external hard drive } \\
\text { will be encrypted, in line with the Carleton mobile technology policy. Only I } \\
\text { have the password. The coding key with identifiable participant } \\
\text { information will be stored separately only my password protected } \\
\text { laptop. Only I have the password. }\end{array}$} \\
\hline & \begin{tabular}{|l|l|} 
& Encrypted \\
\end{tabular} & \\
\hline & \begin{tabular}{l|l}
$\mathrm{X}$ & Password-protected \\
\end{tabular} & \\
\hline & \begin{tabular}{|l|l|}
$\square$ & Physical documents \\
\end{tabular} & \\
\hline & \begin{tabular}{|l|l}
$\square$ & Other \\
\end{tabular} & \\
\hline & & \\
\hline \multirow[t]{7}{*}{$9 \mathrm{E}$} & $\begin{array}{l}\text { Data Disposition (after the } \\
\text { project) }\end{array}$ & \multirow{4}{*}{$\begin{array}{l}\text { After project completion, describe whether and how the data will be } \\
\text { stored for future use. If shared, with whom? If made public, how } \\
\text { (e.g. online)? If archived, provide details. Describe any restrictions } \\
\text { on access. Will personal identifiers be deleted and when? If data will } \\
\text { be destroyed, when? Will participant contact information be kept for } \\
\text { future recruitment? (Include data disposition plans in the consent } \\
\text { materials) (Detailed instructions, Example) }\end{array}$} \\
\hline & \begin{tabular}{l|l}
$\mathrm{x}$ & Stored \\
\end{tabular} & \\
\hline & \begin{tabular}{l|l}
$\mathrm{x}$ & $\begin{array}{l}\text { De-identified data shared } \\
\text { publicly }\end{array}$ \\
\end{tabular} & \\
\hline & 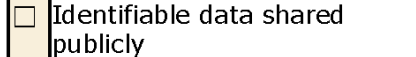 & \\
\hline & \begin{tabular}{|l|l|}
$\square$ & $\begin{array}{l}\text { All identifiers/codes will be } \\
\text { permanently deleted }\end{array}$ \\
\end{tabular} & $\begin{array}{l}\text { The data will remain stored on my external harddrive and laptop } \\
\text { for } 5 \text { years. At that time, I will destroy data, photographs, and } \\
\text { video-recordings. I may use edited footage (videos and }\end{array}$ \\
\hline & \begin{tabular}{|l|l|}
$\square$ Returned to participants \\
\end{tabular} & photographs with blurred faces) in my thesis. \\
\hline & \begin{tabular}{|l|l|}
$\mathrm{x}$ & Destroyed \\
\end{tabular} & \\
\hline
\end{tabular}

Form Version: April 2019 


\begin{tabular}{|c|c|c|}
\hline \multirow[t]{3}{*}{$9 \mathrm{~F}$} & Sharing Study Results & \multirow{2}{*}{$\begin{array}{l}\text { Do you intend to share a report (or summary) of the research } \\
\text { findings with participants once the study is complete? If yes, include } \\
\text { this option in the consent form. (Detailed instructions, Example) }\end{array}$} \\
\hline & \begin{tabular}{|l|l|}
$\mathrm{x}$ & Results will be shared \\
\end{tabular} & \\
\hline & & $\begin{array}{l}\text { Yes, I will share some of my thesis findings and outcomes with } \\
\text { CADS at Snow Mountain. }\end{array}$ \\
\hline \multirow{2}{*}{ 9G } & Data Breach Risks & \multirow{2}{*}{$\begin{array}{l}\text { Describe the likelihood of a data breach and the resulting risks to } \\
\text { participants. If risks are significant, how will they be } \\
\text { mitigated? (Detailed instructions, Example) }\end{array}$} \\
\hline & \begin{tabular}{|l|l|}
$\mathrm{X}$ & No Risks \\
\end{tabular} & \\
\hline \multirow{8}{*}{$\begin{array}{ll}10 . \\
10 A\end{array}$} & \multicolumn{2}{|l|}{ Funding and Approvals } \\
\hline & Project Funding & \multirow{3}{*}{$\begin{array}{l}\text { Who is funding this project? If applicable, include the funding } \\
\text { source/agency/company, program, award name, and number (from } \\
\text { CUResearch). Note if the researcher applied for a release of funds } \\
\text { for this project funding. }\end{array}$} \\
\hline & \begin{tabular}{|l|l|}
$X$ & Unfunded \\
\end{tabular} & \\
\hline & \begin{tabular}{|l|l|}
$\square$ & Tri-Council Funded \\
\end{tabular} & \\
\hline & $\square$ Other Award/Grant & Unfunded \\
\hline & $\square$ Contract Funded & \\
\hline & $\square$ Personal Consulting or & \\
\hline & Scholarship & \\
\hline \multirow[t]{6}{*}{$\overline{10 B}$} & $\begin{array}{l}\text { Researcher Funding (for } \\
\text { research contracts and } \\
\text { personal consulting only) }\end{array}$ & \multirow{3}{*}{$\begin{array}{l}\text { For research that will pay personal income to any researcher: how } \\
\text { will any resulting conflicts of interest be managed? How much } \\
\text { funding (dollar amount and the percentage of the total) will the } \\
\text { researcher(s) receive as income? Provide the title and date of any } \\
\text { contracts. (The REB may review the contract.) } \\
\end{array}$} \\
\hline & \multirow{3}{*}{$\begin{array}{l}\text { Not contract funded research } \\
\text { No funds are paid directly to } \\
\text { income rearcher as personal }\end{array}$} & \\
\hline & & \\
\hline & & \\
\hline & \begin{tabular}{|l|l|}
$\square$ & $\begin{array}{l}\text { The researcher will receive a } \\
\text { portion of the funds as } \\
\text { personal income }\end{array}$
\end{tabular} & \\
\hline & \begin{tabular}{|l|l|}
$\square$ & $\begin{array}{l}\text { A copy of the } \\
\text { contract/agreement has } \\
\text { been submitted to the } \\
\text { Research Compliance Office }\end{array}$ \\
\end{tabular} & \\
\hline \multirow[t]{6}{*}{$10 \mathrm{C}$} & $\begin{array}{l}\text { Additional Approvals } \\
\text { Required }\end{array}$ & \multirow{5}{*}{$\begin{array}{l}\text { Is organizational permission required to conduct research (e.g., } \\
\text { schools, employers, other universities, correctional services, } \\
\text { indigenous communities, or other data collection locations)? If } \\
\text { conducting research in another country, is local permission, } \\
\text { including local ethics review, required? Indicate if } \\
\text { permission/approval has been secured and provide a copy. } \\
\text { Research with biohazards or animals must also secure approval } \\
\text { from the appropriate committee at Carleton University. }\end{array}$} \\
\hline & \begin{tabular}{|l|l} 
No other approvals required \\
\end{tabular} & \\
\hline & \begin{tabular}{|l|l}
$\square$ & Organizational Permission
\end{tabular} & \\
\hline & \begin{tabular}{|l|l}
$\square$ Visa/Travel Permits \\
\end{tabular} & \\
\hline & \begin{tabular}{|l|l}
$\square$ & $\begin{array}{l}\text { Other REBs or Institutional } \\
\text { Approvals }\end{array}$ \\
\end{tabular} & \\
\hline & \begin{tabular}{|l|l|}
$\square$ & Biohazards \\
\end{tabular} & $\begin{array}{l}\text { Please find attached the statement of permission/approval from } \\
\text { the Program Coordinator of CADS at Snow Mountain in Appendix F. }\end{array}$ \\
\hline
\end{tabular}

Form Version: April 2019 


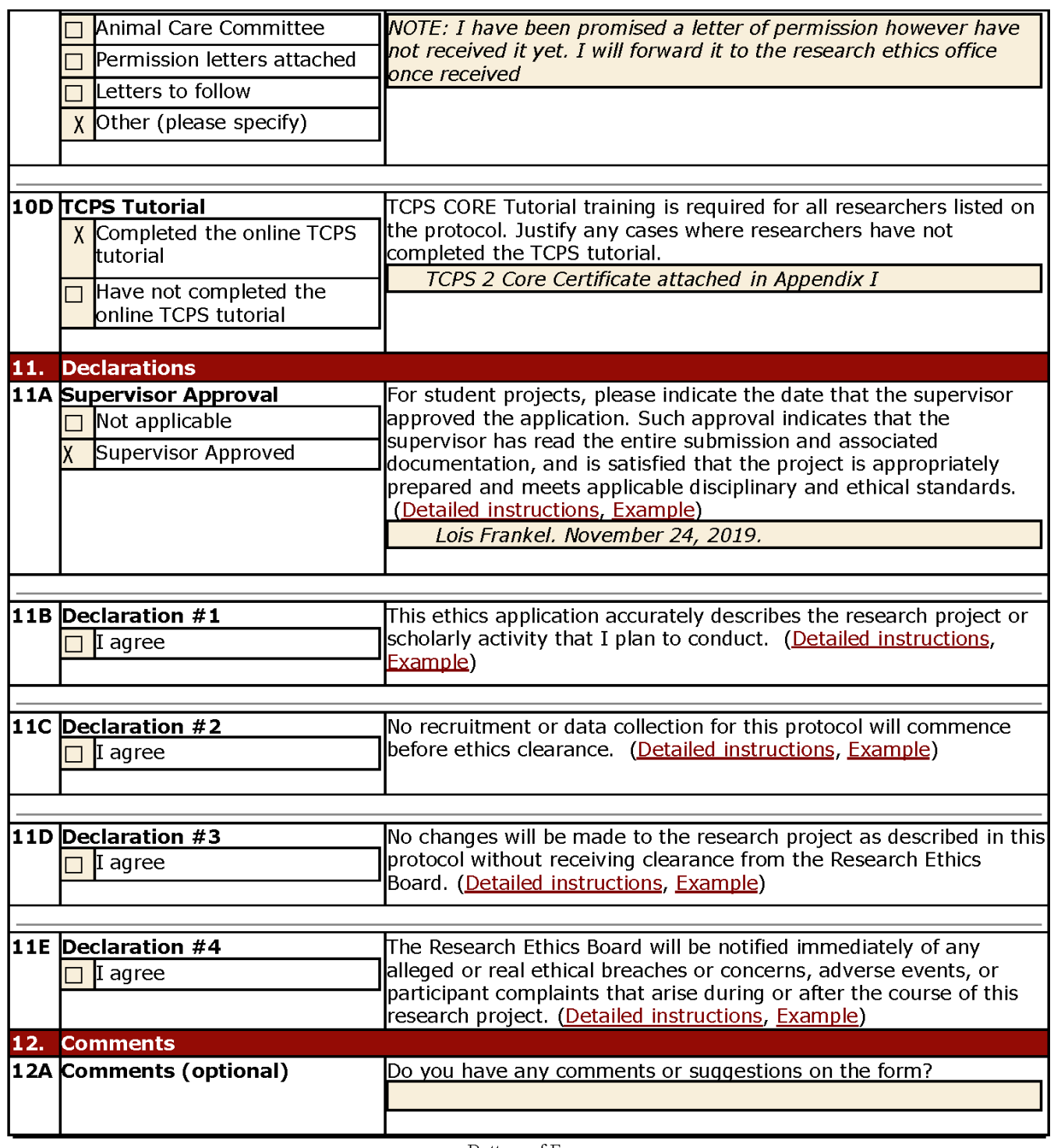

Bottom of Form

Form Version: April 2019

$14 / 14$ 


\section{B.2 Research Ethics Protocol: Phase 2 and Phase 3}

Office of Research Ethics

CARLETON UNIVERSITY

\section{CHANGE TO A CLEARED RESEARCH PROTOCOL}

This form is to be used for amendments to a cleared protocol. Please direct all questions regarding the completion of this form to a Research Ethics Coordinator in the Carleton University Office of Research Ethics at: ethics@carleton.ca.

* Please submit this form and all accompanying documents as an "Event" in CuResearch under the same study file. Please see our CuResearch User Manual for directions on how to submit a new event.

* Note that all of our forms are compatible with Microsoft Office. Students and staff members can download a free copy of MS Office at no charge: Students: https://carleton.ca/its/ms-offer-students/; Staff/Faculty:

https://carleton.ca/its/all-services/computers/site-licensed-software/ms-offer-facultv/

Top of Form

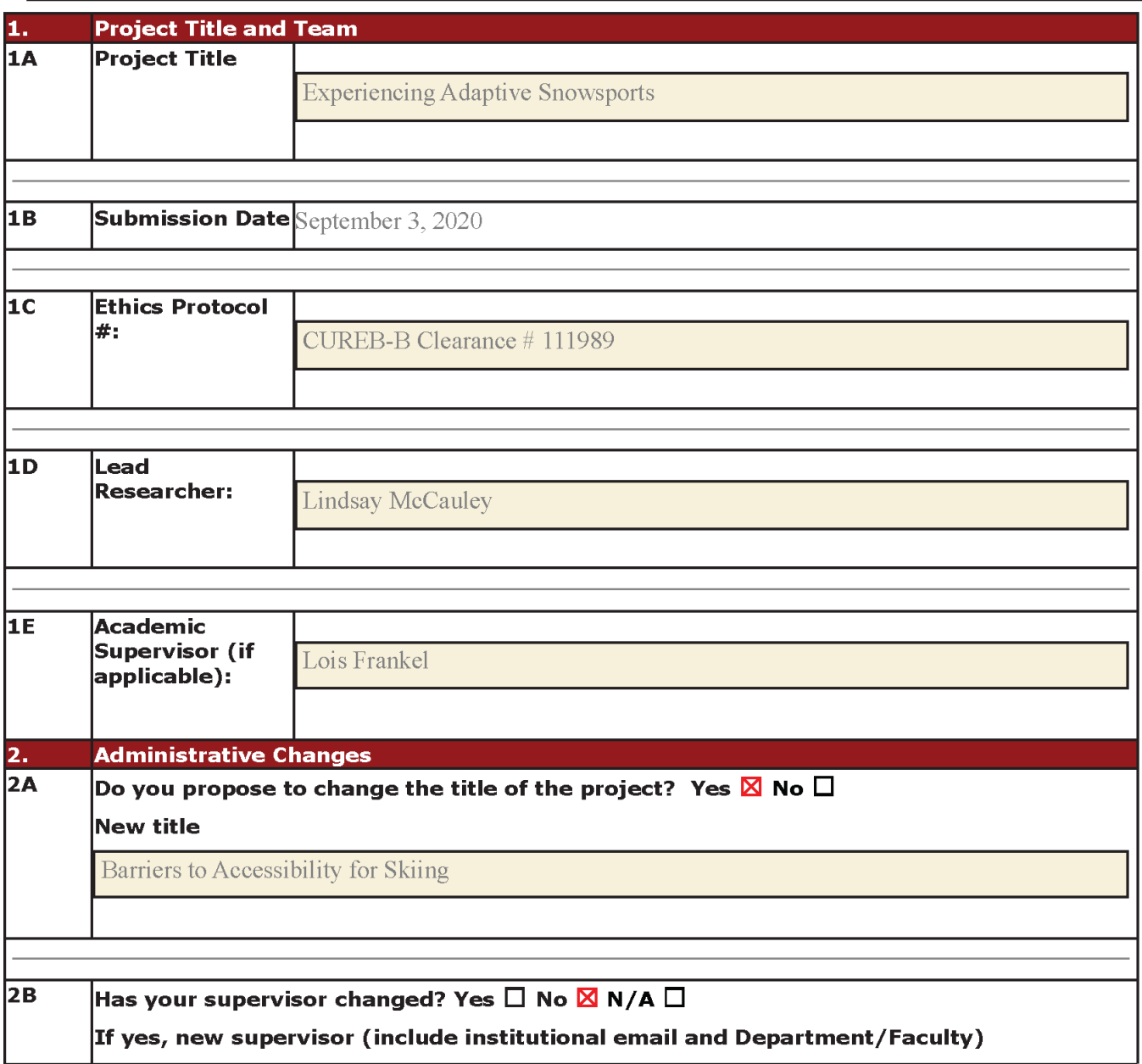




\begin{tabular}{|c|c|c|c|c|c|c|}
\hline \multirow[t]{3}{*}{$2 \mathrm{C}$} & \multicolumn{6}{|c|}{$\begin{array}{l}\text { Have new team members been added? Yes } \square \text { No } \otimes \\
\text { If Yes: Please provide the name, department and contact information of the new researchers and } \\
\text { submit copies of all documentation with the revised information. }\end{array}$} \\
\hline & Name & $\begin{array}{l}\text { EMPLOYEE-STU } \\
\text { DENT NUMBER }\end{array}$ & DEPARTMENT & $\begin{array}{l}\text { CARLETON } \\
\text { EMAIL }\end{array}$ & ROLE IN STUDY & $\begin{array}{l}\text { TCPS2 } \\
\text { TRAINING } \\
\text { COMPLETE } \\
(\mathrm{Y} \text { or } N)\end{array}$ \\
\hline & \multicolumn{6}{|c|}{$\begin{array}{l}\text { To add a row, hover your mouse cursor to the bottom-left corner and click on the "+ "button OR right } \\
\text { click the cell and insert a row below. }\end{array}$} \\
\hline 2D & \multicolumn{6}{|c|}{ Provide the name(s) of the team member(s) being removed. } \\
\hline 3. & \multicolumn{6}{|c|}{ Other Changes } \\
\hline 3A & \multicolumn{6}{|c|}{$\begin{array}{l}\text { Instructions: Please answer Yes or No to the questions in Section } 3 \text {. If you answer Yes } \\
\text { to one or more questions, describe all these changes in Section } 4 \mathrm{~A} \text {, and submit copies of } \\
\text { all revised or new relevant documents. } \\
\text { Are you proposing to change the methodology or project design? } \\
\text { Yes } \otimes \text { No } \square\end{array}$} \\
\hline 3B & \multicolumn{6}{|c|}{$\begin{array}{l}\text { Are you proposing to change the participant group for the project? } \\
\text { Yes } \square \text { No } \otimes\end{array}$} \\
\hline $3 \mathrm{C}$ & \multicolumn{6}{|c|}{$\begin{array}{l}\text { Do you propose to change participant recruitment for the project or changes to any } \\
\text { recruitment materials? } \\
\text { Yes } \otimes \text { No } \square\end{array}$} \\
\hline
\end{tabular}

Form Version: August 2020 


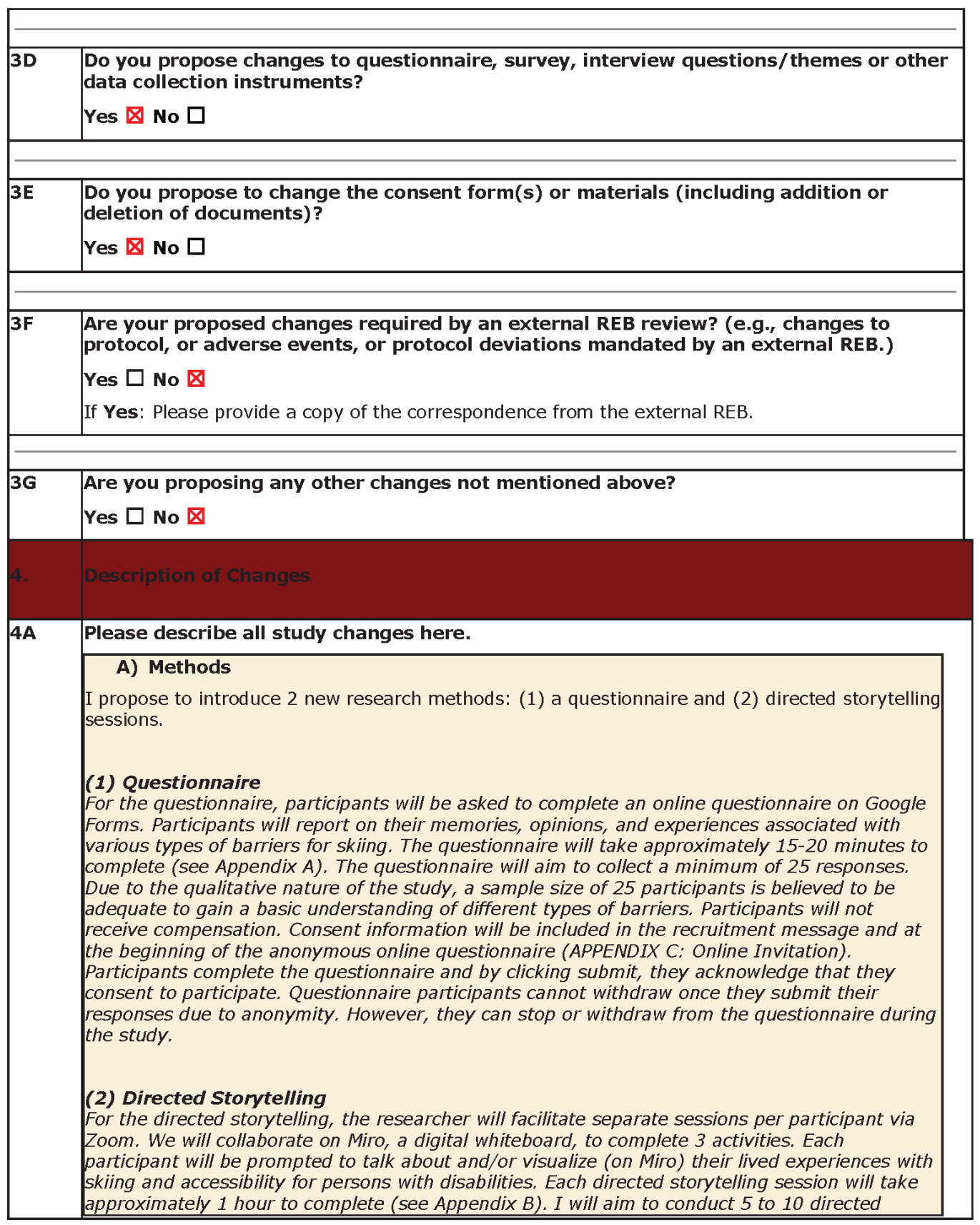

Form Version: August 2020 
storytelling sessions until saturation is achieved. The purpose of the directed storytelling method is to gain an in-depth understanding of individuals' lived experiences. Diversity in the sample (linked to functional impairment and/or relation to skiing for persons with disabilities) will be imperative to learning about different goals and challenges within the experience of skiing for persons with disabilities. Due to COVID-19, the session will be online. Providing a digital signature for signed consent may be a technical challenge for some participants. Thus, consent will be obtained orally at the beginning of each session on Zoom. If a participant is interested in the study and responds to the initial message/email/post, I will share the consent form to be reviewed (APPENDIX E: Consent Form). At the beginning of the directed storytelling session, I will read the consent form out loud and ask for the participant's oral consent. With consent, each session, which includes the initial interview questions, will be recorded (audio mandatory; video optional) using Zoom. For the Zoom recordings, the IP addresses will be disabled. A unique Zoom meeting code and password will be generated for each session. The recordings will be downloaded and removed Zoom directly after the sessions. The recordings will be assigned pseudonyms and saved on my password protected computer. The codes will be saved separately on my password protected external harddrive. The recordings will not be published; they will only be used for analysis by the researcher. After 5 years, the recordings and codes will be permanently destroyed. For the directed storytelling, my contact information will be provided in the same initial message/email/post and will be on the consent form. After the session, the participant will receive a short oral debriefing to close (APPENDIX F: Directed Storytelling Script). Each participant will receive a $\$ 10$ Starbucks eGift Card. Participants of the directed storytelling will be able to contact me via email (provided in initial message and consent form) to withdraw up until 1 week after their session. If a participant requests to withdraw, their data will be permanently deleted. If the participants request to end the session early or for their data to be withdrawn, they will still receive the compensation ( $\$ 10$ Starbucks eGift Card).

\section{B) Recruitment}

Other (Google Groups)

Google Groups is used by CADS at Snow Mountain as a message board to make

announcements. There is one group for volunteers/instructors, and another for participants. The Program Coordinator, Jeff Boucher, is the only person who is able to send group messages. Each message is shared privately, meaning one member cannot see who else is receiving a message and cannot see other replies. Thus, the Program Coordinator will share my message in both the Volunteers and Participants Google Groups. The message will include the link to the Google Forms questionnaire and my contact information for anyone interested in participating in the directed storytelling (APPENDIX C: Online Invitation). If someone contacts me to participate in the directed storytelling, I will share the consent form and discuss scheduling a time for the session (APPENDIX D: Email Response for Directed Storytelling Recruitment).

Please note, this recruitment method was previously approved.

\section{Emails}

I will send emails to potential stakeholders (APPENDIX C: Online Invitation). These stakeholders include other adaptive snowsports programs (i.e. other divisions of CADS, BC Adaptive Snowsports), Abilities Centre Ottawa (i.e. Emily Glossop, former member of the Canadian Para-Alpine Ski Team). Contact information for these stakeholders is available on their websites. The email will include the link to the Google Forms questionnaire and my contact information for anyone interested in participating in the directed storytelling. If someone contacts me to participate in the directed storytelling, I will share the consent form and discuss scheduling a time for the session (APPENDIX D: Email Response for Directed Storytelling Recruitment).

\section{C) New materials}

Appendices

$$
\text { A: Questionnaire }
$$

- B: Directed Storytelling Miro Materials

Form Version: August 2020 


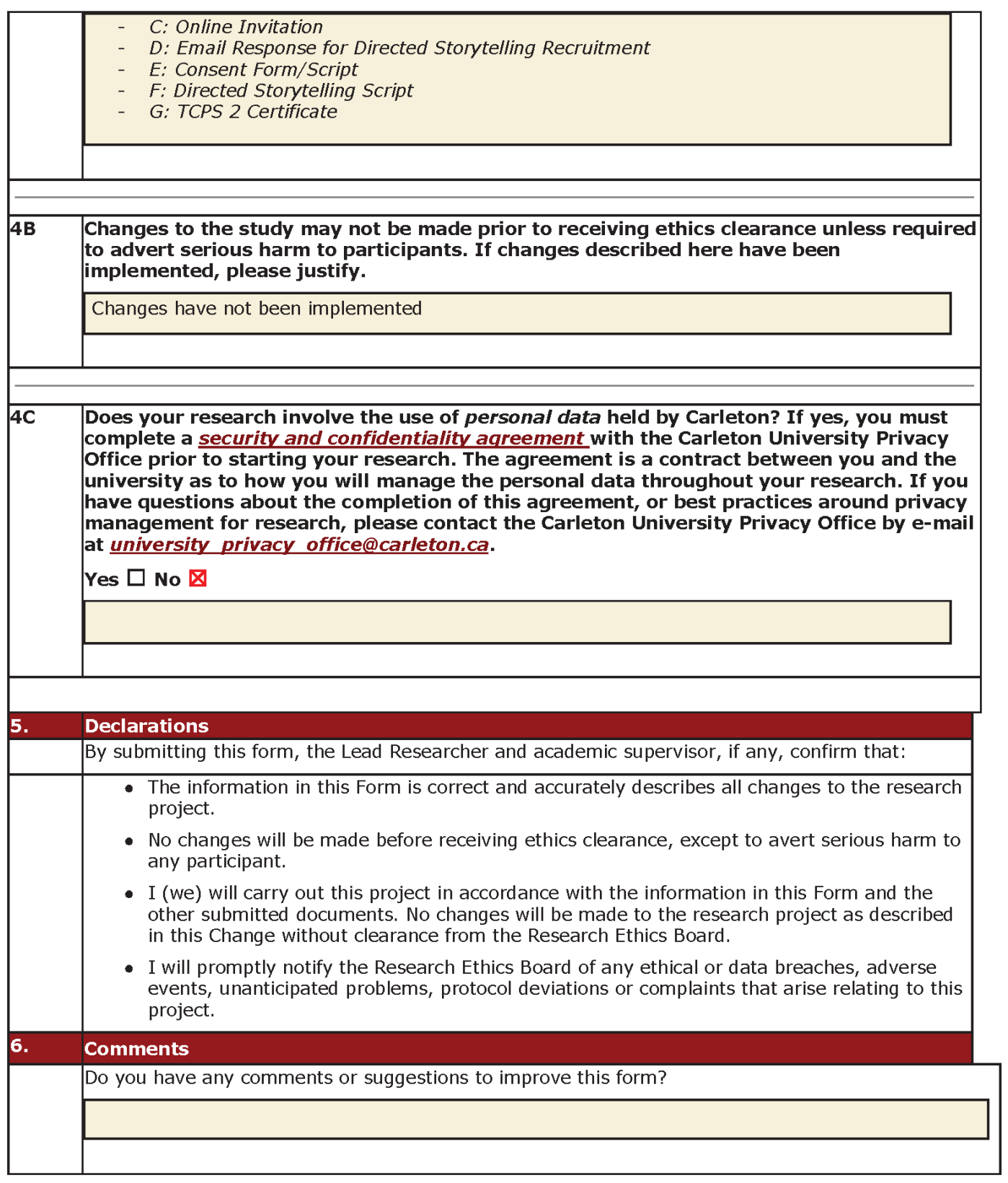

Form Version: August 2020 


\section{Appendix C}

\section{C.1 Ontario Ski Areas Provision of Accessibility Information}

\begin{tabular}{|l|l|l|}
\hline$\#$ & Ski Area & Accessibility Information on Website? \\
\hline 1 & Blue Mountain Resort & Yes \\
\hline 2 & Horseshoe Resort & Limited \\
\hline 3 & Mount St Louis & Limited \\
\hline 4 & Alpine Ski Club-Collingwood & No \\
\hline 5 & Georgian Peaks Club & Yes \\
\hline 6 & Calabogie Peaks & Yes \\
\hline 7 & Mount Pakenham & Yes \\
\hline 8 & Ski Snow Valley & Yes \\
\hline 9 & ockley Valley & No \\
\hline 10 & Hidden Valley Highlands & Limited \\
\hline 11 & Adanac Ski Hill & No \\
\hline 12 & Batawa Ski Hill & Yes \\
\hline 13 & Dagmar & No \\
\hline
\end{tabular}




\begin{tabular}{|c|c|c|}
\hline 16 & Craigleith Ski Club & No \\
\hline 17 & Chicopee & Yes \\
\hline 18 & Caledon & Yes \\
\hline 19 & Boler Mountain & Yes \\
\hline 20 & $\underline{\text { Beaver Valley Ski Club }}$ & No \\
\hline 21 & Laurentian Ski Hill & Yes \\
\hline 22 & Lively Ski Hill & Limited \\
\hline 23 & Loch Lomond & No \\
\hline 24 & Mansfield Ski Club & No \\
\hline 25 & Mount Chinguacousy & No \\
\hline 26 & Mount Dufour & No \\
\hline 27 & Larder Lake Ski Club & No \\
\hline 28 & Kamiskotia Snow Resort & No \\
\hline 29 & Antoine Mountain & No \\
\hline 30 & Osler Bluff Ski Club & No \\
\hline 31 & Pine Ridge Ski Club & No \\
\hline 32 & Remi Ski Club & No \\
\hline
\end{tabular}




\begin{tabular}{|c|c|c|}
\hline 33 & Searchmont & No \\
\hline 34 & Sir Sam's Ski Area & No \\
\hline 35 & Ski Lakeridge & Yes \\
\hline 36 & Brimacombe & Yes \\
\hline 37 & Skyloft Ski Club & No \\
\hline 38 & Trestle Ridge & No \\
\hline 39 & Uplands Ski Centre & No \\
\hline 40 & Mount Baldy & No \\
\hline 41 & Earl Bales & Limited \\
\hline 42 & Mount Evergreen & No \\
\hline 43 & Mount Martin & No \\
\hline 44 & Mount Fairweather & No \\
\hline 45 & Alice Hill Park & No \\
\hline 46 & Mount Molson & No \\
\hline 47 & Cobble Hills & No \\
\hline 48 & Snow Valley & Yes \\
\hline 49 & Caswell & No \\
\hline
\end{tabular}




\begin{tabular}{|l|l|l|}
\hline 50 & Madawaska Mountain & No \\
\hline 51 & Heyden & No \\
\hline 52 & Caribou Mountain & No \\
\hline 53 & Cedar Highlands Ski Club & No \\
\hline 54 & Centennial Park Ski Hill & No \\
\hline 55 & Tri Town & No \\
\hline 56 & Sunday Peaks & No \\
\hline 57 & Boogie Mountain & No \\
\hline
\end{tabular}




\section{Appendix D}

\section{D.1 Phase 2 Questionnaire}

\section{Barriers to Accessibility for Skiing}

Context:

As a whole, ski areas do not consistently and thoroughly implement accessibility. Consequently, a significant percentage of the population of persons with disabilities face barriers to participation for skiing/snowboarding. This research will aim to identify and address the barriers to accessibility for skiing for persons with disabilities.

Time Commitment:

- 15 to 20 minute questionnaire

Eligibility Criteria:

- 18 years of age or older

- You must have at least 1 experience with skiing for persons with disabilities

Data Storage:

All responses will remain anonymous and be kept confidential. Only the researcher will have access to the responses. Data will be retained for a period of 5 years and then securely destroyed.

This research has been cleared by Carleton University Research Ethics Board-B (CUREB-B Clearance \# 111989). Should you have any ethical concerns with the study, please contact the REB Chair, Carleton University Research Ethics Board-B (by phone: 613-520-2600 ext. 4085 or by email: ethics@carleton.ca). For all other questions about the study, please contact the researcher. There will be no compensation for participating in this questionnaire.

You may skip any question that you do not wish to answer. By clicking 'Submit', you will be consenting to participate in this study.

Thank you for your time \& participation!

Researcher:

Lindsay McCauley

Master of Design Student, Carleton University

lindsaymccauley@cmail.carleton.ca

Academic Supervisor:

Prof. Lois Frankel

School of Industrial Design, Carleton University

LoisFrankel@CUNET.CARLETON.CA 
1. Are you 18 years of age or older?

Mark only one oval.

$$
\text { Yes }
$$$$
\text { No }
$$

\section{Part 1}

2. What is your relationship to skiing?

Tick all that apply.

$\square$ I am an adaptive skier

$\square$ I am the parent/guardian of an adaptive skier

$\square$ I am a volunteer/instructor of an adaptive skiing program

Other:

3. Please describe your motivation for skiing.

4. Would you describe yourself as a person with a disability?

Mark only one oval.
$\bigcirc$ Yes
$\bigcirc$ No
I'm not sure 
5. If yes, please define your disability.

6. If no, please describe some of the disabilities of the skiers that you know.

7. Have you ever experienced or witnessed someone else experience a barrier to accessibility for skiing?

Mark only one oval.

$\longrightarrow$ Yes Skip to question 8

$\bigcirc$ No Skip to question 23

I'm not sure Skip to question 8

Part 2

There are five types of barriers to accessibility. 
8. Have you ever experienced/witnessed an attitudinal barrier for skiing?

Attitudinal barriers are behaviours, perceptions, and assumptions that discriminate against persons with disabilities. Examples include: Assuming a person with a disability is inferior; Assuming that someone with a speech impairment cannot understand you; Forming ideas about a person because of stereotypes or a lack of knowledge; Making a person feel as though you are doing them a "special favour" by providing their accommodations.

Mark only one oval.

Yes

No

$\bigcirc$ I'm not sure

9. If yes, please describe a time that you experienced/witnessed an attitudinal barrier for skiing.

10. Any other comments? 
11. Have you ever experienced/witnessed an organizational or systemic barrier for skiing?

Organizational or systemic barriers are policies, procedures, or practices that unfairly discriminate and can prevent individuals from participating fully in a situation. Examples include: A program that requires students to take a full course load; Office hours conducted in person only, or not allowing students to access their professors or administrators by phone, e-mail, or other means of communication; Having poorly defined or unclear learning objectives for a course; Requiring students to express their understanding of course content in only one way.

\section{Mark only one oval.}

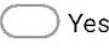

No

I'm not sure

12. If yes, please describe a time that you experienced/witnessed an organizational or systemic barrier for skiing.

13. Any other comments? 
14. Have you ever experienced/witnessed an architectural or physical barrier for skiing?

Architectural or physical barriers are elements of buildings or outdoor spaces that create barriers to persons with disabilities. Examples include: Sidewalks and doorways that are too narrow for a wheelchair, scooter, or walker; Tables that are too high for a person who is using a wheelchair, or other mobility device; Poor lighting that makes it difficult to see for a person with low vision or a person who lip-reads; Doorknobs that are difficult to grasp for a person with arthritis.

Mark only one oval.

$\longrightarrow$ Yes

No

I'm not sure

15. If yes, please describe a time that you experienced/witnessed an architectural or physical barrier for skiing.

16. Any other comments? 
17. Have you ever experienced/witnessed an information or communications barrier for skiing?

Information or communications barriers occur when sensory disabilities, such as hearing, seeing, or learning disabilities, have not been considered. These barriers relate to both the sending and receiving of information. Examples include: Electronic documents that are not properly formatted and cannot be read by a screen reader; Language that is not clear; Print that is too small or in a font that is difficult to read; Videos that are not captioned and don't have transcriptions.

Mark only one oval.
Yes
No
I'm not sure

18. If yes, please describe a time that you experienced/witnessed an information or communications barrier for skiing.

19. Any other comments? 
20. Have you ever experienced/witnessed a technology barrier for skiing?

Technology barriers occur when a device or technological platform is not accessible to its intended audience and cannot be used with an assistive device. Examples include: Electronic documents without accessibility features, such as alternative text (Alt Text), that screen readers read to describe an image; Books that are available only in hard copies; Requiring skiers to use a website that does not meet accessibility standards; Websites that cannot be accessed using screen-reading software.

Mark only one oval.

$\square$ Yes
$\square$ No
I'm not sure

21. If yes, please describe a time that you experienced/witnessed a technology barrier for skiing.

22. Any other comments?

Part 3 
23. If you were planning to visit a ski area for the first time, would you seek information about the accessibility of the ski area?

Mark only one oval.

$\square$ Yes
$\square_{\text {No }}$
$\square$ I'm not sure

24. If yes, how would you seek the accessibility information?

Tick all that apply.
The ski resort's website
Calling the ski resort
Emailing the ski resort
An Internet search
Word of mouth

Other:

25. Has there ever been a time that you could not find accessibility information for a ski area?

Mark only one oval.
Yes
No
I'm not sure 
26. If yes, what was the information that you could not find? What did you do?

Thank you for participating in this study. Please click "Submit" to complete.

If you would be interested in participating in Part 2 of this study, please contact the researcher for more details (lindsaymccauley@cmail.carleton.ca). Part 2 will involve a one on-one design session via Zoom. Together we will map out and discuss some of your experiences relating to skiing for persons with disabilities. The purpose of this design session is to further identify barriers of accessibility for skiing. Each participant in Part 2 will receive a $\$ 10$ Starbucks eGift Card.

All responses will remain anonymous and be kept confidential. You may skip any question that you do not wish to answer. This research has been cleared by Carleton University Research Ethics Board-B (CUREB-B Clearance \# 111989). Should you have any ethical concerns with the study, please contact the REB Chair, Carleton University Research Ethics Board-B (by phone: 613-520-2600 ext. 4085 or by email: ethics@carleton.ca). For all other questions about the study, please contact the researcher

Thank you for your time \& consideration

Lindsay McCauley

Master of Design Student, Carleton University

lindsaymccauley@cmail.carleton.ca

This content is neither created nor endorsed by Google.

\section{Google Forms}




\section{Appendix E}

\section{E.1 Initial Round of Triangulation Using Affinity Diagramming}

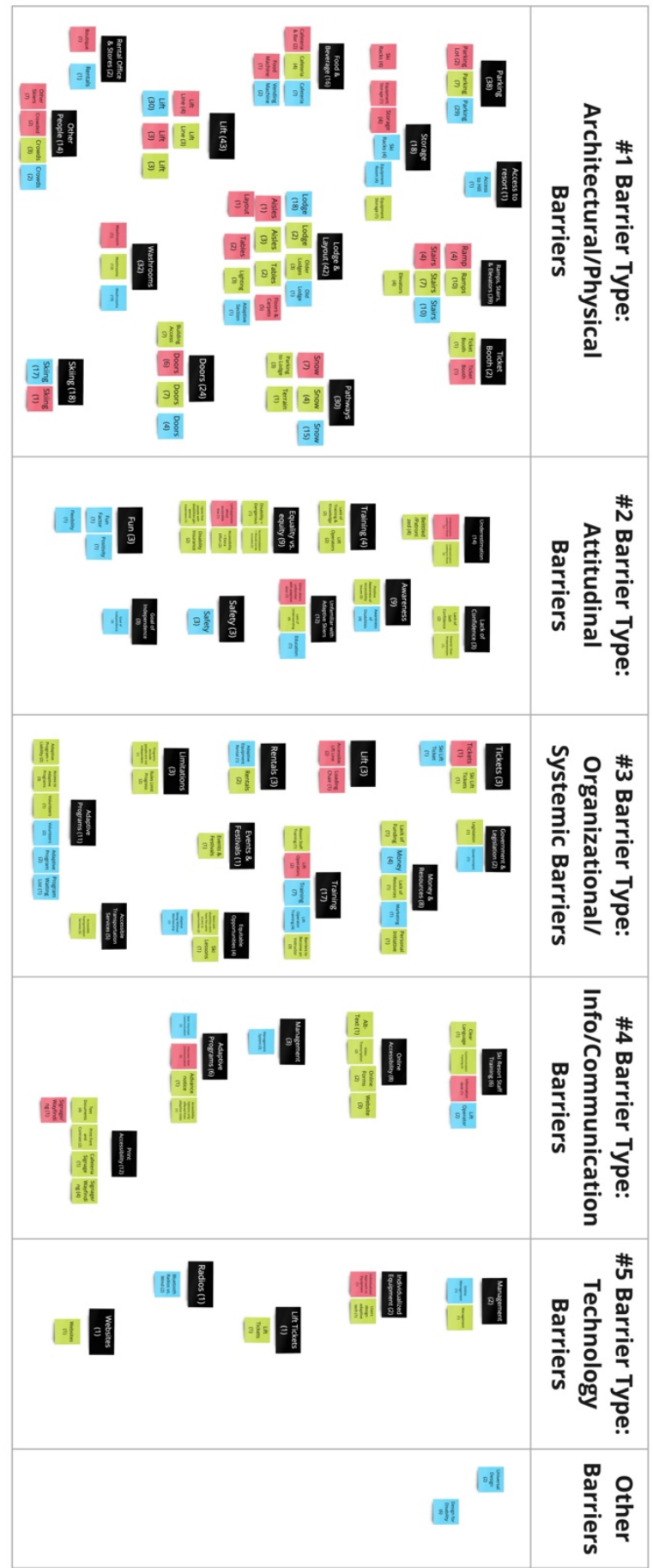


E.2 Second Round of Triangulation Using Affinity Diagramming

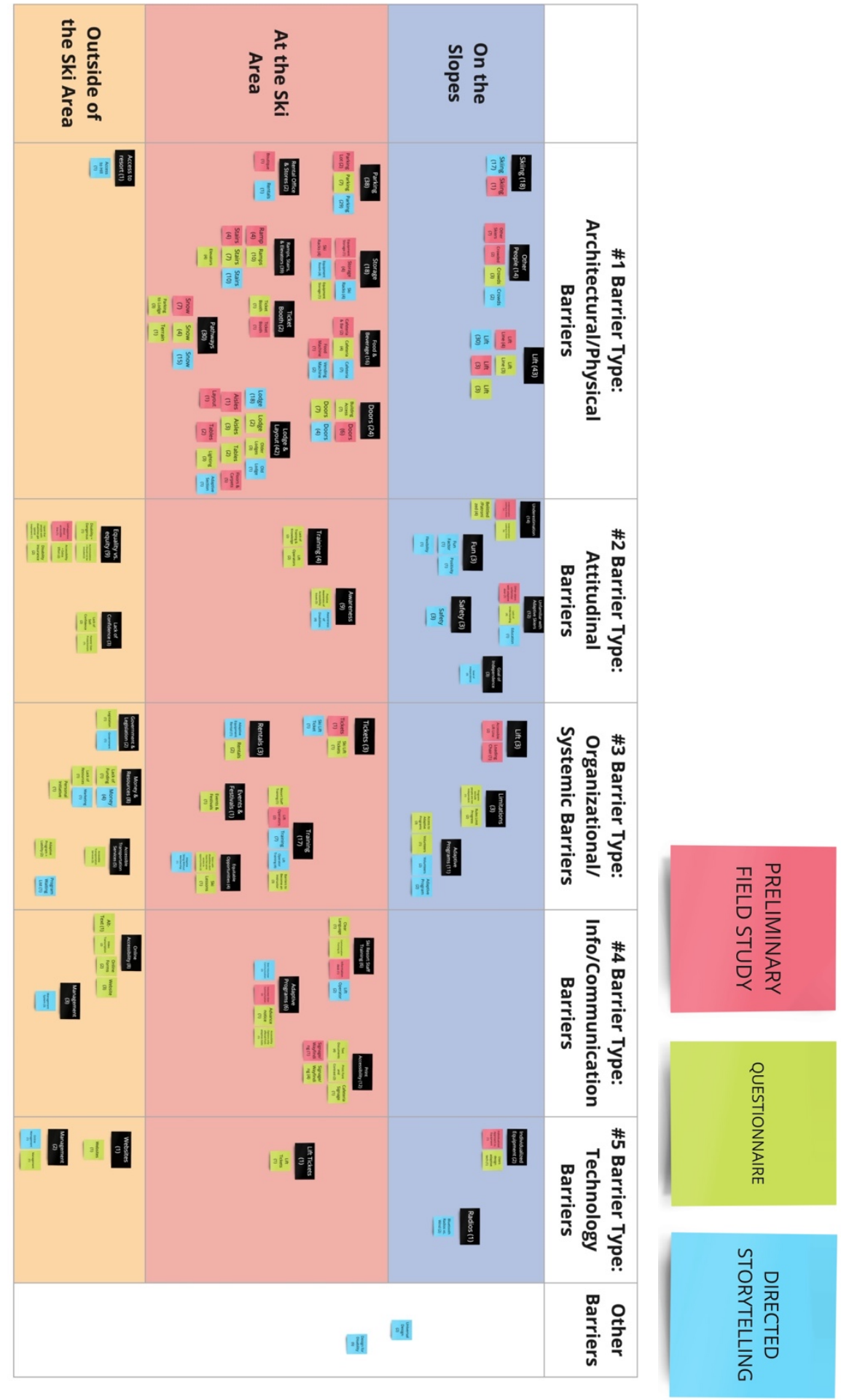




\section{Appendix F}

F.1 Interactive Accessibility Map

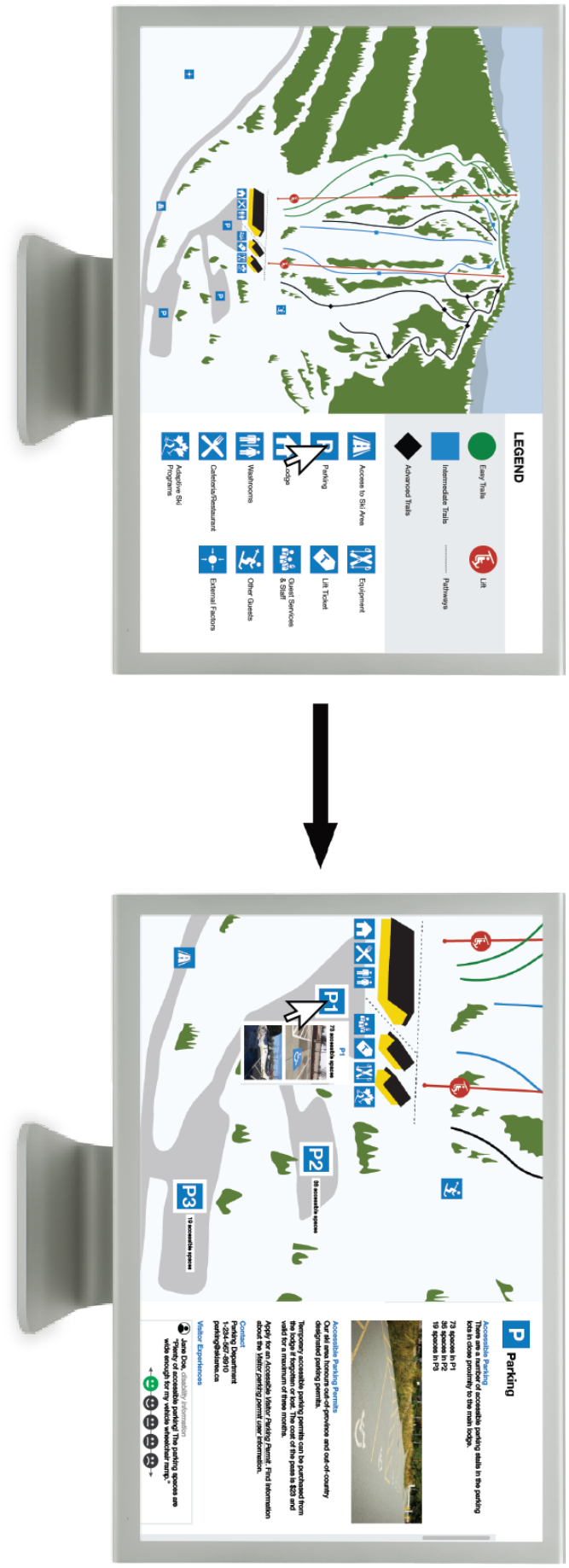

